\title{
Evaluation of Older Bay Mud Sediment from Richmond Harbor, California
}

M. R. Pinza

H. L. Mayhew

J. Q. Word

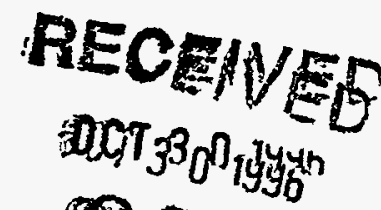

Battelle Marine Sciences Laboratory

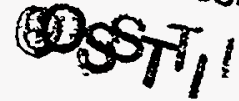

Sequim, Washington

September 1996

Prepared for the

U.S. Army Corps of Engineers - San Francisco District under a Related Services Agreement with the U.S. Department of Energy under Contract DE-AC06-76RLO 1830

Pacific Northwest National Laboratory Operated for the U.S. Department of Energy by Battelle Memorial Institute 


\section{DISCLAIMER}

This report was prepared as an account of work sponsored by an agency of the United States Government. Neither the United States Government nor any agency thereof, nor Battelle Memorial Institute, nor any of their employees, makes any warranty, express or implied, or assumes any legal liability or responsibility for the accuracy, completeness, or usefulness of any information, apparatus, product, or process disclosed, or represents that its use would not infringe privately owned rights. Reference herein to any specific commercial product, process, or service by trade name, trademark, manufacturer, or othenvise does not necessarily constitute or imply its endorsement, recommendation, or favoring by the United States Government or any agency thereof, or Battelle Memorial Institute. The views and opinions of authors expressed herein do not necessarily state or reflect those of the United States Government or any agency thereof.

\section{PACIFIC NORTHWEST NATIONAL LABORATORY operated by \\ BATTELLE MEMORIAL INSTITUTE \\ for the \\ UNITED STATES DEPARTMENT OF ENERGY \\ under Contract DE-AC06-76RLO 1830}

Printed in the United States of Amẹrica

Available to DOE and DOE contractors from the

Office of Scientific and Technical Information, P.O. Box 62, Oak Ridge, TN 37831; prices available from (615) 576-8401.

Available to the public from the National Technical Information Service, U.S. Department of Commerce, 5285 Port Royal Rd., Springfield, VA 22161

This document was printed on recycled paper. 


\title{
EVALUATION OF OLDER BAY MUD SEDIMENT FROM RICHMOND HARBOR, CALIFORNIÁ
}

\author{
M. R. Pinza \\ H. L. Mayhew \\ J. Q. Word
}

Battelle Marine Sciences Laboratory

Sequim, Washington 98382

September 1996

Prepared for the

U.S. Army Corps of Engineers - San Francisco District under a Related Services Agreement with the U.S. Department of Energy under Contract DE-AC06-76RLO 1830

Pacific Northwest National Laboratory Richland, Washington 99352 


\section{DISCLAIMER}

Portions of this document may be illegible in electronic image products. Images are produced from the best available original document. 


\section{DISCLAIMER}

This report was prepared as an account of work sponsored by an agency of the United States Government. Neither the United States Government nor any agency thereof, nor any of their employees, makes any warranty, express or implied, or assumes any legal liability or responsibility for the accuracy, completeness, or usefulness of any information, apparatus, product, or process disclosed, or represents that its use would not infringe privately owned rights. Reference herein to any specific commercial product, process, or service by trade name, trademark, manufacturer, or otherwise does not necessarily constitute or imply its endorsement, recommendation, or favoring by the United States Government or any agency thereof. The views and opinions of authors expressed herein do not necessarily state or reflect those of the United States Government or any agency thereof. 


\section{SUMMARY}

The older bay mud (OBM) unit predates modern man and could act as a barrier to the downward transport of contaminants from the younger bay mud (YBM) because of its hard-packed consistency. However, its chemical and biological nature have not been well characterized. Battelle/Marine Sciences Laboratory (MSL) conducted three independent studies of OBM sediment in January 1993, January 1994, and October 1994. These studies evaluated potential chemical contamination and biological effects of OBM that could occur as a result of dredging and disposal activities. These evaluations were performed by conducting chemical analysis, solid-phase toxicity tests, suspended-particulate-phase (SPP) toxicity tests, and bioaccumulation tests on the OBM sediment. If the sediment chemistry and toxicity results showed no or minimal contamination and toxicological responses, then either the OBM could be left exposed in Richmond Harbor after dredging the YBM without leaving a source of contamination, or if the project depths necessitate, the OBM would be acceptable for disposal at an appropriate disposal site.

In January 1993, OBM sediment was collected from six locations in Richmond Harbor. The six samples were combined in a single composite, OBM COMP. Chemical analyses of the OBM COMP and the three native controls (West Beach control [C-WB], Sequim Bay control [C-SB], and San Pablo-Bay control [C-SPB]) consisted of U.S. Environmental Protection Agency (EPA) priority pollutant polynuclear aromatic hydrocarbons (PAHs), polychlorinated biphenyls (PCBs), chlorinated pesticides, metals, butyltins (tributyltin [TBT] and dibutyltin [DBT]), and conventional sediment parameters. In conjunction with the chemical inventory, a biological evaluation was performed using a solid-phase acute toxicity test with Rhepoxynius abronius, two SPP toxicity tests with Mytilus galloprovincialis larvae and Holmesimysis costata, and one bioaccumulation potential test with Macoma nasuta.

In January 1994, OBM sediment was collected from 23 selected sites in Richmond Harbor. The sediment from the 23 sites was combined into a single composite, OBM COMP. The intent of this study was to confirm the bioaccumulation of tributyltin in the tissues of M. nasuta that was observed in the 1993 study and to perform a more in-depth toxicological analysis of OBM sediment. The OBM COMP and the three reference sediments (the Deep Off-Shelf Reference Area [R-OS], the Bay Farm Borrow Area [R-BF], and the Alcatraz Environs Reference Area [R-AM]) were chemically analyzed for PCBs, chlorinated pesticides, and butyltins. The control sediment was archived for future potential analysis. The OBM COMP was tested in three acute toxicity solid-phase tests using $R$. abronius, $M$. nasuta, and Nephtys caecoides. The SPP prepared from the OBM COMP was exposed to Citharichtys stigmaeus, M. galloprovincialis larvae, and $H$. costata. M. nasuta were exposed to 
the OBM COMP to measure the bioaccumulation potential in the tissues after a 28-day exposure period. The tissues were then analyzed for PCBs, chlorinated pesticides, and butyltins.

In October 1994, OBM sediment was collected from four sites in Richmond Harbor. As in the previous studies, sediment was combined in a single composite. The focus of this study was to examine the low survival of $N$. caecoides exposed to the OBM sediment collected in January 1994. It is suspected that the hard-packed nature of the OBM makes it difficult for N. caecoides to burrow, and it was further suspected that the low concentration of total organic carbon (TOC) represented an inadequate food supply. The OBM COMP and the three reference sediments (R-OS, R-BF, and R-AM) were chemically analyzed for the same parameters as those in the January 1993 study. The control sediment was archived for future potential analysis. The OBM COMP was tested in an acute toxicity solid-phase test using $N$. caecoides in which the OBM COMP sediment was enriched with different food sources and softened with seawater prior to the addition of test organisms.

The results of the $R$. abronius test showed that the OBM COMP from the 1993 study was not acutely toxic relative to any reference treatment. The OBM COMP tested in 1994 was acutely toxic to $R$. abronius relative to both of the in-bay reference treatments. The OBM COMP was not acutely toxic to $M$. nasuta relative to any reference treatment. The results of the $N$. caecoides test showed that the OBM COMP from the 1994 study was acutely toxic when compared with all three reference treatments. The feeding studies conducted in October 1994 showed that this toxicity was caused by a combination of the hard-packed nature of the OBM sediment and its relatively low TOC content. When the OBM was softened with seawater, survival increased to $65 \%$; however, the sediment was still acutely toxic to $N$. caecoides relative to all three reference treatments. However, by first softening the OBM sediment and then amending with food, survival increased and the sediment was not considered acutely toxic to N. caecoides relative to any reference treatment.

Estimates of water column toxicity were evaluated by exposing $M$. galloprovincialis, C. stigmaeus, and H. costata to three concentrations of SPP and a dilution water control (Sequim Bay seawater). Acute toxicity was determined by statistical comparison of the $0 \%$ and $100 \%$ SPP using a t-test and calculations of $L_{50}$ and $E C_{50}$ values using the Trimmed Spearman-Karber estimator. To calculate $\mathrm{LC}_{50}$ or $\mathrm{EC}_{50}$ values, there must be greater than $50 \%$ mortality or some other sublethal effect occurring in the sediment treatments. There was not a $50 \%$ decrease in survival for any test species or a $50 \%$ decrease in the percentage of normal larvae for M. galloprovincialis test.

The potential for bioaccumulation of contaminants was evaluated through a 28-day solidphase exposure of $M$. nasuta to OBM sediments followed by chemical analysis of the tissues. M. nasuta tissue analyses for the 1993 study consisted of PAHs, pesticides, PCBs, metals, and 
butyltins. The analyses for the 1994 study consisted of pesticides, PCBs, and butyltins. PAHs and PCBs were not detected in the tissues of $M$. nasuta exposed to OBM COMP from either study relative to any of the reference treatment tissues; therefore, a statistical evaluation was not conducted. For the 1993 study, the concentrations of four pesticides (4,4'-DDD, 4,4'-DDE, 4,4'-DDT, and dieldrin) were statistically significantly elevated in $M$. nasuta tissues exposed to the OBM COMP. This is contrany to the results of the 1994 study, which showed no detectable concentrations of pesticides in $M$. nasuta tissues. All 10 metals were detected in the tissues of M. nasuta exposed to the OBM COMP. Four metals were statistically significantly elevated in M. nasuta tissues exposed to the OBM COMP relative to at least one reference treatment. The results of the 1993 study showed that both TBT and DBT were statistically significantly elevated in M. nasuta tissue exposed to the OBM COMP. The confirmatory tests conducted in 1994 did not reflect the results of the 1993 study. In the 1994 studies, concentrations of TBT and DBT were not statistically significantly elevated in $M$. nasuta tissues exposed to the OBM COMP relative to any reference treatment.

In summary, the two objectives of this study were to 1) determine whether OBM sediments could be left exposed after YBM sediments were dredged, and 2) determine whether OBM is acceptable for disposal at various disposal sites. OBM is primarily composed of silt and hard-packed clay, has a low percentage of TOC; and contains no detectable concentrations of oil and grease, total petroleum hydrocarbons, pesticides, PCBs, and butyltins, and low concentrations of PAHs, and metals, indicating that OBM does not mix with the overlying YBM sediments. The OBM sediments in Richmond Harbor appear to be an effective barrier to the downward transport of contaminants that are associated with the YBM sediments. The OBM sediments did pass all toxicity testing relative to the ocean site. OBM sediments were acutely toxic to $R$. abronius relative to the in-bay sites. This toxicity is probably caused by the physical nature of the sediment. The decisions regarding leaving OBM sediment exposed during dredging operations and determining suitable disposal sites for this sediment will lie with the regulatory agencies. 



\section{CONTENTS}

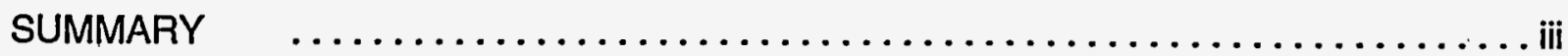

1.0 INTRODUCTION $\ldots \ldots \ldots \ldots \ldots \ldots \ldots \ldots \ldots \ldots \ldots \ldots \ldots \ldots \ldots \ldots \ldots \ldots \ldots$

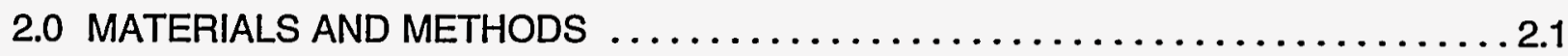

2.1 SEDIMENT AND TEST ORGANISM COLLECTION $\ldots \ldots \ldots \ldots \ldots \ldots \ldots . . \ldots \ldots$

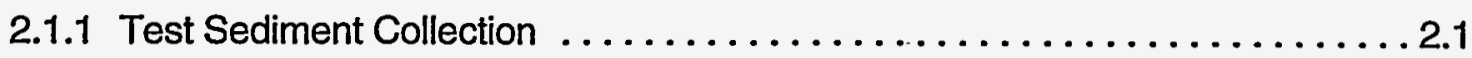

2.1.2 Reference and Control Sediment Collection . . . . . . . . . . . . . 2.1

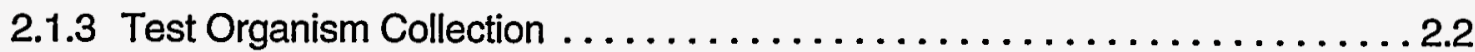

2.2 SEDIMENT SAMPLE PREPARATION $\ldots \ldots \ldots \ldots \ldots \ldots \ldots \ldots \ldots \ldots \ldots$

2.2.1 Geologic Description of Individual Core Samples . . . . . . . . . . . 2.3

2.2.2 Laboratory Glassware and Equipment Preparation ............... 2.3

2.2.3 Preparation of Solid-Phase Treatments for Chemical and

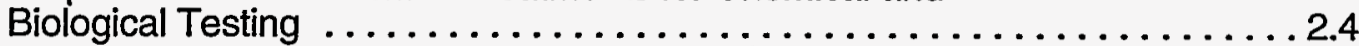

2.2.4 .Preparation of Suspended-Particulate-Phase Samples for

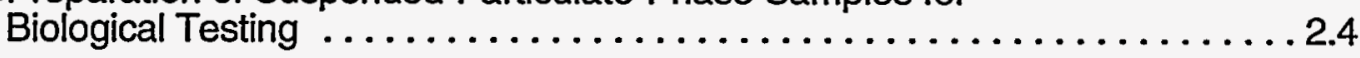

2.3 TOXICOLOGICAL AND BIOACCUMULATION TESTING PROCEDURES $\ldots . .5$

2.3.1 10-Day Solid-Phase Static Test with $R$. abronius . . . . . . . . . . 2.6

2.3.2 10-Day-Solid-Phase Flow-Through Test with $M$. nasuta and $N$. caecoides .. 2.7

2.3.3 28-Day Solid-Phase Flow-Through Test with $M$. nasuta . . . . . . . . . . 2.9

2.3.4 48-Hour Suspended-Particulate-Phase Static Test with M. galloprovincialis $\quad .2 .10$

2.3.5 96-Hour Suspended:Particulate-Phase. Static Test with $C$. stigmaeus . . . . 2.11

2.3.6 96-Hour Suspended-Particulate-Phase Static Test with $H$. costata . . . . . 2.13

2.3.7 10-Day Solid-Phase Flow-Through Preliminary and Definitive Feeding

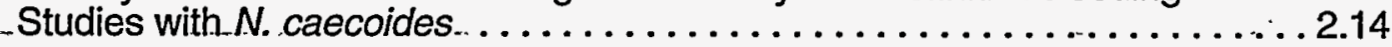

2.3.7.1 Preliminary Test Method . . . . . . . . . . . . . . . . 2.14

2.3.7.2 Definitive Study Method . . . . . . . . . . . . . . . 2.16

2.4 SEDIMENT AND TISSUE CHEMISTRY $\ldots \ldots \ldots \ldots \ldots \ldots \ldots \ldots \ldots \ldots \ldots \ldots$

2.4.1 Conventional Sediment Measurements . . . . . . . . . . . . . 2.17

2.4 .2 Polynuclear Aromatic Hydrocarbons . . . . . . . . . . . . . . . 2.19

2.4.3 Chlorinated Pesticides and Polychlorinated Biphenyls ... . . . . . . 2.21

2.4 .5 Metals . . . . . . . . . . . . . . . . . . . . . . . . . . 22

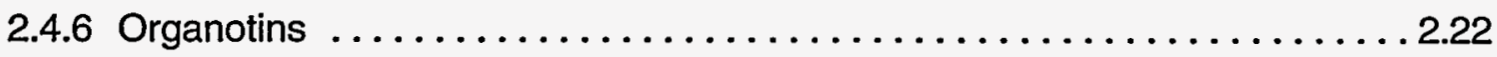

2.5 DATA ANALYSIS AND INTERPRETATION $\ldots \ldots \ldots \ldots \ldots \ldots \ldots \ldots \ldots \ldots . \ldots \ldots$

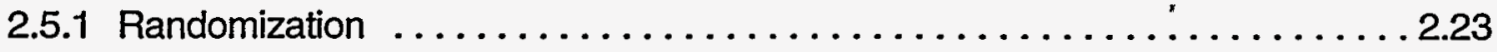

2.5 .2 Statistical Analysis of Solid-Phase Tests . . . . . . . . . . . . . 2.23

2.5.3 Statistical Analysis of Suspended-Particulate-Phase Tests . . . . . . . 2.23

2.5 .4 Statistical Analysis of Bioaccumulation . . . . . . . . . . . . . 2.24 
2.6 QUALITY ASSURANCE/QUALITY CONTROL PROCEDURES ...........2.24

2.6.1 Sample Tracking and Storage . . . . . . . . . . . . . . . . . . . . . 2.25

2.6.2 Quality Control Procedures for Sediment and Tissue Chemistry ......... 2.25

2.6.3 Toxicological Testing Quality Control Procedures $\ldots \ldots \ldots \ldots \ldots \ldots \ldots .2 .26$

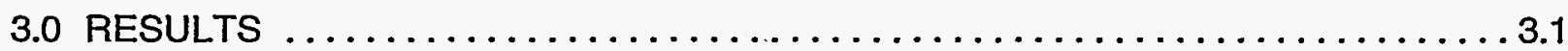

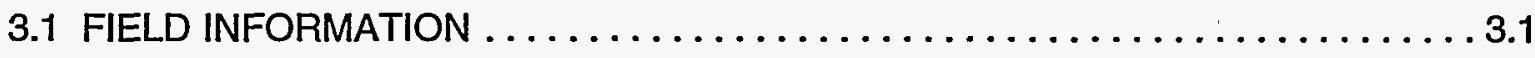

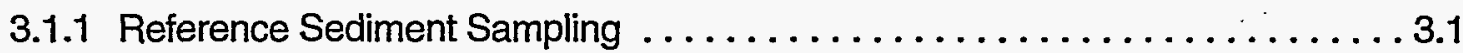

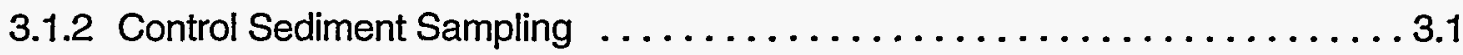

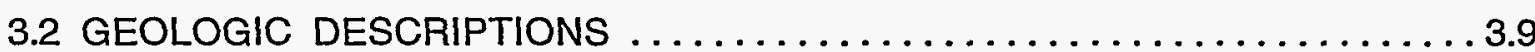

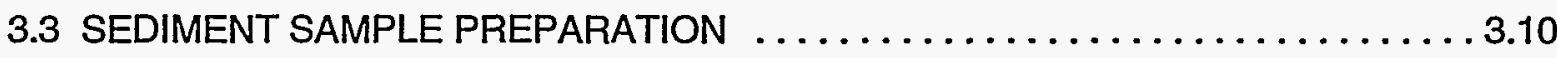

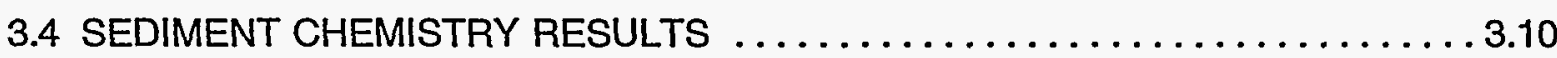

3.4.1 Physical and Chemical Attributes of OBM Sediments from Richmond Harbor . 3.10

3.4.2 Conventional Measurements ............................... 3.11

3.4.3 Polynuclear Aromatic Hydrocarbons . . . . . . . . . . . . . . . . . . . 3.14

3.4.4 Chlorinated Pesticides and Polychlorinated Biphenyls $\ldots \ldots \ldots \ldots \ldots . .16$

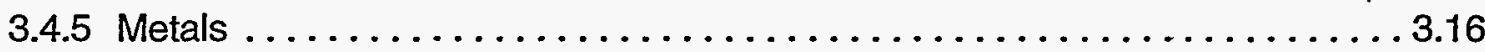

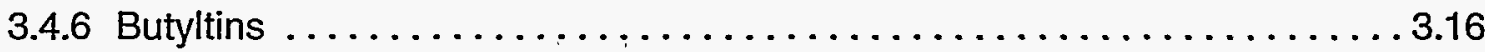

3.5 TOXICOLOGICAL TESTING RESULTS $\ldots \ldots \ldots \ldots \ldots \ldots \ldots \ldots \ldots \ldots \ldots \ldots \ldots \ldots \ldots \ldots$

3.5.1 10-Day Solid-Phase Static Test with $R$. abronius .................17

3.5.2 10-Day Solid-Phase Flow-Through Test with M. nasuta and N. caecoides . . 3.18

3.5.3 28-Day Solid-Phase Flow-Through Bioaccumulation .Test with M. nasuta . . 3.18

3.5.4 48-Hour Suspended-Particulate-Phase Static Test with

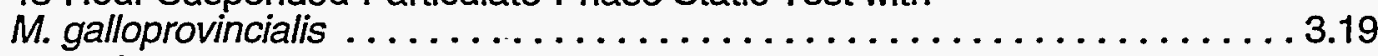

3.5.5 96-Hour-Suspended-Particulate-Phase Static Test with C. stigmaeus . . . . . 3.21

3.5.6 96-Hour Suspended-Particulate-Phase Static Test with $H$. costata . . . . . . 3.22

3.5.7 10-Day Solid-Phase Flow-Through Feeding Tests with $N$. caecoides . .....3.23

3.5.7.1 Results of the Preliminary Feeding Study $\ldots \ldots \ldots \ldots \ldots \ldots . .23$

3.5.7.2 Results of the Definitive Study ......................... 3.24

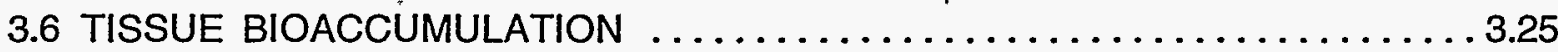

3.6.1 Polynuclear Aromatic Hydrocarbon Bioaccumulation in M. nasuta . . . . . . . 3.25

3.6.2 Chlorinated Pesticides and Polychlorinated Biphenyls Bioaccumulation in M. nasuta .........................................25

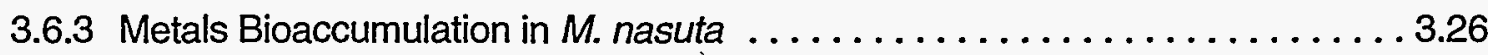

3.6.4 Butyltin Bioaccumulation in $M$. nasuta .......................26

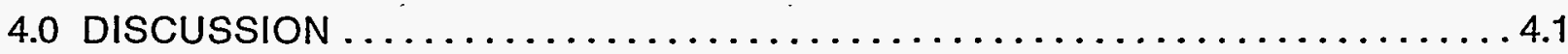

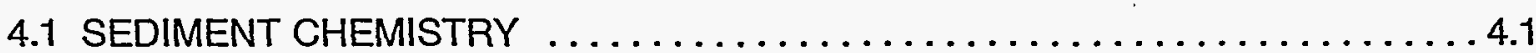

4.2 TOXICOLOGICAL EVALUATIONS $\ldots \ldots \ldots \ldots \ldots \ldots \ldots \ldots \ldots \ldots \ldots \ldots \ldots \ldots \ldots \ldots \ldots$

OLDER BAY MUD 
4.2.1 Deposited Sediment (Solid-Phase) Acute Toxicity ............ 4.1

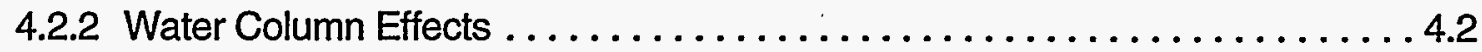

4.3 BIOACCUMULATION RESULTS $\ldots \ldots \ldots \ldots \ldots \ldots \ldots \ldots \ldots \ldots \ldots \ldots \ldots$

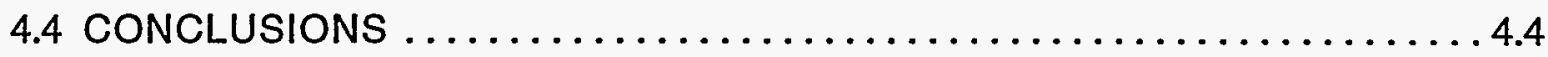

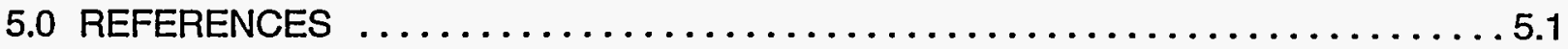

APPENDIX A SEDIMENT CHEMISTRY AND QUALITY ASSURANCE DATA . . . . . . . A.1

APPENDIXB BIOASSAY RESULTS FOR 10-DAY SOLID-PHASE, STATIC TEST

AND 96-HOUR REFERENCE TOXICANT TEST FOR

RHEPOXYNIUS abronius . .....................

APPENDIX C BIOASSAY RESULTS FOR 10-DAY SOLID-PHASE, FLOW-THROUGH

TEST WITH MACOMA nasuta AND NEPHTYS caecoides ............ C.1

APPENDIXD BIOASSAY RESULTS FOR 28-DAY SOLID-PHASE, FLOW-THROUGH

TEST WITH MACOMA nasuta ...................... D.1

APPENDIXE BIOASSAY RESULTS FOR 48-HOUR SUSPENDED-PARTICULATEPHASE TEST AND 48-HOUR REFERENCE TOXICANT TEST FOR

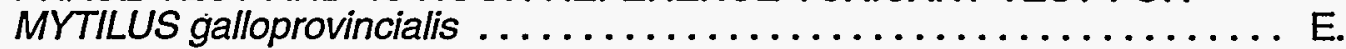

APPENDIXF BIOASSAY RESULTS FOR 96-HOUR SUSPENDED-PARTICULATEPHASE TEST AND 96-HOUR REFERENCE TOXICANT TEST FOR CITHARICHTHYS stigmaeus ......................... 1

APPENDIX G BIOASSAY RESULTS FOR 96-HOUR SUSPENDED-PARTICULATEPHASE TEST AND 96-HOUR REFERENCE TOXICANT TEST FOR HOLMESIMYSIS costata.

APPENDIXH BIOASSAY RESULTS FOR 10-DAY SOLID-PHASE, FLOW-THROUGH TEST WITH NEPHTYS caecoides FOR FEEDING STUDY . . ........ H.1

APPENDIXI TISSUE CHEMISTRY AND QUALITY ASSURANCE DATA FOR

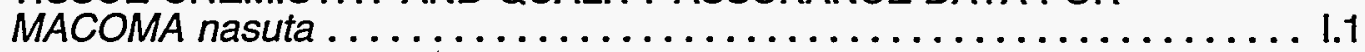

\section{FIGURES}

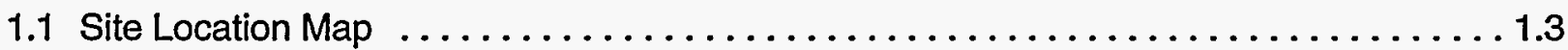

2.1 Flow-Through Aquaria for the 10-Day and the 28-Day M. nasuta and N. caecoides

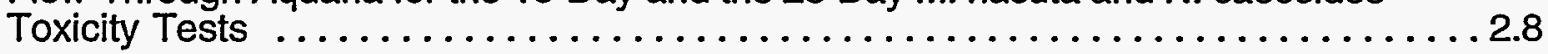

2.2 Linear Regression of Percent TOC vs. Percent Survival of $N$. caecoides $\ldots \ldots \ldots \ldots 2.16$

3.1 Location of Deep Off-Shelf Reference Area $(R-O S) \ldots \ldots \ldots \ldots \ldots \ldots \ldots \ldots \ldots$

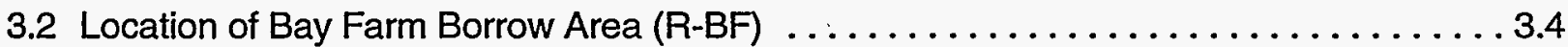

3.3 Location of Alcatraz Environs Reference Area (R-AM) . . . . . . . . . . . 3.5

3.4 Location of M. nasuta Control (C-SB), Sequim Bay, Washington . . . . . . . . . 3.6 
3.5 Location of $R$. abronius Control (C-WB), West Beach, Whidbey Island, Washington . . 3.7 3.6 Location of $N$. caecoides Control (C-NE), Tomales Bay, California . . . . . . . . 3.8

\section{TABLES}

2.1 List of Analytes, Methods, and Target Detection Limits $\ldots \ldots \ldots \ldots \ldots \ldots \ldots \ldots 2.20$

3.1 Sediment Contribution of each Sampling Site for Chemical and Biological Testing,

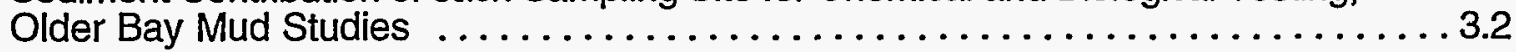

3.2 Summary of Sediment Treatment Strategy for Chemical and Biological Testing,

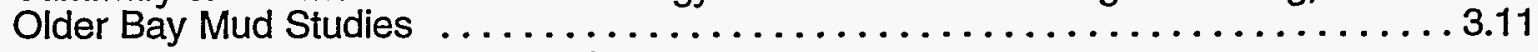

3.3 Physical and Chemical Results of the Older Bay Mud Sediments, The Older Bay

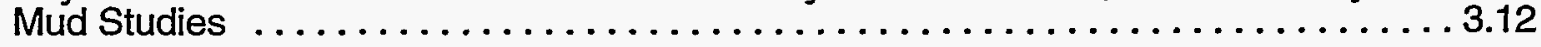

3.4 Conventional Sediment Measurement Results for the Older Bay Mud Studies . . . . . . 3.13

3.5 Detected Total PAHs, Pesticides, PCBs, Metals, and Butyltins in the Three Older

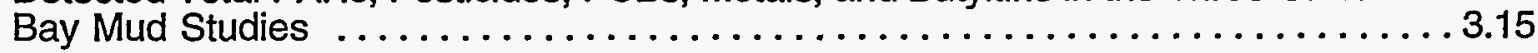

3:6. Summary Results of the 10-Day Solid-Phase Static Test with $R$. abronius ........ 3.18

3.7 Summary Results of the 10-Day Solid-Phase Flow-Through Test with M. nasuta . . : 3.19

3.8 Summary Results of the 10-Day Solid-Phase Flow-Through Test with $N$. caecoides

3.9... Summary Results of the 28-Day Solid-Phase Flow-Through Test with M. nasuta ....... 3.20

3.10 Summary Results of the-48-Hour Suspended-Particulate-Phase Test with

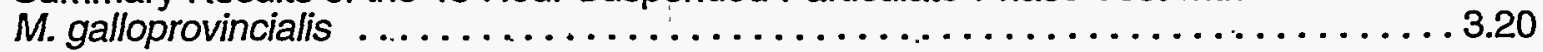

3.11 Summary Results of the 96-Hour Suspended-Particulate-Phase Test with C. stigmaeus

3.12 Summary Results of the 96-Hour Suspended-Particulate-Phase Test with H. costata

3.13 Summary Results for the 10-Day N. caecoides Preliminary Test . . . . . . . . . . . 3.24

3.14 Measurements of TOC in the OBM Sediments Mixed with Different Amounts of

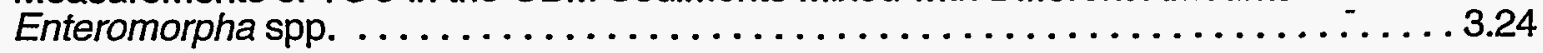

3.15 Summary of the 10-Day $N$. caecoides Results for the Definitive Test . . . . . . . 3.26

3.16 Tissue Contaminant Concentrations in $M$. nasuta Tissues Exposed to the OBM Comp, Reference Sediments, and Control Sediments for Bioaccumulation Tests.

4.1 Summary of Solid-Phase Toxicity Results $\ldots \ldots \ldots \ldots \ldots \ldots \ldots \ldots \ldots \ldots .2$

4.2 Summary of the Suspended-Particulate-Phase Toxicity Test Results, Older Bay

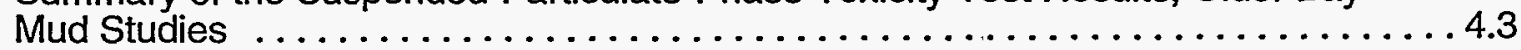

4.3 Comparison of FDA Action Levels With Contaminant Levels in M. nasuta Exposed

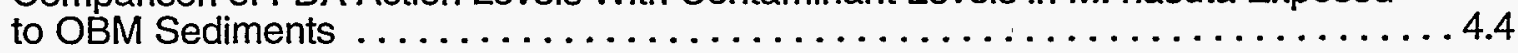


4.4 Summary of Statistically Significant Acute Toxicity and Bioaccumulation for the Older Bay Mud Studies 4.5 


\subsection{INTRODUCTION}

Richmond Harbor lies on the eastern shoreline of central San Francisco Bay in California and has been studied extensively through chemical and biological evaluations, such as Environmental Evaluations for Deepening of Richmond Harbor and Santa Fe Channels, Task 4: Chemistry Program (Brown et al. 1990), Ecological Evaluation of Proposed Dredged Material from Richmond Harbor (Pinza et al. 1992), Ecological Evaluation of Richmond Harbor Maintenance Sediments (Pinza and Word 1993, letter report), and Ecological Evaluation of Proposed Dredged Material from Richmond Harbor Deepening Project (Pinza et al. 1995). These studies have evaluated the potential chemical contamination and biological effects of younger bay mud (YBM), which is one of the two main geologic units in the area. The YBM is underlain by the more compacted older bay mud (OBM). These two geologic units can be distinguished on the basis of consistency and color. The firm to hard, very dry OBM sediments include both estuarine and terrestrial deposits and are various shades of red, brown, yellow, or gray. The YBM sediments are recent marine deposits that are soft and dark gray to black in color.

The OBM unit predates modern man and could act as a barrier to the downward transport of contaminants from the YBM because of its hard-packed consistency. However, its chemical and biological nature have not been well characterized. Battelle/Marine Sciences Laboratory (MSL) conducted three independent studies of OBM sediment in January 1993, January 1994, and October 1994. These studies evaluated potential chemical contamination and biological effects of OBM that could occur as a result of dredging and disposal activities. These evaluations were performed by conducting chemical analysis, solid-phase toxicity tests, suspended-particulate-phase (SPP) toxicity tests, and bioaccumulation tests on the OBM sediment. If the sediment chemistry and toxicity results showed no or minimal contamination and toxicological responses, then either the OBM could be left exposed in Richmond Harbor after dredging the YBM without leaving a source of contamination, or if the project depths necessitate, the OBM would be acceptable for disposal at an appropriate disposal site.

Test organism selections followed the guidelines in the Evaluation of Dredged Material Proposed for Ocean Disposal (Testing Manual) (EPA/USACE 1991), also referred to as the 1991 Implementation Manual. The species chosen for acute toxicity solid-phase tests were the infaunal burrowing amphipod, Rhepoxynius abronius, the polychaete, Nephtys caecoides, and the bentnose clam, Macoma nasuta. Larvae of the bivalve, Mytilus galloprovinicialis, the mysid, Holmesimysis costata, and the juvenile speckled sanddab, Citharichthys stigmaeus, were used for the SPP testing. The bentnose clam, M. nasuta, was chosen as the test species to measure potential OBM contaminant availability. These species have been successfully used in other programs conducted by the MSL. 
The purpose of the solid-phase tests was to examine the potential acute toxicity of the OBM to benthic organisms. The SPP toxicity tests were designed to measure the effects of any suspended and dissolved contaminants on water column organisms after allowing for initial mixing of the proposed dredged material. The bioaccumulation of contaminants in the tissues of M. nasuta measured the potential availability of any polynuclear aromatic hydrocarbons (PAHs), chlorinated pesticides, polychlorinated biphenyls (PCBs), metals, and butyltins. Validation of test results is accomplished by observing the response of the test organisms exposed to their native control sediment.

In January 1993, OBM sediment was collected from six locations in Richmond Harbor (Figure 1.1). The six samples were combined in a single composite, OBM COMP. Chemical analyses of the OBM COMP and the three native controls (West Beach control [C-WB], Sequim Bay control [C-SB], and San Pablo Bay control [C-SPB]) consisted of U.S. Environmental Protection Agency (EPA) priority pollutant PAHs, PCBs, chlorinated pesticides, metals, butyltins, and conventional sediment parameters. In conjunction with the chemical inventory, a biological evaluation was performed using a solid-phase acute toxicity test with $R$. abronius, two SPP toxicity tests with $M$. galloprovincialis larvae and $H$. costata, and one bioaccumulation potential test with $M$. nasuta.

In January 1994, OBM sediment was collected from 23 selected sites in Richmond Harbor as shown in Figure 1.1. The sediment from the 23 sites was combined into a single composite, OBM COMP. The intent of this study was to confirm the bioaccumulation of tributyltin in the tissues of $M$. nasuta that was observed in the 1993 study and to perform a more in-depth toxicological analysis of OBM sediment. The OBM COMP and the three reference sediments (the Deep Off-Shelf Reference Area [R-OS], the Bay Farm Borrow Area [R-BF], and the Alcatraz Environs Reference Area [R-AM]) were chemically analyzed for PCBs, chlorinated pesticides, and butyltins. The control sediment was archived for future potential analysis. The OBM COMP was tested in three acute toxicity solid-phase tests using $R$. abronius, $M$. nasuta, and $N$. caecoides. The SPP prepared from the OBM COMP was exposed to $C$. stigmaeus, M. galloprovincialis larvae, and $H$. costata. M. nasuta were exposed to the OBM COMP to measure the bioaccumulation potential in the tissues after a 28-day exposure period. The tissues were then analyzed for PCBs, chlorinated pesticides, and butyltins.

- In October 1994, OBM sediment was collected from four sites in Richmond Harbor as shown in Figure 1.1. As in the previous studies, sediment was combined in a single composite. The focus of this study was to examine the low survival of $N$. caecoides exposed to the OBM sediment collected in January 1994. It is suspected that the hard-packed nature of the OBM makes it difficult for $N$. caecoides to burrow, and it was further suspected that the low concentration of total organic carbon (TOC) represented an inadequate food supply. The OBM 


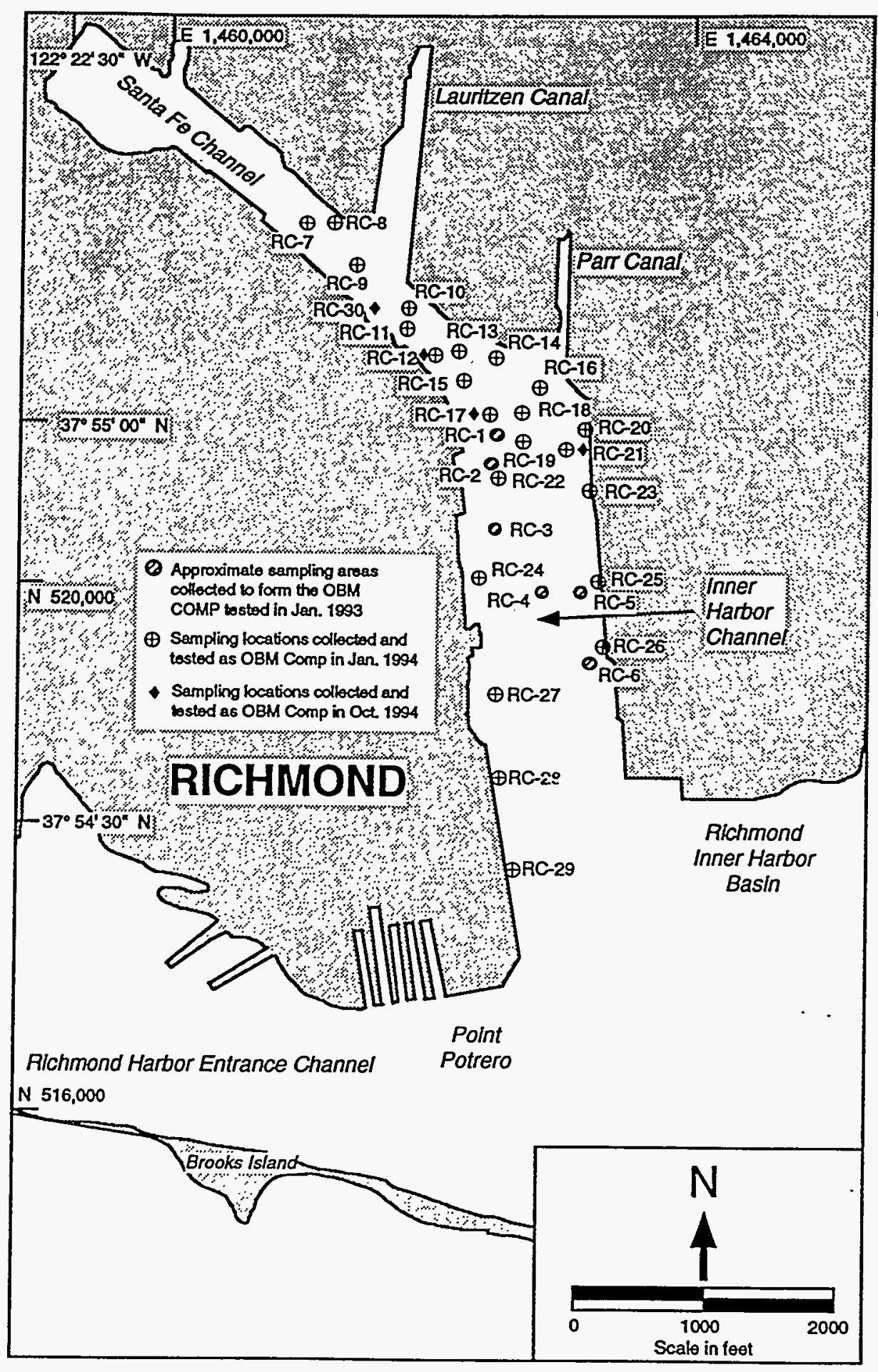

FIGURE 1.1. Site Location Map 
COMP and the three reference sediments (R-OS, R-BF, and R-AM) were chemically analyzed for the same parameters as those in the January 1993 study. The control sediment was archived for future potential analysis. The OBM COMP was tested in an acute toxicity solid-phase test using $N$. caecoides in which the OBM COMP sediment was enriched with different food sources and softened with seawater prior to the addition of test organisms.

This report describes the characteristics of the OBM sediments from the three studies and is divided into five sections. Section 1.0 is the introduction, containing a brief overview of the project. Section 2.0 describes the materials and methods used for sample preparation and handling, biological testing, physical and chemical analyses of sediments and tissues, data analysis, and quality assurance requirements. Section 3.0 presents the results of the physical and chemical sediment chemistry analyses and the biological toxicity/bioaccumulation testing for the three OBM composites. Section 4.0 is the discussion of the results and conclusions. Section 5.0 lists the literature cited in support of this document. Appendixes containing detailed data for the following areas are presented as follows:

Appendix A Sediment Chemistry and Quality Control Data Appendix B-H Toxicity Test Data

Appendix I M. nasuta Tissue Chemistry and Quality Control Data. 


\subsection{MATERIALS AND METHODS}

\subsection{SEDIMENT AND TEST ORGANISM COLLECTION}

Sediment samples were collected from Richmond Harbor during January 1993, January 1994, and October 1994. After each field collection, OBM sediment used for each study was submitted for chemical and biological analysis.

\subsubsection{Test Sediment Collection}

The January 1993 study included sampling locations for the Inner Channel of Richmond Harbor (RC-1 through RC-6). Samples of sediments were obtained using a 4-in. diameter vibratory hammer core and were stored in the noncontaminating Lexan polycarbonate tubes contained in the core barrel. These core tubes maintain the stratigraphic integrity of the sediments and allowed a geologist to vertically characterize the sediment types present at each field station. Selected sites in Richmond Harbor (RC-7 through RC-29) were sampled for the January 1994 study using a 12-in. diameter vibratory hammer core. The OBM from these sites was taken from the 12-in. core barrel and placed into epoxy coated buckets. The sediments collected for the October 1994 study (RC-12, RC-17, RC-21, and RC-30) were obtained using a 4-in. core barrel. Sediments were maintained at approximately $4^{\circ} \mathrm{C}$ during shipment in a refrigerated van to Sequim, Washington. Upon arrival at the MSL, sediments were transferred to a climate-controlled cold room and maintained at $4^{\circ} \mathrm{C}$ until processed for chemical analysis and toxicological testing.

\subsubsection{Reference and Control Sediment Collection}

Reference sediment samples R-AM, R-BF and R-OS were collected using a pipe dredge deployed from the FV Cobra, a charter boat owned and operated by Bob Smith Sportfishing. Sampling locations were determined by LORAN $C$ and variable fix and range radar systems aboard the vessel and by a Raytheon Global Positioning System (GPS). The vessel navigation systems were verified at known fixed locations, such as the Golden Gate channel pilot buoy. Reference sampling records were maintained in a log book, and consisted of station position, date, time, replicate, water depth, sediment type, and comments. All reference samples were kept in labeled coolers on board the sampling vessel until they were off-loaded to the refrigerated van.

The native control sediment sampling locations were Whidbey Island, Washington, (R. abronius), Sequim Bay, Washington ( $M$. nasuta), and Tomales Bay/Dillon Beach, California ( $N$. caecoides). Control sediment and test organisms from Whidbey Island were collected by MSL personnel using a 19-ft Boston Whaler. The sampling location was determined by reference to shoreline features. Whidbey Island sediment was collected with a small, MSL-designed, anchor-dredge sampler that also obtained sufficient quantities of test organisms. The dredge was 
deployed in approximately $15 \mathrm{ft}$ of water. Experimental control sediment from Sequim Bay was collected with a modified van Veen grab sampler $\left(0.1 \mathrm{~m}^{2}\right)$ deployed from an MSL research vessel. The Tomales Bay/Dillon Beach sediment was collected using a shovel, bucket, and sieve. In addition to the three toxicity test native controls, a fine-grained control was collected from San Pablo Bay, California, and was tested during the January 1993 study only. This control was analyzed for sediment chemistry to provide a basis of comparison with the OBM.

\subsubsection{Test Organism Collection}

Six species of organisms were used to evaluate sediments from the OBM segments of the Richmond Harbor study area:

- the amphipod Rhepoxynius abronius

- the polychaete Nephtys caecoides

- $\quad$ the bivalve Macoma nasuta

- the speckled sanddab Citharichthys stigmaeus

- $\quad$ larvae of the mussel Mytilus galloprovincialis

- the invertebrate Holmesimysis costata.

All test organisms were collected either by a commercial supplier or by MSL personnel. The organisms were shipped in native sediment or in a way designed to ensure their viability. After receipt at the MSL, test organisms were gradually acclimated to test conditions. Animals acting abnormally or exhibiting stress were not used in toxicological tests. $R$. abronius were collected from Whidbey Island and were transported in clean coolers containing approximately $10 \mathrm{~cm}$ of sediment and $5 \mathrm{gal}$ of clean seawater at a temperature approximating natural conditions. $N$. caecoides were collected from mud flats in Tomales Bay, and placed into clean coolers containing sediment and seawater from the collection site. Prior to overnight shipment to the MSL, the seawater in each cooler was supersaturated with oxygen (22 ppm). M. nasuta were collected from the intertidal zones of beaches in Discovery Bay, near Gardiner, Washington, by Gunstone and Johnson, commercial suppliers. The clams were held in large tanks of clean Sequim Bay sediment with flowing $15^{\circ} \mathrm{C}$ seawater. C. stigmaeus were collected from Tomales Bay, in $12 \mathrm{ft}$ to $15 \mathrm{ft}$ of water, using a small trawl with a 0.25 -in. mesh net. The trawl was held close to the work boat so a dip net could be used to directly transfer $C$. stigmaeus into double plastic bags containing oxygen-saturated seawater. $H$. costata were collected by Brezina and Associates with a plankton dip net and transferred to a holding container aboard the work boat, where they were sorted by appropriate age and size class and then shipped to the MSL in bags containing oxygen-saturated water. The M. galloprovincialis were purchased from Taylor United, Inc. in Quilcene, Washington. These organisms were wrapped in moist paper towels and shipped in styrofoam coolers containing blue ice to maintain an ambient temperature of approximately $15^{\circ} \mathrm{C}$. 


\subsection{SEDIMENT SAMPLE PREPARATION}

Sediment sample preparation involved all steps in the laboratory from delivery of the samples to the MSL to the preparation of sediments for chemical and/or biological testing. Sediment used for biological testing was prepared within the 6-week holding period as specified in the 1991 Implementation Manual. During this holding time, the samples were received at the MSL, inventoried against chain-of-custody forms, processed for testing, subsampled for sediment chemistry parameters, and used in the biological tests. The following sections describe the methods for geologic description of cores, equipment preparation, compositing strategy, preparation of sediments for chemistry, and solid-phase and SPP testing.

\subsubsection{Geologic Description of Individual Core Samples}

A geologic description of the sediment contained in the 4-in. cores from each sampling location was conducted by an MSL geologist during the January 1993 and October 1994 studies. The OBM collected in January 1994 was transferred from the 12-in. core barrel to epoxy-coated buckets in the field; therefore, the cores were not described. All 4-in. core sections from one station were removed from storage and the Lexan tube was cut longitudinally with a circular saw. A linoleum knife was used to split the core open, exposing the sediment profile. The geologist measured and described the entire core from mudline to bottom, recording information on a core data log. The geologic characterization protocol was consistent with American Society of Testing Materials (ASTM) Method D2488-84 (ASTM 1984). The OBM segments of each core were removed from the core tube and composited into one sediment treatment for testing.

\subsubsection{Laboratory Glassware and Equipment Preparation}

All glassware, stainless-steel or titanium utensils, Nalgene, Teflon, and other laboratory containers and equipment underwent stringent cleaning procedures to avoid contamination of samples. Glassware, including test containers, aquaria, and sediment transfer dishes, was washed with warm, soapy water, rinsed five times with deionized water, then soaked in a $5 \%$ reagent grade nitric acid bath for a minimum of $4 \mathrm{~h}$. After soaking, glassware was rinsed with deionized water five times and allowed to dry. Polyvinyl chloride (PVC), Nalgene, and Teflon tools were also washed and soaked in acid baths in the same manner as for glassware.

Stainless-steel bowls, spoons, spatulas, and other utensils were washed with warm, soapy water, rinsed five times with deionized water, and allowed to air dry. They were then rinsed with methylene chloride under a fume hood, and the methylene chloride was allowed to evaporate under the hood.

Neoprene stoppers and polyethylene sheets or other porous materials were washed with warm, soapy water and rinsed five times with deionized water. These items were then "seasoned" by continuous soaking in $0.45-\mu \mathrm{m}$-filtered seawater for at least 2 days prior to use. 
Large pieces of laboratory equipment, such as the epoxy-coated mixer that is used to mix sediment, were washed with a mild soap solution and thoroughly rinsed with tap water followed by deionized water.

Equipment used to determine water quality, such as $\mathrm{pH}$, dissolved oxygen (DO), temperature, salinity, and ammonia were calibrated according to the manufacturer's specifications and internal MSL procedures.

\subsubsection{Preparation of Solid-Phase Treatments for Chemical and Biological Testing}

Solid phase refers to the sediment itself, as opposed to sediment suspended or dissolved in water. In the biological tests, the solid phase of sediments represents 1) dredged material once it has settled at an aquatic disposal site, or 2) the native environment of a benthic test organism (control sediment). The OBM sediments from the Richmond Harbor sampling sites for each study were homogenized into one sediment composite for each study and evaluated for toxicity relative to the appropriate control treatments. To thoroughly homogenize the OBM COMP for each study, the OBM sediment was grated using a stainless steel grater and then mixed in an epoxy-coated cement mixer until the composite was homogeneous. All solid-phase samples were thoroughly homogenized before use in biological tests or chemical analysis.

Control sediments were press sieved through a $1.0-\mathrm{mm}$ screen to remove predators. Test sediments were processed by combining the sediment from all contributing stations into an epoxy-coated mixer and mixing until a homogenous color and texture were evident. Between mixing of the test and control sediments, all equipment was thoroughly rinsed with $0.45-\mu \mathrm{m}$-filtered seawater to avoid cross-contamination. After compositing, sample aliquots for chemical analyses were placed in cleaned and labeled containers appropriate for the parameters to be measured and a subsample of each sediment treatment was archived. All sediment treatments (test and control) were then placed in precleaned containers that were sealed, labeled and maintained at $4^{\circ} \mathrm{C} \pm 2^{\circ} \mathrm{C}$ until needed for biological testing.

\subsubsection{Preparation of Suspended-Particulate-Phase Samples for Biological Testing}

The SPP of sediment samples was used to evaluate potential water-column effects that could occur during dredging or after disposal at open-water dredged material disposal sites. The SPP is the liquid supernatant that remains after mixing sediment with seawater and allowing heavier particles to settle to the bottom. Because the SPP preparation does not involve filtration, this phase contains suspended particles as well as dissolved constituents. The SPP tests evaluate effects caused by both the physical presence of the suspended particles and the chemical toxicity of contaminants associated with the particles or dissolved constituents. The process is intended to approximate exposure conditions created as a result of the disturbance 
materials during the dredging process or after discharge through the water column during dredge material disposal operations.

The SPP is prepared by creating a 4:1 (volume:volume) water to sediment slurry in 1-L glass jars with Teflon-lined lids. The jars were marked at $200 \mathrm{~mL}, 400 \mathrm{~mL}$, and $1 \mathrm{~L}$. Filtered seawater $(0.45-\mu \mathrm{m})$ was added to the $200-\mathrm{mL}$ mark, then homogenized sediment was added until the water was displaced to the $400-\mathrm{mL}$ mark. The jar was then filled to $1 \mathrm{~L}$ with filtered seawater. Twelve jars of sediment and water were placed on a shaker table and agitated for $30 \mathrm{~min}$ at a shaking rate of 120 to $150 \mathrm{cycles} / \mathrm{min}$. After shaking, the slurry was poured into $500-\mathrm{mL}$ Teflon containers with tightly fitting lids. These containers were placed in a centrifuge and spun for 10 to $15 \mathrm{~min}$ at a g-force of 777 (equivalent to a 24 -h settling period). The centrifugation was necessary to ensure that larval test organisms would be visible at the first microscopic observation after exposure to SPP test treatments. After centrifugation, the supernatant was poured into clean, labeled, 1-gal jars and used in the SPP tests as soon as possible (within $24 \mathrm{~h}$ ). The Teflon jars were rinsed out after each use and the above process was continued until an adequate amount of SPP was produced for one sediment treatment. Between sediment treatments, the Teflon jars were cleaned as described in Section 2.2.2.

\subsection{TOXICOLOGICAL AND BIOACCUMULATION TESTING PROCEDURES}

Toxicological tests involving six test species were conducted in support of the three OBM studies. The following solid-phase tests were conducted: a 10-day solid-phase static acute toxicity test using the amphipod $R$. abronius, a 10-day solid-phase flow-through acute toxicity test using $M$. nasuta and $N$. caecoides, and a 10-day solid-phase flow-through acute toxicity test with $N$. caecoides subjected to different concentrations of TOC and food sources. A 28-day solid-phase flow-through test was conducted to evaluate the bioaccumulation potential of OBM contaminants in tissues of the clam M. nasuta. Each test had five replicates of OBM sediment plus five replicates of the appropriate native control. Three SPP tests were conducted: 1) a 48-h exposure using the larvae of the mussel $M$. galloprovincialis, 2) a 96-h exposure using the mysid $H$. costata, and 3 ) a 96-h exposure using the sanddab $C$. stigmaeus. The SPP treatments were prepared as described in Section 2.2.4. There were three replicates of each SPP concentration: $10 \%, 50 \%$, and $100 \%$ (SPP) and three replicates of the 0\% SPP (dilution water). All test containers were placed in random positions in the water tables.

The MSL facilities provided the required conditions for flow-through solid-phase tests, static solid-phase tests, and static SPP tests. Laboratory equipment included a controlledtemperature environment, flow-through seawater supply, lighting control, and air supply. 


\subsubsection{0-Day Solid-Phase Static Test with $R$. abronius}

The $R$. abronius were held in a large holding tank containing their native sediment with flowing $15^{\circ} \mathrm{C}$ seawater. Organisms were not fed during the holding period, which was less than two weeks before test initiation. The $R$. abronius test was conducted in 1-qt static Mason jars, which were placed in random positions on a water table maintained at $15^{\circ} \mathrm{C}$. Prior to test initiation, sediment was added to the jars to a depth of $2 \mathrm{~cm}$, then each jar was slowly filled with $0.45-\mu \mathrm{m}$ filtered seawater to a total volume of $750 \mathrm{~mL}$. The jars were placed on the water table overnight to stabilize to test conditions. After settling, initial water quality parameters were measured in each container and recorded on water quality forms. Gentle aeration was applied to each jar, and the test was conducted under 24-h illumination.

The $R$. abronius test was initiated by adding 20 organisms to each test container. The amphipods were gently sieved from the holding tank into clean seawater and counted into small transfer containers. The number of organisms was then confirmed by a second observer before organisms were transferred into the test containers. The $R$. abronius were observed daily during testing, and the number of organisms floating on the surface, swimming in the jar, or on the sediment surface were recorded on observation forms. Amphipods floating on the surface were gently pushed below the water surface with a pipet tip, and observations were made as to whether they remained on the sediment surface, buried below the sediment, or returned to the surface of the water.

For the January 1994 study, two additional tests were set up for each sediment treatment. These additional replicates, referred to as dummy jars, were prepared in the same manner as the test containers, with the exception that no organisms were added. The dummy jars were sacrificed to obtain a porewater ammonia measurement; therefore, the porewater ammonia measurements of the sediment treatments were conducted prior to start of the test and on Day 10 (termination).

Water temperature, salinity, $\mathrm{pH}$, and $\mathrm{DO}$ were measured daily in one replicate of each sediment treatment, and in all containers at initiation and termination of the test. For the January 1994 study, ammonia was measured in the overlying water on Days 0, 1, 3, 7, and 10 and in the porewater on Days 0 and 10. Acceptable ranges for water quality parameters for the static $R$. abronius test were as follows:

$\begin{array}{ll}\text { DO } & \geq 6.0 \mathrm{mg} / \mathrm{L} \\ \text { pH } & 7.8 \pm 0.5 \text { units } \\ \text { Salinity } & 30 \pm 2.0 \% \circ \\ \text { Temperature } & 15 \pm 2.0^{\circ} \mathrm{C} \\ \text { Ammonia (porewater) } & \leq 30 \mathrm{mg} / \mathrm{L} .\end{array}$

At the end of the test (Day 10), the contents of each jar were sieved through a $0.5-\mathrm{mm}$ Nytex screen to collect the $R$. abronius. The organisms were placed in clean seawater in a glass 
dish labeled with the sediment treatment and replicate number. The number of live and dead organisms was counted and examined under a dissecting microscope. The presence or absence of body parts recovered at the end of the test was also noted. If an individual organisms did not respond to gentle probing it was considered dead. At least $10 \%$ of the mortality counts were confirmed by a second observer.

The cadmium (Cd) reference toxicant test was conducted at the same time as the 10-day test and was used to assess the health and relative sensitivity of the test organisms. The reference toxicant concentration series for each study is as follows: the January 1993 study was $0,0.5,1.0,2.0$, and $4.0 \mathrm{mg} \mathrm{Cd} / \mathrm{L}$ and the January 1994 study was $0,0.38,0.75,1.5$, and $3.0 \mathrm{mg} \mathrm{Cd} / \mathrm{L}$. The reference toxicant test followed the same testing procedure as the 10-day test.

A 96-h ammonia reference toxicant test was also conducted to establish the expected response of the test organisms to ammonia. The ammonia reference toxicant test was conducted in the same manner as the $\mathrm{Cd}$ reference toxicant test. $R$. abronius were exposed to a seawater control plus six nominal concentrations of ammonia $(10,20,40,80,120$, and $160 \mathrm{mg} / \mathrm{L}$ as ammonium chloride). The actual concentrations of ammonia were measured in this experiment and are reported in Section 3.0 of this report. There were three replicates of each concentration.

\subsubsection{0-Day Solid-Phase Flow-Through Test with M. nasuta and N. caecoides}

This test was performed only during the January 1994 study. Prior to testing, N. caecoides were held in their native sediment in shallow trays covered with well-aerated $15^{\circ} \mathrm{C}$ seawater from a gravity-fed flow-through system. M. nasuta were held in large water tables or holding tanks containing clean sediment with flow-through $15^{\circ} \mathrm{C}$ seawater. Temperature, $\mathrm{pH}, \mathrm{DO}$, and salinity of water in each holding tank were monitored daily. The organisms were not fed during the holding period.

The flow-through test with $M$. nasuta and $N$. caecoides was conducted in 10-gal aquaria placed in random positions on water tables. Figure 2.1 shows the system used for flow-through tests. Each aquarium was filled with approximately $8 \mathrm{~L}$ of sand-filtered seawater via the flowthrough system. Then, sediment was added to $a$ depth of $3 \mathrm{~cm}$ by measuring the required amount $(3870 \mathrm{~mL}$ ) into a glass container and pouring it into the aquarium while washing it with seawater to distribute the sediment evenly over the bottom. The flow-through system was initiated, and aquaria were allowed to fill to a total volume of approximately $36 \mathrm{~L}$. For $4 \mathrm{~h}$, the sediment in the aquaria was allowed to settle in the absence of flowing seawater. Then the flowthrough system was adjusted and calibrated to deliver $125 \pm 10 \mathrm{~mL} / \mathrm{min}$ of seawater flow to each aquarium. The system was allowed to operate overnight before the addition of test organisms. 


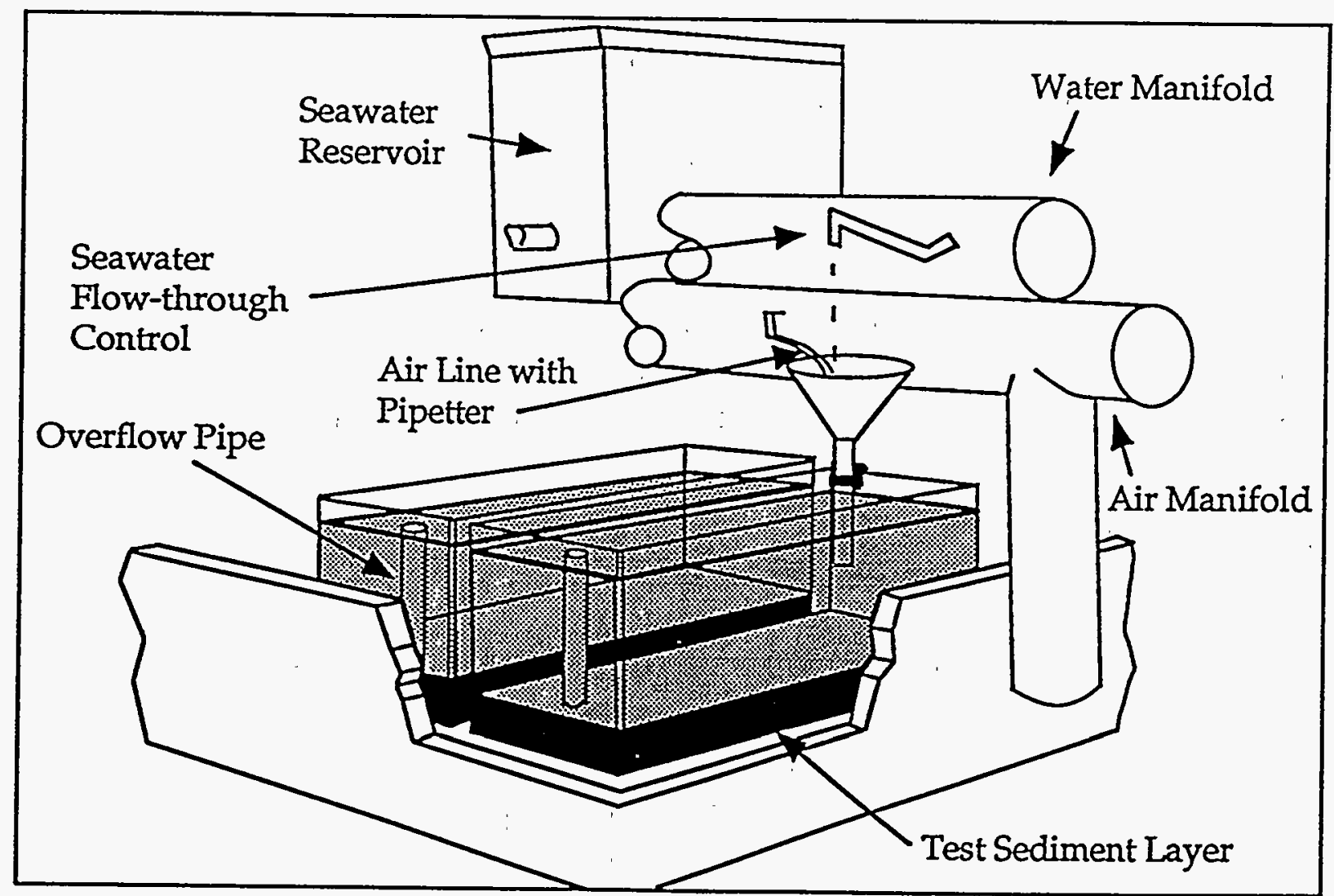

FIGURE 2.1. Flow-Through Aquaria for the 10-Day and the 28-Day M. nasuta and N. caecoides Toxicity Tests 
To initiate the test, $25 \mathrm{M}$. nasuta and $20 \mathrm{~N}$. caecoides were collected from the holding tanks and placed in each aquarium. Each test aquarium was labeled with initiation time/date and the initials of the examiner who placed the organisms in each chamber.

Daily observations of test-organism behavior were made and recorded on data forms. The number of $M$. nasuta on the sediment surface and the number of those with their siphons exposed was noted, as well as the number of $N$. caecoides on the sediment surface and the number of those with only their heads exposed. In addition, the number of dead organisms in each aquarium was recorded on daily observation forms. Dead organisms were removed from the aquaria and incinerated; no replacement of dead organisms occurred during testing. If any dead N. caecoides was removed, it was identified as a whole animal, a head, or a tail portion.

Water quality parameters (below) were measured daily in at least one replicate of each sediment treatment and recorded on water quality data sheets. The water quality parameters and ranges established for the tests were as follows:

$\begin{array}{ll}\text { DO } & \geq 6.0 \mathrm{mg} / \mathrm{L} \\ \text { pH } & 7.30-8.30 \\ \text { Salinity } & 30 \% \circ \pm 2.0 \% \circ \\ \text { Temperature } & 15.0^{\circ} \mathrm{C} \pm 2.0^{\circ} \mathrm{C} \\ \text { Flow Rates } & 125 \pm 10 \mathrm{~mL} \text { min } \\ \text { Ammonia } & \text { measured but presently not established. }\end{array}$

A replicate of each sediment treatment dummy jar was used to measure the interstitial porewater ammonia of the sediment treatments prior to initiation of the organisms and on Day 10 (termination).

At the end of the 10-day test, water quality measurements were performed in all replicates, and the contents of each aquarium were gently passed through a 1.0-mm Nytex screen to recover, the $N$. caecoides and $M$. nasuta. The organisms were placed in glass dishes and labeled with the sediment treatment number. At this time, the number of dead and live organisms of each species was counted. Death was determined by observing whether the $N$. caecoides reacted to gentle probing; if there was no movement, the organism was considered dead. Death of $M$. nasuta was determined by the presence of gaping shells. The mortality data were recorded on the termination forms. At least $10 \%$ of the mortality counts were confirmed by a second observer.

\subsubsection{8-Day Solid-Phase Flow-Through Test with M. nasuta}

The procedure for conducting the 28-day solid-phase flow-through test with $M$. nasuta was identical to that of the 10-day test, with three exceptions: 1) only M. nasuta were exposed in the bioaccumulation test; 2) the exposure period was increased from 10 to 28 days; 3) the surviving test organisms were depurated, and the tissues were sampled for chemical analysis. The ranges for water quality parameters, as well as the test conditions, such as temperature and 
flow rate, were the same for the 28-day test as for the 10-day test. Water quality parameters were measured, and mortality of the test organisms monitored at the same frequency for both tests.

When the 28-day test was terminated, the living $M$. nasuta were collected for chemical evaluation of bioaccumulation. To ensure that tissue chemistry results would not be biased by contaminants associated with sediment grains in the digestive tract, the test organisms were allowed to depurate, or void the digestive tract, for $48 \mathrm{~h}$ following the 28-day exposure. The surviving $M$. nasuta were placed in a glass dish (without sediment), and placed in an aquarium with flowing seawater. After $48 \mathrm{~h}$ of depuration, the $M$. nasuta shells were cleaned with a scrub brush prior to the removal of tissues using titanium knives. The tissues were placed into clean jars and submitted for chemical analysis.

\subsubsection{8-Hour Suspended-Particulate-Phase Static Test with M. galloprovincialis}

Mussels were held in flowing, unfiltered Sequim Bay seawater at ambient temperatures for approximately 5 days. Chambers for the bivalve-larvae test were 500-mL glass jars, labeled with sediment treatment code, concentration, position number, and replicate number. Dilutions of SPP $(0 \%, 10 \%, 50 \%$, and $100 \%)$ were made with Sequim Bay seawater and prepared individually for each test replicate. After all chambers reached testing temperatures $\left(16^{\circ} \mathrm{C} \pm 2^{\circ} \mathrm{C}\right)$, initial water quality parameters were measured in all replicates. Test chambers were placed in random positions on a water table and provided with gentle aeration.

Spawning was induced by placing adult M. galloprovincialis into $15^{\circ} \mathrm{C}$, filtered Sequim Bay seawater and then rapidly raising the holding water temperature to $20^{\circ} \mathrm{C}$. Spawning generally occurred within $1 \mathrm{~h}$ of temperature elevation. Spawning males and females were isolated in individual jars with filtered Sequim Bay seawater and allowed to shed gametes for approximately $45 \mathrm{~min}$. Eggs from each female were then filtered into separate jars through a $75 \mu \mathrm{m}$ Nytex screen to remove feces, detritus, and byssal fibers. Sperm from at least three males were pooled, and $10 \mathrm{~mL}$ of sperm solution was then added to the individual egg stocks. Egg-sperm solutions were mixed every $10 \mathrm{~min}$ with a perforated plunger. Fertilization proceeded for $1 \mathrm{~h}$, then the fertilization rate (percentage fertilized) was determined by removing a subsample and observing the number of multi-cell stage embryos. Fertilization was considered successful if greater than $90 \%$ of the embryos were in the multi-cell stage. To prevent polyspermy, egg stocks with greater than $90 \%$ fertilization were rinsed on a $20-\mu \mathrm{m}$ Nytex screen to remove excess sperm. Embryo stock-solution density was estimated by removing a $0.1 \mathrm{~mL}$ subsample and counting all multi-cell embryos, then multiplying by 10 to yield embryo density (embryos $/ \mathrm{mL}$ ). Stock solution was diluted or concentrated to yield 7500 to $9000 \mathrm{embryos} / \mathrm{mL}$. The test was initiated by introducing $1 \mathrm{~mL}$ of stock solution into each test chamber to produce embryo densities of 25 to $30 \mathrm{embryos} / \mathrm{mL}$. Test initiation date and time were recorded on data sheets. Following 
initiation, $10 \mathrm{~mL}$ stocking density subsamples were removed from each container and preserved in $10 \%$ formaldehyde to determine actual stocking density. Water quality parameters were measured in one replicate per treatment daily throughout the test. Acceptable ranges for water quality parameters were as follows:

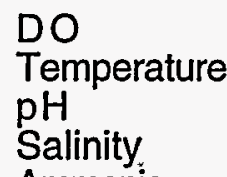

Ammonia

\author{
$\geq 4.0 \mathrm{mg} / \mathrm{L}$ \\ $16^{\circ} \mathrm{C} \pm 2^{\circ} \mathrm{C}$ \\ 7.30 to 8.30 \\ $30 \pm 2.0 \%$ \\ measured but presently not established.
}

The bivalve test was terminated after $48 \mathrm{~h}$, when greater than $90 \%$ of the larvae in the controls had reached the $\mathrm{D}$-cell stage (prodissoconch $\mathrm{l}$ ). Final water quality parameters were recorded for all replicates. In addition, ammonia concentrations were measured in one replicate of all $0 \%$ SPP and $100 \%$ SPP treatments.

Each chamber was then homogenized with a perforated plunger, and a 10-mL subsample was removed and placed into $20-\mathrm{mL}$ scintillation vial. The subsample was then fixed with $1 \mathrm{~mL}$ of $50 \%$ formaldehyde in seawater. Samples were scored for the appearance of normal D-shaped larvae (prodissoconch I), abnormal prodissoconch I larvae, developmentally delayed/abnormal larvae, and total number of larvae. At least $10 \%$ of the counts were confirmed by a second observer.

A 48-h copper (Cu) reference toxicant test was conducted with each batch of test larvae to establish the health and expected response of the test organisms. The reference toxicant test was set up and conducted in the same manner as the SPP tests. M. galloprovincialis larvae were exposed to a filtered Sequim Bay seawater control plus copper sulfate concentrations of $1 \mu \mathrm{g} / \mathrm{L}, 4 \mu \mathrm{g} / \mathrm{L}, 16 \mu \mathrm{g} / \mathrm{L}$, and $64 \mu \mathrm{g} / \mathrm{L}$ as $\mathrm{Cu}$, with three replicates per concentration. Because not all treatments could be tested concurrently, a separate reference test was performed with each round of tests to compare gamete sensitivity to a known toxicant.

A 48-h ammonia reference toxicant test was conducted in January 1994 to establish the sensitivity of test organisms to ammonia. M. galloprovincialis were exposed to a seawater control plus four nominal concentrations of ammonia $(1,10,20,80$, and $100 \mathrm{mg} / \mathrm{L}$ as ammonium chloride) and was conducted in the same manner as the SPP tests. Actual ammonia concentrations were measured for this experiment and are reported in Section 3.0 of this report. There were three replicates of each concentration.

\subsubsection{6-Hour Suspended-Particulate-Phase Static Test with C. stigmaeus}

The test chambers for the January 1994 SPP test with C. stigmaeus were 10-gal static aquaria randomly positioned on the water tables, with 20 to 24 aquaria per table. Test temperature was maintained by a circulating water bath on the water table. Aeration was 
provided through a glass pipet connected by silastic tubing to an overhead air manifold. Aquaria were labeled with a sediment treatment code, concentration, and replicate number. The volume of test material in each aquarium was $10 \mathrm{~L}$. To obtain the $100 \%$ SPP treatment, $10 \mathrm{~L} \mathrm{of} 100 \%$ SPP was added directly to the aquarium; the $0 \%$ SPP treatment consisted of $10 \mathrm{~L}$ of $0.45-\mu \mathrm{m}$-filtered Sequim Bay seawater. To prepare the $10 \%$ and $50 \%$ SPP concentrations, appropriate volumes of $100 \%$ SPP and $0.45-\mu \mathrm{m}$-filtered Sequim Bay dilution water were mixed directly in the test aquaria and filled to a volume of $10 \mathrm{~L}$.

After SPP preparation and placement of containers on the water table, aeration was started and initial water quality parameters were measured in all replicates. Ten $C$. stigmaeus were then removed from the holding tanks, using a net, and added to each test container. The test population for each concentration was 50 individuals (200 individuals per SPP treatment). Initiation time and date were documented on test containers and data forms.

Observations of $C$. stigmaeus activity and behavior in each test container were made at test initiation and at $4,24,48$, and $72 \mathrm{~h}$. An organism was considered dead if it did not respond to gentle probing.

C. stigmaeus were not fed during the 96-h exposure. After initiation, $\mathrm{DO}, \mathrm{pH}$, salinity, and temperature were measured daily in at least one replicate. Ammonia was measured in at least one replicate of the $100 \%$ SPP prior to initiation of test organisms and at the end of the 96-h test. Acceptable ranges for the water quality parameters during the experiment were as follows:
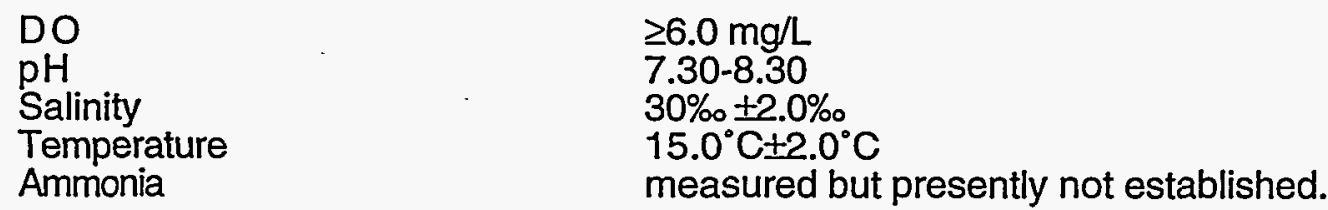

Before termination of the test at $96 \mathrm{~h}$, water quality parameters were measured in all replicates. At $96 \mathrm{~h}$, the number of live and dead organisms was counted in each test container. As a quality control check, a second observer confirmed at least $10 \%$ of the mortality counts.

A 96-h Cu reference toxicant test was also conducted to establish the health and expected response of the test organisms. The reference toxicant test was conducted in the same manner as the SPP tests. C. stigmaeus were exposed to a seawater control plus four concentrations of copper sulfate $(0.5,1.0,1.5$, and $2.0 \mathrm{mg} / \mathrm{L}$ as $\mathrm{Cu})$. There were three replicates of each concentration.

A 96-h ammonia reference toxicant test was also conducted to establish the expected response of the test organisms to ammonia. The ammonia reference toxicant test was conducted in the same manner as the SPP tests. C. stigmaeus were exposed to a seawater control plus four nominal concentrations of ammonia $(15,20,25$, and $30 \mathrm{mg} / \mathrm{L}$ as ammonium chloride). The 
actual concentrations of ammonia were measured in this experiment and are reported in Section 3.0 of this report. There were three replicates of each concentration.

\subsubsection{6-Hour Suspended-Particulate-Phase Static Test with H. costata}

Prior to testing, Holmesimysis costata were held for at least 48-h in static, aerated aquaria maintained at test temperature $\left(15^{\circ} \mathrm{C} \pm 2^{\circ} \mathrm{C}\right)$. In the holding tanks, $H$. costata were fed a dense solution of brine shrimp nauplii (Artemia salina) twice a day, and water quality parameters were monitored daily.

Test chambers for the $H$. costata were $500-\mathrm{mL}$ glass jars placed in random positions on water tables. Test temperature was maintained by immersing these containers in a circulating water bath. Aeration was provided through a pipet connected by silastic tubing to an overhead air manifold. Appropriate volumes of $100 \%$ SPP and $0.45-\mu$ m-filtered Sequim Bay seawater were added to 1-gal jars to make $0 \%, 10 \%, 50 \%$, and $100 \%$ SPP concentrations for the $H$. costata test. A total of $1500 \mathrm{~mL}$ was prepared for each dilution to provide the test volume of $300 \mathrm{~mL}$ in each of five replicates. All test chambers were labeled with position number, treatment code, concentration, and replicate number.

After the SPP concentrations were prepared and placed on the water table, gentle aeration was started and water quality parameters were measured in all test chambers. $H$. costata were then randomly removed from the holding tank using a wide-bore pipet. To initiate the test, 10 individuals were added to each container to produce a test population of 50 individuals per concentration. In the January 1993 study, three replicates were tested to produce a test population of 30 individuals per concentration.

Observations of test organisms were made at test initiation and at 4,24, 48, and $72 \mathrm{~h}$, using a light table to enhance visibility of the $H$. costata. During the $96-\mathrm{h}$ exposure period, $H$. costata were fed brine shrimp daily. Excess food was removed with a small pipet before daily observations, using extra caution not to disturb test animals. Molted exoskeletons and any particulates that had settled from the SPP solution were also removed.

After test initiation, water quality parameters were measured daily in at least one replicate per SPP concentration. Ammonia was measured in at least one replicate of the $100 \%$ SPP prior to initiation of the organisms and at the end of the 96-h test. Acceptable ranges for the water quality parameters during the experiment were as follows:

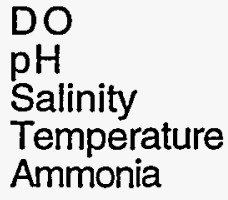

Ammonia $\geq 4.0 \mathrm{mg} / \mathrm{L}$

$7.8 \pm 0.5$ units

$30+2.0 \%$ o

$15.0+2.0^{\circ} \mathrm{C}$

measured but presently not established. 
Prior to test termination, water quality parameters were measured in all replicates. At $96 \mathrm{~h}$, the number of live and dead animals was counted in each test chamber. An organism was considered dead if it did not respond to gentle probing. As a quality control check, a second observer recounted surviving test organisms in at least $10 \%$ of the test containers.

A 96-h Cu reference toxicant test was conducted to establish the health and expected response of the test organisms. The reference toxicant test was conducted in the same manner as the SPP test. In the January 1993 study, H. costata were exposed to a seawater control along with four concentrations of copper $(50,100,200$, and $400 \mu \mathrm{g} / \mathrm{L}$ as $\mathrm{Cu})$. In the January 1994 study, $H$. costata were exposed to a seawater control and four concentrations of copper $(50,100,150$, and $200 \mu \mathrm{g} / \mathrm{L}$ as $\mathrm{Cu})$. There were three replicates of each treatment.

A 96-h ammonia reference toxicant test was conducted in January 1994 to establish the expected response of the test organisms to concentrations of ammonia. The ammonia reference toxicant test was conducted in the same manner as the SPP tests. $H$. costata were exposed to a seawater control plus 11 concentrations of ammonia $(0.25,0.5,1,2,5,10,20,40,60$, 80, and $100 \mathrm{mg} / \mathrm{L}$ as ammonium chloride). Actual ammonia measurements were determined for this experiment and are reported in Section 3.0 of this report. There were three replicates of each concentration.

\subsubsection{0-Day Solid-Phase Flow-Through Preliminary and Definitive Feeding Studies with N. caecoides}

These tests were performed only during the October 1994 study and follow the same methods of testing described in Section 2.3.2, with the exception that 2.5-gal aquaria were used instead of $10-\mathrm{gal}$ and no $M$. nasuta were included in the test containers. The following paragraphs describe the method of food additions for both the preliminary and definitive studies.

\subsubsection{Preliminary Test Method}

The preliminary study was conducted to determine the following: 1) the most appropriate food source for $N$. caecoides; 2) the amount of food to be used; and 3 ) the best method for food distribution.

The three food sources, alfalfa, the algae Enteromorpha spp., and Tetramin, were chosen based on previous work conducted with the test species Neanthes arenaceodentata (Johns 1989). The alfalfa and Tetramin were obtained from a commercial supplier, and the Enteromorpha spp. was collected at low tide from the beach located at the MSL and then dried overnight. All three food sources were ground in a Waring blender and then sieved through a $0.5-\mathrm{mm}$ sieve to achieve a fine powder.

The OBM sediment was prepared for testing by grating it into smaller particle sizes and mixing it in a large-capacity epoxy-coated mixer with approximately $10-\mathrm{L}$ of filtered seawater. 
The addition of the filtered seawater was necessary to achieve a "smooth" consistency that allowed an even distribution of sediment and food. A total of 12 gal of OBM sediment was prepared in this manner for the feeding study. An additional five gal of OBM sediment were grated and mixed in the epoxy-coated mixer without the addition of seawater. This was done to assess whether the softening of OBM sediments increases $N$. caecoides survival.

The quantities of food were selected based upon the regression depicted in Figure 2.2 that shows a high degree of correlation between TOC (ranging between $0.17 \%$ to $1.23 \%$ ) and N. caecoides survival. The data points used in this regression were taken from studies previously conducted at the MSL. The sediment treatments for the feeding study were the following: OBM sediment, OBM sediment softened with seawater, and OBM sediment softened with seawater and amended with food to approximate a TOC range of $0.4 \%, 0.8 \%$, and $1.2 \%$.

To achieve the desired TOC percentages, the following three variables were determined: the percentage of dry weight of OBM sediment, the percentage of TOC of OBM sediment, and the wet weight of the volume of OBM sediment required for one test aquarium. For these experiments, it was assumed that the weight of each food source was entirely organic carbon. The following equations were used to determine how much food to dispense to each test aquarium:

- $950 \mathrm{~mL}$ of OBM sediment was required for each 2.5-gal aquarium

- $950 \mathrm{~mL}$ of wet OBM sediment weighs $1666 \mathrm{~g}$

- weight of wet sediment * percent dry weight = dry weight of sediment; $1666 \mathrm{~g}$ wet sediment ${ }^{*} 67 \%$ dry weight $=1116.2 \mathrm{~g}$ of dry sediment

- the amount of organic carbon already present in $1116.2 \mathrm{~g}$ of dry sediment $=$ $1116.2 \mathrm{~g} * 0.18 \%$ organic carbon $=2.01 \mathrm{~g}$ of organic carbon

- the $0.4 \%$ organic carbon level desired for testing was $1116.2 \mathrm{~g}$ of OBM sediment ${ }^{*} 0.4 \%$ organic carbon $=4.46 \mathrm{~g}$ of food. Since OBM already contains $2.01 \mathrm{~g}$ of organic carbon, an additional $2.45 \mathrm{~g}$ of food was added to reach $0.4 \%$ organic carbon.

The other percentages of TOC used in the preliminary and definitive studies were calculated using the same equations.

Two methods were used to deliver the food to each test aquarium to determine which was more suitable for the test species $N$. caecoides. The first feeding method required mixing the food sources directly into the sediment in a clean 0.5 -gal container using a stainless steel spoon. A preweighed amount of OBM and food were added to the container and then placed on a roller table for $24 \mathrm{~h}$. Once a homogenous consistency of OBM and food was achieved by using the rolling technique, the mixture was layered in a 2.5-gal aquarium. Each container on the roller table represented the amount of sediment and food necessary to supply one test chamber. 


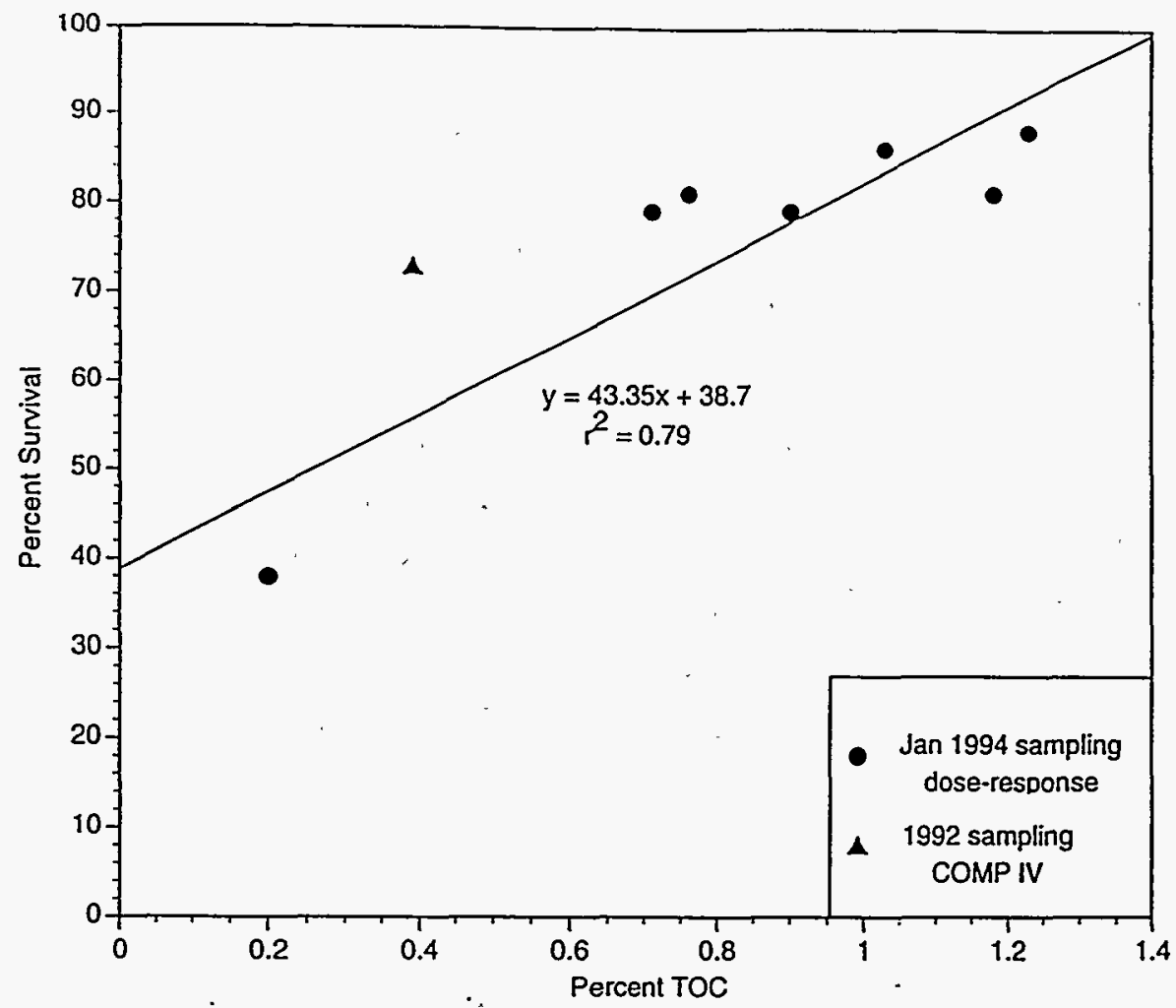

Figure 2.2 Linear Regression of Percentage TOC vs. Percentage Survival of N. caecoides

The second feeding method required the food to be sprinkled into each test container. Before the food was sprinkled into the 2.5-gal aquarium, the flow-through system was turned off, the food was added to the water and allowed to settle on top of the sediment. After the food had settled, the flow-through system was turned on. The amount of food $(0.8 \%$ TOC) to be sprinkled in each aquarium was separated into three portions. One portion was sprinkled in the aquarium at the beginning of the test, and if the food disappeared from the sediment, the second aliquot was added. This was done to minimize the impact of uneaten food decaying on the sediment surface. Only one aliquot of food was added to each test aquarium, because it appeared as though the food were virtually uneaten by the test organisms. By the end of the test, the food was decaying, and a visible scum was present on the uneaten food.

\subsubsection{Definitive Study Methods}

The results of the preliminary study were evaluated and used to determine the test design for the definitive study. The Enteromorpha spp. was chosen for the definitive study using the roller method. This food source was chosen because it is natural and it represents a potential food source most likely encountered by the test species. The procedures for preparing Enteromorpha spp., the OBM sediment, and the mixing method are the same as previously described for the preliminary study. 
The experimental design included OBM sediment, OBM sediment softened with filtered seawater, and softened OBM mixed with food, to represent TOC concentrations (including TOC already present in the OBM sediment) of $0.4 \%, 0.6 \%, 1.0 \%$, and $1.4 \%$. These were estimated TOC levels based on the amount of Enteromorpha spp. added to the sediment. Aliquots of the OBM sediment mixed with Enteromorpha spp. were analyzed for TOC by Analytical Resources, Inc. (ARI). The actual TOC levels present in the OBM sediment were approximately half of the estimated percentages.

\subsection{SEDIMENT AND TISSUE CHEMISTRY}

The OBM COMP sediment from Richmond Harbor and all control sediments collected in January 1993 were analyzed for conventional and other chemical parameters. Conventional parameters included grain size, total solids, TOC, total volatile solids (TVS), and oil and grease. Sediments were analyzed for PAHs, PCB/pesticides, metals, and butyltins. Samples representing $M$. nasuta tissue exposed to the OBM COMP sediment treatment were also analyzed for chlorinated pesticides, PCBs, PAHs,-metals, and butyltins.

In January 1994, the OBM COMP, the reference sediments, and the M. nasuta tissues exposed to the OBM COMP and reference sediments, were analyzed for PCBs, pesticides, and butylitins. The OBM COMP collected and tested in October 1994 was analyzed for the same conventional parameters and organic and inorganic analytes as the January 1993 study, with the addition of total petroleum hydrocarbon (TPH). analysis. Table 2.1:presents the analytical parameters, the method used to perform each analysis, and the target-analytical detection limits.

The following sections briefly describe the methods used for analysis of sediments and tissues, which followed established EPA procedures, where applicable. Quality control samples included method blanks, matrix spikes (MS), standard reference materials (SRM), and analytical replicates. The MS and SRMs were used as a measurement of analytical accuracy. The analytical replicates were used to evaluate analytical precision.

\subsubsection{Conventional Sediment Measurements}

Grain size analysis and total solids for all three studies were conducted by Soil Technology, Bainbridge Island, Washington. In January 1993, four grain size fractions (expressed in microns) were quantified as: gravel $(>2000 \mu \mathrm{m})$, sand $(62.5-2000 \mu \mathrm{m})$, silt ( $3.9-62.5 \mu \mathrm{m})$, and clay $(<3.9 \mu \mathrm{m})$. In the 1994 studies, 16 grain size fractions were determined by a combination of sieve and pipet techniques from the Puget Sound Estuary Program (PSEP) Protocols for Measuring Selected Environmental Variables in Puget Sound (PSEP 1986). These methods are consistent with ASTM Method D2217 (ASTM 1985) D422 (ASTM 1972) (with the substitution of a No. 100 sieve for a No. 140 sieve). These data are reported as "apparent" grain 
size, since organic material is included in the analysis. An additional measurement for salt content was performed, and each grain size fraction was corrected for this salt measurement.

Approximately $25 \mathrm{~g}$ of each sediment sample was analyzed for total solids, and another 10-g to 100-g aliquot was weighed for grain size analysis. To separate the coarser sand and gravel fraction from the silt/clay fraction, sediment was washed with distilled water through a 63.5- $\mu \mathrm{m}$ (4.0 phi) sieve into a 1-L graduated cylinder. The coarse fraction was dried, weighed, and shaken through a nest of sieves to yield the required seven coarse subfractions. Any material still passing through the final $63.5-\mu \mathrm{m}$ sieve was added to the previous fines in the $1-L$ graduated cylinder. The siltclay fraction was then subdivided by a pipet technique based on Stoke's Law of differential settling velocities for different sized particles. The siltclay fraction was disassociated by adding a dispersant (sodium hexametaphosphate) to distilled water contained in a 1-L graduated cylinder. At specified time intervals and specified depths below the surface, 20-mL aliquots were withdrawn from the graduated cylinder, delivered to a preweighed container, and dried at $90^{\circ} \mathrm{C} \pm 2^{\circ} \mathrm{C}$ to a constant weight. Replicate analyses of a sample from each batch of samples were performed-as a quality control measure. Other quality control measures, such as spikes, SRMs, or minimum detection limits, do not apply to grain size analysis.

Analysis of TOC consisted of measuring the amount of nonvolatile, partially volatile, volatile, and particulate organic carbon compounds in a sample. The analyses of TOC for the January 1993 and January 1994 studies were performed by Global Geochemistry in Canoga Park, California, following modified Method SW846. EPA.9060 (EP.A 1986). Each sediment treatment was dried and ball milled to a fine powder. Before combustion, inorganic carbon in the sample was removed by-acidification. The TOC in sediment was then determined by measuring the quantity of carbon dioxide released during combustion of the sample and reporting the release as percentage of dry weight. Quality control measures included method blanks and replicate analyses for each batch of samples. Analysis of TOC for the October 1994 study was performed by ARI in Seattle, Washington. Briefly, ARI used the method described in Plumb (1981), which involves direct combustion at $850^{\circ} \mathrm{C}$ in a resistance furnace. Combustion products are carried in the oxygen stream through a catalytic converter (to assure complete oxidation to $\mathrm{CO}_{2}$ ) and into the infrared spectrophotometer (IR). Prior to analysis, samples are purged of inorganic carbon by acidification, dried at $70^{\circ} \mathrm{C}$, and then ground to pass through a 120- $\mathrm{\mu m}$ mesh sieve. The methods used by ARI and Global Geochemistry are comparable in performing TOC analysis.

Analyses of TVS measures the fraction of total solids that are lost on ignition at a higher temperature than that used to determine total solids. Analysis of TVS was performed by the MSL using EPA 160.4 (EPA 1979) in the January 1993 study and performed at ARI using PSEP (1986) in the January 1994 and October 1994 studies. The method used by the two 
laboratories to perform TVS analysis are similar. The sample is first oven-dried to constant weight, removed and combusted at $550^{\circ} \mathrm{C}$, cooled in a desiccator, and then reweighed. The amount of sample lost during ignition was then defined as the volatile solids fraction. The TVS measurements are used as an estimate for the amount of organic matter in the total solids. Operationally, TVS is defined by the combustion temperature and does not always represent the organic content of a sample, because some of the more volatile organic material can be lost during drying, and some inorganic material can be lost during combustion. Quality control measures include method blanks and replicate analyses for each batch of samples.

Total oil and grease includes vegetable oils, animal fats, soaps, waxes, and any other carbon-hydrogen material extractable by the solvent Freon. The TPH comprises the nonpolar mineral fraction of total oil and grease that is not removed by silica gel absorption. The oil and grease and TPH analyses was performed by ARI for all three studies. The IR was used to determine concentrations of oil and grease (Method 413.2, EPA 1979) and petroleum hydrocarbons (Method 418.1, EPA 1979). A 20-g aliquot of sample was dried with anhydrous sodium sulfate, then extracted with Freon. For total oil.and grease, sample extracts were scanned from 4000 to $600 \mathrm{~cm}-1$ on an IR, and the peak height measured at $2930 \mathrm{~cm}^{-1}$. Since this wavelength represents the $-\mathrm{CH}_{2}$ configurations of hydrocarbons, it was the standard used to determine oil and grease. For TP.H, silica gel was added to the extract to remove the more polar animal- and vegetable-based oils. The extract was then shaken and allowed to settle. An aliquot was then removed and scanned the same way as was the oil and grease sample. The relationship of peak height to oil concentration was determined by regressing the peak height versus a known concentration of fuel oil and vegetable oil for TPH and oil and grease, respectively. Quality control measures include method blanks, matrix spikes, and replicate analyses for each batch of samples.

\subsubsection{Polynuclear Aromatic Hydrocarbons}

Analyses for 16 PAHs (Table 2.1) in the OBM COMP sediment were performed by ARI in January 1993 and by the MSL in January 1994 and October 1994 studies. The analyses of tissue samples were performed by the MSL for the January 1993 study and 1994 studies. The semivolatile organic compounds analyzed in sediments and tissues were the 16 PAHs listed in EPA Method 610. These compounds were extracted with methylene chloride in accordance with the National Oceanic and Atmospheric Administration (NOAA) Status and Trends method (Krahn et al. 1988) or SW-846 organic extraction method (EPA 1986). The extracts were dried over sodium sulfate, passed through a cleanup column, and concentrated in preparation for further cleanup by liquid chromatography. Surrogate compounds were added to all samples prior to extraction to assess extraction efficiency. The PAHs in sample extracts were analyzed via high resolution capillary gas chromatography/mass spectroscopy (GC/MS) in the selective ion mode 
TABLE 2.1 List of Analytes, Methods, and Target Detection Limits(a)

\begin{tabular}{l}
\multicolumn{1}{c}{ Analyte } \\
\hline Grain Size \\
Total Solids \\
Total Organic Carbon \\
Oil and Grease \\
Total Volatile Solids \\
Metals (Sediment) \\
Arsenic \\
Cadmium \\
Chromium \\
Copper \\
Lead \\
Mercury \\
Nickel \\
Selenium \\
Silver \\
Zinc \\
Metals (Tissues) \\
Arsenic \\
Cadmium \\
Chromium \\
Copper \\
Lead \\
Mercury \\
Nickel \\
Selenium \\
Silver. \\
Zinc \\
Pesticides \\
Aldrin \\
$\alpha$-BHC \\
$\beta$-BHC \\
$\gamma$-BHC (Lindane) \\
$\delta$-BHC \\
Chlordane \\
$4,4 '$-DDD \\
4,4 -DDE \\
$4,4^{\prime}$-DDT \\
Dieldrin \\
Endosulfan I \\
Endosulfan II \\
Endosulfan sulfate \\
Endrin \\
Endrin aldehyde \\
Heptachlor \\
Heptachlor epoxide \\
\end{tabular}

$\begin{array}{lll}\text { Reference Method } & & \text { Detection } \\ \text { ASTM D2217 \& D422 } & & 1.0 \% \\ \text { 160.3 (EPA 1979) } & & 1.0 \% \\ 9060 \text { (EPA 1986) } & & 0.1 \% \\ 413.2 \text { (EPA 1979) } & & 20 \mathrm{mg} / \mathrm{kg} \\ 160.4 \text { (EPA 1979) } & & 0.1 \%\end{array}$

PNL SOP for XRF Method

$2.5 \mathrm{mg} / \mathrm{kg}$ 200.9 (EPA 1991)

$0.1 \mathrm{mg} / \mathrm{kg}$

PNL SOP for XRF Method

$33 \mathrm{mg} / \mathrm{kg}$

PNL SOP for XRF Method

$5.5 \mathrm{mg} / \mathrm{kg}$

PNL SOP for XRF Method

$6.2 \mathrm{mg} / \mathrm{kg}$

Bloom and Crecelius 1983

$0.01 \mathrm{mg} / \mathrm{kg}$

PNL SOP for XRF Method

200.9 (EPA 1991)

$7.5 \mathrm{mg} / \mathrm{kg}$

$0.2 \mathrm{mg} / \mathrm{kg}$

200.9 (EPA 1991)

$0.02 \mathrm{mg} / \mathrm{kg}$

PNL SOP for XRF Method

$7.8 \mathrm{mg} / \mathrm{kg}$

PNL SOP-for XRF Method

$2.0 \mathrm{mg} / \mathrm{kg}$

200.8 (EPA 1991)

200.8 (EPA 1991)

$0.1 \mathrm{mg} / \mathrm{kg}$

$1.0 \mathrm{mg} / \mathrm{kg}$

PNL SOP for XRF Method

200.8 (EPA 1991)

Bloom and Crecelius 1983

200.8 (EPA 1991)

PNL SOP. for XRF Method

200.8 (EPA 1991)

PNL SOP for XRF Method

$4.3 \mathrm{mg} / \mathrm{kg}$

$1.0 \mathrm{mg} / \mathrm{kg}$

$0.01 \mathrm{mg} / \mathrm{kg}$

$1.0 \mathrm{mg} / \mathrm{kg}$

$1.0 \mathrm{mg} / \mathrm{kg}$

$0.1 \mathrm{mg} / \mathrm{kg}$

$35 \mathrm{mg} / \mathrm{kg}$

8080 (EPA 1986)

8080 (EPA 1986)

8080 (EPA 1986)

8080 (EPA 1986)

8080 (EPA 1986)

8080 (EPA 1986)

8080 (EPA 1986)

8080 (EPA 1986)

8080 (EPA 1986)

8080 (EPA 1986)

8080 (EPA 1986)

8080 (EPA 1986)

8080 (EPA 1986)

8080 (EPA 1986)

8080 (EPA 1986)

8080 (EPA 1986)

8080 (EPA 1986)

8080 (EPA 1986)

$2.0 \mu \mathrm{g} / \mathrm{kg}$

$2.0 \mu \mathrm{g} / \mathrm{kg}$

$2.0 \mu \mathrm{g} / \mathrm{kg}$

$2.0 \mu \mathrm{g} / \mathrm{kg}$

$2.0 \mu \mathrm{g} / \mathrm{kg}$

$30 \mu \mathrm{g} / \mathrm{kg}$

$2.0 \mu \mathrm{g} / \mathrm{kg}$

$2.0 \mu \mathrm{g} / \mathrm{kg}$

$2.0 \mu \mathrm{g} / \mathrm{kg}$

$2.0 \mu \mathrm{g} / \mathrm{kg}$

$2.0 \mu \mathrm{g} / \mathrm{kg}$

$2.0 \mu \mathrm{g} / \mathrm{kg}$

$2.0 \mu \mathrm{g} / \mathrm{kg}$

$2.0 \mu \mathrm{g} / \mathrm{kg}$

$2.0 \mu \mathrm{g} / \mathrm{kg}$

$2.0 \mu \mathrm{g} / \mathrm{kg}$

$2.0 \mu \mathrm{g} / \mathrm{kg}$

$30 \mu \mathrm{g} / \mathrm{kg}$ 
TABLE 2.1 (Contd)

Analyte

PCBs

Aroclor, 1242

Aroclor, 1248

Aroclor, 1254

Aroclor, 1260

PAHS

Acenaphthene

Acenaphthylene

Anthracene

Benzo(a)anthracene

Benzo(a)pyrene

Benzo(b)fluoranthene

Benzo(g,h,i)perylene

Benzo(k)fluoranthene

Chrysene

Dibenzo(a,h)anthracene

Fluoranthene

Fluorene

Indeno(1,2,3-cd)pyrene

Naphthalene

Phenanthrene

Pyrene

Butyltins

Monobutyltin

Dibutyltin

Tributyltin
Reference Method

Detection Limit

$\begin{array}{ll}8080 \text { (EPA 1986) } & 20 \mu \mathrm{g} / \mathrm{kg} \\ 8080 \text { (EPA 1986) } & 20 \mu \mathrm{g} / \mathrm{kg} \\ 8080 \text { (EPA 1986) } & 20 \mu \mathrm{g} / \mathrm{kg} \\ 8080 \text { (EPA 1986) } & 20 \mu \mathrm{g} / \mathrm{kg}\end{array}$

8270 (EPA 1986)

8270 (EPA 1986)

8270 (EPA 1986)

8270 (EPA 1986)

8270 (EPA 1986)

8270 (EPA 1986)

8270 (EPA 1986)

8270 (EPA 1986)

8270 (EPA 1986)

8270 (EPA 1986)

8270 (EPA 1986)

8270 (EPA 1986)

8270 (EPA 1986)

8270 (EPA 1986)

8270 (EPA 1986)

8270 (EPA 1986)

$20 \mu \mathrm{g} / \mathrm{kg}$

$20 \mu \mathrm{g} / \mathrm{kg}$

$20 \mu \mathrm{g} / \mathrm{kg}$

$20 \mu \mathrm{g} / \mathrm{kg}$

$20 \mu \mathrm{g} / \mathrm{kg}$

$20 \mu \mathrm{g} / \mathrm{kg}$

$20 \mu \mathrm{g} / \mathrm{kg}$

$20 \mu \mathrm{g} / \mathrm{kg}$

$20 \mu \mathrm{g} / \mathrm{kg}$

$20 \mu \mathrm{g} / \mathrm{kg}$

$20 \mu \mathrm{g} / \mathrm{kg}$

$20 \mu \mathrm{g} / \mathrm{kg}$

$20 \mu \mathrm{g} / \mathrm{kg}$

$20 \mu \mathrm{g} / \mathrm{kg}$

$20 \mu \mathrm{g} / \mathrm{kg}$

$20 \mu \mathrm{g} / \mathrm{kg}$

Unger et al. 1986

Unger et al. 1986

Unger et al. 1986
$10 \mu \mathrm{g} / \mathrm{kg}$

$10 \mu \mathrm{g} / \mathrm{kg}$

$10 \mu \mathrm{g} / \mathrm{kg}$

(a) Detection limits are in dry weight for all sediment parameters and for metals in tissues. Detection limits are in wet weight for all organic tissue parameters.

(SIM) following modified EPA SW-846 Method 8270 (EPA 1986). In the SIM mode, each PAH compound was monitored simultaneously for the presence of a parent ion and a confirming second ion. Tissue extracts were run through gel permeation chromatography (GPC) prior to analysis to remove any additional interferences. Quality control measures include method blanks, matrix spikes, SRMs, and replicates for each batch of samples. Concentrations for both sediments and tissues are reported in $\mu \mathrm{g} / \mathrm{kg}$.

\subsubsection{Chlorinated Pesticides and Polychlorinated Biphenyls}

The PCB and pesticide analyses for the OBM COMP sediment was performed by ARI in January 1993 and by the MSL in January 1994 and October 1994. The tissue analyses were performed by the MSL in the January 1993 study and the 1994 studies. Chlorinated pesticides 
and $\mathrm{PCBs}$ in sediments and tissues were quantified by gas chromatography/electron capture detection (GC/ECD) following modified EPA SW-846 Method 8080 (EPA 1986).

Chlorinated pesticides and PCBs were extracted simultaneously with the PAH compounds. The procedure involved methylene chloride extraction using sonication or roller technique for sediments and the roller technique for tissues. The extract was then concentrated and cleaned up using a column packed with deactivated alumina and silica by the NOAA Status and Trends Method (Krahn et al. 1988). The extracts then were subjected to an additional cleanup treatment using high performance liquid chromatography (HPLC) to remove other interferences. Analytical quantification was performed using $\mathrm{GC} / E C D$ analysis. Surrogates were added to each sample before extraction to assess extraction efficiency. Quality.control measures include method blanks, matrix spikes, SRMs, and replicates for each batch of samples.

Concentrations for both sediments and tissues are reported in $\mu \mathrm{g} / \mathrm{kg}$.

\subsubsection{Metals}

The metals analyses.for all three studies were performed by Battelle Pacific Northwest National Laboratory (PNNL). in Richland, Washington; and the MSL. Ten metals were analyzed in sediment and tissue samples: arsenic (As),-Cd, chromium (Cr), $\mathrm{Cu}$, lead (Pb), mercury (Hg), nickel ( $\mathrm{Ni})$, selenium (Se), silver ( $\mathrm{Ag}$ )-and zinc $(\mathrm{Zn})$. The four techniques used for the analysis of . metals were as-follows:-1) energy-diffusive-X-ray fluorescence (XRF), following a PNL standard operating procedure; 2)-Zeeman graphite-furnace-atomic absorption spectroscopy (GFAA), following modified EPA 200.9:(EPA-1991); 3) cold-vapor atomic absorption spectroscopy (CVAA), according to the-method of Bloom and-Crecelius (-1983); and 4) inductively coupled plasma mass spectroscopy (ICP/MS); following modified EPA 200:8 (EPA 1991).

To prepare sediment:and tissues for analysis, samples were freeze-dried, then blended in a Spex mixer-mill. Approximately $5 \mathrm{~g}$ of this mixed sample was then ground in a ceramic ball mill. The XRF analysis was performed on a $0.5-\mathrm{g}$ aliquot of dried, ground material pressed into a pellet with a diameter of $2 \mathrm{~cm}$. For GFAA, CVAA, and ICP/MS analyses, 0.2-g aliquots of dried homogenous sample went through an acid digestion process to separate and isolate the metals from the matrix. Concentrations for both sediments and tissues are reported in $\mathrm{mg} / \mathrm{kg}$.

\subsubsection{Organotins}

Organotins in sediment and tissue samples for all three studies were analyzed at the MSL in Sequim, Washington. Butyltin compounds in sediment and tissue were analyzed using gas chromatography/flame photometric detection (GC/FPD) following the methods of Unger et al. (1986). Wet samples were extracted with methylene chloride and tropolone. Tripentyltin was added before extraction as a surrogate compound to assess extraction efficiency. The mono-, di-, and tributyltin compounds extracted from the sediment, and tissues were derivatized to a less 
volatile, more thermally stable form (nonionic n-hexyl/or n-pentyl derivatives). The extracts, were passed through a Florisil liquid chromatography column for cleanup, and the butyltins were quantified by GC/FPD. Concentrations for both sediments and tissues are reported in $\mu \mathrm{g} / \mathrm{kg}$.

\subsection{DATA ANALYSIS AND INTERPRETATION}

Several statistical analyses were conducted to determine the magnitude and significance of toxicity or the magnitude of bioaccumulation of contaminants in OBM sediments. Each statistical test was based on a completely randomized design that controlled bias between treatments.

\subsubsection{Randomization}

All solid-phase and SPP toxicity test organisms were designed as completely random tests, and treatments were randomly positioned on water tables. To determine the randomization, a random number table was generated for each toxicity test using the discrete uniform random number generator in the Excel spreadsheet software. For the SPP tests, $H$. costata and C. stigmaeus individuals and $M$. galloprovincialis larvae were randomly allocated to SPP replicates for all concentrations.

\subsubsection{Statistical Analysis of Solid-Phase Tests.}

Solid-phase toxicity of all sediment treatments was evaluated by analysis of variance (ANOVA) tests on the arcsine square root of the proportion of organisms surviving the test. The arcsine square-root transformation stabilizes the within-class variances to meet the assumptions of the ANOVA. All treatments were compared using the conservative Dunn's Test for comparison of all means (Dunn 1961), using an experiment-wise error rate of $\alpha=0.05$. The Dunn's Test is a multiple-range comparison test that provides information about how each sediment treatment compares with all other treatments: For the purposes of this report, the OBM results obtained for the 1993 study were compared with the OBM and reference results obtained during the 1994 studies. These comparisons assessed the reproducibility of the results among the different studies, the uniformity of the OBM sediments throughout the Richmond Harbor area, añd the determination of whether OBM sediments are considered acutely toxic as defined in the 1991 Implementation Manual. A test treatment was considered acutely toxic if the difference was statistically significant from any of the reference sediments and if the survival of the test organisms exposed to the test treatment was $\geq 10 \%$ lower than the survival in the reference sediment ( $\geq 20 \%$ lower than reference for $R$. abronius).

\subsubsection{Statistical Analysis of Suspended-Particulate-Phase Tests}

Two statistical tests are presented in the 1991 Implementation Manual for the interpretation of SPP tests. The first test is a one-sided t-test between survival in control 
replicates and survival in the $100 \%$ SPP replicates. This test is performed only when survival in the $100 \%$ SPP is less than control (0\% SPP) survival and when control survival is greater than $90 \%$ for nonlarval test and $70 \%$ for larval tests (indicating test validity). Prior to conducting the t-test, angular transformation (arcsine of the square root) of the proportion surviving in test replicates is performed to reduce possible heterogeneity of variance between control and $100 \%$ SPP mean survivals. The second test required by the 1991 Implementation Manual is an $\mathrm{LC}_{50}$ or $\mathrm{EC}_{50}$ calculation, the concentration of SPP that is lethal or produces an effect to $50 \%$ of the individuals tested. The $\mathrm{LC}_{50}$ or $\mathrm{EC}_{50}$ values for these tests were calculated using the Trimmed Spearman-Karber Method (Finney 1971). The Spearman Karber estimator is appropriate only if there is increasing mortality with increasing concentration and if $50 \%$ or greater mortality is observed in test solutions when normalized to control survival. If $50 \%$ mortality does not occur in the $100 \%$ SPP dilutions for any treatments, then $L_{50}$ values are reported as $>100 \%$ SPP. The same method was used to calculate $\mathrm{EC}_{50}$ values.

\subsubsection{Statistical Analysis of Bioaccumulation}

Before statistical analysis of $\dot{M}$ : nasuta tissue concentrations, tissue chemistry data were reviewed. If the review showed that a compound was undetected in the replicate samples in test treatments, or that the mean tissue concentration in the reference treatments was greater than that: in the test treatments, no further analysis was performed. If a compound was detected in at least one replicate of a test-treatment and it exceeded that of any reference treatment replicate, statistical analysis was performed. In all cases, dry weight detection limits were used in numerical calculations when a compound was undetected.

Contaminant levels in tissues of $M$. nasuta exposed to potential dredged material test treatments were compared with those exposed to sediment from each of the three reference areas. Bioaccumulation data were statistically analyzed using Dunn's Test $(\alpha=0.05)$. Any statistically significant bioaccumulation was reported along with the magnitude of the difference between mean contaminant concentrations found in the test treatment tissues and the mean concentration found in the tissues exposed to each of the reference sediments.

\subsection{QUALITY ASSURANCE/QUALITY CONTROL PROCEDURES}

The quality assurance/quality control (QA/QC) procedures followed for these studies were consistent with the 1991 Implementation'Manual and the EPA protocols (EPA 1986). The procedures were documented by the PNNL Quality Engineering Division in a QA Plan (QAP). Data accumulation notebooks were assigned to each portion of the study and served as records of day-to-day activities during the research. All entries in the notebooks were signed, dated, and reviewed by both the project manager and the quality assurance engineer. The following 
discussion summarizes QAVC procedures followed for the three main portions of these studies: sediment sampling, biological testing, and chemical testing.

\subsubsection{Sample Tracking and Storage}

All sediment samples were accompanied by chain-of-custody forms from the time of collection to receipt at the MSL. After sample selection and compositing, a new set of custody forms was initiated for the sediment subsamples requiring chemical analyses. These accompanied the samples to the appropriate laboratory where the forms were signed and returned to the MSL project manager. Custody forms were also initiated for all tissue samples upon completion of the biological testing. These forms accompanied the samples to the appropriate laboratory for chemical analyses.

All sediment collected for these studies was stored in glass, cellulose acetate butyrate containers, or steel drums lined with 9-C-4-A-phenolic epoxy, a noncontaminating coating. Sediment core and grab samples were stored at $4^{\circ} \mathrm{C} \pm 2^{\circ} \mathrm{C}$ prior to biological testing. Subsamples for chemical analyses were obtained prior to biological testing. These subsamples were stored frozen (except for grain size, which was held at $4^{\circ} \mathrm{C}$ ) until chemical analyses were performed. Samples for organic analyses were stored frozen up to 2 months (PSEP 1986). Samples for metals were freeze-dried upon receipt at the laboratory and held up to 6 months (PSEP 1986; EPA/USACE 1991).

Tissue samples were frozen immediately upon completion of the bioaccumulation tests. Samples for organic analyses and metals were stored in precleaned glass jars with Teflon-lined lids and samples for metals analyses were stored in precleaned plastic jars. Prior to analyses, samples for organic analyses were held for up to 2 months.

\subsubsection{Quality Control Procedures for Sediment and Tissue Chemistry}

Chemical testing procedures require that specific QAVQ protocols be followed. The QA/QC guidelines specific to this project were provided in a PNNL Quality Assurance Division QAP. These guidelines include the following:

- analysis of a method blank with each batch of samples

- replicate analysis on at least $5 \%$ of the samples (triplicate analyses where possible) to assess analytical precision

- analysis of matrix spikes on $5 \%$ of the samples (where applicable) with appropriate compounds to assess accuracy

- analysis of SRMs at a frequency of $5 \%$, if available for the analytes of interest and sample matrix

- $\quad$ archiving of all instrument printouts (e.g., raw data and chromatograms from GC analyses) for future review. 


\subsection{RESULTS}

\subsection{FIELD INFORMATION}

The OBM sediment samples were collected for three separate studies in January 1993, January 1994, and October 1994, using a vibratory-hammer coring device deployed from the derrick barge supplied by Manson Construction in Richmond Harbor, California (Figure 1.1). Each of the OBM COMPs for the three studies were collected from selected sites in Richmond Harbor as shown in Table 3.1. Control and reference sediments were collected by MSL personnel or obtained from a commercial supplier for use in the biological toxicity tests. The reference sediment from Bay Farm Borrow Area, Alcatraz Environs Reference Area, and Deep Off-Shelf Reference Area were collected for the two studies in January 1994 and October 1994. Control sediment from Sequim Bay, West Beach, and Tomales Bay were also collected for each of the three studies. All sediment samples were stored in noncontaminating containers, epoxy-lined 5-gal buckets or seasoned coolers at approximately $4^{\circ} \mathrm{C}$ until ready for processing at the MSL. OBM sediment and reference-sediment.samples were shipped via refrigerated van to the MSL upon completion of the sampling effort.

\subsubsection{Reference Sediment Sampling}

The Deep Off-Shelf Reference Area is located approximately 50 nautical miles southwest of the Golden Gate Bridge (Figure 3.1), off the continental shelf, in about $1500 \mathrm{~m}$ of water. Sediment samples from this area were collected using a pipe dredge deployed from the FV Cobra as described in Section 2.1.2. The R-BF and R-AM-sediments were also collected using the FV Cobra. The Bay Farm Borrow Area, located in San Francisco Bay (Figure 3.2), was sampled at four locations and the sediments were combined to form one R-BF composite, representative of this area. The Alcatraz Environs Reference Area was sampled at eight locations (Figure 3.3) during the January 1994 field cruise and seven locations during the October 1994 field cruise. Station R-AM-F was omitted from the October cruise after the results from the individual stations surrounding R-AM showed that R-AM-F had much higher levels of low-molecular-weight PAHs (LPAHs) and high-molecular-weight PAHs (HPAHs) relative to the other stations. For both of the field cruises, the individual R-AM stations were combined to form one R-AM composite that was used for all chemical and biological evaluations.

\subsubsection{Control Sediment Sampling}

Control sediments for use in solid-phase toxicity tests were collected from Sequim Bay (Figure 3.4), West Beach (Figure 3.5), and Tomales Bay (Figure 3.6). Sequim Bay sediment (C-SB) was used in all solid-phase tests as an experimental control as well as for the native control for the clam, M. nasuta. West Beach control sediment (C-WB) was used as the native 
TABLE 3.1. Sediment Contribution of each Sampling Site for Chemical and Biological Testing, Older Bay Mud Studies

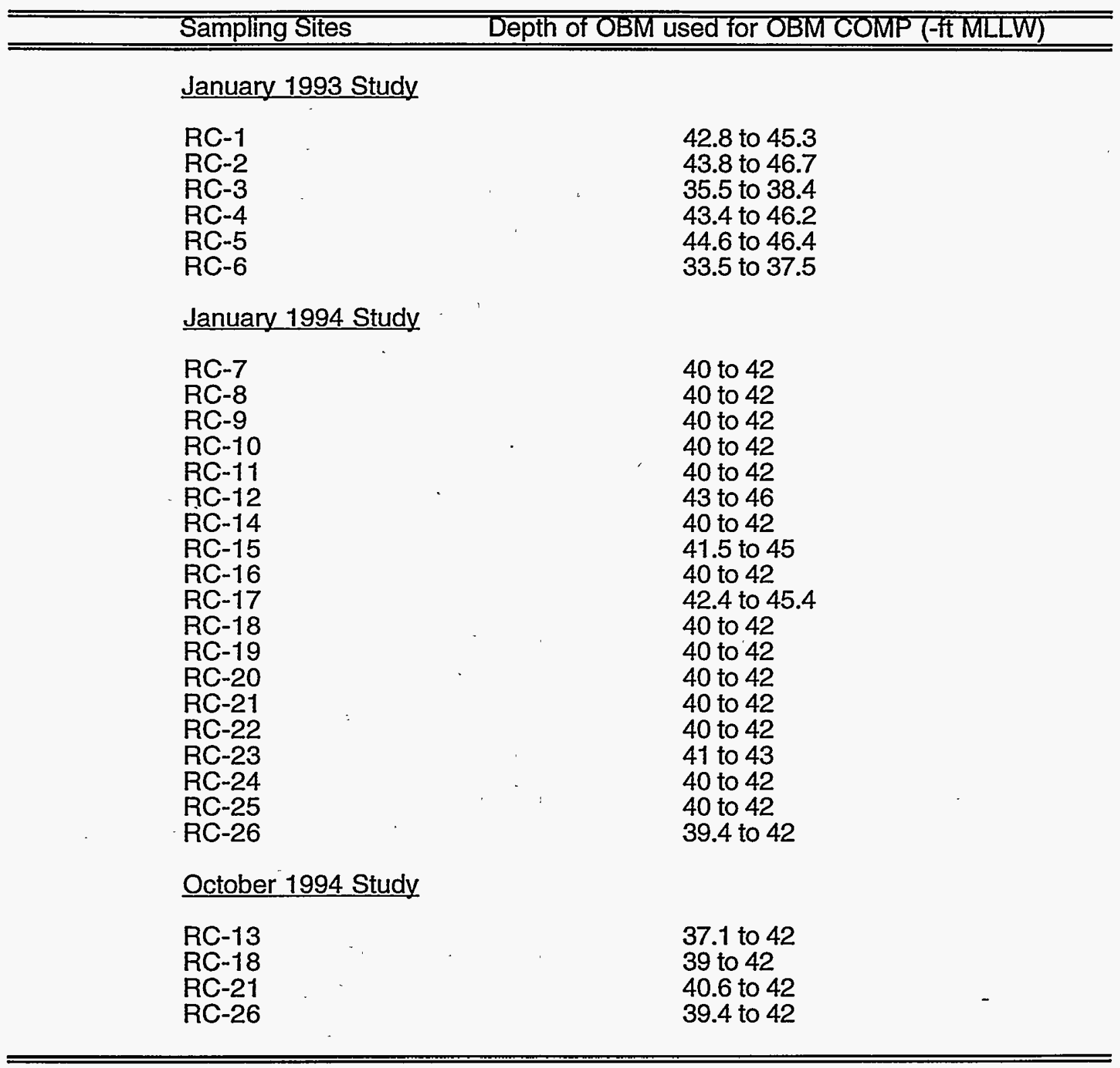




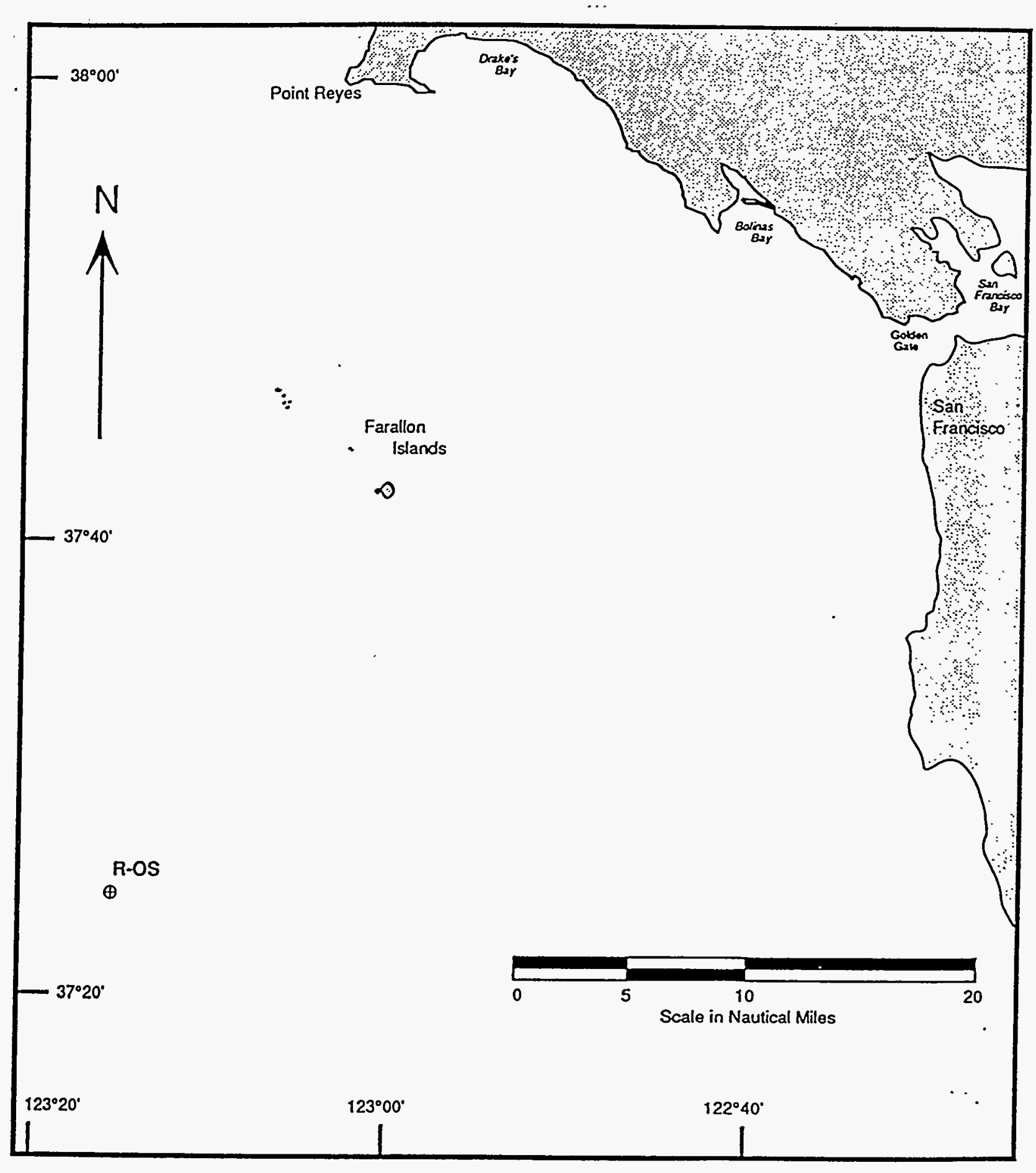

FIGURE 3.1. Location of Deep Off-Shelf Reference Area (R-OS) 


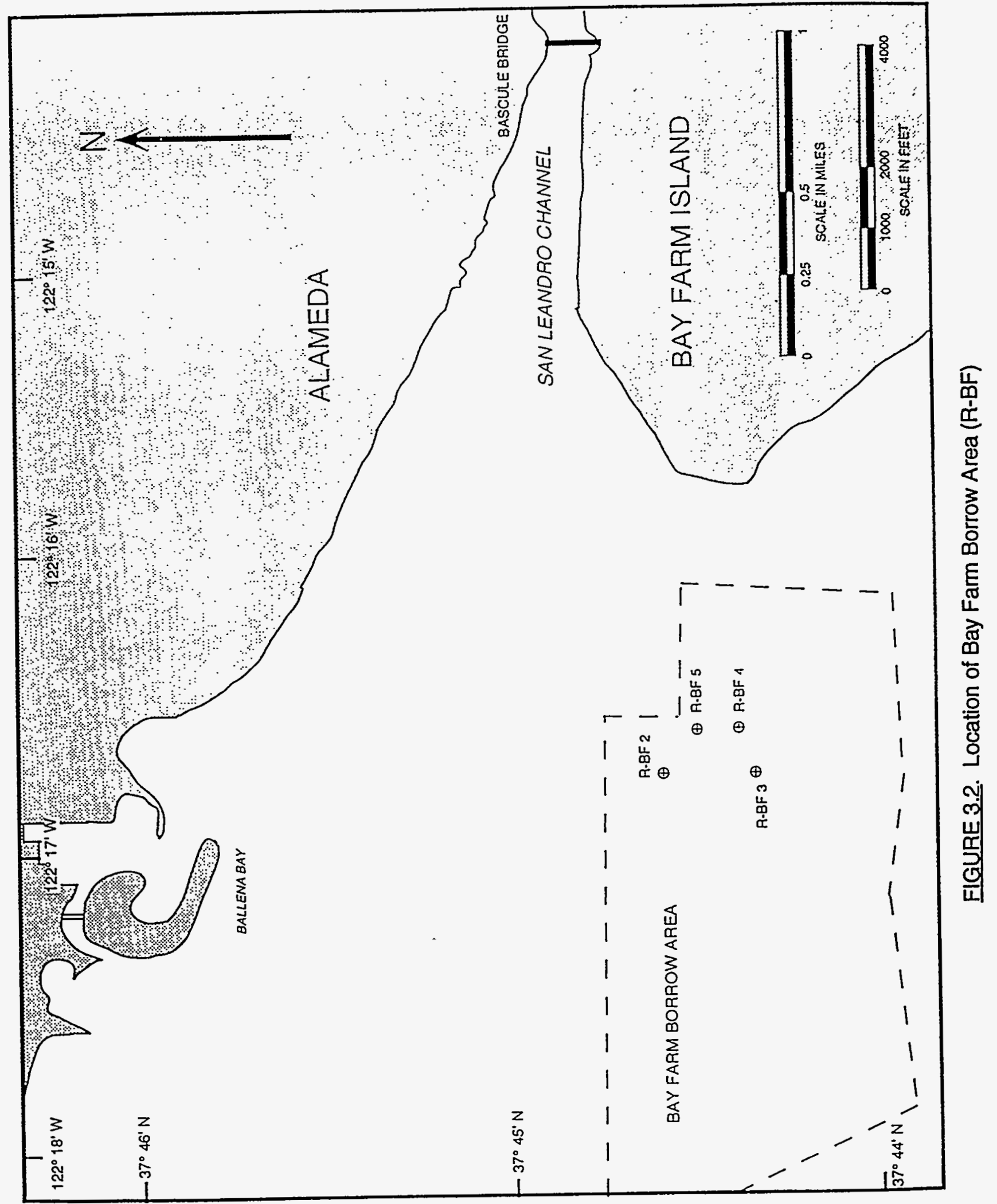

OLDER BAY MUD

3.4 


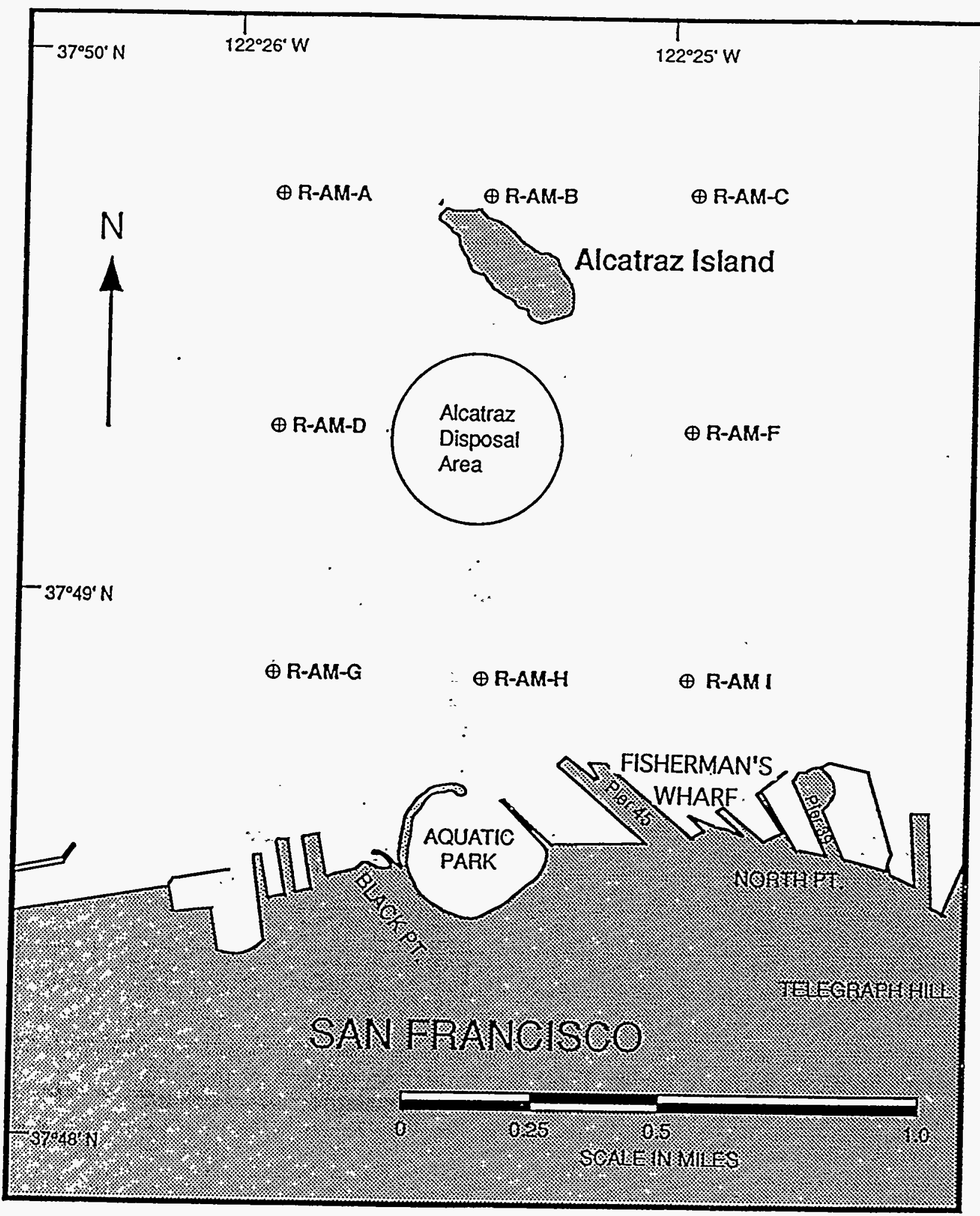

FIGURE 3.3. Location of Alcatraz Environs Reference Area (R-AM) 


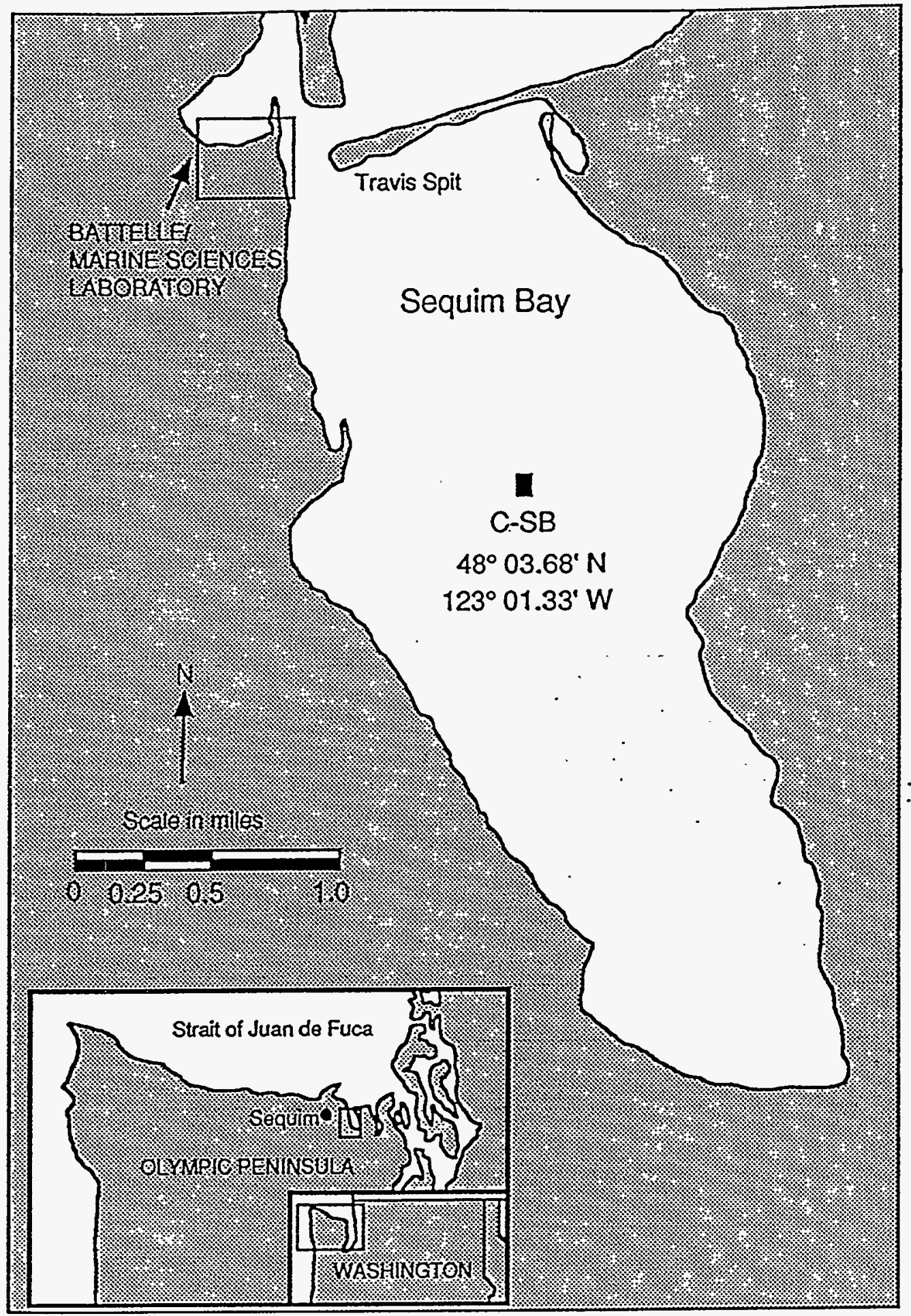

FIGURE 3.4. Location of M. nasuta Control (C-SB), Sequim Bay, Washington 
罗

$\dot{v}$

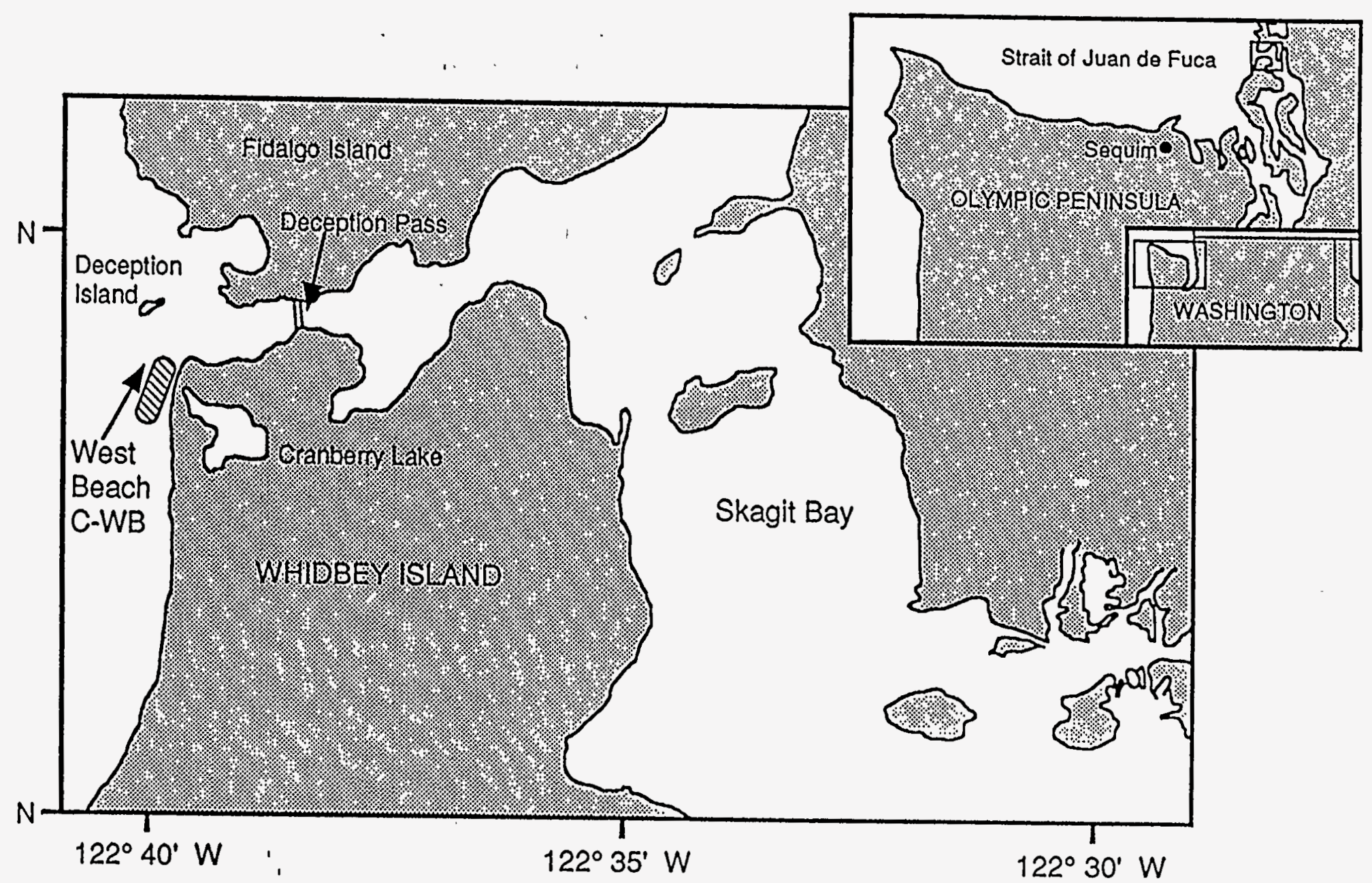

EIGURE 3.5. Location of R. abronius Control (C-WB), West Beach, Whidbey Island, Washington 


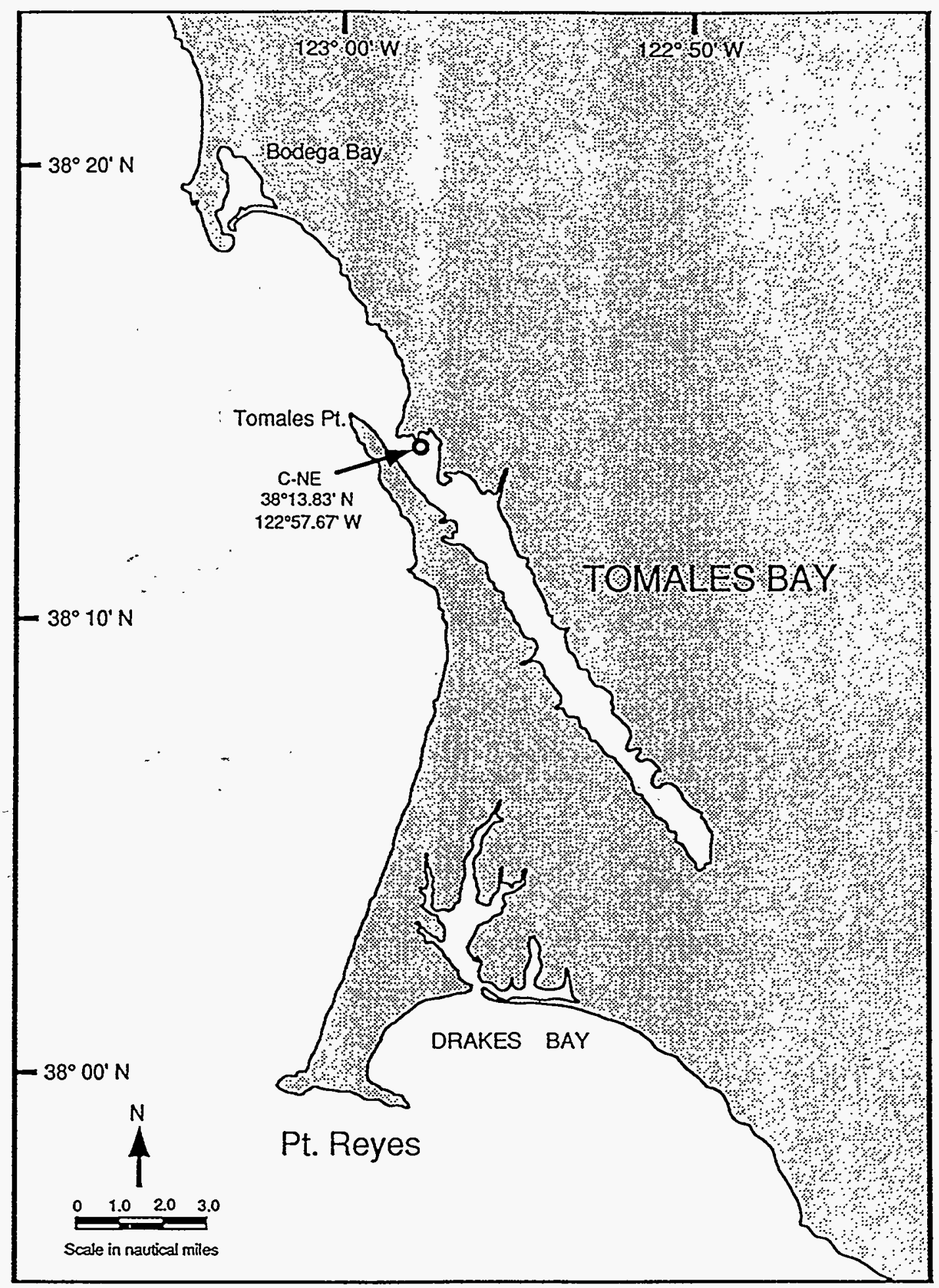

FIGURE 3.6. Location of N. caecoides Control (C-NE), Tomales Bay, California 
control for the amphipod, $R$. abronius. Tomales Bay is the source of native sediment for the polychaete, N. caecoides, and was used in the 10-day toxicity test.

The sediment for the 1993 study was collected with a 4-in. core barrel. The standard procedure for processing sediment involves cutting the 4-in. core in half longitudinally, brushing off all in the Lexan shavings before opening the core, and then taking a pie-shaped wedge out of the sediment, using care to avoid processing any sediment that could have come in contact with the core tube. This is important because when each core is collected, the sediment is pushed up through the core tube and the upper, more contaminated, layers come in contact with the entire length of core. For the 1993 study, most of the sediment in the core tube was needed for testing; therefore, it is possible that the OBM sediments that came in contact with the core tube could have been processed and tested. The results obtained for the 1994 study, particularly for oil, grease, and pesticides, do not confirm those of the 1993 study. The 1994 data were collected using the 12-in. core barrel, and great care was taken to ensure that cross-contamination of YBM and OBM would not be an issue. For these reasons, the 1993 data should not be used to make decisions regarding sediment suitability.

\subsection{GEOLOGIC DESCRIPTIONS}

- Marine sediment throughout Inner Richmond Harbor consists of two geologic units: the YBM and the underlying OBM. (Goldman 1969). This report focuses on the OBM sediments that are fine-grained, consolidated, and generally olive or gray in color. It is believed that the OBM was deposited in shallow marine and terrestrial environments during the interglacial epoch immediately preceding the formation of the. Wisconsin ice sheet, and was exposed and subjected to erosion during the first Wisconsonian glacial advance (Goldman 1969). While exposed, the OBM sediments desiccated and consolidated. The OBM is up to $200 \mathrm{ft}$ thick, but appears to be about $50 \mathrm{ft}$ thick in the Richmond area. The OBM in Richmond Harbor is underlain by interbedded sandstone and shale bedrock of the Franciscan Formation, which outcrops at Point Potrero (Helley and Lajoie 1979).

During the January 1993 study, sediment was included in the composite if more than $1.5 \mathrm{ft}$ of OBM remained in the 4-in. core after the required sediment was removed for the other MSL projects. The OBM COMPs from the January 1994 and October 1994 studies were collected from the $-40 \mathrm{ft} \mathrm{MLLW}$ to $-42 \mathrm{ft} \mathrm{MLLW} \mathrm{section} \mathrm{of} \mathrm{the} \mathrm{12-in.} \mathrm{cores.} \mathrm{The} \mathrm{OBM} \mathrm{collected} \mathrm{from} \mathrm{the}$ Inner Harbor Channel was composed of firm to hard homogeneous silts and clays. The silt and clay was generally dark gray or olive brown in color. Gypsum nodules up to 6 in. in diameter and roots were observed in some cores. 


\subsection{SEDIMENT SAMPLE PREPARATION}

The core samples for each composite were combined, mixed, and homogenized into one sediment composite that was analyzed for selected chemical parameters and used in the biological tests. During the January 1993 study, sediment from the native controls for $R$. abronius and $M$. nasuta were also processed and sampled for chemical analysis. For the January 1994 and October 1994 studies, the three reference samples were collected and used for comparison purposes in the biological and chemical tests. An aliquot of the control samples collected for the January 1994 and October 1994 studies were archived for future potential chemical analysis, and the remainder was used for validating the biological tests. Table 3.2 presents the sediment treatment strategy and the appropriate chemistry and/or toxicity testing for the OBM sediment treatments.

\subsection{SEDIMENT CHEMISTRY RESULTS}

The OBM COMPs, control sediments, and reference sediments were analyzed for a variety of:selected contaminants. The sediments collected in the January 1993 and . October 1994 studies were analyzed for the following: conventional parameters (grain size, TOC, oil and grease, TPH, total solids and total volatile solids), PAHs, chlorinated pesticides, PCBs, metals, and butyltins. The sediments collected in the January 1994 study were only analyzed for PCBs; pesticides, and butyltins: These three parameters were analyzed again to confirm the results of the 1993 study. Section 3.4.1 summarizes the chemical attributes of OBM sediments. Section 3.4.2 is a comparison of OBM sediments with reference sediments to determine appropriate disposal of OBM sediments. The complete sediment chemistry results, and quality control summaries and results, are presented in Appendix A.

\subsubsection{Physical and.Chemical Attributes of OBM Sediments from Richmond Harbor}

Older bay mud sediments are primarily fine-grained ( $82 \%$ to $85 \%$ silt or clay) with low concentrations of TOC $(0.16 \%$ to $0.18 \%$ ), oil and grease (undetected at $11 \mathrm{mg} / \mathrm{kg} 1994$ data only), and TPH ( undetected at $11 \mathrm{mg} / \mathrm{kg}$ ) as shown in Table 3.3. The concentrations of total volatile solids (1.9\% to $2.3 \%$ ) are higher than would be predicted when compared with the low TOC content of this sediment. The OBM composite from the 1993 and 1994 studies had low total PAH concentrations ( $12 \mu \mathrm{g} / \mathrm{kg}$ to $57 \mu \mathrm{g} / \mathrm{kg}$ ), undetected levels of pesticides (except 4,4'-DDD in January 1993), PCBs, and organotins. Metals were detected in the OBM composites from the 1993 and October 1994 studies at levels similar to those obtained for the control sediments (1993 study) and the reference sediments (October 1994 study). 
TABLE 3.2. Summary of Sediment Treatment Strategy for Chemical and Biological Testing, Older Bay Mud Studies

\begin{tabular}{llcll}
\hline $\begin{array}{l}\text { Sediment } \\
\text { Composite }\end{array}$ & $\begin{array}{c}\text { Sediment } \\
\text { Chemistry }\end{array}$ & $\begin{array}{c}\text { Solid-Phase } \\
\text { Toxicity }\end{array}$ & $\begin{array}{c}\text { SPP } \\
\text { Toxicity }\end{array}$ & $\begin{array}{c}\text { Bioaccumulation } \\
\text { Test }\end{array}$ \\
\hline \hline January 1993 & & & & \\
OBM COMP & YES & YES & YES & YES \\
C-WB & YES & YES & NO & NO \\
C-SPB & YES & YES & NO & NO \\
C-SB & YES & YES & NO & YES \\
January 1994 & & & & \\
OBM COMP & YES & YES & YES & YES \\
R-OS & YES & YES & NO & YES \\
R-BF & YES & YES & NO & YES \\
R-AM & YES & YES & NO & YES \\
C-SB & NO & YES & NO & YES \\
C-WB & NO & YES & NO & YES \\
C-NE & NO & YES & NO & YES \\
October 1994 & & & & \\
OBM COMP & & & & NO \\
R-OS & YES & YES & NO & NO \\
R-BF & YES & YES & NO & NO \\
R-AM & YES & YES & NO & NO \\
C-SB & YES & YES & NO & NO \\
C-WB & NO & YES & NO & NO \\
C-NE & NO & YES & NO & NO \\
\hline \hline & NO & YES & & NO \\
\hline
\end{tabular}

\subsubsection{Conventional Measurements}

Conventional parameters measured in sediment are summarized in Table 3.4. The conventional results and quality control data for all the conventional parameters are presented in Appendix A, Tables A.1 through A.5. All sediment parameters are discussed on a dry weight basis.

The grain size results for the OBM COMP were similar for the January 1993 and October 1994 studies and showed that the OBM COMP was composed primarily of fine-grained sediments represented by $82 \%$ to $85 \%$ of the sediment in the silt and clay categories. Two of 
TABLE 3.3. Physical and Chemical Results of the Older Bay Mud Sediments, the Older Bay Mud Studies

\begin{tabular}{|c|c|c|c|c|}
\hline Analyte & January 1993 & January 1994 & October 1994 & Mean \\
\hline \multicolumn{5}{|l|}{ Percent } \\
\hline $\begin{array}{l}\text { gravel } \\
\text { sand } \\
\text { silt } \\
\text { clay }\end{array}$ & $\begin{array}{r}0 \\
15 \\
47 \\
38\end{array}$ & $\begin{array}{l}\text { NM(a) } \\
N M \\
N M \\
N M\end{array}$ & $\begin{array}{r}0 \\
18 \\
56 \\
26\end{array}$ & $\begin{array}{l}0 \\
16.5 \\
51.5 \\
32\end{array}$ \\
\hline $\begin{array}{l}\text { TOC } \\
\text { Solids } \\
\text { TVS }\end{array}$ & $\begin{array}{c}0.18 \\
76.4 \\
2.29\end{array}$ & $\begin{array}{l}\text { NM } \\
\text { NM } \\
\text { NM }\end{array}$ & $\begin{array}{c}0.16 \\
74.1 \\
1.90\end{array}$ & $\begin{array}{l}0.17 \\
75.3 \\
2.1\end{array}$ \\
\hline \multicolumn{5}{|l|}{$\mathrm{mg} / \mathrm{kg}$} \\
\hline $\begin{array}{l}\text { oil \& grease } \\
\text { TPH }\end{array}$ & $\begin{array}{r}501(b) \\
\text { NM }\end{array}$ & $\begin{array}{l}\text { NM } \\
\text { NM }\end{array}$ & $\begin{array}{l}11 U(c) \\
11 U^{(c)}\end{array}$ & $\begin{array}{l}11 U \\
11 U\end{array}$ \\
\hline \multicolumn{5}{|l|}{$\mu \mathrm{g} / \mathrm{kg}$} \\
\hline $\begin{array}{l}\text { TPAH } \\
4,4^{\prime}-\mathrm{DDD}\end{array}$ & $\begin{array}{c}21.3 \\
1.85\end{array}$ & $\begin{array}{l}12 \\
0.13 \mathrm{U}\end{array}$ & $\begin{array}{l}57 \\
0.22 \mathrm{U}\end{array}$ & $\begin{array}{l}30.1 \\
N A(d)\end{array}$ \\
\hline \multicolumn{5}{|l|}{ mgikg } \\
\hline $\begin{array}{l}\mathrm{Ag} \\
\mathrm{As} \\
\mathrm{Cd} \\
\mathrm{Cr} \\
\mathrm{Cu} \\
\mathrm{Hg} \\
\mathrm{Ni} \\
\mathrm{Pb} \\
\mathrm{Se} \\
\mathrm{Zn}\end{array}$ & $\begin{array}{c}0.11 \\
3.30 \\
0.84 \\
148 \\
32.9 \\
0.057 \\
70.0 \\
14.6 \\
0.30 \\
72.4\end{array}$ & $\begin{array}{l}\text { NM } \\
\text { NM } \\
\text { NM } \\
\text { NM } \\
\text { NM } \\
\text { NM } \\
\text { NM } \\
\text { NM } \\
\text { NM } \\
\text { NM }\end{array}$ & $\begin{array}{c}0.11 \\
3.28 \\
0.56 \\
142 \\
27.4 \\
0.044 \\
62.7 \\
10.6 \\
0.17 \mathrm{U} \\
68.3\end{array}$ & $\begin{array}{c}0.11 \\
3.29 \\
0.70 \\
145 \\
30.2 \\
0.05 \\
66.5 \\
12.6 \\
N A \\
70.1\end{array}$ \\
\hline \multicolumn{5}{|c|}{$\begin{array}{l}\text { (a) NM Not measured for this study. } \\
\text { (b) Value probably reflects cross-contamination, and is not used for interpretation of results. } \\
\text { (c) UUndetected at or above the detection limit. } \\
\text { (d) NA Not applicable. }\end{array}$} \\
\hline
\end{tabular}


TABLE 3.4. Conventional Sediment Measurement Results for the Older Bay Mud Studies

\begin{tabular}{lllllllll}
\hline \multirow{2}{*}{ Parameters } & \multicolumn{3}{c}{ January 1993 } & \multicolumn{2}{c}{ October 1994 } \\
\cline { 2 - 5 } & OBM & COMP & C-SB & C-WB & C-SPB & OBM COMP R-OS R-BF R-AM(a) \\
\hline
\end{tabular}

Percent dry weight

Gravel

Sand

Silt

Clay

Percent Total Solids

TOC for OBM

OBM $-0.4 \%$ TOC(c)

OBM $-0.6 \%$ TOC(c)

OBM $-1.0 \%$ TOC(c)

OBM-1.4\% TOC(c)

$\omega$ Percent TVS

mg/kg dry weight

TPH
Oil and Grease

0
15
47
38

76.4

0.18 (b)

NA(d)

NA

NA

NA

2.29

501

NA

$\begin{array}{rrr}0 & \\ 33 & 99 \\ 31 & & 0\end{array}$

$31.6(\mathrm{~b})$

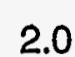

NA

NA

NA

NA

2.15(b)

$0 \quad O(b)$

$99 \quad 12(b)$

1 42(b)

42(b)

78.0

36.0

0.06

NA

NA

1.23

NA

NA

NA

2.08

0
18
56

0
26

26
53

$\begin{array}{rr}0 & 0 \\ 1 & 99 \\ 39 & 0 \\ 60 & 1\end{array}$

74.1

53.0

$36.5 \quad 82.4(b)$

$\begin{array}{llll}0.16 & 1.0 & 1.4 & 0.096(b)\end{array}$

$0.24 \quad N A \quad N A \quad N A$

$0.27 \quad N A \quad N A \quad N A$

0.39 NA NA NA

$0.44 \quad N A \quad N A \quad N A$

$\begin{array}{llll}1.9 & 2.4 & 2.3 & 0.6\end{array}$

(a) Composite of R-AM stations excluding R-AM-F.

(b) Mean of replicate values.

(c) Prior to analysis, TOC was estimated in the OBM sediments; the actual values obtained from analysis are shown in the TOC column.

(d) NA Not applicable. 
the control sediments were also fine-grained with $67 \%$ and $89 \%$ silt and clay for C-SB and C-SPB, respectively. The control C-WB and reference R-AM were $\geq 99 \%$ sand. Two reference sediments, R-OS and R-BF, were composed primarily of silt and clay $(74 \%$ and $99 \%$ fine-grained material, respectively).

The percentages of TOC found in the OBM COMP were comparable across studies and ranged from $0.16 \%$ to $0.18 \%$ dry weight. The percentages of TOC in the control sediments ranged from $0.06 \%$ in C-WB to $2.01 \%$ in C-SB. The reference sediments had percentages of TOC ranging from $0.096 \%$ in R-AM to $1.4 \%$ in R-BF. Fine-grained reference sediments had higher percentages of TOC than coarser-grained sediments. When OBM was amended with Enteromorpha spp. during the definitive feeding study, the percentages of TOC in the OBM sediments ranged from $0.24 \%$ to $0.44 \%$.

Higher TVS percentages were found in the finer-grained sediments. The TVS percentages in the OBM COMP, ranged from $1.9 \%$ to $2.29 \%$ dry weight, control sediments ranged from $0.5 \%$ in $\mathrm{C}-\mathrm{WB}$ to $2.2 \%$ in $\mathrm{C}-\mathrm{SB}$, and reference sediments ranged from $0.6 \%$ in $\mathrm{R}$-AM to $2.4 \%$ in R-OS.

The oil and grease concentration in the OBM COMP was $501 \mathrm{mg} / \mathrm{kg}$ in the January 1993 study and undetected in the October 1994 study. The concentration of oil and grease in the control sediments ranged from $327 \mathrm{mg} / \mathrm{kg}$ in C-WB to $1380 \mathrm{mg} / \mathrm{kg}$ in C-SB. The oil and grease concentrations in the reference sediments ranged from undetected in R-AM sediment to $130 \mathrm{mg} / \mathrm{kg}$ dry weight in R-BF. Oil and grease values for the OBM COMP are much higher in the January 1993 data relative to the 1994 data:-Although the QAVC data are acceptable, the oil and grease data for the 1993 study are probably cross-contaminated with YBM sediments and are not used to evaluate OBM sediments. The analysis performed in October 1994 shows that TPH was not detected in the OBM COMP and that the concentrations in the reference sediments ranged from undetected in R-AM sediments to $100 \mathrm{mg} / \mathrm{kg}$ dry weight in R-BF.

\subsubsection{Polynuclear Aromatic Hydrocarbons}

Sixteen PAHs were analyzed in the OBM COMP, the control sediments, and the reference sediments. The PAHs are reported in units of $\mu \mathrm{g} / \mathrm{kg}$ as LPAHs and HPAHs. The quality control summaries and results for PAH analysis are located in Appendix A, Tables A.6 through A.11.

Table 3.5 summarizes the LPAH, HPAH, and total PAH concentrations in sediments. The results of $\mathrm{PAH}$ analysis obtained for all three studies were similar, indicating that the $\mathrm{PAH}$ load is similar in OBM sediments throughout Richmond Harbor and has not increased substantially during these studies. The concentrations of LPAHs in the OBM COMP were either not detected or ranged from $8 \mu \mathrm{g} / \mathrm{kg}$ to $29 \mu \mathrm{g} / \mathrm{kg}$ dry weight. The HPAH concentrations in the OBM COMP 
TABLE 3.5. Detected Total PAHs, Pesticides, PCBs, Metals, and Butyltins in the Three Older Bay Mud Studies

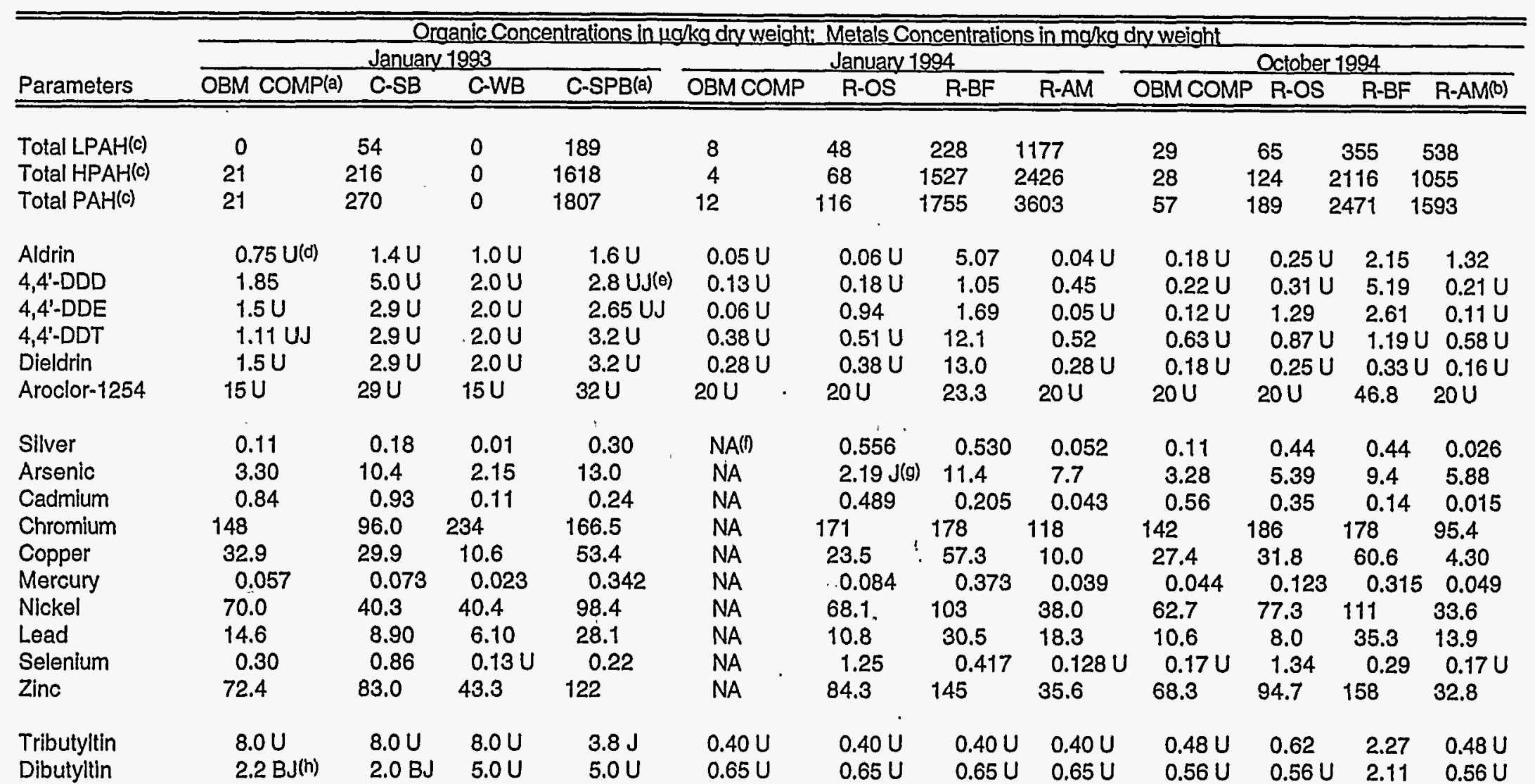

(a) Mean of replicate values.

(b) Composite of R-AM stations excluding R-AM-F.

(c) Values are the sum of detected values.

(d) U Undetected at or above the detection limit.

(e) UJ Undetected or detected below the method detection limit in all replicates.

(f) NA Not applicable.

(g) J Analyte was detected below the method detection limit (MDL), but above the instrument detection limit (IDL).

(h) BJ All replicates had analytes that were either detected below the method detection limit or present in the blank associated with the samples. 
ranged from $4 \mu \mathrm{g} / \mathrm{kg}$ to $28 \mu \mathrm{g} / \mathrm{kg}$ dry weight. The highest total PAH concentrations in the control sediments was C-SPB (1807 $\mu \mathrm{g} / \mathrm{kg}$ dry weight). In the January $1994 \mathrm{study}$, the highest total $\mathrm{PAH}$ concentrations in the reference sediments was found in R-AM ( $3603 \mu \mathrm{g} / \mathrm{kg}$ dry weight). Measurements of the individual stations comprising R-AM were also analyzed in 1993. Station R-AM-F had high levels of PAHs and was subsequently excluded from the R-AM composite tested in the October 1994 study. The reference sediment R-BF had the highest concentration of total PAHs of $2471 \mu \mathrm{g} / \mathrm{kg}$ dry weight for the October 1994 study.

\subsubsection{Chlorinated Pesticides and Polychlorinated Biphenyls}

Chlorinated pesticide and PCB concentrations that were detected in the sediment treatments are summarized in Table 3.5. All data associated with these summaries and related QA measurements can be found in Appendix A, Tables A.12 through A.18.

Nineteen chlorinated pesticides and four PCBs as Aroclors were analyzed in the sediment treatments. Most of the pesticide and PCB compounds were not detected in the OBM COMP above the target detection limits of $2 \mu \mathrm{g} / \mathrm{kg}$ and $20 \mu \mathrm{g} / \mathrm{kg}$, respectively. The OBM COMP had detectable concentrations of 4,4'-DDD and 4,4'-DDT with values of $1.85 \mu \mathrm{g} / \mathrm{kg}$ (average of three replicates) and $1.11 \mu \mathrm{g} / \mathrm{kg}$, respectively: The control sediment C-SPB had a mean detectable concentrations of $4,4^{\prime}-\mathrm{DDE}(2.7 \mu \mathrm{g} / \mathrm{kg})$ and $4,4^{\prime}-\mathrm{DDD}(2.8 \mu \mathrm{g} / \mathrm{kg})$. The three reference sediments had detected concentrations of one or more of the pesticides shown in Table 3.5, but at concentrations $\leq 13 \mu \mathrm{g} / \mathrm{kg}$ dry weight. No PCBs were detected in the OBM COMP or the control sediments above the detection limit of $20 \mu \mathrm{g} / \mathrm{kg}$. Aroclor 1254 was detected in R-BF sediments for both the January 1994 and October 1994 studies.

\subsubsection{Metals}

Ten metals were analyzed in the sediment treatments. All results and quality control summaries are found in Appendix A, Tables A.19 and A.20. Table 3.5 shows that all 10 metals were detected in the OBM COMP, the control sediments, and the reference sediments. The metals results were similar for the OBM sediment analyzed during the 1993 and 1994 studies.

\subsubsection{Butyltins}

Butyltin concentrations are summarized in Table 3.5. All data associated with these summaries and related quality assurance measurements are found in Appendix A, Tables A.21 and A.22.

Tributyltin was not detected in the OBM COMP. Dibutyltin was either undetected or detected in the OBM COMP at an average concentration of $2.2 \mu \mathrm{g} / \mathrm{kg}$; however, these levels are probably due to blank contamination. Tributyltin was present only in C-SPB at a concentration of $3.8 \mu \mathrm{g} / \mathrm{kg}$. Dibutyltins were found in C-SB at $2.0 \mu \mathrm{g} / \mathrm{kg}$ and are also probably caused by blank contamination. The reference sediments R-OS and R-BF analyzed in the October 1994 
study had detected concentrations of tributyltin and/or dibutylin at concentrations ranging from $0.62 \mu \mathrm{g} / \mathrm{kg}$ to $2.27 \mu \mathrm{g} / \mathrm{kg}$ dry weight.

\subsection{TOXICOLOGICAL TESTING RESULTS}

In January 1993, several bioassays were conducted to assess the toxicity of potential contaminants from OBM sediments: a solid-phase test using $R$. abronius, two SPP tests using $H$. costata and the bivalve M. galloprovinciallis, and a bioaccumulation test with $M$. nasuta was performed. In January 1994, three solid-phase tests using M. nasuta, N. caecoides, and $R$. abronius; three SPP tests using C. stigmaeus, H. costata, and M. galloprovinciallis; and a bioaccumulation test with $M$. nasuta were performed. In October 1994, a solid-phase test using $N$. caecoides exposed to varying concentrations of TOC and food sources was performed. The appropriate controls for each species were also used in the toxicity tests to ensure test validity by acceptable control survival. Three reference sediments were tested concurrently with the OBM COMP for the January 1993 and 1994 studies. The reference results were compared with the OBM results to provide information regarding suitable disposal options for OBM sediments. The results of the bioassay testing are presented in Appendixes $B$ through $\mathrm{H}$.

\subsubsection{0-Day Solid-Phase Static Test with $R$. abronius}

The results of the 10-day solid-phase static test with $R$. abronius are presented in Table 3.6. The water quality data and test results are in Appendix.B.- The water quality data for the 10-day test and the 96-h Cd reference toxicant tests were all within the acceptable ranges established in the QAP, with the exception of salinity in one OBM COMP replicate and $\mathrm{pH}$ in a $\mathrm{C}-\mathrm{SB}$ replicate. These water quality exceedences did not appear to affect the validity of the test. In the January 1993 study, survival of $R$. abronius exposed to the OBM COMP was $85 \%$ and the test was validated by $98 \%$ survival in the native control sediment C-WB. In the January 1994 study, survival of $R$. abronius exposed to the OBM COMP was $72 \%$ and the test was validated by $98 \%$ survival in the control sediment C-WB. Survival of $R$. abronius exposed to the three reference sediments ranged from $89 \%$ to $99 \%$.

Results of the Dunn's Test showed that the difference in survival of $R$. abronius exposed to the OBM COMP tested in both studies was not statistically significant. The difference in survival in OBM COMP and in R-AM from the January 1993 study was statistically significant but since the difference in survival was not $>20 \%$, it is not considered acutely toxic. The OBM COMP from the January 1994 study was statistically significantly different and had a $>20 \%$ difference in survival from both R-AM and R-BF. 
TABLE 3.6. Summary Results of the 10-Day Solid-Phase Static Test with $R$. abronius

\begin{tabular}{lcc}
\hline Sediment Treatment & Mean Percent Survival & Statistical Grouping \\
\hline \hline January 1993 & & \\
OBM COMP & 85 & ab \\
C-WB & 98 & NA(a) \\
January 1994 & & \\
OBM COMP & 72 & a \\
R-OS & 89 & b \\
R-BF & 94 & bc \\
R-AM & 99 & c \\
C-WB & 98 & NA \\
C-SB & 93 & \\
\hline (a) NA Not applicable. & & \\
\hline \hline
\end{tabular}

The Cd reference toxicant test for the January 1993 and January 1994 studies produced $L C_{50}$ values of $0.65 \mathrm{mg} / \mathrm{L}$ and $0.90 \mathrm{mg} / \mathrm{L}$, respectively. These values are similar to those from previous MSL studies that provided a reference toxicant range of 0.4 to $1.94 \mathrm{mg} \mathrm{Cd} / \mathrm{L}$.

\subsubsection{0-Day Solid-Phase Flow-Through Test with $M_{\text {: }}$ nasuta and $N$. caecoides}

The results of the 10-day solid-phase flow-through test.with $M$. nasuta and $N$. caecoides are presented in Tables 3.7 and 3.8. The water quality data and test results are presented in Appendix $C$. The water quality data for the 10-day test were all within the acceptable ranges established in the QAP. M. nasuta exposed to the OBM COMP had a survival of $98 \%$, which was not statistically significantly different from the survival in the three reference sediments (all had $100 \%$ survival). This test was validated by $100 \%$ survival of $M$. nasuta exposed to the native control sediment C-SB. The survival of $N$. caecoides exposed to the OBM COMP was $38 \%$, whereas the survival in the reference sediments and control sediments ranged from $91 \%$ to $96 \%$. The OBM COMP was acutely toxic to $N$. caecoides, shown by the statistically significant difference and the $\geq 10 \%$ difference in survival of the organisms after exposure to each of the three reference sediments.

\subsubsection{8-Day Solid-Phase Flow-Through Bioaccumulation Test with M. nasuta}

The results of the 28-day solid-phase flow-through test with $M$. nasuta are presented in Table 3.9. The water quality data and test results are presented in Appendix D. The water quality data for the 28-day test were all within the acceptable ranges established in the QAP, with the exception of temperature measurements in a few replicates that were as high as $17.3^{\circ} \mathrm{C}$ (target range of $13^{\circ} \mathrm{C}$ to $17^{\circ} \mathrm{C}$ ). These exceedences did not appear to affect the validity. of the

OLDER BAY MUD $\quad \therefore \quad 3.18$


TABLE 3.7. Summary Results of the 10-Day Solid-Phase Flow-Through Test with M. nasuta Sediment Treatment Mean Percent Survival Statistical Grouping

January 1994

OBM COMP

R-OS

R-BF

R-AM

98

100

100

100

100

100

$a$
$a$
$a$
$a$
$N A(a)$
$N A$

NA

(a) NA Not applicable.

test. Statistical comparisons were not performed on this data, since the purpose of the 28-day solid-phase test was to provide information regarding the bioaccumulation potential of the OBM COMP. The January 1993 study results showed that survival of $M$. nasuta exposed to the OBM COMP was greater than $97 \%$, with control survival exceeding $98 \%$. In the January 1994 study, M. nasuta survival in the OBM COMP was. $94 \%$ and the survival in the three reference sediments and one control sediment ranged from $91 \%$ to $96 \%$.

\subsubsection{8-Hour Suspended-Particulate-Phase Static Test with M. galloprovincialis}

The results of the 48-h SPP static tests with $M$. galloprovincialis are summarized in Table 3.10. The water quality data and test results are presented in Appendix $E$. The water quality data for the SPP test and the reference toxicant test were all within acceptable ranges.

The mean percent survival was calculated by adding the number of normal $D$-shaped larvae, the abnormal larvae, and the other.larvae and dividing the total by the average stocking density larval count. In the January 1993 study, the test was validated by $100 \%$ survival in the

TABLE 3.8. Summary Results of the 10-Day Solid-Phase Flow-Through Test with $N$. caecoides

Sediment Treatment $\quad$ Mean Percent Survival Statistical Grouping

January 1994

OBM COMP 38

R-OS 96

R-BF 91

R-AM 96

C-NE 94

C-SB 96

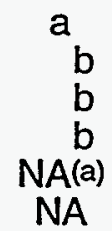


TABLE 3.9. Summary Results of the 28-Day Solid-Phase Flow-Through Test with M. nasuta

\begin{tabular}{lc}
\hline \hline Sediment Treatment & Mean Percent Survival \\
\hline \hline January 1993 & \\
OBM COMP & 97 \\
C-SB & 99 \\
January 1994 & \\
OBM COMP & \\
R-OS & 94 \\
R-BF & 96 \\
R-AM & 94 \\
C-SB & 94 \\
\hline \hline
\end{tabular}

TABLE 3.10. Summary Results of the 48-Hour-Suspended-Particulate-Phase Test with M. galloprovincialis

\begin{tabular}{|c|c|c|c|}
\hline Sediment Treatment & Percent SPP & $\begin{array}{c}\text { Mean } \\
\text { Proportion Survival }\end{array}$ & $\begin{array}{c}\text { Mean } \\
\text { Proportion Normal }\end{array}$ \\
\hline \multicolumn{4}{|l|}{ January 1993} \\
\hline $\begin{array}{l}\text { OBM COMP } \\
\text { OBM COMP } \\
\text { OBM COMP } \\
\text { OBM COMP }\end{array}$ & $\begin{array}{c}0 \\
10 \\
50 \\
100\end{array}$ & $\begin{array}{l}1.00 \\
0.99 \\
0.97 \\
1.00\end{array}$ & $\begin{array}{l}0.99 \\
0.98 \\
0.96 \\
1.00\end{array}$ \\
\hline \multicolumn{4}{|l|}{ January 1994} \\
\hline $\begin{array}{l}\text { OBM COMP } \\
\text { OBM COMP } \\
\text { OBM COMP } \\
\text { OBM COMP }\end{array}$ & $\begin{array}{c}0 \\
10 \\
50 \\
100\end{array}$ & $\begin{array}{l}0.98 \\
0.96 \\
0.91 \\
0.98\end{array}$ & $\begin{array}{l}0.98 \\
0.95 \\
0.91- \\
0.96\end{array}$ \\
\hline
\end{tabular}


control (0\% SPP). Survival was $97 \%$ or greater for the $0 \%, 10 \%, 50 \%$, and $100 \%$ SPP preparations. In the January 1994 study, the test was validated by $98 \%$ survival in the control (0\% SPP). Survival was $91 \%$ or greater for all SPP preparations. These results indicate that the OBM COMP was not acutely toxic to $M$. galloprovincialis.

The mean percent normal development was calculated by dividing the normal D-shaped larvae by the average stocking density larval count. In the January 1993 study, the percentage of normal larvae was $96 \%$ or greater for all SPP preparations. In the January 1994 study, the percentage normal larvae was $91 \%$ or greater for all SPP preparations. These results indicate that the SPP made from the OBM COMP did not affect the development of $M$. galloprovincialis larvae.

The Cu reference toxicant tests for the January 1993 and January 1994 studies produced $\mathrm{LC}_{50}$ values of $15.99 \mu \mathrm{g} / \mathrm{L}$ and $12.1 \mu \mathrm{g} / \mathrm{L}$, respectively, and $\mathrm{EC}_{50}$ values of $8.13 \mu \mathrm{g} / \mathrm{L}$ and $8.0 \mu \mathrm{g} / \mathrm{L}$, respectively. These responses were within the MSL ranges previously established of 5.8 to $35 \mu \mathrm{g} / \mathrm{L}$. of copper for the $\mathrm{LC}_{50}$ and 5.7 . to $21 \mu \mathrm{g} / \mathrm{L}$ of copper for the $\mathrm{EC}_{50}$, indicating comparable test organism sensitivity. The ammonia reference toxicant test for the January 1994 study produced an $\mathrm{LC}_{50}$ value of $43.2 \mathrm{mg} / \mathrm{L}$ total ammonia and an: $\mathrm{EC}_{50}$ value of $2.76 \mathrm{mg} / \mathrm{L}$ total ammonia. A database of the response of $M$. galloprovincialis to ammonia is currently being established; therefore, an acceptable range of sensitivity has not been determined.

\subsubsection{6-Hour Suspended-Particulate-Phase Static Test with $C$. stigmaeus}

The results of the 96-h SPP test with $C$. stigmaeus are presented in Table 3.11. The water quality data and test results are presented in Appendix $F$. The water quality data for the test and reference toxicant tests were all within the acceptable ranges established in the QAP. The test was validated by $100 \%$ survival of $C$. stigmaeus in the $0 \%$ SPP. The survival of C. stigmaeus exposed to the OBM COMP was $100 \%$ in the $10 \%$ SPP, $98 \%$ in the $50 \%$ SPP, and $100 \%$ in the $100 \%$ SPP. An LC $_{50}$ value could not be calculated because there was not a $50 \%$ reduction in survival of $C$. stigmaeus.

The Cu reference toxicant test produced an $\mathrm{LC}_{50}$ value of $0.88 \mathrm{mg} / \mathrm{L} \mathrm{Cu}$. These results are slightly below the $\mathrm{LC}_{50}$ range established from previous MSL studies (1.2 to $1.6 \mathrm{mg} / \mathrm{L} \mathrm{Cu}$ ) indicating that the test organisms were slightly more sensitive than species used in previous studies. This does not appear to have affected the results, based on the high survival of C. stigmaeus in all concentrations of SPP.

The ammonia reference toxicant test produced an $\mathrm{LC}_{50}$ value of $23.9 \mathrm{mg} / \mathrm{L}$ total ammonia. One other study has been conducted at the MSL with ammonia and $C$. stigmaeus; it resulted in an $\mathrm{LC}_{50}$ value of $30.9 \mathrm{mg} / \mathrm{L}$ total ammonia. 
TABLE 3.11. Summary Results of the 96-Hour Suspended-Particulate-Phase Test with C. stigmaeus

\begin{tabular}{lcc}
\hline Sediment Treatment & Percent SPP & Mean Percent Survival \\
\hline \hline January 1994 & & \\
OBM COMP & & \\
OBM COMP & 0 & 100 \\
OBM COMP & 10 & 100 \\
OBM COMP & 50 & 98 \\
\hline \hline
\end{tabular}

\subsubsection{6-Hour Suspended-Particulate-Phase Static Test with H. costata}

The results of the 96-h SPP test with $H$. costata are presented in Table 3.12. The water quality data and test results are presented in Appendix G. The water quality data for the test and reference toxicant tests were all within the acceptable ranges established in the QAP. In the January 1993 study; the OBM-COMP had survival of $93 \%$ for the $10 \%, 50 \%$, and $100 \%$ SPP, indicating no toxicity to any of the SPP concentrations. The $H$. costata test was validated by $93 \%$ survival in the control (0\% SPP). In the Janurary 1994 study, the OBM COMP had survival of $94 \%$ in the $10 \%$ SPP., $98 \%$ in the $50 \%$ SPP, and $96 \%$ in the $100 \%$ SPP, again indicting no toxicity to any-of the SPP concentrations. The test was validated by $98 \%$ survival in the control (0\% SPP).

TABLE 3.12: Summary:Results of the 96-Hour Suspended-Particulate-Phase Test with H. costata

\begin{tabular}{lcc}
\hline \hline Sediment Treatment & Percent SPP & Mean Percent Survival \\
\hline \hline January 1993 & & \\
OBM COMP & 0 & \\
OBM COMP & 10 & 93 \\
OBM COMP & 50 & 93 \\
OBM COMP & 100 & 93 \\
January 1994 & & 93 \\
OBM COMP & & \\
OBM COMP & 0 & \\
OBM COMP & 10 & 98 \\
OBM COMP & 50 & 94 \\
& 100 & 96 \\
\hline \hline
\end{tabular}


The Cu reference toxicant tests for the January 1993 and January 1994 studies produced $\mathrm{LC}_{50}$ values of $120 \mu \mathrm{g} / \mathrm{L} \mathrm{Cu}$ and $70.7 \mathrm{mg} / \mathrm{L} \mathrm{Cu}$, respectively. The results of the $\mathrm{H}$. costata copper reference toxicant test conducted previously at the MSL produced an $L_{50}$ value of $68.3 \mu \mathrm{g} / \mathrm{L} \mathrm{Cu}$. The ammonia reference toxicant test for the January 1994 study produced an $\mathrm{LC}_{50}$ value of $39.8 \mathrm{mg} / \mathrm{L}$ total ammonia. Currently, there is no database of ammonia effects on H. costata.

\subsubsection{0-Day Solid-Phase Flow-Through Feeding Tests with N. caecoides}

The OBM COMP was acutely toxic to N. caecoides during the Richmond Harbor Project conducted in January 1994. The consolidated character of OBM and its relatively low TOC content (average of $0.17 \%$ ) create an environment in which the organisms have a hard time burrowing into the sediment and finding an adequate food supply.

To further assess the toxicity of OBM sediments to $N$. caecoides, two tests, referred to as the preliminary test and the definitive test, were conducted in October 1994 using sediment from stations RC-12, RC-17; RC-21, and RC-30 that were composited to form one OBM COMP (Figure 1.1). The purpose of these tests was to determine whether the addition of a food source, or the softening of OBM sediments with filtered seawater, increases the survival of this test species exposed to OBM sediments.

\subsubsection{Results of the Preliminary Feeding Study}

The results of the preliminary feeding study are shown in Table 3.13. This test was validated by $99 \%$ survival of $N$. caecoides in their native control sediment (C-NE). The survival of $N$. caecoides in the OBM in the absence of additional food or water was $32 \%$. The OBM sediment softened. with the addition of seawater had an increase in survival to $77 \%$. The addition of food to the OBM showed survival ranging from $63 \%$ to $87 \%$.

A statistical analysis was performed that compared all the sediment treatments (with the exception of the control) with one another. The Dunn's test was conduced with an $\alpha=0.05$ using the arcsine square-root transformation of the mean proportion surviving data. This comparison, shown in Table 3.13, indicates that there was a statistically significant decrease in survival of $N$. caecoides exposed to the untreated OBM COMP sediment when compared with all food types and methods, except OBM- $0.8 \%$ TOC (sprinkled with tetramin). The $0.8 \%$ TOC (estimated measurement) appeared to be the optimum level of TOC for $N$. caecoides, as all three food types had greater than $85 \%$ survival using the mixed method. Two treatments, OBM-0.8\% TOC (sprinkled with tetramin) and OBM-1.2\% TOC (mixed with alfalfa), had $N$. caecoides survival values of $63 \%$ and $67 \%$, respectively. 
TABLE 3.13. Summary Results for the 10-Day N. caecoides Preliminary Test

\begin{tabular}{lcc}
\hline Sediment & $\begin{array}{c}\text { Mean } \\
\text { Treatment }\end{array}$ & $\begin{array}{c}\text { Statistical } \\
\text { Grouping }\end{array}$ \\
\hline \hline OBM COMP & 32 & $\mathrm{a}$ \\
OBM-0.8\% TOC (sprinkled with tetramin) & 63 & ab \\
OBM-1.2\% TOC (mixed with alfalfa) & 67 & $\mathrm{~b}$ \\
OBM with water (mixal & 77 & $\mathrm{~b}$ \\
OBM-0.4\% TOC (mixed with alfalfa) & 81 & $\mathrm{~b}$ \\
OBM-0.8\% TOC (mixed with tetramin) & 85 & $\mathrm{bc}$ \\
OBM-0.8\% TOC (sprinkled with Enteromorpha spp.) & 85 & $\mathrm{bc}$ \\
OBM-0.8\% TOC (mixed with alfalfa) & 87 & $\mathrm{bc}$ \\
OBM-0.8\% TOC (mixed with Enteromorpha spp.) & 87 & $\mathrm{bc}$ \\
OBM-0.8\% TOC (sprinkled with alfalfa) & 87 & $\mathrm{bc}$ \\
C-NE & 99 & $\mathrm{c}$ \\
\hline \hline
\end{tabular}

\subsubsection{Results of the Definitive Study}

The Enteromorpha spp. was chosen as the food source for the definitive study using the roller method technique. This food source.was chosen because it is found in nature and represents a potential food source most likely.encountered by the test species. The experimental design included OBM sediment, OBM sediment softened with filtered seawater, and OBM mixed with food, to represent TOC concentrations (including TOC already present in the OBM sediment) of $0.4 \%, 0.6 \%, 1.0 \%$, and $1.4 \%$. These were estimated TOC levels based on the assumption that all of the Enteromorpha spp. added to the sediment was TOC. Aliquots of the OBM sediment mixed with Enteromorpha spp. were then sent to ARI for analysis of TOC. The actual TOC levels present in the OBM sediment were approximately half of the estimated - values. The actual levels of TOC present in the OBM sediment and the results are shown in Table 3.14.

TABLE 3.14. Measurements of TOC in the OBM Sediments Mixed with Different Amounts of Enteromorphaspp.

\begin{tabular}{lcc}
\hline $\begin{array}{l}\text { Sediment } \\
\text { Treatment }\end{array}$ & $\begin{array}{c}\text { Estimate of } \\
\% \text { TOC }\end{array}$ & $\begin{array}{c}\text { Actual } \\
\% \text { TOC }\end{array}$ \\
\hline \hline OBM COMP & 0.08 & 0.16 \\
& & \\
OBM COMP + 2.45 g of Enteromorpha spp. & 0.4 & 0.24 \\
OBM COMP + 4.69 g of Enteromorpha spp. & 0.6 & 0.27 \\
OBM COMP + 9.15 g of Enteromorpha spp. & 1.0 & 0.39 \\
OBM COMP +13.62 g of Enteromorpha spp. & 1.4 & 0.44 \\
\hline \hline
\end{tabular}


The results of this study confirmed those of the preliminary study and suggest that when OBM is softened with seawater, $N$. caecoides are able to burrow into the sediment and their survival is increased to $65 \%$ (Table 3.15). The addition of food also enhanced $N$. caecoides survival in this softened sediment with a range in survival of $78 \%$ to $89 \%$. This test was validated by $100 \%$ survival in the native control sediment C-NE.

The percent survival results of the definitive study were compared to the survival results from the OBM COMP and the reference treatments tested in January 1994 using the Bonferroni/Dunn multiple comparison test. This comparison showed that the OBM sediments, when softened and amended with food, were not acutely toxic to $N$. caecoides relative to any of the reference treatments.

\subsection{TISSUE BIOACCUMULATION}

The bioaccumulation potential of OBM sediments was evaluated with $M$. nasuta in a 28-day solid-phase test. The OBM COMP was tested with the M. nasuta control C-SB in January 1993, and with the three reference-treatments (R-OS, R-BF, and R-AM) and C-SB in January 1994. The tissues of $M$. nasuta tested in January 1993 were analyzed for PAHs, pesticides, PCBs, metals, and butyltins. The tissues of $M$. nasuta tested in January 1994 were only analyzed for pesticides, PCBs, and butylins. Complete tissue chemistry results in both wet and dry weight, quality control data and quality control summaries for $M$. nasuta are presented in Appendix I. Table 3.16 shows the mean tissue concentrations of the contaminants that were elevated above the reference treatments. Table 3.16 shows the test treatment mean and the magnitude of elevation above each of the reference treatment-means.

\subsubsection{Polynuclear Aromatic Hydrocarbon Bioaccumulation in M. nasuta}

A total of 16 PAH compounds was analyzed in the tissues of $M$. nasuta exposed to the OBM COMP collected in January 1993. Complete M. nasuta tissue chemistry data in $\mu \mathrm{g} / \mathrm{kg}$ for both wet and dry weight $\mathrm{PAH}$ concentrations, quality control data, and quality control summaries are contained in Appendix I, Tables I.1 through I.9. No PAH compounds were detected in the tissues of $M$. nasuta exposed to this composite.

\subsubsection{Chlorinated Pesticides and Polychlorinated Biphenyls Bioaccumulation in M. nasuta}

A total of 19 chlorinated pesticide and 4 PCBs as Aroclors were analyzed in the tissues of $M$. nasuta. Complete $M$. nasuta tissue chemistry data in $\mu \mathrm{g} / \mathrm{kg}$ for both wet and dry weight pesticide and PCB concentrations, quality control data, and quality control summaries are contained in Appendix I, Tables I.10 through I.19. A summary of detectable tissue concentrations are presented in Table 3.15. The analytes 4, $4^{\prime}-\mathrm{DDD}, 44^{\prime}-\mathrm{DDE}, 4,4^{\prime}-\mathrm{DDT}$, and dieldrin were statistically significantly elevated in the tissues of $M$. nasuta. The magnitudes of elevation of 
TABLE 3.15. Summary of the 10-Day N. caecoides Results for the Definitive Test

\begin{tabular}{lcc}
\hline Sediment & $\begin{array}{c}\text { Mean } \\
\text { Treatment }\end{array}$ & $\begin{array}{c}\text { Statistical } \\
\text { Grouping }\end{array}$ \\
\hline \hline October 1994 OBM COMP & 20 & a \\
January 1994 OBM COMP & 38 & ab \\
OBM with water & 65 & bc \\
OBM-0.44\% TOC (mixed with Enteromorpha spp.) & 78 & cd \\
OBM-0.27\% TOC (mixed with Enteromorpha spp.) & 80 & cd \\
OBM-0.39\% TOC (mixed with Enteromorpha spp.) & 87 & cd \\
OBM-0.24\% TOC (mixed with Enteromorpha spp.) & 89 & cd \\
R-BF & 91 & d \\
R-AM & 96 & d \\
R-OS & 96 & d \\
C-NE & & NA(a) \\
& & \\
(a) NA Not applicable. & 100 & \\
\hline \hline
\end{tabular}

4,4-DDD in M. nasuta tissues exposed to the 1993 OBM COMP ranged from 87 times above $\mathrm{R}-\mathrm{BF}$ to 112 times above R-OS. The M. nasuta tissues exposed to the 1994 OBM COMP had no detectable concentrations of any of the pesticides or PCBs analyzed.

\subsubsection{Metals Bioaccumulation in M. nasuta}

Metals bioaccumulation were only evaluated during the 1993 study: Ten metals were analyzed in the tissues of M. nasuta exposed to the 1993 OBM COMP, the three reference treatments, the control treatment $\mathrm{C}-\mathrm{SB}$, and $M$. nasuta background samples. Metals concentrations in the tissues of $M$. nasuta, expressed in $\mathrm{mg} / \mathrm{kg}$ dry weight, are presented in Table 3.16. Complete $M$. nasuta tissue chemistry data in both wet and dry weight metals concentrations, quality control data, and quality control summaries are contained in Appendix I, Tables 1.20 through 1.22. All ten metals were detected in $M$. nasuta tissues. Four metals, $\mathrm{Cd}, \mathrm{Cr}$, $\mathrm{Cu}$, and $\mathrm{Hg}$, were statistically significantly higher in $M$. nasuta tissues exposed to OBM COMP relative to at least one reference treatment.

\subsubsection{Butyltin Bioaccumulation in M. nasuta}

Mean butyltin concentrations ( $\mu \mathrm{g} / \mathrm{kg}$ dry weight) in $M$. nasuta tissues are summarized in Table 3.16. Complete $M$. nasuta tissue chemistry data in both wet and dry weight organotin concentrations, quality control data, and quality control summaries are contained in Appendix I, Tables I.23 and I.24. M. nasuta tissues exposed to the 1993 OBM COMP had TBT concentrations ranging from $50.7 \mu \mathrm{g} / \mathrm{kg}$ to $63.6 \mu \mathrm{g} / \mathrm{kg}$ and DBT concentrations ranging from 


TABLE 3.16. Tissue Contaminant Concentrations in M. nasuta Tissues Exposed to the OBM Comp, Reference Sediments,
and Control Sediments for Bioaccumulation Tests
significantly different compared to at least one of the three reference treatments)


$35.0 \mu \mathrm{g} / \mathrm{kg}$ to $61.4 \mu \mathrm{g} / \mathrm{kg}$. The elevation of both TBT and DBT levels in the 1993 OBM COMP over that of all three reference sediments was statistically significant. Due to the relatively high levels of butyltins in $M$. nasuta tissues, butyltins were reexamined in $M$. nasuta tissues for the January 1994 study. M. nasuta tissues exposed to the 1994 OBM COMP had TBT concentrations ranging from $11.5 \mu \mathrm{g} / \mathrm{kg}$ to $15.5 \mu \mathrm{g} / \mathrm{kg}$, and DBT concentrations ranging from undetected at $9.58 \mu \mathrm{g} / \mathrm{kg}$ to $13.1 \mu \mathrm{g} / \mathrm{kg}$. The increases in values in the 1994 OBM COMP compared with those of any of the reference sediments did not show statistically significant increases. 


\subsection{DISCUSSION}

This section provides an overall summary of the results from chemical analyses and biological testing of the OBM sediments. The OBM composites tested in the 1993 and 1994 studies were compared, and each was compared with the reference data collected during the 1994 studies using the Dunn's multiple comparison test.

\subsection{SEDIMENT CHEMISTRY}

OBM sediments were fine-grained with a low TOC content (less than $0.2 \%$ ) and a higher level of TVS than might be expected relative to the TOC concentrations. Concentrations of oil and grease and TPH were high in the 1993 study, but as stated in Section 3.4.1, those data are suspect and only the 1994 results should be used. The 1994 data showed that oil and grease, TPH, pesticides, PCBs, and butyltins were not detected in the OBM COMP. Metals were found in the OBM COMP at levels lower than or comparable to concentrations found in one or more reference treatment. Typical concentrations of OBM sediment constituents are shown in Table 3.1.

\subsection{TOXICOLOGICAL EVALUATIONS}

\subsubsection{Deposited Sediment (Solid-Phase) Acute Toxicity}

Deposited sediment toxicity was determined by exposing $R$ : abronius, $M$. nasuta and $N$. caecoides to the OBM sediment, the native control sediments, and the reference sediments. The toxicity results from these tests are presented in Table 4:1. Sediments are considered toxic if mortality is statistically significantly higher and if it exceeds a reference sediment mortality by $20 \%$ or greater for $R$. abronius, and $10 \%$ or greater for $M$. nasuta or $N$. caecoides. The results of the $R$. abronius test showed that the OBM COMP from the 1993 study was not acutely toxic relative to any reference treatment. The OBM COMP tested in 1994 was acutely toxic to $R$. abronius relative to both of the in-bay reference treatments. The OBM COMP was not acutely toxic to $M$. nasuta relative to any reference treatment. The results of the $N$. caecoides test showed that the OBM COMP from the 1994 study was acutely toxic when compared with all three reference treatments. The feeding studies conducted in October 1994 showed that this toxicity was caused by a combination of the hard-packed nature of the OBM sediment and its relatively low TOC content. When the OBM was softened with seawater, survival increased to $65 \%$; however, the sediment was still acutely toxic to $N$. caecoides relative to all three reference treatments. However, by first softening the OBM sediment and then amending with food, survival increased and the sediment was not considered acutely toxic to $N$. caecoides relative to any reference treatment. 
TABLE 4.1. Summary of Solid-Phase Toxicity Results

\begin{tabular}{|c|c|c|c|c|c|c|}
\hline \multirow[b]{2}{*}{$\begin{array}{l}\text { Sediment } \\
\text { Treatment }\end{array}$} & \multicolumn{2}{|c|}{ R. abronius } & \multicolumn{2}{|c|}{$\overline{M . n a s u t a}$} & \multicolumn{2}{|c|}{$\bar{N}$. caecoides } \\
\hline & $\begin{array}{l}\text { Percent } \\
\text { Survival } \\
\end{array}$ & $\begin{array}{l}\text { Statistical } \\
\text { Grouping }\end{array}$ & $\begin{array}{l}\text { Percent } \\
\text { Survival } \\
\end{array}$ & $\begin{array}{l}\text { Statistical } \\
\text { Grouping }\end{array}$ & $\begin{array}{l}\text { Percent } \\
\text { Survival }\end{array}$ & $\begin{array}{l}\text { Statistical } \\
\text { Grouping }\end{array}$ \\
\hline \multicolumn{7}{|l|}{ January 1993} \\
\hline $\begin{array}{l}\text { OBM COMP } \\
\text { C-WB }\end{array}$ & $\begin{array}{l}85 \\
98\end{array}$ & $\begin{array}{l}a b \\
N A\end{array}$ & $\begin{array}{l}\text { NA(a) } \\
\text { NA }\end{array}$ & $\begin{array}{l}\text { NA } \\
\text { NA }\end{array}$ & $\begin{array}{l}\text { NA } \\
\text { NA }\end{array}$ & $\begin{array}{l}\text { NA } \\
\text { NA }\end{array}$ \\
\hline \multicolumn{7}{|l|}{ January 1994} \\
\hline $\begin{array}{l}\text { OBM COMP } \\
\text { R-OS } \\
\text { R-BF } \\
\text { R-AM } \\
\text { C-WB } \\
\text { C-SB } \\
\text { C-NE }\end{array}$ & $\begin{array}{l}72 \\
89 \\
94 \\
99 \\
98 \\
93 \\
\text { NA }\end{array}$ & $\begin{array}{l}a \\
b \\
b c \\
c \\
N A \\
N A \\
N A\end{array}$ & $\begin{array}{r}98 \\
100 \\
100 \\
100 \\
\text { NA } \\
100 \\
100\end{array}$ & $\begin{array}{l}a \\
a \\
a \\
a \\
\text { NA } \\
\text { NA } \\
\text { NA }\end{array}$ & $\begin{array}{l}38 \\
96 \\
91 \\
96 \\
\text { NA } \\
96 \\
94\end{array}$ & $\begin{array}{l}a \\
b \\
b \\
b \\
N A \\
N A \\
N A\end{array}$ \\
\hline (a) NA Not & & & & & & \\
\hline
\end{tabular}

\subsubsection{Water Column Effects}

Estimates of water column toxicity were evaluated by exposing $M$. galloprovincialis, C. stigmaeus, and $H$. costata to three concentrations of SPP and a dilution water control (Sequim Bay seawater). Acute toxicity was determined by statistical comparison of the $0 \%$ and $100 \%$ SPP using a t-test and calculations of $\mathrm{LC}_{50}$ and $\mathrm{EC}_{50}$ values using the Trimmed Spearman-Karber estimator. To calculate $\mathrm{LC}_{50}$ or $\mathrm{EC}_{50}$ values, there must be greater than $50 \%$ mortality or some. other sublethal effect occurring in the sediment treatments. There was not a $50 \%$ decrease in survival for any test species or a $50 \%$ decrease in the percentage of normal larvae for M. galloprovincialis test (Table 4.2). Using 1991 Implementation Manual guidelines, the limiting permissible concentrations (LPC) of dissolved plus suspended contaminants cannot exceed 0.01 of the acutely toxic concentration at the boundaries of the disposal site after allowing $4 \mathrm{~h}$ for initial mixing. An LPC could not be calculated for OBM, since its SPP was not toxic to the test organisms.

\subsection{BIOACCUMULATION RESULTS}

The potential for bioaccumulation of contaminants was evaluated through a 28-day solidphase exposure of $M$. nasuta to OBM sediments followed by chemical analysis of the tissues. M. nasuta tissue analyses for the 1993 study consisted of PAHs, pesticides, PCBs, metals, and butyltins. The analyses for the 1994 study consisted of pesticides, PCBs, and butyltins. PAHs 
TABLE 4.2. Summary of the Suspended-Particulate-Phase Toxicity Test Results, Older Bay Mud Studies

\begin{tabular}{|c|c|c|c|c|}
\hline & & 48-h M. galloprovincialis & 96-h C. stigmaeus & 96-h H. costata \\
\hline $\begin{array}{l}\text { Sediment } \\
\text { Treatment }\end{array}$ & $\begin{array}{l}\text { Percent } \\
\text { SPP }\end{array}$ & $\begin{array}{cc}\text { Mean Percent } & \text { Mean Percent } \\
\text { Survival } & \text { Normal }\end{array}$ & $\begin{array}{l}\text { Mean Percent } \\
\text { Survival }\end{array}$ & $\begin{array}{l}\text { Mean Percent } \\
\text { Survival }\end{array}$ \\
\hline
\end{tabular}

January 1993

$\begin{array}{lcrrrr}\text { OBM COMP } & 0 & 100 & 99 & \text { NA } & 93 \\ \text { OBM COMP } & 10 & 99 & 98 & \text { NA } & 93 \\ \text { OBM COMP } & 50 & 97 & 96 & \text { NA } & 93 \\ \text { OBM COMP } & 100 & 100 & 100 & \text { NA } & 93\end{array}$

January 1994

$\begin{array}{lccrrr}\text { OBM COMP } & 0 & 98 & 98 & 100 & 98 \\ \text { OBM COMP } & 10 & 96 & 95 & 100 & 94 \\ \text { OBM COMP } & 50 & 91 & 91 & 98 & 98 \\ \text { OBM COMP } & 100 & 98 & 96 & 100 & 96\end{array}$

and PCBs were not detected in the tissues of. $M$. nasuta exposed to OBM COMP from either . study relative to any of the reference treatment tissues; therefore, a statistical evaluation was not conducted. For the 1993 study, the concentrations of four pesticides (4,4'-DDD, 4,4'-DDE,

- 4;4'-DDT, and dieldrin) were statistically -significantly elevated in M-nasuta tissues exposed tothe OBM COMP. This is contrary to the results of the 1.994 study, which showed no detectable concentrations of pesticides in M. nasuta tissues."-All 10 metals were detected in the tissues of $M$. nasuta exposed to the OBM COMP. Four metals were statistically significantly elevated in M. nasuta tissues exposed to the OBM COMP relative to at least one reference treatment. The results of the 1993 study showed that both tributyltin and dibutyltin were statistically significantly elevated in $M$. nasuta tissue exposed to the OBM COMP. The confirmatory tests conducted in 1994 did not reflect the results of the 1993 study. In the 1994 studies, concentrations of tributyltin and dibutyltin were not statistically significantly elevated in $M$. nasuta tissues exposed to the OBM COMP relative to any reference treatment.

One possible explanation for the difference in bioaccumulation results of pesticides and butyltins between the January 1993 and 1994 data could be due to the potential cross-contamination of OBM with YBM. The sediments for the 1993 study were collected using the 4-in. core barrel and then used in the bioaccumulation test. The correct procedure for processing sediments from the 4-in. liner is to split the core vertically and then to remove sediment from the inside of the core, leaving the sediment in contact with the liner behind. However, some of the sediment that came in contact with the liner was inadvertently processed into the 
OBM sediment and used for the bioaccumulation studies, as evidenced by the presence of oil and grease, some pesticides, and butyltins in the sediments and the elevation of these compounds in the tissues of $M$. nasuta relative to what was found in tissues exposed to the reference treatment. For the 1994 studies, the sediments were collected with the 12-in. barrel. Sediments were removed from this barrel by opening the hinged door, which cut the sediment sample in half. A wedge of sediment was then taken out of the middle of the sample. This method ensures that sediment in contact with the walls of the core barrel is not included in the sample.

The tissue contaminant levels from OBM were compared to existing Food and Drug Administration (FDA) limits (Table 4.3). M. nasuta tissue contaminant concentrations were orders of magnitude below the FDA action limits after exposure to OBM sediments.

\subsection{CONCLUSIONS}

Table 4.4 is a summary of the biological testing results for the OBM Study. No OBM sediment was acutely toxic to $M$. nasuta, $M$. galloprovincialis, $C$. stigmaeus, and $H$. costata relative to any reference treatment. The results from the 1994 study with $R$. abronius did show acute toxicity of OBM sediment relative to R-BF and R-AM. The N. caecoides definitive study showed that the hard-packed nature of the OBM sediment and its low TOC content contributed to its toxicity to $N$. caecoides. It is-suspected that the lower $R$. abronius survival when exposed to OBM sediment could also be due to these factors.

Due to the potential cross-contamination problem discussed in Section 4.3, conclusions regarding the bioaccumulation potential of OBM sediments should be drawn from the 1994 data

TABLE 4.3. Comparison of FDA Action Levels With Contaminant Levels in M. nasuta Exposed to OBM Sediments

\begin{tabular}{lcc}
\hline \hline Contaminant & $\begin{array}{c}\text { FDA Action Level } \\
\text { (mg/kg wet weight) }\end{array}$ & $\begin{array}{c}\text { Maximum Concentration (mg/kg wet weight) } \\
\text { in M. nasuta Tissues - }\end{array}$ \\
\hline \hline Chlordane & 0.3 & $0.013 \mathrm{U}(\mathrm{a})$ \\
DDT + DDE & 5.0 & 0.04 \\
Dieldrin + Aldrin & 0.3 & 0.003 \\
Endrin & 0.3 & $0.001 \mathrm{U}$ \\
Heptachlor + Heptachlor Epoxide & 0.3 & $0.001 \mathrm{U}$ \\
Toxaphene & 5.0 & $0.016 \mathrm{U}$ \\
PCBs & 2.0 & $0.0032 \mathrm{U}$ \\
& & \\
(a) U Undetected above given concentration.
\end{tabular}


IABLE 4.4. Summary of Statistically Significant Acute Toxicity and Bioaccumulation for the Older Bay Mud Study

\begin{tabular}{|c|c|c|c|c|c|c|}
\hline$\overline{\text { Sediment }}$ & Acute & & M. nasuta BI & accum & & \\
\hline Treatment & Toxicity & $\mathrm{PAH}$ & Pesticides & $\mathrm{PCB}$ & Metals & Tributyltins \\
\hline Jan. 1993 OBM COMP & $R(a)$ & $\ldots$ (b) & DDD,DDE,DDT,Dieldrin & $\cdots$ & $\mathrm{Cd}, \mathrm{Cr}, \mathrm{Cu}, \mathrm{Hg}$ & TBT, DBT \\
\hline Jan. 1994 OBM COMP & $R(c), N(d)$ & $N A(\theta)$ & $\cdots$ & $\cdots$ & NA & $\cdots$ \\
\hline $\begin{array}{l}\text { (a) Rhepoxynius acutel } \\
\text { (b) --- Not statistically d } \\
\text { (c) Rhepoxynius acutel } \\
\text { (d) 10-day Nephtys cae } \\
\text { (e) NA Not applicable; }\end{array}$ & $\begin{array}{l}\text { when com } \\
\text { when com } \\
\text { when com } \\
\text { test acute } \\
\text { lyzed for } p\end{array}$ & $\begin{array}{l}\text { with } R \\
\text { with } t \\
\text { with } R \\
c \text { wher }\end{array}$ & $\begin{array}{l}\text { M. } \\
\text { references. } \\
\text { S, R-BF, and R-AM. } \\
\text { ompared with R-OS, R-B }\end{array}$ & and & & \\
\hline
\end{tabular}


only. Based on these data, PAHs, pesticides, PCBs, and butyltins were not present in the sediments or were present at low levels and did not bioaccumulate in $M$. nasuta tissues exposed to the OBM COMP relative to all three reference treatments. The metals were not tested in the 1994 bioaccumulation study; therefore, no definitive conclusions can be drawn regarding their potential to bioaccumulate into $M$. nasuta tissues. However, the metals were detected in the sediments at levels similar to those found in at least two of the three reference sediments. Therefore, bioaccumulation of metals in $M$. nasuta tissues exposed to OBM sediments would probably not have been statistically significantly different than the tissues exposed to the reference sediments, particularly $\mathrm{R}-\mathrm{OS}$ and $\mathrm{R}-\mathrm{BF}$.

In summary, the two objectives of this study were to 1) determine whether OBM sediments could be left exposed after YBM sediments were dredged, and 2) determine whether OBM is acceptable for disposal at various disposal sites. OBM is primarily composed of silt and hard-packed clay, has a low percentage of TOC, and contains no detectable concentrations of oil and grease, TPH, pesticides, PCBs, and butyltins, and low concentrations of PAHs, and metals, indicating that OBM does not mix with the overlying YBM sediments. The OBM sediments in Richmond Harbor appear to be an effective barrier to the downward transport of contaminants that are associated with the YBM sediments. The OBM sediments did pass all toxicity testing relative to the ocean site. OBM sediments were acutely toxic to $R$. abronius relative to the inbay sites. As stated earlier, this toxicity is probably caused by the physical nature of the sediment. The decisions regarding leaving OBM sediment exposed during dredging operations and determining suitable disposal sites for this sediment will lie with the regulatory agencies. 


\subsection{REFERENCES}

ASTM (American Society for Testing and Materials). 1972. Determination of Soil Constants and Standard Method for Particle-Size Analysis of Soils (16 fractions). Method D-422. American Society for Testing and Materials, Philadelphia, Pennsylvania.

ASTM (American Society for Testing and Materials). 1984. Standard Practice for Description and Identification of Soils. D2488-84, American Society for Testing and Materials, Philadelphia, Pennsylvania.

ASTM (American Society for Testing and Materials). 1985. Standard Method for Wet Preparation of Soil Samples for Particle-Size Analysis. Method D-2217. American Society for Testing and Materials, Philadelphia, Pennsylvania.

Bloom, N.S., and E.A. Crecelius. 1983. "Determination of Mercury in Seawater at Sub-Nanogram per Liter Levels." Marine Chemistry 21:337-390.

Brown, B.N., N.P. Kohn, J.A. Ward, and B.N. Bjornstad. 1990. Environmental Evaluations for Deepening of Richmond Harbor and Santa Fe Channels. PNL-7614, Pacific Northwest Laboratory, Richland, Washington.

Dunn, O.J. 1961. "Multiple Comparisons Among Means." Journal of the American Statistical Association. Vol. 56, pp. 52-64.

EPA (U.S. Environmental Protection Agency). 1979. Methods for Chemical Analysis of Water and Wastes. EPA-600 4-79-020 Methods 160.4, 413.2, 418.1; Environmental Monitoring and Support Laboratory, Cincinnati, Ohio.

EPA (U.S. Environmental Protection Agency). 1986. Determination of Total Organic Carbon in Sediment. Environmental Protection Agency Region 11, Environmental Services Division, Monitoring Management Branch, Edison, New Jersey.

EPA (U.S. Environmental Protection Agency). 1991. Methods for the Determination of Metals in Environmental Samples. EPA-600/4-91-010 Methods 200.8, 200.9, Environmental Services Division, Monitoring Management Branch, Cincinnati, Ohio.

EPA/USACE (U.S. Environmental Protection Agency/U.S. Army Corps of Engineers). 1991. Evaluation of Dredged Material Proposed for Ocean Disposal (Testing Manual).

EPA-68-C8-0105, U.S. Environmental Protection Agency, Office of Marine and Estuarine Protection, Washington, D.C.

Finney, D.J. 1971. Probit Analysis. 3rd Ed. Cambridge University Press, Boston, Massachusetts.

Goldman, H.B. 1969. "Geology of San Francisco Bay." In Geologic and Engineering Aspects of San Francisco Bay Fill, Report 97, pp. 9-30. California Division of Mines and Geology, San Francisco, California.

Helley, E.J., and K.R. Lajoie. 1979. Flatland Deposits - Their Geology and Engineering Properties and Their Importance to Comprehensive Planning. U.S. Geological Survey Professional Paper 943, Washington, D.C.

Johns, D.M., T.C. Ginn, and D.J. Reish. 1989. Interim Protocol for Juvenile Neanthes Bioassay. Ecology No. C0089018. PTI Environmental Services, Bellevue, Washington. 
Krahn, M.M., C.A. Wigren, R.W. Pearce, L.K. Moore., R.G. Bogar, W.D. MacLeod, Jr., S.L. Chan, and D.W. Brown. 1988. "New HPLC Cleanup and Revised Extraction Procedures for Organic Contaminants." NOAA Technical Memorandum NMFS f/NWC-153. NOAA/NMFS/NWFSC, Silverspring, Maryland.

PSEP (Puget Sound Estuary Program). 1986. Recommended Protocols for Measuring Selected Environmental Variables in Puget Sound. Vols. 1 and 2. Prepared by Tetra Tech, Inc. for the Puget Sound Estuary Program, Bellevue, Washington.

Pinza, M.R., J.A. Ward, H.L. Mayhew, J.Q. Word, D.K. Niyogi, and N.P. Kohn. 1992. Ecological Evaluation of Proposed Dredged Material from Richmond Harbor. PNL-8389, Pacific Northwest Laboratory, Richland, Washington.

Pinza, M.R., H.L. Mayhew, L.M. Karle, N.P. Kohn, P.J. White, J.Q. Word, and L.L. Michaels. 1995. Ecological Evaluation of Proposed Dredged Material from Richmond Harbor Deepening Project and the Intensive Study of the Turning Basin. PNL-10627, Pacific Northwest Laboratory, Richland, Washington.

Plumb, R. H. 1981. Procedures for Handling and Chemical Analysis of Sediment and Water Samples. U.S. Army Engineer Waterways Experiment Station, Vicksburg, Mississippi.

Unger, M.A., W.G. Macintyre, J. Greaves, and R.J. Huggett. 1986. "GC Determination of Butyltins in Natural Waters by Flame Photometric Detection of Hexyl Derivatives with Mass Spectrometric Confirmation." Chemosphere 15(4):461-470. 


\section{APPENDIX A}

\section{SEDIMENT CHEMISTRY AND QUALITY ASSURANCE DATA}




\section{QAVQ SUMMARY}

PROGRAM

LABORATORY:

MATRIX:

PARAMETER:

METHOD

HOLDING TIMES

DETECTION LIMITS

METHOD BLANKS

MATRIX SPIKES

REPLICATES

\section{Older Bay Mud Study \\ Soil Technology, Bainbridge Island, Washington \\ Sediment \\ Grain Size}

Grain size was measured for 4 fractions (gravel, sand, silt and clay) using a combination of sieve and pipette techniques following

ASTM Methods D-2217 for wet sieving and D-422 modified.

Tabular results are presented as fractional percent for each category.

The holding time of 6 months was met for all grain size analyses.

Target detection limits of $1 \%$ by weight were met for each sediment sample.

Not applicable.

Not applicable.

One sample, C-SPB, was analyzed in duplicate. Precision was measured by calculating the relative percent difference (RPD) between the replicate results. The RPDs ranged from $0 \%$ to $9 \%$ which is within the QAVC limits of $\pm 20 \%$ established for precision.

One QC sample was analyzed in triplicate. Precision was measured by calculating the relative standard deviation (RSD) among the replicate results. The RSD's ranged from $0 \%$ to $2 \%$ which is within the QAVC limits of $\pm 20 \%$ established for precision.

Not applicable.

SRMs

\section{REFERENCES}

ASTM (American Society for Testing and Materials). 1972. Determination of Soil Constants and Standard Method for Particle-Size analysis of Soils (16 fractions). Method D-422, American Society for Testing and Materials, Philadelphia, Pennsylvania.

ASTM (American Society for Testing and Materials). 1985. Standard Method for Wet Preparation of Soil Samples for Particle-size Analysis. Method D-2217, American Society for Testing and Materials, Philadelphia, Pennsylvania. 
PROGRAM

LABORATORY:

MATRIX:

PARAMETER:

METHOD BY GLOBAL

METHOD BY ARI

HOLDING TIMES

DETECTION LIMITS

METHOD BLANKS

MATRIX SPIKES

REPLICATES

SRMs

\section{REFERENCES}

EPA (U.S. Environmental Protection Agency). 1986. Test Methods for Evaluating Solid Waste: Physical/Chemical Methods. SW-846. U.S. Document No. 955-001-00000, U.S. Environmental Protection Agency, Washington D.C.

Plumb, R. H. 1981. Procedures for Handling and Chemical Analysis of Sediment and Water Samples. U.S. Army Engineer Waterways Experiment Station, Vicksburg, Mississippi.

\author{
Older Bay Mud Study \\ Global Geochemistry, Canoga Park, California and \\ Analytical Resources, Inc., Seattle, Washington \\ Sediment \\ Total Organic Carbon
}

TOC was analyzed using EPA method 9060 (EPA 1986).

Samples were dried and ball milled prior to analysis using a carbon analyzer. Global analyzed TOC for the January 1993 and 1994 studies.

ARI's method follows Plumb 1981, which involves direct combustion at $850^{\circ} \mathrm{C}$ in a resistance furnace. ARI analyzed TOC for the October 1994 study.

The holding time of 6 months was met for all TOC analyses.

Target detection limits of $0.1 \%$ were met for each sample.

Three method blanks were analyzed with the sediment samples. TOC was detected in the blanks and ranged from $0.0018 \%$ to $0.003 \%$ which was below the target detection limit.

One sample, R-AM, was spiked in duplicate. Matrix spike recoveries were $96 \%$ and $107 \%$ which is within the QA/QC recovery range of $50 \%$ to $150 \%$. Precision was measured by comparing the relative percent difference (RPD) between percent recoveries. The RPD was $10 \%$ indicating acceptable precision.

One sample, OBM COMP, was analyzed in duplicate. Precision was measured by calculating the relative percent difference (RPD) between the replicate results. The RPD was $6 \%$, which is within the $\pm 10 \%$ QA/QC limit established for precision.

One sample, R-AM, was analyzed in triplicate. Precision was measured by calculating the relative standard deviation (RSD) among replicate results. The RSD was $13 \%$ which is slightly higher than the $\pm 10 \%$ QA/QC limit established for precision.

Two SRMs, MESS-1 and NBS 2704, were analyzed for TOC. Although MESS-1 is not certified for TOC, in-house values have been 2.6 \pm 0.2 . The MESS-1 value reported in this study was within this range. NBS 2074 is certified at $3.35 \%$. The values reported here are within $30 \%$ of the certified value. 


\section{QA/QC SUMMARY}

PROGRAM

LABORATORY:

MATRIX:

PARAMETER:

METHOD

HOLDING TIMES

DETECTION LIMITS

METHOD BLANKS

MATRIX SPIKES

REPLICATES

SRMs

\section{REFERENCES}

EPA (U.S. Environmental Protection Agency). 1979. Methods for Chemical Analysis of Water and Wastes. EPA-600 4-79-020 Method 160.4, Environmental Monitoring and Support Laboratory, Cincinnati, Ohio.
Older Bay Mud Study

Battelle Marine Sciences Laboratory, Sequim, Washington Sediment Total Volatile Solids

Total volatile solids were analyzed according to EPA Method 160.4 (EPA 1979) by heating dried solids to $550^{\circ} \mathrm{C}$ for 1 hour and measuring the weight percentage lost during this process.

A holding time is not specified for TVS analyses.

Target detection limits of $0.1 \%$ by weight were met for each sediment sample.

Two method blanks were analyzed with the sediment samples.

The blank level was undetected at $1.0 \%$.

Not applicable.

Two samples, C-SB and R-AM, were analyzed in duplicate. Precision was measured by calculating the relative percent difference (RPD) between the replicate results. The RPD ranged from $6 \%$ to $18 \%$, which is within the $\pm 30 \%$ QA/QC Limit established for precision.

Not applicable. 


\section{QA/QC SUMMARY}

\section{PROGRAM \\ LABORATORY: \\ MATRIX: \\ PARAMETER:}

METHOD

HOLDING TIMES

DETECTION LIMITS

METHOD BLANKS

MATRIX SPIKES

REPLICATES

\author{
Older Bay Mud Study \\ Analytical Resources, Inc., Seattle, Washington \\ Sediment \\ Oil and Grease
}

Oil and grease was analyzed using EPA Method 413.2. A 20-g sample was dried and extracted with Freon. The samples were then analyzed using infrared spectrophotometry.

The 30-day holding time specified in the QAVC Plan was met for all sediment samples analyzed for the January 1993 and 1994 studies. The samples analyzed in October 1994 had to be reanalyzed to obtain acceptable method blank results. This reanalysis occurred within 60 days of sample receipt at the laboratory.

Target detection limits of $20 \mathrm{mg} / \mathrm{kg}$ were met for each sediment sample.

Two method blanks were analyzed with the sediment samples. The blank levels were undetected at up to $13 \mathrm{mg} / \mathrm{kg}$ which is below the target detection limit of $20 \mathrm{mg} / \mathrm{kg}$.

Two samples, C-WB and R-AM, were spiked with oil and grease. Matrix spike recoveries ranged from $99 \%$ to $121 \%$ which is within the QA/QC recovery range of $50 \%$ to $150 \%$. Precision was measured by comparing the relative percent difference (RPD) between matrix spike and matrix spike duplicate recoveries. The RPD was $6 \%$ indicating acceptable precision.

One sample, C-WB, was analyzed in duplicate. Precision was measured by calculating the relative percent difference (RPD) between the replicate results. The RPD was $26 \%$, which is within the $\pm 30 \%$ QAVQC limit established for precision.

One sample, R-AM, was analyzed in triplicate. Precision was measured by calculating the relative standard deviation among triplicate results. All of the triplicate values were undetected; therefore, an RSD could not be calculated.

Not applicable.

SRMS

\section{REFERENCES}

EPA (U.S. Environmental Protection Agency). 1979. Methods for Chemical Analysis of Water and Wastes. EPA-600 4-79-020 Method 413.2, Environmental Monitoring and Support Laboratory, Cincinnati, Ohio. 


\section{QA/QC SUMMARY}

PROGRAM

LABORATORY:

MATRIX:

PARAMETER:

METHOD

HOLDING TIMES

DETECTION LIMITS

METHOD BLANKS

MATRIX SPIKES

REPLICATES

SRMS
Older Bay Mud. Study

Analytical Resourcés, Inc., Seattle, Washington Sediment Total Petroleum Hydrocarbons

Total petroleum hydrocarbons comprise the nonpolar mineral fraction of total oil and grease that is not removed by silica gel absorption. An aliquot of sample material was dried with anhydrous sodium sulfate and extracted with Freon. Silica gel was added to the extract to remove the more polar animal and vegetable based oils. The extract was shaken, allowed to settle, removed, and scanned from 4000 to $600 \mathrm{~cm}^{-1}$ by infrared spectrophotometry (IR). The peak height measured at $2930 \mathrm{~cm}^{-1}$ was used to quantify the concentration of hydrocarbons in the sample.

The 30-day holding time specified in the QAVC Plan was met for all sediment samples analyzed for the January 1993 and 1994 studies. The samples analyzed in October 1994 had to be reanalyzed to obtain acceptable method blank results. This reanalysis occurred within 60 days of sample receipt at the laboratory.

Target detection limits of $20 \mathrm{mg} / \mathrm{kg}$ were met for each sediment sample.

One procedural blank was processed with each batch of samples. No hydrocarbons were detected in the method blanks at concentrations above the detection limit.

One matrix spike (MS) was analyzed with each batch of samples. The percent recovery was $95 \%$ which is within the QAVC recovery range of $50 \%$ to $150 \%$.

One sample, R-AM, was analyzed in triplicate. Precision was measured by calculating the relative standard deviation among triplicate results. All of the triplicate values were undetected; therefore, an RSD could not be calculated.

Not applicable.

\section{REFERENCES}

EPA (U.S. Environmental Protection Agency). 1979. Methods for Chemical Analysis of Water and Wastes. EPA-600 4-79-020 Method 413.2, Environmental Monitoring and Support Laboratory, Cincinnati, Ohio. 


\section{QA/QC SUMMARY}

PROGRAM

LABORATORY:

MATRIX:

PARAMETER:

METHOD

HOLDING TIMES

DETECTION LIMITS

METHOD BLANKS

MATRIX SPIKES

\section{REPLICATES}

Older Bay Mud Study

Analytical Resources, Inc., Seattle, Washington, and Battelle Marine Sciences Laboratory, Sequim, Washington Sediment Polynuclear Aromatic Hydrocarbons (PAHs)

PAHs were analyzed using EPA SW 846 Method 8270 for samples analyzed at ARI and were analyzed using the National Ocean and Atmospheric Administration (NOAA) Status and Trends method (Krahn et al. 1988) for samples analyzed at the MSL.

In the January 1993 study, sediment samples were received at ARI, extracted, and analyzed by GC/MS within 30 days which is within EPA's recommended holding time of 40 days for organics (EPA 1986).

In the January 1994 and October 1994 studies, sediment samples were stored at Battelle at $-20^{\circ} \mathrm{C}$ until ready for extraction and were analyzed within 60 days (January) and 30 days (October) of receipt of the samples.

Target detection limits of $20 \mu \mathrm{g} / \mathrm{kg}$ were met for each sediment sample.

Four method blanks were analyzed with the sediment samples. Six PAHs (naphthalene, phenanthrene, fluoranthene, pyrene, benzo(a)anthracene, and benzo(a)pyrene) were detected in the blanks at concentrations of $\leq 11.5 \mu \mathrm{g} / \mathrm{kg}$. Some sediment concentrations were flagged with a " $\mathrm{B}$ " flag to indicate that a specific analyte was detected in the sample at concentrations less than five times the value in the associated method blank.

Three samples, C-WB, QC sample, and OBM Comp, were spiked with PAHs. Matrix spike recoveries ranged from $79 \%$ to $681 \%$. Four percent recoveries were outside the QA/QC recovery range of $40 \%$ to $120 \%$. Precision was measured by calculating the relative percent difference (RPD) between matrix spike and matrix spike duplicate recoveries. The RPDs were $0 \%$ which indicates excellent precision.

One sample, OBM COMP, was analyzed in duplicate. Precision was measured by calculating the RPD between the replicate results. All detected values were $<10$ times the MDL; therefore, the precision criterion does not apply.

Three samples, QC sample, R-AM, and QC sample, were analyzed in triplicate. Precision was measured by calculating the RSDs among the replicate results. The RSDs ranged from $2 \%$ to $81 \%$. Fourteen of the calculated RSD's were outside the QAVQ limit of $<30 \%$ established for precision. 


\section{QA/QC SUMMARY (contd)}

SRMs

SURROGATES
Four SRMs, SQ-1 and 1941a, were analyzed with the sediment samples. One LPAH value and ten HPAH values were outside of the QAVQC goal of $\leq 30 \%$, indicating acceptable accuracy of the method.

For the January 1993 study, prior to extraction, two compounds, diphenyl-d10 and p-Terphenyl-d14 were added to the sediment samples to assess the efficiency of the method. Recoveries ranged from $50 \%$ to $83 \%$ which were within the QA/QC range of $40 \%$ to $120 \%$.

In the January and October 1994 studies, five isotopically labelled compounds were added prior to extraction to assess the efficiency of the method. These were d8-Naphthalene, d8-Acenaphthene, d12-Chrysene, d10-Pyrene (January), d10-Perylene (October), and d14-Dibenzo(a,h)anthracene. Recoveries of all surrogates were within the quality control limits of $40 \%$ to $120 \%$.

\section{REFERENCES}

EPA (U.S. Environmental Protection Agency). 1986. Test Methods for Evaluating Solid Waste: Physical/Chemical Methods. SWP-846 Method 8270. EPA-955-001-00000, U.S. Government Printing Office, Washington D.C.

Krahn, M.M., C.A. Wigren, R.W. Pearch, L.K. Moore, R.G. Bogar, W.D. MacLeod, Jr., S.L. Chan, and D.W. Brown. 1988. "A Rapid High-Performance Liquid Chromatographic Method for Isolating Organic Contaminants from Tissue and Sediment Extracts." NOAA Technical Memorandum NMFS F/NWC-153, Silver Spring, Maryland. 
PROGRAM

LABORATORY:

MATRIX:

PARAMETER:

METHOD

HOLDING TIMES

DETECTION LIMITS

METHOD BLANKS
Older Bay Mud Study

Analytical Resources, Inc., Seattle, Washington, and Battelle Marine Sciences Laboratory, Sequim, Washington Sediment

Pesticide

For the January 1993 study, pesticides were analyzed by ARI using EPA SW 846 Method 8080.

For the January and October 1994 studies, pesticides were analyzed by Battelle Marine Sciences Laboratory. Sediment samples were extracted with methylene chloride using a roller under ambient conditions following a procedure based on EPA method 3510 and 8080 (EPA 1986) and NOAA status and trends methodology (Krahn et al. 1988). Samples were then cleaned using silica/alumina ( $5 \%$ deactivated) chromatography followed by HPLC cleanup (Krahn et al. 1988). Modifications in the clean-up method were required in the January study to adequately recover the phthalate ester compounds required by the project. The Si column clean-up step was either eliminated or the extracts were eluted through silica and alumina, but twice the usual amount of methylene chloride was used. The column used was a J\&W DB-17 and the confirmatory column was a DB-1701, both capillary columns ( $30 \mathrm{~m} \times 0.25 \mathrm{~mm}$ ID).

In the January 1993 study, sediment samples were received at ARI, extracted, and analyzed by GC/MS within 30 days which is within EPA's recommended holding time of 40 days for organics (EPA 1986).

In the January 1994 and October 1994 studies, sediment samples were stored at Battelle at $-20^{\circ} \mathrm{C}$ until ready for extraction and were analyzed within 60 days (January) and 30 days (October) of receipt of the samples.

Target detection limits of $2 \mu \mathrm{g} / \mathrm{kg}$ were set for 19 pesticides. Ten of the pesticides met the detection limit requirements. The remaining nine pesticides had detection limits ranging from undetected at $0.75 \mu \mathrm{g} / \mathrm{kg}$ to $11 \mu \mathrm{g} / \mathrm{kg}$. Toxaphene detection limits ranged from undetected at $75 \mu \mathrm{g} / \mathrm{kg}$ to $160 \mu \mathrm{g} / \mathrm{kg}$.

Six method blanks were analyzed with the sediment samples. For all of the blanks except Blank 3 , the levels of pesticides were below the detection limit for every pesticide except toxaphene. The levels of pesticides in Blank 3 were undetected at a higher level due to the fact that only one-half the sample weight was used to calculate the blank concentrations. All of the sediment samples were undetected, no corrective action was taken. 


\section{QA/QC SUMMARY (contd)}

\section{MATRIX SPIKES}

REPLICATES : : Three samples, OBM COMP, C-SPB, and QC sample, were analyzed in duplicate. Precision was measured by calculating the RPD between the replicate results. The RPD's ranged from $0 \%$ to $30 \%$, which is within the QAVQC limit of $\leq 30 \%$ established for precision.

Three samples, QC sample, R-AM, and QC sample, were analyzed in triplicate. Precision was measured by calculating the RSD between the replicates. The RSD's ranged from $4 \%$ to $26 \%$, which is within the QA/QC limit of $\leq 30 \%$ established for precision.
SRMs

SURROGATES
Not applicable.

For the January 1993 study, prior to extraction, two compounds decachlorobiphenyl and tetrachlorometacylene were added to the sediment samples to assess the efficiency of the method.

Recoveries ranged from $10 \%$ to $114 \%$, with only four surrogate values exceeding the QAVC range of $40 \%$ to $120 \%$.

\section{REFERENCES}

EPA (U.S. Environmental Protection Agency). 1986. Test Methods for Evaluating Solid Waste: Physical/Chemical Methods. SWP-846 Method 8080. EPA-955-001-00000, U.S. Government Printing Office, Washington D.C.

Krahn, M.M., C.A. Wigren, R.W. Pearch, L.K. Moore, R.G. Bogar, W.D. MacLeod, Jr., S.L. Chan, and D.W. Brown. 1988. "A Rapid High-Performance Liquid Chromatographic Method for Isolating Organic Contaminants from Tissue and Sediment Extracts." NOAA Technical Memorandum NMFS F/NWC-153, Silver Spring, Maryland. 
PROGRAM

LABORATORY:

MATRIX:

PARAMETER:

METHOD

HOLDING TIMES

DETECTION LIMITS

METHOD BLANKS

MATRIX SPIKES
Older Bay Mud Study

Analytical Resources, Inc., Seattle, Washington, and Battelle Marine Sciences Laboratory, Sequim, Washington Sediment Polychlorinated Biphenyls (PCBs)

For the January 1993 study, PCBs were analyzed using EPA SW 846 Method 8080.

For the January and October 1994 studies, PCBs were analyzed by Battelle Marine Sciences Laboratory. Sediment samples were extracted with methylene chloride using a roller under ambient conditions following a procedure based on EPA method 3510 and 8080 (EPA 1986) and NOAA status and trends method (Krahn et al. 1988). Samples were then cleaned using silica/alumina (5\% deactivated) chromatography followed by HPLC cleanup (Krahn et al. 1988). Modifications in the clean-up method were required in the January study to adequately recover the phthalate ester compounds required by the project. The Si column clean-up step was either eliminated or the extracts were eluted through silica and alumina, but twice the usual amount of methylene chloride was used. The column used was a J\&W DB-17 and the confirmatory column was a DB-1701, both capillary columns (30 $\mathrm{m} \times 0.25 \mathrm{~mm} \mathrm{ID)}$.

In the January 1993 study, sediment samples were received at ARI, extracted, and analyzed by GC/MS within 30 days which is within EPA's recommended holding time of 40 days for organics (EPA 1986).

In the January 1994 and October 1994 studies, sediment samples were stored at the $\mathrm{MSL}$ at $-20^{\circ} \mathrm{C}$ until ready for extraction and were analyzed within 60 days (January) and 30 days (October) of receipt of the samples.

Target detection limits of $20 \mu \mathrm{g} / \mathrm{kg}$ were met for OBM COMP and the reference samples. Some of the other samples had higher detection limits due to limited sample volume.

Six method blanks were analyzed with the sediment samples. The levels of PCBs in all blanks except Blank 3 were below the detection limits. The levels of PCBs in Blank 3 were undetected at a higher level because only one-half the sample weight was used to calculate the blank concentrations. All of the sediment samples were undetected, no corrective action was taken.

Three samples QC sample, QC sample, and OBM COMP were spiked with Aroclor 1254. Matrix spike recoveries ranged from $98 \%$ to $110 \%$ which is within the QA/QC limits of $50 \%$ to $150 \%$. 


\section{QAVC SUMMARY (contd)}

\section{REPLICATES}

SRMS

SURROGATES
Three samples, OBM COMP, C-SPB, and QC sample, were analyzed in duplicate. Precision was measured by calculating the relative percent difference (RPD) between the replicate results. Calculations could not be performed for most Aroclors because all replicate values were undetected. The RPD for Aroclor 1254 was $30 \%$ which is within the QA/QC limit of $\leq 30 \%$ established for precision.

$\therefore \quad$ Three samples, QC sample, R-AM, and QC sample, were analyzed in triplicate. Precision was measured by calculating the relative standard deviation (RSD) among the replicate results. Only the RSD for Aroclor 1254 could be calculated at $10 \%$ which is within the QAVQC limit of $\leq 30 \%$ established for precision.

Not applicable.

For the January 1993 study, prior to extraction, two compounds, decachlorobiphenyl and tetrachlorometacylene were added to the sediment samples to assess the efficiency of the method.

Recoveries ranged from $10 \%$ to $114 \%$, with only four surrogate values exceeding the QAVQC range of $40 \%$ to $120 \%$.

For the January and October 1994 studies, two compounds, PCB congeners 103 and 198 , were added to all samples prior to extraction to assess the efficiency of the analysis. These compounds are also used to correct all sample results and are considered surrogate internal standards (SIS). Recoveries of these compounds were within the QC guidelines of $40 \%$ to $120 \%$ for all samples analyzed.

\section{REFERENCES}

EPA (U.S. Environmental Protection Agency). 1986. Test Methods for Evaluating Solid Waste: Physical/Chemical Methods. SWP-846 Method 8080. EPA-955-001-00000, U.S. Government Printing Office, Washington D.C.

Krahn, M.M., C.A. Wigren, R.W. Pearch, L.K. Moore, R.G. Bogar, W.D. MacLeod, Jr., S.L. Chan, and D.W. Brown. 1988. "A Rapid High-Performance Liquid Chromatographic Method for Isolating Organic Contaminants from Tissue and Sediment Extracts." NOAA Technical Memorandum NMFS F/NWC-153, Silver Spring, Maryland. 


\section{QA/QC SUMMARY}

PROGRAM

LABORATORY:

MATRIX:

PARAMETER:

METHOD

HOLDING TIMES

DETECTION LIMITS

METHOD BLANKS

MATRIX SPIKES
Older Bay Mud Study

Battelle Marine Sciences Laboratory, Sequim, Washington

Sediment

Metals

A total of 10 metals was analyzed for silver (Ag), arsenic (As), cadmium (Cd), chromium (Cr), copper (Cu), mercury ( $\mathrm{Hg})$, nickel $(\mathrm{Ni})$, lead $(\mathrm{Pb})$, selenium ( $\mathrm{Se}$ ) and zinc $(\mathrm{Zn})$. Six metals (As, $\mathrm{Cr}$, $\mathrm{Cu}, \mathrm{Ni}, \mathrm{Pb}$, and $\mathrm{Zn}$ ) were analyzed by energy diffusive $\mathrm{x}$-ray fluorescence (XRF) following the method of a PNL SOP. Three metals ( $\mathrm{Ag}, \mathrm{Cd}$, and Se) were analyzed using Zeeman Graphite Furnace Atomic Absorption (GFAA) spectrometry following the EPA Method 200.9. The metal Hg was analyzed using cold-vapor atomic absorption spectroscopy (CVAA) according to the method of Bloom and Crecelius (1983).

Samples were received in good condition and were placed into Battelle's log-in system. Samples were frozen to $-80^{\circ} \mathrm{C}$ and subsequently freeze-dried within approximately 7 days of sample receipt. Samples were all analyzed within 180 days of collection. The metal $\mathrm{Hg}$ was analyzed within the 28 day holding time.

The samples from the January and October 1994 studies were frozen to $-80^{\circ} \mathrm{C}$ and subsequently freeze-dried within approximately 14 days of sample receipt. Samples were analyzed within 180 days of sample receipt with the exception of $\mathrm{Hg}$, which was analyzed within 30 days of receipt.

Target detection limits were met for all metals with the exception of $\mathrm{Hg}$. The achieved detection limits for $\mathrm{Hg}$ were $0.02 \mathrm{mg} / \mathrm{kg}$, slightly above the target of $0.01 \mathrm{mg} / \mathrm{kg}$. Mercury was detected in all samples above the achieved detection limit.

Two method blanks were analyzed for $\mathrm{Ag}, \mathrm{Cd}$, Se and $\mathrm{Hg}$ with each batch of sediment samples. Silver was detected in Blanks 1 and 2 at the target detection limit and $\mathrm{Cd}$ was detected in Blank 2 at $0.032 \mathrm{mg} / \mathrm{kg}$. All metals data are blank corrected; therefore, no data was flagged. Method blanks are not analyzed by XRF.

Two samples, C-SPB and QC sample, were spiked with Ag, Cd, $\mathrm{Hg}$ and Se. Matrix spike recoveries ranged from $77 \%$ to $117 \%$, which is within the QAVC limits of $75 \%$ to $125 \%$. Samples for $\mathrm{XRF}$ are analyzed whole and cannot be spiked. 


\section{QAVQC SUMMARY METALS (contd)}

REPLICATES

SRMs
One sample, C-SPB, was digested in duplicate and analyzed. Precision was measured by calculating the relative percent difference (RPD) between the replicate results. The RPDs ranged from $0 \%$ to $23 \%$. All metals were within the QA/QC limits of $\pm 20 \%$ with the exception of $\mathrm{Pb}$ which had an RPD of $23 \%$. Samples for $\mathrm{XRF}$ are not processed, limiting the chance for contamination or loss due to handling. The exceedance for $\mathrm{Pb}$ is most likely due to nonhomogeneity of the sample.

One sample, QC sample, was analyzed in triplicate. Precision was measured by calculating the relative standard deviation (RSD) among the replicate results. The RSD's ranged from $0 \%$ to $43 \%$ with one RSD outside the QAVQC limit of $\leq 20 \%$ established for precision.

. One SRM, 1646 (an estuarine sediment obtained from the National Institute for Standards and Technology, NIST), was analyzed for all metals and were within $\pm 30 \%$ of the certified value, indicating acceptable accuracy.

One SRM, BEST-1 (1646), was analyzed for $\mathrm{Hg}$ and was within the $\pm 30 \%$ of the certified value, indicating acceptable accuracy.

\section{REFERENCES}

Bloom, N.S., and E.A. Crecelius. 1983. "Determination of Mercury in Seawater at Sub-Nanogram per Liter Levels." Marine Chemistry 21:337-390.

EPA (U.S. Environmental Protection Agency). 1991. Methods for the Determination of Metals in Environmental Samples. EPA-600/4-91-010 Methods 200.8, 200.9, Environmental Services Division, Monitoring Management Branch, Cincinnati, Ohio. 


\section{QAVQ SUMMARY}

\section{PROGRAM \\ LABORATORY: \\ MATRIX: \\ PARAMETER:}

METHOD

HOLDING TIMES

DETECTION LIMITS

METHOD BLANKS

SURROGATES

MATRIX SPIKES

\section{Older Bay Mud Study \\ Battelle Marine Sciences Laboratory, Sequim, Washington \\ Sediment \\ Butyltins}

Butyltin analyses were performed following the method of Unger et al. (1986).

Samples were placed into Battelle log-in system and stored at approximately $-20^{\circ} \mathrm{C}$ until extraction. Samples were extracted and extracts were analyzed by GC/FPD within EPAs recommended holding time of 40 days for organic extracts (EPA 1986).

Target detection limits of $10 \mu \mathrm{g} / \mathrm{kg}$ dry weight were met for all butyltin compounds. Actual detection limits ranged from 5 to $8 \mu \mathrm{g} / \mathrm{kg}$ for non-detected analytes. These detection limits represent quantitation limits (LOQs) defined as 10 times the standard deviation of results from 7 replicate low level matrix spikes. Note that some values were flagged with a " $J$ " flag indicating the levels present were below the LOQ but above the MDL. The MDLs are defined as 3 times the standard deviation of 7 replicate spike results

Four method blanks were analyzed with the sediment samples. Tributyltin was detected in Blank 4 at $0.55 \mu \mathrm{g} / \mathrm{kg}$. Dibutyltin was detected in Blank 1 just below the LOQ at $4.3 \mu \mathrm{g} / \mathrm{kg}$ and at $0.65 \mu \mathrm{g} / \mathrm{kg}$ in Blank 3 . These values are less than the target detection limit of $10 \mu \mathrm{g} / \mathrm{kg}$; therefore, no data was flagged and no other corrective actions were taken.

One compound, Tripentyltin chloride, is added prior to extraction to assess the efficiency of the method. This compound also is used as an internal standard as all data is corrected for the recovery of the compound. Recoveries ranged from $78 \%$ to $113 \%$, within the QAVQC limits of $40 \%$ to $120 \%$.

One sample,C-WB, was spiked in duplicate with mono-, di- and tributyltin. Matrix spike recoveries ranged from $83 \%$ to $94 \%$ for the di- and tributyltins, which were within the QAVQC limits of $40 \%$ to $120 \%$. Relative Percent Differences between MS and MSD recoveries ranged from $2 \%$ to $7 \%$, within the $\$ 30 \%$ QAVQC limit for all butyltins, indicating acceptable precision.

Three samples, QC sample, R-AM, and QC sample, were spiked with butyltins. Matrix spike recoveries ranged from $53 \%$ to $128 \%$ with one recovery outside the QA/QC limits of $40 \%$ to $120 \%$. 


\section{QA/QC SUMMARY BUTYLTINS (contd)}

REPLICATES

SRMs
One sample, C-SPB, was extracted in duplicate. Precision was measured by calculating the RPDs between the replicate results. The RPD for tributyltin was $0 \%$, indicating acceptable precision. The RPDs could not be calculated due to undetected values in the replicates.

Three samples, QC sample, QC sample, and R-OS, were analyzed in triplicate. Precision was measured by calculating the RSDs among the replicate results. The RSDs ranged from $10 \%$ to $12 \%$ which are within the QAVQC acceptable limit of $\leq 20 \%$ established for precision.

PACS-1, a marine sediment obtained from the National Research Council of Canada (NRCC) was analyzed with each batch of sediment samples. The TBT value for Batch 1 and the DBT value for Batch 3 were below $\pm 30 \%$ of the certified value. Historically, results obtained for dibutyltin and tributyltin from analysis of PACS-1 have been closer to the lower certified range. This has been corroborated by other laboratories.

\section{REFERENCES}

Unger, M.A., W.G. Macintyre, J. Greaves, and R.J. Huggett. 1986. "GC Determination of Butyltins in Natural Waters by Flame Photometric Detection of Hexyl Derivatives with Mass Spectrometric Confirmation." Chemosphere. 15(4):461-470.

EPA (U.S. Environmental Protection Agency). 1986. Test Methods for Evaluating Solid Waste: Physical/Chemical Methods. SW-846. EPA-955-001-00000, U.S. Government Printing Office, Washington D.C. 
TABLE A.1. Summary of Sediment Grain Size Including Quality Control Data, 0lder Bay Mud Study

Sediment

Treatment

January 1993

OBM COMP

C-SB

$C-W B$

C-SPB, Replicate 1

C-SPB, Replicate 2

October 1994

OBM COMP

$\mathrm{R}-\mathrm{OS}$

$\mathrm{R}-\mathrm{BF}$

R-AM

Quality Control Data

Analytical Replicates

January 1993

C-SPB, Rep Ticate 1

C-SPB, Replicate 2

RPD

I-Stat

October 1994

QC Sample, Replicate 1

QC Sample, Replicate 2

QC Sample, Replicate 3

RSD

(a) NA Not applicable.
Total Percent (Dry Weight)

\begin{tabular}{cccc}
\hline & Sand & Silt & \\
Grave & $62.5-$ & $3.9-$ & Clay \\
$\geq 2000 \mu \mathrm{m}$ & $2000 \mu \mathrm{m}$ & $\underline{62.5 \mu \mathrm{m}}$ & $\leq 3.9 \mu \mathrm{m}$ \\
\hline
\end{tabular}

$\begin{array}{ll}1 & 0 \\ 1 & 0 \\ 1 & 0 \\ 1 & 0 \\ 1 & 0\end{array}$

15

33

99

12

11

47

36

0

46

48

38

31

1

42

41

$\begin{array}{rrrrr}2 & 0 & 18 & 56 & 26 \\ 2 & 0 & 26 & 53 & 21 \\ 2 & 0 & 1 & 39 & 60 \\ 2 & 0 & 99 & 0 & 1\end{array}$


TABLE A.2. Sediment Total Organic Carbon (TOC), Total Percent Solids, and Total Volatile Solids (TVS), Older Bay Mud Study

Sediment

Treatment

Target $\mathrm{DL}^{(\mathrm{a})}$

January 1993

OBM COMP, Replicate 1

OBM COMP, Replicate 2

C-SB, Replicate 1

C-SB, Replicate 2

$C-W B$

C-SPB
Batch

1
1
1
1
1
1

October 1994

\section{OBM COMP}

$O B M-0.4 \% \operatorname{TOC}^{(c)}$

$O B M-0.6 \%$ TOC $^{(c)}$

$O B M-1.0 \%$ TOC ${ }^{(c)}$

OBM-1.4\% TOC ${ }^{(c)}$

$\mathrm{R}-\mathrm{OS}$

$\mathrm{R}-\mathrm{BF}$

R-AM, Replicate 1

R-AM, Replicate 2
2
2
2
2
2
2
2
2
2
Percent dry weight

$\begin{array}{lll}\text { Total } & \text { TOC TVS } \\ \text { Solids }\end{array}$

1.0

0.1

0.1

76.38

$N A^{(b)}$

0.17

0.18

2.01

31.58

31.57

77.97

35.99

NA

0.06

1.23

2.29

NA

2.21

2.09

0.496

2.08

(a) DL Detection Timit.

(b) NA Not applicable.

(c) Prior to analysis, TOC was estimated in the OBM sediments; the actual values obtained from analysis are shown in the TOC column. 
TABLE A.3. Quality Control Data for Sediment Total Organic Carbon (TOC), Total Percent Solids, and Total Volatile Solids (TVS), Older Bay Mud Study

Sediment

Treatment

Method Blank

B] ank-1

Biank-2

Blank

Matrix Spike

\section{$\mathrm{R}-\mathrm{AM}$}

R-AM, MS

Concentration Recovered

Amount Spiked

Percent Recovery

R-AM

R-AM, MSD

Concentration Recovered

Amount Spiked

Percent Recovery

RPD

I-Stat

Standard Reference Material

\section{Consensus}

value MESS-1

MESS-1

MESS-1

Certified value

SRM NBS 2704

NBS 2704

NBS 2704
2

NA

NA

NA

$N S^{(b)}$

NA

2

NA

NA

NA

NS

NA

NA

NA

NA

NA

$\frac{1}{2}$

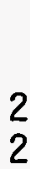

NA

NA

NA

NA

NA
Percent dry weight

TOC

TVS

0.003

$<1.0$

NA

$0.0018<1.0$

NA

NA

NA

NS

NA

$\begin{array}{ll}.547 & \text { NS } \\ 107 \% & \text { NA }\end{array}$

0.0962

0.782

0.686

0.711

NA

NA

NA

NS

NA

NA

NA

$\begin{array}{ll}10 \% & \text { NA } \\ 0.05 & \text { NA }\end{array}$

2.60

NA

NA

$2.55^{(\mathrm{c})}$

$2.80^{\text {(c) }}$

NA

NA

3.35

NA

2.87

3.37

NA

NA 
TABLE A.3. (contd)

Sediment

Treatment

Analytical Replicates

OBM COMP, Replicate 1

OBM COMP, Replicate 2

RPD

I-Stat

C-SB, Replicate 1

C-SB, Replicate 2

RPD

I-Stat

R-AM, Replicate 1

R-AM, Replicate 2

R-AM, Replicate 3

RSD/RPD

\begin{tabular}{lcc}
\multicolumn{3}{c}{ Percent dry weight } \\
\hline Total & TOC & TVS \\
Solids & &
\end{tabular}

Batch

$1 \quad N A$

NA

0.17

0.18

NA

NA

NA

NA

0.03

NA

NA

$1 \quad 31.58$

31.57

2.21

NA

2.09

$0 \%$

NA

$6 \%$

0.00

NA

0.03

82.1

82.6

0.096

0.096

0.12

0.5

NA

$13 \%$

$18 \%$

(a) NA Not applicable.

(b) NS Not spiked.

(c) MESS-1 not certified for TOC, but frequent analysis at MSL indicates a value of $2.6 \%$. 
TABLE A.4. Sediment $0 i 7$ and Grease and Total Petroleum Hydrocarbons (TPH) Results, 01der Bay Mud Study

Sediment

Treatment

Target $\mathrm{DL}^{(\mathrm{a})}$

January 1993

\section{OBM COMP}

$C-S B$

C-WB, Replicate 1

C-WB, Replicate 2

C-SPB

October 1994

OBM COMP

$R-O S$

$R-B F$

$R-A M$
Batch

$\begin{array}{rr}1 & 501 \\ 1 & 1380 \\ 1 & 284 \\ 1 & 370 \\ 1 & 772\end{array}$

2
2
2
2 $\mathrm{mg} / \mathrm{kg}$ dry weight

$0 \mathrm{i} 1$ and

Grease $\quad \mathrm{TPH}$

20

20

380

284

370

772

(a) Detection Limit

(b) NA Not applicable.

(c) U Undetected at or above detection limit.

$\begin{array}{cc}11 \mathrm{U}^{(\mathrm{c})} & 11 \mathrm{U} \\ 100 & 77 \\ 130 & 100 \\ 10 \mathrm{U} & 10 \mathrm{U}\end{array}$


TABLE A.5. Quality Control Data for Sediment $0 i 1$ and Grease and Total Petroleum Hydrocarbons. (TPH) Analyses, 01der Bay Mud Study

Sediment

Treatment

Method Blank

Blank

Blank

Matrix Spike

C-WB, Replicate 1

C-WB, Rep1 icate 1 MS

Concentration Recovered

Amount Spiked

Percent Recovery

C-WB, Replicate 1

C-WB, Replicate 1 MSD

Concentration Recovered

Amount Spiked

Percent Recovery

RPD

I-Stat

R-AM

R-AM, MS

Concentration Recovered

Amount Spiked

Percent Recovery

Analytical Replicates

C-WB, Replicate 1

C-WB, Replicate 2

$\mathrm{RPD}$

I-Stat

R-AM, Replicate 1

R-AM, Replicate 2

R-AM, Replicate 3

RSD $\mathrm{mg} / \mathrm{kg}$ dry weight
$0 i 7$ and

Grease $\frac{1}{2}$

1

1

2

1

1

2

2

2
284

8930

8646

7570

$114 \%$

284

6200

5916

4900

$121 \%$

$6 \%$

0.03

$11 \mathrm{U}$

12700

12700

12800

$99 \%$
TPH

$N A^{(a)}$

11

NA

NA

NA

$N S^{(b)}$

NA

NA

NA

NA

NS

NA

NA

NA

$11 \mathrm{U}$

10600

10600

11100

$95 \%$
284

370

$26 \%$

0.13

$11 \mathrm{U}$

$11 \mathrm{U}$

$10 \mathrm{U}$

NA
NA

NA

NA

NA

$11 \mathrm{U}$

$11 \mathrm{U}$

$10 \mathrm{U}$

NA

(a) NA Not applicable.

(b) NS Not spiked.

(c) $U$ Undetected at or above detection limit.

OLDER BAY MUD

A. 6 
TABLE A.6. Sediment Total Polynuclear Aromatic Hydrocarbons (PAHs), 01der Bay Mud Study

Sediment

Treatment

January 1993

OBM COMP, Replicate 1

OBM COMP, Replicate 2

$\mathrm{C}-\mathrm{SB}$

$C-W B$

C-SPB

January 1994

OBM COMP

$\mathrm{R}-\mathrm{OS}$

$R-B F$

R-AM, Replicate 1

R-AM, Replicate 2

R-AM, Replicate 3

October 1994

OBM COMP

$R-0 S$

$R-B F$

R-AM

$\begin{array}{rr}1 & 0 \\ 1 & 0 \\ 1 & 54 \\ 1 & 0 \\ 1 & 188\end{array}$

$\begin{array}{rr}2 & 8 \\ 3 & 48\end{array}$

228

1507

773

1251

29

65

355

538

\section{0}

$\mu \mathrm{g} / \mathrm{kg}$ dry weight Total High Molecular

Weight PAHS

Total

PAHS

\section{ar}

$\begin{array}{rr}24 & \\ 18 & 18 \\ 216 & 270 \\ 0 & 0 \\ 1618 & 1806\end{array}$

$\begin{array}{rr}4 & 12 \\ 68 & 116 \\ 1527 & 1755 \\ 3229 & 4736 \\ 1772 & 2545 \\ 2277 & 3528\end{array}$

$\begin{array}{rr}28 & 57 \\ 124 & 189 \\ 2116 & 2471 \\ 1055 & 1593\end{array}$


TABLE A.7. Sediment Low Molecular Weight Polynuclear Aromatic Hydrocarbons (LPAHs), 0Tder Bay Mud Study

Sediment

Treatment

Batch

\begin{tabular}{|c|c|}
\hline $\begin{array}{l}\text { Naptha- } \\
\text { lene }\end{array}$ & $\begin{array}{l}\text { Acenaph- } \\
\text { thylene }\end{array}$ \\
\hline 20 & 20 \\
\hline 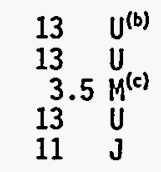 & $\begin{array}{ll}13 & U \\
13 & U \\
20 & U \\
13 & U \\
10 & J\end{array}$ \\
\hline
\end{tabular}

LPAHs ( $\mu \mathrm{g} / \mathrm{kg}$ dry weight)

Target $\mathrm{DL}^{(\mathbf{a})}$

January 1993

OBM COMP, Replicate 1

OBM COMP, Replicate 2

$\mathrm{C}-\mathrm{SB}$

C-WB

C-SPB

1
1
1
1
1

$3.94 \mathrm{~B}^{(\mathrm{t})}$
12.3
40.1
46.0
29.6
38.1

$1.47 \mathrm{U}$
$2.37^{(f)} \mathrm{B}$
15.3
63.6
32.6
56.6

$1.62^{(f)}$

$0.98 \mathrm{U}$

12.2

32.4

37.8

$20.5^{(t)}$

Fluoren

$\begin{aligned} & \text { Phenan- } \\ & \text { threne }\end{aligned}$
Anthra-
cene

20

20

20

R-BF

R-AM, Replicate 1

R-AM, Replicate

56.6

$9.29 \mathrm{~B}$

$16.5 \mathrm{~B}$

55.0

$28.8 \quad B$

$3.27^{(f)}$
$2.97 \mathrm{U}$
$19.8^{(f)}$
24.0

4.87

6.80
14.7

$\mathrm{R}-\mathrm{BF}$
$\mathrm{R}-\mathrm{AM}$

$\begin{array}{lcc}4 & 9.29 & B \\ 4 & 16.5 & B \\ 4 & 55.0 & \\ 4 & 28.8 & B\end{array}$

24.0

14.7
9.39

$\begin{array}{cc}13 & U \\ 13 & U \\ 4.3 & M \\ 13 & U \\ 11 & J\end{array}$

$13 U$
$13 U$
39
$13 U$
110

$\begin{array}{ll}13 & U \\ 13 & U_{1} \\ 13 & J^{(0)} \\ 40 & \end{array}$

(a) DL Detection limit.

(b) U Undetected at or above detection limit.

(c) $M$ Indicates an estimated value of analyte found and confirmed by analyst, but with low spectral match parameters.

(d) J Analyte detected below method detection limit (MDL), but above instrument detection limit (IDL).

(e) B Analyte detected in sample is less than five times the value in associated method blank.

(f) Ratio of confirmation ion between the primary and secondary column is outside of the theoretical ratio of $20 \%$ established for EPA-CLP programs. 

TABLE A.8. Sediment High Molecular Weight Polynuclear Aromatic Hydrocarbons (HPAHs),
Older Bay Mud Study

HPAH ( $\mu \mathrm{g} / \mathrm{kg}$ dry weight)

Sediment

Treatment

Target $\mathrm{DL}^{(\mathrm{a})}$

\begin{tabular}{|c|c|c|}
\hline Batch & $\begin{array}{l}\text { Fluor- } \\
\text { anthene }\end{array}$ & Pyrene \\
\hline & 20 & 20 \\
\hline $\begin{array}{l}1 \\
1 \\
1 \\
1 \\
1\end{array}$ & $\begin{array}{l}13 U^{(b)} \\
13 U \\
34 \\
13 U \\
220\end{array}$ & $\begin{array}{ll} & 3.3 \mathrm{~J}(\mathrm{c}) \\
2.6 \mathrm{~J} & \\
30 & \\
13 & \mathrm{U} \\
230 & \end{array}$ \\
\hline
\end{tabular}

Benzo[a]
anthra-
cene Chrysene

Benzo [b] Benzo[k]

fluor- fluor-

fluor- Benzo[a]

20

20

20

20

20

\begin{tabular}{ccc} 
Indeno & Dibenzo- & \\
{$[1,2,3-$} & {$[a, h]$} & Benzo- \\
$c, d]$ & anthra- & {$[g, h, i]$} \\
pyrene & cene & perylene \\
\hline
\end{tabular}

January 1993

OBM COMP, Replicate 1

C-SB

C-WB

220
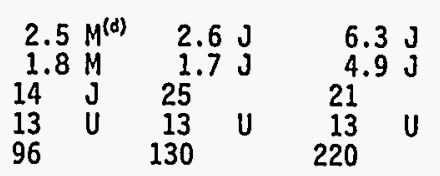

$\begin{array}{rr}6.3 & \mathrm{~J} \\ 4.9 & \mathrm{~J} \\ 21 & \\ 13 & \mathrm{U} \\ 220 & \end{array}$

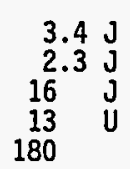

20

20

20

January 1994

OBM COMP

$\mathrm{R}-O S$
$\mathrm{R}-\mathrm{BF}$

R-AM, Repljcate 1

R-AM, Replicate

R-AM, Replicate 3

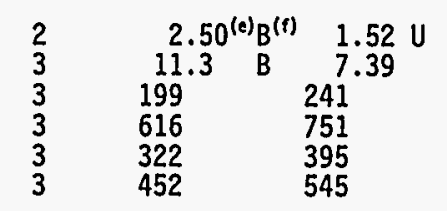

$1.37^{(\ell)} \mathrm{B}$
6.88
94.7
386
194
261

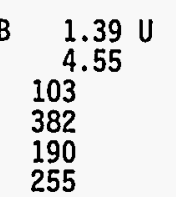

$0.64 \mathrm{U}$
9.30
200
290
167
200

$1.40 \mathrm{U}$
3.41
66.7
105
59.8
71.3

$1.52 U$
2.58
175
308
185
215

$13 U$
$13 U$
22
$13 U$
190

$\begin{array}{ll}13 & \mathrm{U} \\ 13 & \mathrm{U} \\ 15 \mathrm{~J} \\ 13 \mathrm{U} \\ 32\end{array}$

$13 \mathrm{U}$

October 1994

\section{OBM COMP}

$R-0 S$

$R-B F$

$\begin{array}{llll}4 & 8.64^{(e)} \mathrm{B} & 11.2 & \mathrm{~B} \\ 4 & 22.7^{3} & \mathrm{~B} & 27.1 \\ 4 & 287 & & 337 \\ 4 & 199 & & 238\end{array}$

$\begin{array}{ll}4.61^{(e)} & 0.78 \mathrm{U} \\ 9.85 & 8.10 \\ 114 & 147 \\ 113 & 133\end{array}$

$1.49 \mathrm{U}$
18.7
280
96.5

$2.52 \mathrm{U}$
$3.72 \mathrm{U}$
110
42.7

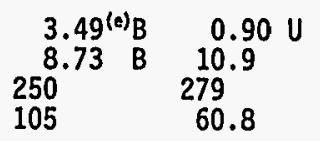

$\begin{array}{lc}1.14 \mathrm{U} & 0.82 \mathrm{U} \\ 4.50(0) & 13.5 \\ 29.8 & 282 \\ 14.0 & 53.0\end{array}$

(a) DL Detection limit

(b) U Undetected at or above detection limit.

(c) J Analyte detected below method detection limit (MDL), but above instrument detection limit.

(d) $M$ Indicates an estimated value of analyte found and confirmed by analyst, but with low spectral match parameters.

(e) Ratio of confirmation ion between the primary and secondary column is outside of the theoretical ratio of 20\%

(f) B Analyte detected in sample is less than five times the value in associated method blank. 


\section{TABLE A.9. Quality Control Data for Sediment Low Molecular Weight Polynuclear Aromatic Hydrocarbons (LPAHs), Dry Weight, 01 der Bay Mud Study}

Sediment

Treatment

Method Blank

Blank
Blank
Blank
Blank

Matrix Spike

$C-W B$

C-WB MS

Concentration Recovered

Amount Spiked

Percent Recovery

C-WB

C-WB MSD

Concentration Recovered

Amount Spiked

Percent Recovery

RPD

I-Stat

QC Sample

QC Sample, MS

Concentration Recovered

Amount Spiked

Percent Recovery

QC Sample

QC Sample, MS

Concentration Recovered

Amount Spiked

Percent Recovery

OBM COMP

OBM COMP, MS

Concentration Recovered

Amount Spiked

Percent Recovery

Standard Reference Material

SQ-1

Non-certified value

SQ-1

Certified Value

NIST 1941a

SRM 1941a

SRM 1941a

SRM 1941a

$N A^{(c)}$
$N A$
$N S^{(d)}$
$N A$

1

NA

NA

NA

NS

NA

NA

NA

2

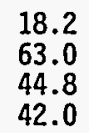

63.0
44.8

42.0

$107 \%$

3

36.4
54.6
18.2
28.5

28.5

4

$\begin{array}{ll}9.29 & 3.27^{(b)} \\ 29.5 & 22.1 \\ 20.2 & 18.8 \\ 22.0 & 22.0 \\ 92 \% & 86 \%\end{array}$

7.82
47.0
39.2
42.0
$93 \%$

11.4
44.2
32.8
28.5
$115 \%$
$3.27^{(b)}$
22.1
18.8
22.0
$86 \%$

LPAHs $(\mu \mathrm{g} / \mathrm{kg}$ dry weight)

Acenaph-

Anthra-

Fluorene threne

cene

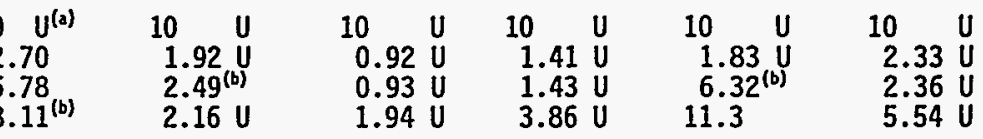

\begin{tabular}{|c|c|c|c|}
\hline $\begin{array}{l}\text { NA } \\
\text { NA } \\
\text { NA } \\
\text { NS } \\
\text { NA }\end{array}$ & $\begin{array}{rr}13 & \text { U } \\
309 & \\
309 & \\
392 & \\
& \\
& \end{array}$ & $\begin{array}{l}\text { NA } \\
\text { NA } \\
\text { NA } \\
\text { NS } \\
\text { NA }\end{array}$ & $\begin{array}{l}\text { NA } \\
\text { NA } \\
\text { NA } \\
\text { NS } \\
\text { NA }\end{array}$ \\
\hline $\begin{array}{l}\text { NA } \\
\text { NA } \\
\text { NA } \\
\text { NS } \\
\text { NA }\end{array}$ & $\begin{array}{rr}13 & \text { U } \\
311 & \\
311 & \\
394 & \\
& \end{array}$ & $\begin{array}{l}\text { NA } \\
\text { NA } \\
\text { NA } \\
\text { NS } \\
\text { NA }\end{array}$ & $\begin{array}{l}\text { NA } \\
\text { NA } \\
\text { NA } \\
\text { NS } \\
\text { NA }\end{array}$ \\
\hline $\begin{array}{l}\text { NA } \\
\text { NA }\end{array}$ & 0.00 & $\begin{array}{l}\text { NA } \\
\text { NA }\end{array}$ & $\begin{array}{l}\text { NA } \\
\text { NA }\end{array}$ \\
\hline
\end{tabular}

4.48

49.4

44.9

42.0

$107 \%$

6.57

52.5

45.9

42.0

$109 \%$

60.8

126

65.2

42.0

5.09

33.0

$12.4^{(b)}$

27.9

28.5

45.0

32.6

28.5

4.87

24.8

19.9

22.0

$91 \%$

$3.59 \mathrm{U}$

20.1

20.1

22.0

$91 \%$

113
197

84.0

28.5 $295 \%(c)$

17.4

73.2

55.8

42.0

$155 \%^{(e)} \quad 133 \%^{(e)}$

11.4

28.7

17.3

22.0

41.9

132

90.1

28.5

$316 \%(e)$

$5.15 \mathrm{U}$

19.3

19.3

22.0

$88 \%$

$\begin{array}{lrrrr}\text { NC(f) } & 120 & 120 & 130 & 100 \\ \text { NC } & \pm 7 & \pm 7 & \pm 9 & \pm 7 \\ \text { NA } & 100 & 100 & 160 & 110 \\ \text { NC } & \text { NC } & 97.3 & 489 & 184 \\ \text { NC } & \text { NC } & \pm 8.6 & \pm 23 & \pm 14 \\ \text { NA } & \text { NA } & 83.8 & 455 & 193 \\ \text { NA } & \text { NA } & 90.6 & 508 & 208 \\ \text { NA } & \text { NA } & 92.3 & 608 & 242^{(g)}\end{array}$

OLDER BAY MUD 
TABLE A.9. (contd)

Sediment

Treatment

Analytical Replicates

OBM COMP, Replicate 1

OBM COMP, Replicate 2

RPD

I-Stat

QC Sample, Replicate 1

QC Sample, Replicate 2

QC Sample, Replicate 3

RSD

R-AM, Replicate I

R-AM, Replicate 2

R-AM, Replicate 3

RSD

QC Sample, Replicate 1

QC Sample, Replicate 2

QC Sample, Replicate 3

RSD
Batch

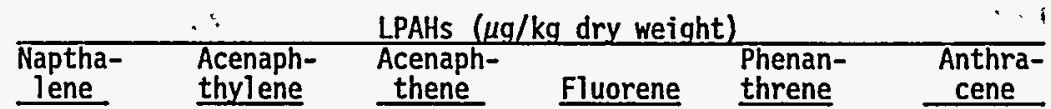

$113 \mathrm{U} \quad 13 \mathrm{U}$

$13 \mathrm{U}$

$13 \mathrm{U}$

$13 \mathrm{U}$

$13 \mathrm{U}$
$13 \mathrm{U}$

$13 \mathrm{U}$

$13 U$

NA NA

NA

NA

NA

15.5

17.2

26.5

9.76
13.0

12.1

NA

NA

NA NA

2
2
2

43.1

42.9

$3 \%$

$30 \%$

$14 \%$

18.0

22.3

33.9

112

139

314

$33 \%^{(h)}$

$58 \%^{(h)}$

84.4

268

$46.0 \quad 63.6$

29.6

63.6
32.6

56.6

32.4
37.8

37.8
$20.5^{(b)}$

92.2

44.3

94.0

925
456

783

$22 \%$

$32 \%^{(h)}$

$29 \%$

$37 \%^{(h)}$

$33 \%^{(\mathrm{h})}$

$34 z^{(h)}$

$12.5{ }^{B^{(1)}}$
$11.8^{(b)} \mathrm{B}$
$15.7 \mathrm{~B}$

$2.46 \mathrm{U}$

5.98
6.25

6.03

5.97

$18.4 \mathrm{~B}$

$16.2 \mathrm{~B}$

19.28

$6.31 \mathrm{U}$

$2.31 \mathrm{U}$

5.48

5.60

$4 \%$

$9 \%$

$6.23 \mathrm{U}$

$5.92 \mathrm{U}$

$16 \%$

NA

$7 \%$

NA

(a) U Undetected at or above detection Timit.

(b) Ratio of confirmation ion between the primary and secondary column is outside of the theoretical ratio of $20 \%$ established for EPA-CLP programs.

(c) NA Not applicable.

(d) NS Not spiked.

(e) Outside quality control criteria (40\%-120\%) for matrix spike recoveries.

(f) NC Not certified.

g) Outside quality control criteria ( $\pm 30 \%$ ) for SRMs.

(h) Exceeds quality control criteria $(\leq 30 \%)$ for precision.

(i) B Analyte detected in sample at less than five times the value in associated method blank. 
TABLE A.10. Quality Control Data for Sediment High Molecular Weight Polynuclear Aromatic Hydrocarbons (HPAHs), Older Bay Mud Study

\begin{tabular}{|c|c|c|c|c|c|c|c|c|c|c|c|}
\hline & & \multicolumn{10}{|c|}{ HPAHs ( $\mu \mathrm{g} / \mathrm{kg}$ dry woight) } \\
\hline $\begin{array}{l}\text { Sediment } \\
\text { Treatment }\end{array}$ & Batch & $\begin{array}{l}\text { Fluor- } \\
\text { anthene }\end{array}$ & Pyrene & $\begin{array}{l}\text { Benzo[a] } \\
\text { anthra- } \\
\text { cene }\end{array}$ & Chrysene & $\begin{array}{l}\text { Benzo[b] } \\
\text { fluor- } \\
\text { anthene }\end{array}$ & $\begin{array}{l}\text { Benzo[k] } \\
\text { fluor- } \\
\text { anthene }\end{array}$ & $\begin{array}{l}\text { Benzo[a] } \\
\text { pyrene }\end{array}$ & $\begin{array}{c}\text { Indeno } \\
{[1,2,3-} \\
c, d] \\
\text { pyrene }\end{array}$ & $\begin{array}{l}\text { Dibenzo- } \\
\text { [a,h] } \\
\text { anthra- } \\
\text { cene }\end{array}$ & $\begin{array}{l}\text { Benzo } \\
{[\mathrm{g}, \mathrm{h}]} \\
\text { perylene }\end{array}$ \\
\hline
\end{tabular}

Method Blank

Blank

Blank

Blank

Blank

$\begin{array}{ll}10 U^{(a)} & 10 \quad U \\ 2.85 & 1.99 U \\ 4.522^{\text {(b) }} & 2.02 \mathrm{U}\end{array}$

$10 \mathrm{U}$

\section{$10 \mathrm{U}$}

$10 \mathrm{U}$

$10 \mathrm{U}$

$10 \mathrm{U}$

$10 \mathrm{U}$

$.10 \mathrm{U}$

$10 \mathrm{U}$

$1.78 \quad 1.83 U-0.84 U=1.84 U$

$1.99 \mathrm{U}$

$3.90 \mathrm{U} \quad 5.62 \mathrm{U}$

$0.76 \mathrm{U}$

$1.85 \mathrm{U}$
$0.84 \mathrm{U}$

$0.85 \mathrm{U}$
$1.60 \mathrm{U}$

$2.70 \mathrm{U}$

$2.93^{(b)}$

$0.97 U \quad 1.22 U$

$0.88 \mathrm{U}$

Matrix Spike

C-WB
C-WB, MS
Concentration Recovered
Amount Spiked
Percent Recovery
C-WB
C-WB, MSD
Concentration Recovered
Amount Spiked
Percent Recovery
RPD
I-Stat
QC Sample
QC Sample, MS
Concentration Recovered
Amount Spiked
Percent Recovery
QC Sample
QC Sample, MS
Concentration Recovered
Amount Spiked
Percent Recovery

\begin{tabular}{|c|c|c|c|c|c|c|c|c|c|c|}
\hline 1 & $\begin{array}{l}13 \mathrm{U} \\
317 \\
317\end{array}$ & $\begin{array}{l}N A \text { (c) } \\
N A \\
N A\end{array}$ & $\begin{array}{l}13 \cup \\
319 \\
319\end{array}$ & $\begin{array}{l}\text { NA } \\
\text { NA } \\
\text { NA }\end{array}$ & $\begin{array}{l}\text { NA } \\
\text { NA } \\
\text { NA }\end{array}$ & $\begin{array}{l}\text { NA } \\
\text { NA } \\
\text { NA }\end{array}$ & $\begin{array}{l}\text { NA } \\
\text { NA } \\
\text { NA }\end{array}$ & $\begin{array}{l}\text { NA } \\
\text { NA } \\
\text { NA }\end{array}$ & $\begin{array}{l}\text { NA } \\
\text { NA } \\
\text { NA }\end{array}$ & $\begin{array}{l}\text { NA } \\
\text { NA } \\
\text { NA }\end{array}$ \\
\hline & $\begin{array}{l}392 \\
81 \%\end{array}$ & $\begin{array}{l}N S^{(d)} \\
N A\end{array}$ & $\begin{array}{l}392 \\
81 \%\end{array}$ & $\begin{array}{l}\text { NS } \\
\text { NA }\end{array}$ & $\begin{array}{l}\text { NS } \\
\text { NA }\end{array}$ & $\begin{array}{l}\text { NS } \\
\text { NA }\end{array}$ & $\begin{array}{l}\text { NS } \\
\text { NA }\end{array}$ & $\begin{array}{l}\text { NS } \\
\text { NA }\end{array}$ & $\begin{array}{l}\text { NS } \\
\text { NA }\end{array}$ & $\begin{array}{l}\text { NS } \\
\text { NA }\end{array}$ \\
\hline 1 & $\begin{array}{c}13 \mathrm{U} \\
332 \\
332 \\
394\end{array}$ & $\begin{array}{l}\text { NA } \\
N A \\
N A \\
N S\end{array}$ & $\begin{array}{c}13 \mathrm{U} \\
321 \\
321 \\
394\end{array}$ & $\begin{array}{l}\text { NA } \\
\text { NA } \\
\text { NA } \\
\text { NS }\end{array}$ & $\begin{array}{l}\text { NA } \\
\text { NA } \\
\text { NA } \\
\text { NS }\end{array}$ & $\begin{array}{l}\text { NA } \\
\text { NA } \\
\text { NA } \\
\text { NS }\end{array}$ & $\begin{array}{l}\text { NA } \\
\text { NA } \\
\text { NA } \\
\text { NS }\end{array}$ & $\begin{array}{l}\text { NA } \\
\text { NA } \\
\text { NA } \\
\text { NS }\end{array}$ & $\begin{array}{l}\text { NA } \\
\text { NA } \\
\text { NA } \\
\text { NS }\end{array}$ & $\begin{array}{l}\text { NA } \\
\text { NA } \\
\text { NA } \\
\text { NS }\end{array}$ \\
\hline & $84 \%$ & NA & $81 \%$ & NA & NA & NA & NA & NA & NA & NA \\
\hline & $\begin{array}{r}4 \% \\
0.02\end{array}$ & $\begin{array}{l}\text { NA } \\
\text { NA }\end{array}$ & $\begin{array}{r}0 \% \\
0.00\end{array}$ & $\begin{array}{l}N A \\
\text { NA }\end{array}$ & $\begin{array}{l}\text { NA } \\
\text { NA }\end{array}$ & $\begin{array}{l}\text { NA } \\
\text { NA }\end{array}$ & $\begin{array}{l}\text { NA } \\
\text { NA }\end{array}$ & $\begin{array}{l}\text { NA } \\
\text { NA }\end{array}$ & $\begin{array}{l}N A \\
N A\end{array}$ & $\begin{array}{l}\text { NA } \\
\text { NA }\end{array}$ \\
\hline 2 & $\begin{array}{l}105 \\
150 \\
45.0 \\
42.0 \\
107 \%\end{array}$ & $\begin{array}{l}142 \\
189 \\
47.0 \\
42.0 \\
112 \%\end{array}$ & $\begin{array}{l}51.1 \\
98.9 \\
47.8 \\
42.0 \\
114 \%\end{array}$ & $\begin{array}{l}56.0 \\
100 \\
44.0 \\
42.0 \\
105 \%\end{array}$ & $\begin{array}{c}110 \\
157 \\
47.0 \\
42.0 \\
112 \%\end{array}$ & $\begin{array}{l}35.0 \\
81.2 \\
46.2 \\
42.0 \\
110 \%\end{array}$ & $\begin{array}{c}104 \\
149 \\
45.0 \\
42.0 \\
107 \%\end{array}$ & $\begin{array}{l}97.3 \\
142 \\
44.7 \\
42.0 \\
106 \%\end{array}$ & $\begin{array}{l}12.8 \\
58.6 \\
45.8 \\
42.0 \\
109 \%\end{array}$ & $\begin{array}{c}107 \\
147 \\
40.0 \\
42.0 \\
95 \%\end{array}$ \\
\hline 3 & $\begin{array}{c}85.9 \\
236 \\
150 \\
28.5 \\
527 \%{ }^{\text {(e) }}\end{array}$ & $\begin{array}{c}109 \\
303 \\
194 \\
28.5 \\
681 \%{ }^{(0)}\end{array}$ & $\begin{array}{c}54.1 \\
189 \\
135 \\
28.5 \\
473 \% \text { (ө) }\end{array}$ & $\begin{array}{r}54.6 \\
238 \\
183 \\
28.5 \\
644 \%\end{array}$ & $\begin{array}{c}42.6 \\
203 \\
160 \\
28.5 \\
563 \% \text { (ө) }\end{array}$ & $\begin{array}{c}15.9 \\
84.8 \\
68.9 \\
28.5 \\
242 \%(\theta)\end{array}$ & $\begin{array}{c}44.4 \\
217 \\
173 \\
28.5 \\
606 \%\end{array}$ & $\begin{array}{c}32.3 \\
182 \\
150 \\
28.5 \\
525 \% \text { (日) }\end{array}$ & $\begin{array}{c}7.84 \\
52.9 \\
45.1 \\
28.5 \\
158 \%\end{array}$ & $\begin{array}{c}30.2 \\
175 \\
145 \\
28.5 \\
508 \%(\theta)\end{array}$ \\
\hline
\end{tabular}


TABLEA.10. (contd)

\begin{tabular}{|c|c|c|c|c|c|c|c|c|c|c|c|}
\hline \multirow[b]{2}{*}{$\begin{array}{l}\text { Sediment } \\
\text { Treatment }\end{array}$} & \multirow[b]{2}{*}{ Batch } & \multicolumn{10}{|c|}{ HPAHs ( $\mu g / k g$ dry weight) } \\
\hline & & $\begin{array}{c}\text { Fluor- } \\
\text { anthene }\end{array}$ & Pyrene & $\begin{array}{c}\text { Benzo[a] } \\
\text { anthra- } \\
\text { cene }\end{array}$ & Chrysene & $\begin{array}{l}\text { Benzo[b] } \\
\text { fluor- } \\
\text { anthene }\end{array}$ & $\begin{array}{l}\text { Benzo[k] } \\
\text { fluor- } \\
\text { anthene }\end{array}$ & $\begin{array}{l}\text { Benzo[a] } \\
\text { pyrene }\end{array}$ & $\begin{array}{c}\text { Indeno } \\
{[1,2,3-} \\
c, 0] \\
\text { pyrene } \\
\end{array}$ & $\begin{array}{l}\text { Dibenzo- } \\
\text { [a,h] } \\
\text { anthra- } \\
\text { cene } \\
\end{array}$ & $\begin{array}{c}\text { Benzo } \\
\text { [g,h] } \\
\text { perylene } \\
\end{array}$ \\
\hline \multicolumn{12}{|l|}{ Matrix Spike (contd) } \\
\hline $\begin{array}{l}\text { OBM COMP } \\
\text { OBM COMP, MS }\end{array}$ & 4 & $\begin{array}{l}8.64^{(b)} \\
26.8\end{array}$ & $\begin{array}{l}11.2 \mathrm{U} \\
27.1\end{array}$ & $\begin{array}{l}4.61^{\text {(b) }} \\
22.2\end{array}$ & $\begin{array}{l}0.78 \mathrm{U} \\
23.8\end{array}$ & $\begin{array}{l}1.49 \mathrm{U} \\
24.2\end{array}$ & $\begin{array}{l}2.52 \mathrm{U} \\
28.9\end{array}$ & $\begin{array}{l}3.49^{(b)} \\
21.2\end{array}$ & $\begin{array}{l}0.90 . \mathrm{U} \\
22.1^{\circ}\end{array}$ & $\begin{array}{l}1.14 U \\
22.2\end{array}$ & $\begin{array}{l}0.82 \mathrm{U} \\
21.4\end{array}$ \\
\hline Concentration Recovered & & 18.2 & 27.1 & 17.6 & 23.8 & 24.2 & 28.9 & 17.7 & 22.1 & 22.2 & 21.4 \\
\hline Amount Spiked & & 22.0 & 22.0 & 22.0 & 22.0 & 22.0 & 22.0 & 22.0 & 22.0 & 22.0 & 22.0 \\
\hline Percent Recovery & & $83 \%$ & $123 \%^{(e)}$ & $80 \%$ & $108 \%$ & $110 \%$ & $131 \%^{(0)}$ & $81 \%$ & $100 \%$ & $101 \%$ & $97 \%$ \\
\hline \multicolumn{12}{|l|}{ Standard Reference Material } \\
\hline$S Q-1$ & & 130 & 110 & 110 & 150 & NC & NC & 130 & NC & 74 & NC \\
\hline Non-certified value & & \pm 13 & \pm 8 & \pm 9 & \pm 9 & & & \pm 13 & & \pm 7 & \\
\hline SQ1 & 1 & 140 & 110 & 110 & 120 & NA & NA & 120 & NA & $100^{(1)}$ & NA \\
\hline Certified value & & 981 & 811 & 427 & 380 & 740 & 361 & 628 & 501 & 73.9 & 525 \\
\hline NIST 1941a & & \pm 78 & \pm 24 & \pm 25 & \pm 24 & \pm 110 & \pm 18 & \pm 52 & \pm 72 & \pm 9.7 & \pm 67 \\
\hline SRM NIST $1941 a$ & 2 & 718 & 609 & 371 & 483 & $1010^{(1)}$ & 327 & 508 & 489 & $123^{(1)}$ & 453 \\
\hline SRM NIST 1941a & 3 & $768^{10}$ & 625 & 421 & $519^{(1)}$ & $1010^{(1)}$ & 343 & 519 & 532 & $130^{(1)}$ & 476 \\
\hline SRM NIST $1941 a$ & 4 & 921 & 739 & 442 & $603^{(1)}$ & $1100^{(1)}$ & 382 & 579 & 580 & $128^{(1)}$ & 503 \\
\hline \multicolumn{12}{|l|}{ Analytical Replicates } \\
\hline OBM COMP, Replicate 1 & & $13 U$ & $3.3 J^{(g)}$ & $2.5 \mathrm{M}^{(\mathrm{h})}$ & $2.6 \mathrm{~J}$ & $6.3 \mathrm{~J}$ & $6.3 \mathrm{~J}$ & $3.4 \mathrm{~J}$ & $13 U$ & $13 U$ & $13 U$ \\
\hline OBM COMP, Replicate 2 & & $13 U$ & $2.6 \mathrm{~J}$ & $1.8 \mathrm{M}$ & $1.7 \mathrm{~J}$ & $4.9 \mathrm{~J}$ & $4.9 \mathrm{~J}$ & $2.3 \mathrm{~J}$ & $13 U$ & $13 U$ & $13 U$ \\
\hline RPD & & NA & $24 \%$ & $33 \%(1)$ & $42 \%(1)$ & $25 \%$ & $25 \%$ & $39 \%(1)$ & NA & NA & NA \\
\hline I-Stat & & NA & 0.12 & 0.16 & 0.21 & 0.12 & 0.12 & 0.19 & NA & NA & NA \\
\hline QC Sample, Replicate 1 & 2 & 312 & 480 & 200 & 324 & 637 & 222 & 447 & 291 & 81.9 & 293 \\
\hline QC Sample, Replicate 2 & 2 & 235 & 438 & 194 & 332 & 685 & 236 & 466 & 297 & 80.2 & 296 \\
\hline $\begin{array}{l}\text { RPD } \\
\text { I-Stat }\end{array}$ & & $\begin{array}{l}28 \% \\
0.14\end{array}$ & $\begin{array}{r}9 \% \\
0.05\end{array}$ & $\begin{array}{r}3 \% \\
0.02\end{array}$ & $\begin{array}{r}2 \% \\
0.01\end{array}$ & $\begin{array}{r}7 \% \\
0.04\end{array}$ & $\begin{array}{r}6 \% \\
0.03\end{array}$ & $\begin{array}{r}4 \% \\
0.02\end{array}$ & $\begin{array}{r}2 \% \\
0.01\end{array}$ & $\begin{array}{r}2 \% \\
0.01\end{array}$ & $\begin{array}{r}1 \% \\
0.01\end{array}$ \\
\hline
\end{tabular}


TABLEA.10. (contd)

HPAHs ( $\mu \mathrm{g} / \mathrm{kg}$ dry weight)

\begin{tabular}{|c|c|c|c|c|c|c|c|c|c|c|c|}
\hline \multirow[b]{2}{*}{$\begin{array}{l}\text { Sediment } \\
\text { Treatment }\end{array}$} & \multirow[b]{2}{*}{ Batch } & \multicolumn{10}{|c|}{ HPAHs ( $\mu \mathrm{g} / \mathrm{kg}$ dry weight) } \\
\hline & & $\begin{array}{l}\text { Fluor- } \\
\text { anthene }\end{array}$ & Pyrene & $\begin{array}{l}\text { Benzo[a] } \\
\text { anthra- } \\
\text { cene }\end{array}$ & Chrysene & $\begin{array}{l}\text { Benzo[b] } \\
\text { fluor- } \\
\text { anthene }\end{array}$ & $\begin{array}{l}\text { Benzo[k] } \\
\text { fluor- } \\
\text { anthene }\end{array}$ & $\begin{array}{l}\text { Benzo[a] } \\
\text { pyrene }\end{array}$ & $\begin{array}{c}\text { Indeno } \\
{[1,2,3-} \\
c, d] \\
\text { pyrene }\end{array}$ & $\begin{array}{l}\text { Dibenzo- } \\
\text { [a,h] } \\
\text { anthra- } \\
\text { cene }\end{array}$ & $\begin{array}{l}\text { Benzo } \\
{[g, h]} \\
\text { perylene }\end{array}$ \\
\hline
\end{tabular}

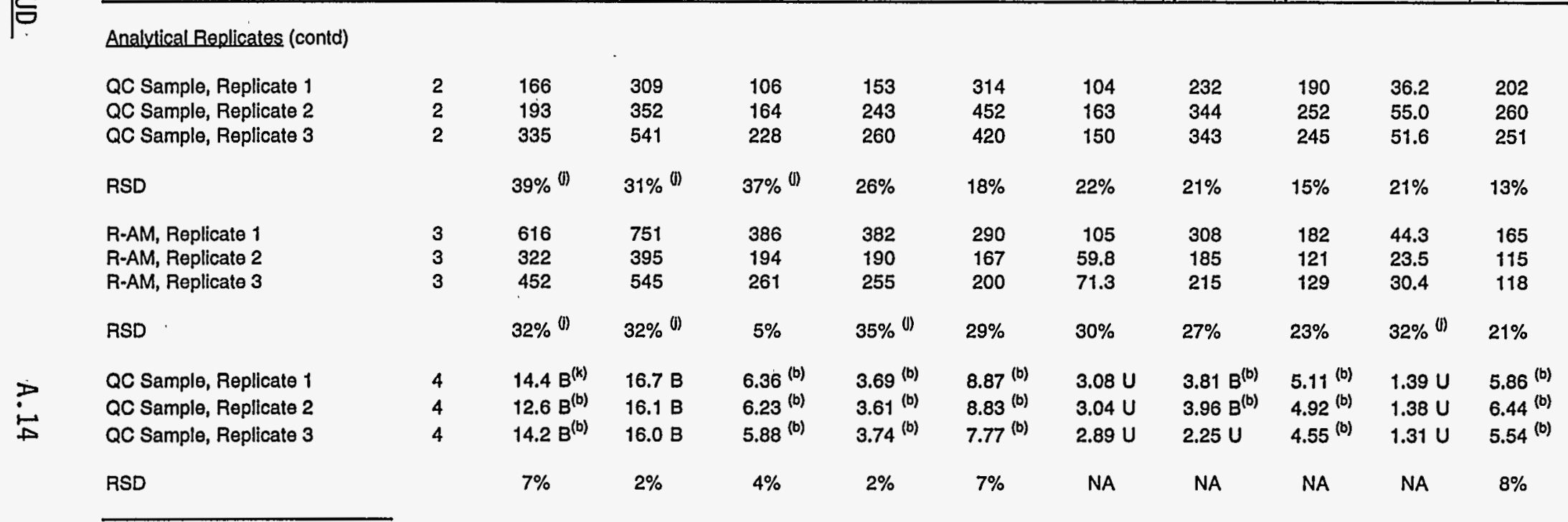

(a) $U$ Undetected at or above detection limit.

(b) Ratio of confirmation ior between the primary and secondary column is outside of the theoretical ratio of $20 \%$ established for EPA-CLP programs.

(c) NA Not applicable.

(d) NS Not spiked.

(e) Outside quality control criteria $(40 \%-120 \%)$ for matrix spike recoveries.

(i) Outside quality control criteria $( \pm 30 \%)$ for SAMs.

(g) J Analyte detected below method detection limit (MDL), but above instrument detection limit (IDL).

(h) $M$ Indicates an estimated value of analyte found and confirmed by analyst but with low spectral match parameters.

(i) Precision criteria does not apply because sample results are $<10$ times the MDL.

(i) Exceeds quality control criteria $(\leq 30 \%)$ for precision.

(k) B Analyte detected in sample at less than five times the value in the associated method blank. 
TABLE A.11. Surrogate Percent Recoveries for Polynuclear Aromatic Hydrocarbons (PAHs) Including Quality Control Data for Sediment, 01der Bay Mud Study

Sediment

Treatment

Batch

January 1993

OBM COMP, Replicate 1

OBM COMP, Replicate 2

C-SB

$C-W B$

C-SPB

Quality Control Data

Method Blank

Blank

1

75

84

Matrix Spike

C-WB MS

C-HB MSD

Standard Reference Material

SQ1

January 1994

OBM COMP

R-OS

$\mathrm{R}-\mathrm{BF}$

R-AM, Replicate 1

R-AM, Replicate 2

R-AM, Replicate 3

October 1994

OBM COMP

R-OS

$R-B F$

R-AM

$\frac{1}{1}$

73
67

80

Surrogate Percent Recoveries

Diphenyl d10

$\begin{array}{ll}50 & 65 \\ 65 & 77 \\ 55 & 76 \\ 70 & 74 \\ 70 & 60\end{array}$

Quality Control Data

\section{Method Blank}

B] ank

Blank

Blank

$\begin{array}{ll}2 & 84 \\ 3 & 85 \\ 4 & 46\end{array}$

81
78
56

90

80

ND

ND

75

69

Matrix Spike

QC Sample

QC Sample, MS

QC Sample

QC Sample, MS

OBM COMP

OBM COMP, MS $\begin{array}{ll}2 & 69 \\ 2 & 74\end{array}$

69
74

73
77

86
64

69
75

85
95

$63 \quad 66$

$61 \quad 64$
63
66
67
70

$\begin{array}{ll}\text { ND(a) } & 79 \\ \text { ND } & 90 \\ \text { ND } & 83 \\ \text { ND } & 84 \\ \text { ND } & 75 \\ \text { ND } & 84\end{array}$

Dibenzo $(a, h, i)$ anthracene 
TABLE A.11. (contd)

Sediment

Treatment

Analytical Replicates

QC Sample, Replicate 1 QC Sample, Replicate 2

QC Sample, Replicate 1 QC Sample, Replicate 2 QC Sample, Replicate 3

R-AM, Replicate 1

R-AM, Replicate

R-AM, Replicate 3

QC Sample, Replicate 1

QC Sample, Repl icate 2

QC Sample, Replicate 3

(a) ND No data.
Batch

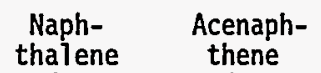

thalene

thene

d8

d10

Chrysene
d12 $\quad \begin{gathered}\text { Perylene } \\ \mathrm{d} 12\end{gathered}$

Dibenzo $(a, h, i)$ anthracene d14

$\begin{array}{ll}2 & 75 \\ 2 & 65 \\ 2 & 68 \\ 2 & 56 \\ 2 & 72 \\ 3 & 71 \\ 3 & 65 \\ 3 & 69 \\ & \\ 4 & 69 \\ 4 & 63 \\ 4 & 65\end{array}$

78
68
75
65
75
72
67
71
72
66
68

68

89

87

$\begin{array}{ll}\text { ND } & 80 \\ \text { ND } & 75 \\ \text { ND } & \\ \text { ND } & 86 \\ \text { ND } & 76 \\ & 83\end{array}$

83

91

76
83

65

72

67

94

85
93

ND

ND

ND

84

75

$64 \quad 70$

66

65
80
72

68

65

67
64

64
63 


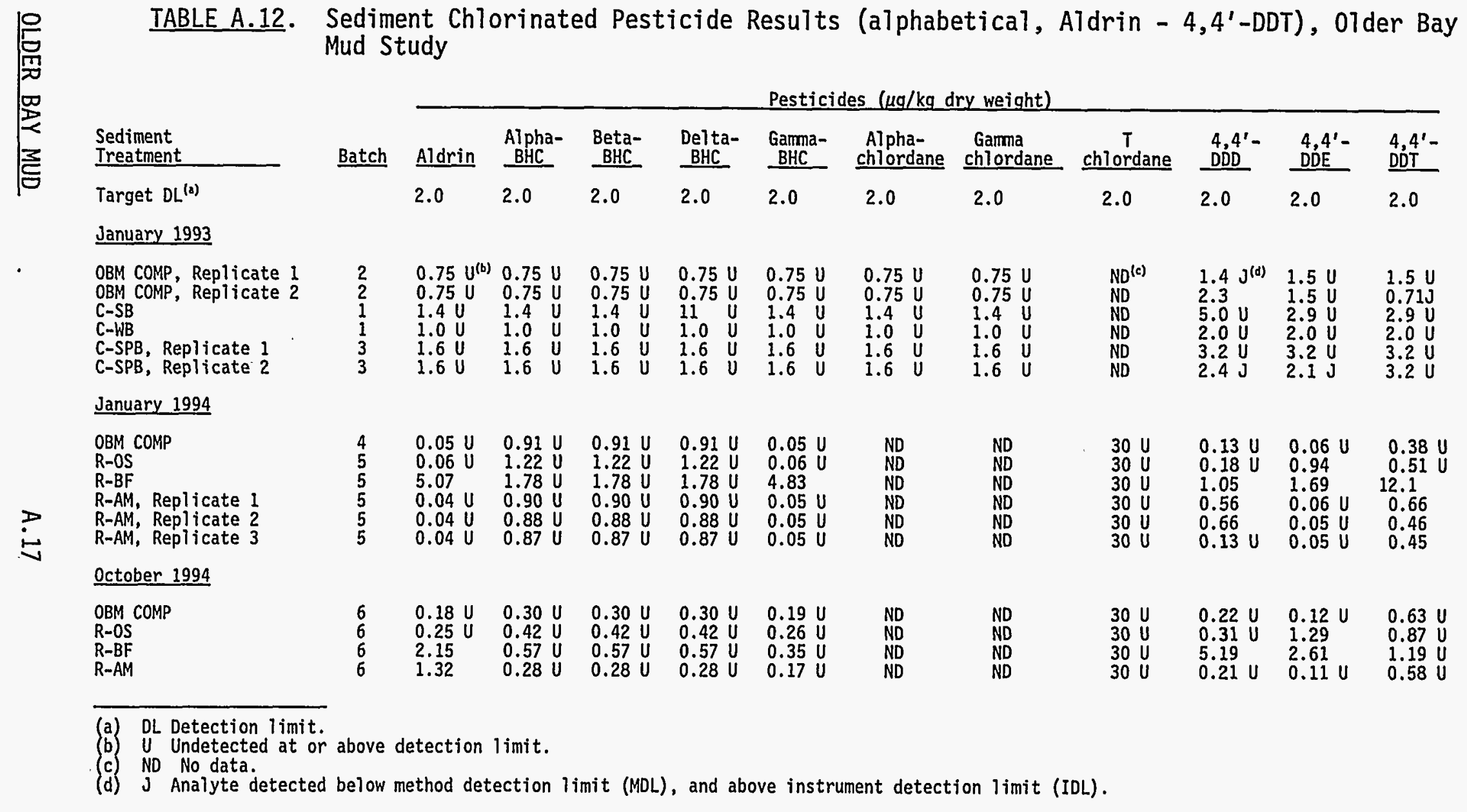




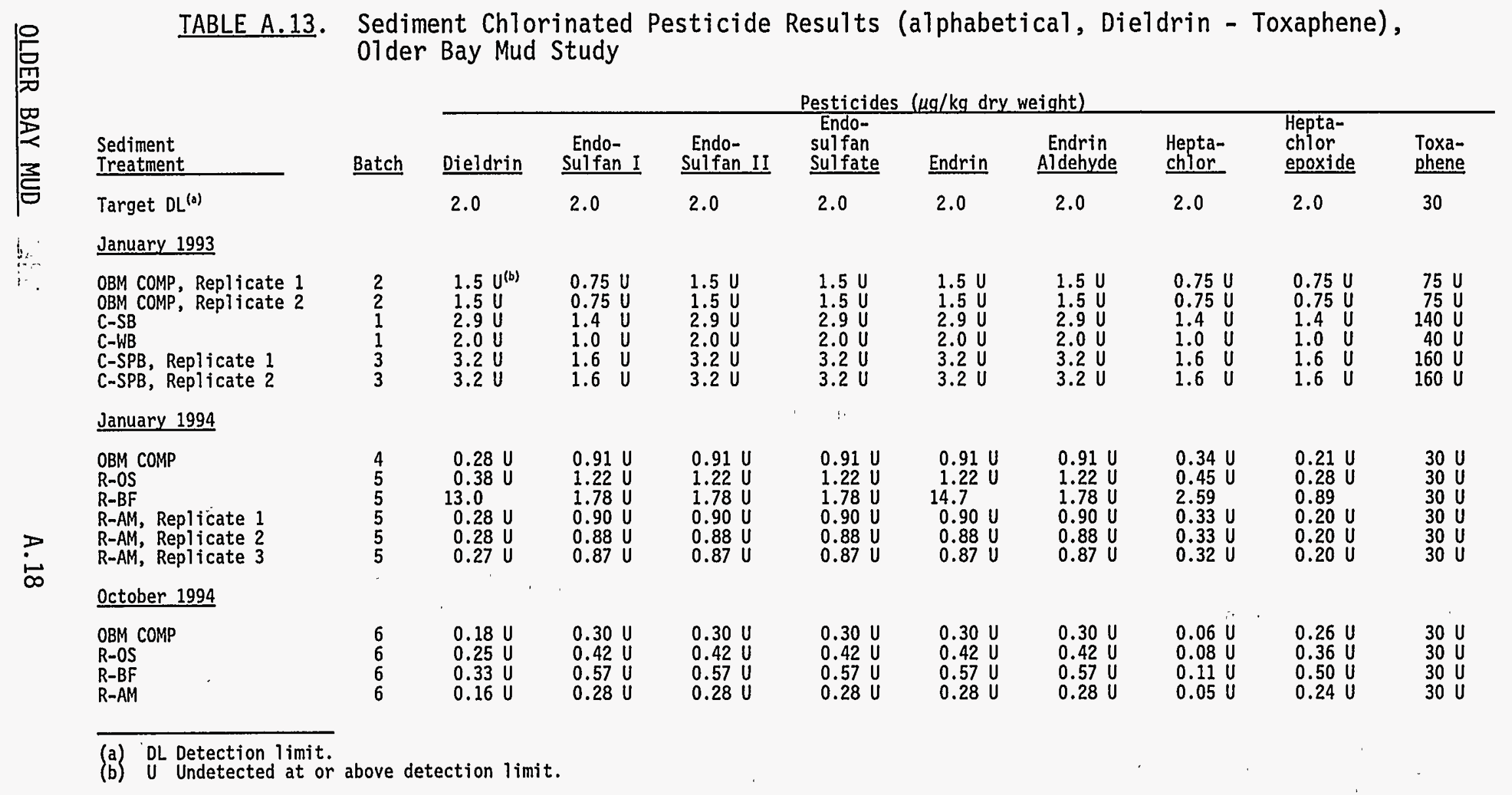




\begin{tabular}{|c|c|c|c|c|c|c|c|c|c|c|c|c|}
\hline \multirow[b]{2}{*}{$\begin{array}{l}\text { Sediment } \\
\text { Treatment }\end{array}$} & \multirow[b]{2}{*}{ Batch } & \multicolumn{11}{|c|}{ Pesticides ( $\mu \mathrm{g} / \mathrm{kg}$ dry weight) } \\
\hline & & Aldrin & $\begin{array}{l}\text { Alpha- } \\
\text { BHC }\end{array}$ & $\begin{array}{l}\text { Beta- } \\
\text { BHC }\end{array}$ & $\begin{array}{l}\text { Delta- } \\
\text { BHC }\end{array}$ & $\begin{array}{l}\text { Gamma- } \\
\text { BHC }\end{array}$ & $\begin{array}{c}\text { Alpha- } \\
\text { chlordane }\end{array}$ & $\begin{array}{l}\text { Gamma- } \\
\text { chlordane }\end{array}$ & $\begin{array}{c}T^{T} \\
\text { chlordane }\end{array}$ & $\begin{array}{l}4,4^{\prime}- \\
\text { DDD }\end{array}$ & $\begin{array}{l}4,4- \\
\text { DDE }\end{array}$ & $\begin{array}{l}4,4{ }^{-}- \\
\text {DDT }\end{array}$ \\
\hline Method Blank & & & & & & & & & & & & \\
\hline $\begin{array}{l}\text { Blank } \\
\text { Blank } \\
\text { Blank } \\
\text { Blank } \\
\text { Blank } \\
\text { Blank }\end{array}$ & $\begin{array}{l}1 \\
2 \\
3 \\
4 \\
5 \\
6\end{array}$ & $\begin{array}{c}1.0 U^{(a)} \\
0.75 U \\
1.6 U \\
0.06 U \\
0.06 U \\
0.23 U\end{array}$ & $\begin{array}{r}1.0 \mathrm{U} \\
0.75 \mathrm{U} \\
1.6 \mathrm{U} \\
1.20 \mathrm{U} \\
1.21 \mathrm{U} \\
0.39 \mathrm{U}\end{array}$ & $\begin{array}{r}1.0 \mathrm{U} \\
0.75 \mathrm{U} \\
1.6 \mathrm{U} \\
1.20 \mathrm{U} \\
1.21 \mathrm{U} \\
0.39 \mathrm{U}\end{array}$ & $\begin{array}{r}1.0 U \\
0.75 U \\
1.6 U \\
1.20 U \\
1.21 U \\
0.39 U\end{array}$ & $\begin{array}{r}1.0 U \\
0.75 U \\
1.6 U \\
0.06 U \\
0.06 U \\
0.24 U\end{array}$ & $\begin{array}{c}1.0 \mathrm{U} \\
0.75 \mathrm{U} \\
1.6 \mathrm{U} \\
\text { ND } \\
\text { ND } \\
\text { ND }\end{array}$ & $\begin{array}{c}1.0 U \\
0.75 U \\
1.6 U \\
\text { ND } \\
\text { ND } \\
\text { ND }\end{array}$ & $\begin{array}{l}\text { ND } \\
\text { (b) } \\
\text { ND } \\
30 \cup \\
30 \cup \\
30 U\end{array}$ & $\begin{array}{r}2.0 U \\
1.5 U \\
3.2 U \\
0.17 U \\
0.18 U \\
0.29 U\end{array}$ & $\begin{array}{l}2.0 U \\
1.5 U \\
3.2 U \\
0.07 U \\
0.08 U \\
0.16 U\end{array}$ & $\begin{array}{l}2.0 U \\
1.5 U \\
3.2 U \\
0.50 U \\
0.50 U \\
0.83 U\end{array}$ \\
\hline Matrix Spike & & & & & & & & & & & & \\
\hline $\begin{array}{l}\text { C.WB } \\
\text { C-WB MS } \\
\text { Concentration Recovered } \\
\text { Amount Spiked } \\
\text { Percent Recovery }\end{array}$ & 1 & $\begin{array}{l}1.0 \mathrm{U} \\
2.99 \\
2.99 \\
3.92 \\
76 \%\end{array}$ & $\begin{array}{l}\text { NA (c) } \\
\text { NA } \\
\text { NA } \\
\text { NS (d) } \\
\text { NA }\end{array}$ & $\begin{array}{l}\text { NA } \\
\text { NA } \\
\text { NA } \\
\text { NS } \\
\text { NA }\end{array}$ & $\begin{array}{l}\text { NA } \\
\text { NA } \\
\text { NA } \\
\text { NS } \\
\text { NA }\end{array}$ & $\begin{array}{c}1.0 \mathrm{U} \\
3.1 \\
3.1 \\
3.92 \\
79 \%\end{array}$ & $\begin{array}{l}\text { NA } \\
\text { NA } \\
\text { NA } \\
\text { NS } \\
\text { NA }\end{array}$ & $\begin{array}{l}\text { NA } \\
\text { NA } \\
\text { NA } \\
\text { NS } \\
\text { NA }\end{array}$ & $\begin{array}{l}\text { NA } \\
\text { NA } \\
\text { NA } \\
\text { NS } \\
\text { NA }\end{array}$ & $\begin{array}{l}\text { NA } \\
\text { NA } \\
\text { NA } \\
\text { NS } \\
\text { NA }\end{array}$ & $\begin{array}{l}\text { NA } \\
\text { NA } \\
\text { NA } \\
\text { NS } \\
\text { NA }\end{array}$ & $\begin{array}{l}2.0 \mathrm{U} \\
6.25 \\
6.25 \\
7.84 \\
80 \%\end{array}$ \\
\hline $\begin{array}{l}\text { C-WB } \\
\text { C-WB MSD } \\
\text { Concentration Recovered } \\
\text { Amount Splked } \\
\text { Percent Recovery }\end{array}$ & 1 & $\begin{array}{l}1.0 \mathrm{U} \\
3.04 \\
3.04 \\
3.94 \\
77 \%\end{array}$ & $\begin{array}{l}\text { NA } \\
\text { NA } \\
\text { NA } \\
\text { NS } \\
\text { NA }\end{array}$ & $\begin{array}{l}\text { NA } \\
\text { NA } \\
\text { NA } \\
\text { NS } \\
\text { NA }\end{array}$ & $\begin{array}{l}\text { NA } \\
\text { NA } \\
\text { NA } \\
\text { NS } \\
\text { NA }\end{array}$ & $\begin{array}{l}1.0 \mathrm{U} \\
3.17 \\
3.17 \\
3.94 \\
80 \%\end{array}$ & $\begin{array}{l}\text { NA } \\
\text { NA } \\
\text { NA } \\
\text { NS } \\
\text { NA }\end{array}$ & $\begin{array}{l}\text { NA } \\
\text { NA } \\
\text { NA } \\
\text { NS } \\
\text { NA }\end{array}$ & $\begin{array}{l}\text { NA } \\
\text { NA } \\
\text { NA } \\
\text { NS } \\
\text { NA }\end{array}$ & $\begin{array}{l}\text { NA } \\
\text { NA } \\
\text { NA } \\
\text { NS } \\
\text { NA }\end{array}$ & $\begin{array}{l}\text { NA } \\
\text { NA } \\
\text { NA } \\
\text { NS } \\
\text { NA }\end{array}$ & $\begin{array}{l}2.0 U \\
6.45 \\
6.45 \\
7.89 \\
82 \%\end{array}$ \\
\hline $\begin{array}{l}\text { RPD } \\
\text { l-Stat }\end{array}$ & & $0.01 \%$ & $\begin{array}{l}\text { NA } \\
\text { NA }\end{array}$ & $\begin{array}{l}\text { NA } \\
\text { NA }\end{array}$ & $\begin{array}{l}\text { NA } \\
\text { NA }\end{array}$ & $\begin{array}{l}2 \% \\
0.01\end{array}$ & $\begin{array}{l}\text { NA } \\
\text { NA }\end{array}$ & $\begin{array}{l}\text { NA } \\
\text { NA }\end{array}$ & $\begin{array}{l}N A \\
N A\end{array}$ & $\begin{array}{l}\text { NA } \\
\text { NA }\end{array}$ & $\begin{array}{l}\text { NA } \\
\text { NA }\end{array}$ & $\begin{array}{l}3 \% \\
0.01\end{array}$ \\
\hline $\begin{array}{l}\text { QC Sample } \\
\text { QC Sample, MS } \\
\text { Concentration Recovered } \\
\text { Amount Splked } \\
\text { Percent Recovery }\end{array}$ & 4 & $\begin{array}{l}1.26 \\
4.37 \\
3.11 \\
4.20 \\
74 \%\end{array}$ & $\begin{array}{l}\text { NA } \\
\text { NA } \\
\text { NA } \\
\text { NS } \\
\text { NA }\end{array}$ & $\begin{array}{l}\text { NA } \\
\text { NA } \\
\text { NA } \\
\text { NS } \\
\text { NA }\end{array}$ & $\begin{array}{l}\text { NA } \\
\text { NA } \\
\text { NA } \\
\text { NS } \\
\text { NA }\end{array}$ & $\begin{array}{l}0.06 \mathrm{U} \\
4.07 \\
4.07 \\
4.20 \\
97 \%\end{array}$ & $\begin{array}{l}\text { NA } \\
\text { NA } \\
\text { NA } \\
\text { NS } \\
\text { NA }\end{array}$ & $\begin{array}{l}\text { NA } \\
\text { NA } \\
\text { NA } \\
\text { NS } \\
\text { NA }\end{array}$ & $\begin{array}{l}\text { NA } \\
\text { NA } \\
\text { NA } \\
\text { NS } \\
\text { NA }\end{array}$ & $\begin{array}{l}\text { NA } \\
\text { NA } \\
\text { NA } \\
\text { NS } \\
\text { NA }\end{array}$ & $\begin{array}{l}\text { NA } \\
\text { NA } \\
\text { NA } \\
\text { NS } \\
\text { NA }\end{array}$ & $\begin{array}{l}0.73 \\
20.0 \\
19.3 \\
16.8 \\
115 \%\end{array}$ \\
\hline $\begin{array}{l}\text { QC Sample } \\
\text { QC Sample, MS } \\
\text { Concentratlon Recovered } \\
\text { Amount Splked } \\
\text { Percent Recovery }\end{array}$ & 5 & $\begin{array}{l}0.04 \mathrm{U} \\
2.89 \\
2.89 \\
2.85 \\
101 \%\end{array}$ & $\begin{array}{l}\text { NA } \\
\text { NA } \\
\text { NA } \\
\text { NS } \\
\text { NA }\end{array}$ & $\begin{array}{l}\text { NA } \\
\text { NA } \\
\text { NA } \\
\text { NS } \\
\text { NA }\end{array}$ & $\begin{array}{l}\text { NA } \\
\text { NA } \\
\text { NA } \\
\text { NS } \\
\text { NA }\end{array}$ & $\begin{array}{l}0.04 \mathrm{U} \\
2.48 \\
2.48 \\
2.85 \\
87 \%\end{array}$ & $\begin{array}{l}\text { NA } \\
\text { NA } \\
\text { NA } \\
\text { NS } \\
\text { NA }\end{array}$ & $\begin{array}{l}\text { NA } \\
\text { NA } \\
\text { NA } \\
\text { NS } \\
\text { NA }\end{array}$ & $\begin{array}{l}\text { NA } \\
\text { NA } \\
\text { NA } \\
\text { NS } \\
\text { NA }\end{array}$ & $\begin{array}{l}0.12 \mathrm{U} \\
11.1 \\
11.1 \\
11.6 \\
96 \%\end{array}$ & $\begin{array}{l}\text { NA } \\
\text { NA } \\
\text { NA } \\
\text { NS } \\
\text { NA }\end{array}$ & $\begin{array}{l}\text { NA } \\
\text { NA } \\
\text { NA } \\
\text { NS } \\
\text { NA }\end{array}$ \\
\hline
\end{tabular}


TABLEA.14. (contd)

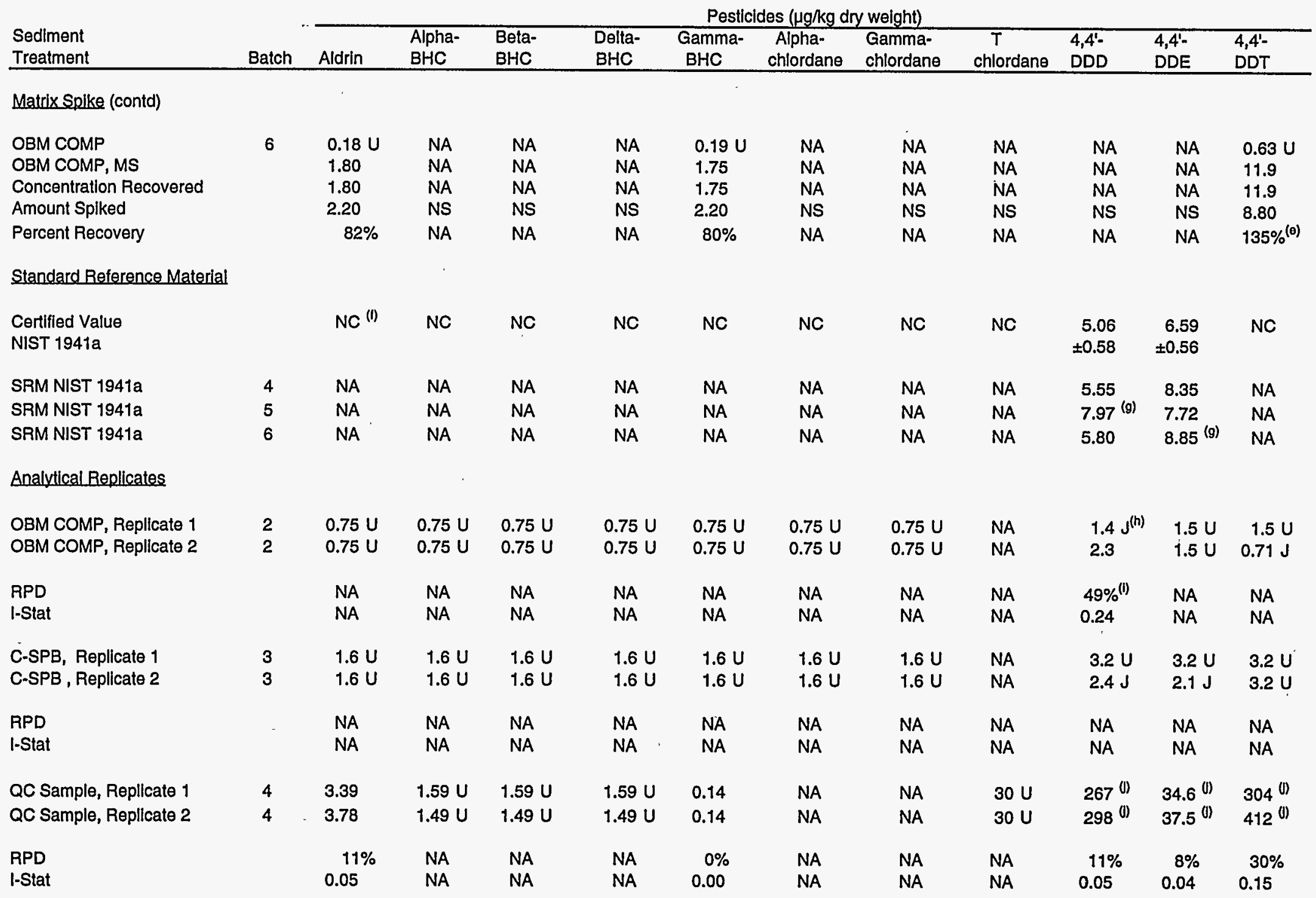


QC Sample, Replicate 1

QC Sample, Replicate 2

QC Sample, Replicate 3

RSD

R-AM, Repllcate 1

R-AM, Replicate 2

R-AM, Replicate 3

5

$0.04 \mathrm{U}$

$0.04 U$

RSD

QC Sample, Replicate 1

QC Sample, Replicate 2

QC Sample, Replicate 3

$\begin{array}{llll} & N A & N A & N A \\ 6 & 0.36 U & 0.59 U & 0.59 U \\ 6 & 0.35 U & 0.59 U & 0.59 U \\ 6 & 0.33 U & 0.56 U & 0.56 U\end{array}$

is

RSD .

NA

NA

NA

TABLEA.14. (contd)

Pesticides (ug/kg dry weight)

Gamma- Alpha- Gamma

Alpha- Gamma-

$\stackrel{T}{\text { chiordane }}$

4,4'-

4,4:-

DDE

4,4'-

$1.30 \mathrm{U}$

$\mathrm{BHC}$

NA NA

$0.07 U$

$0.07 \mathrm{U}$
$0.08 \mathrm{U}$

NA

$\begin{array}{lll}1.54 U & 0.08 U \quad N A\end{array}$

NA

$30 \mathrm{U}$

$\left.30 \mathrm{U} \quad 114^{(0)} \quad 19.2^{(0)} \quad 68.2^{0}\right)$

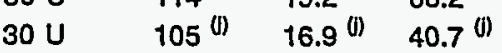

NA NA NA NA

NA

$30 \mathrm{U}$

$30 \mathrm{U}$

$$
4 \% \quad 9 \% \quad 26 \%
$$

$0.90 \mathrm{U} \quad 0.05 \mathrm{U}$

$\begin{array}{ll}0.88 U & 0.05 U \\ 0.87 U & 0.05 U\end{array}$

NA

NA

$30 \mathrm{U}$

0.56

$\begin{array}{lll}0.13 \cup & 0.06 \cup \quad 0.66\end{array}$

NA NA

NA NA NA

NA

NA

NA

$0.05 \cup \quad 0.45$
(a) U Undetected at or above detection limit.
(b) ND No data.
(c) NA Not applicable.
(d) NS Not spiked.
(e) Outside quality control criteria $(40 \%-120 \%)$ for matrix spike recoveries.
(f) NC Not certifled.
(g) Outside quality control criteria $( \pm 30 \%)$ for SRMs.
(h) J Analyte detected below method detection Ilmit (MDL), but above instrument detectlon Iimit (IDL)
(i) Precision criteria does not apply because sample results are $<10$ times the method detectlon limit (MDL).
(j) Sample was diluted and analyzed due to analyte concentrations above the instrument linear range of calibration. 


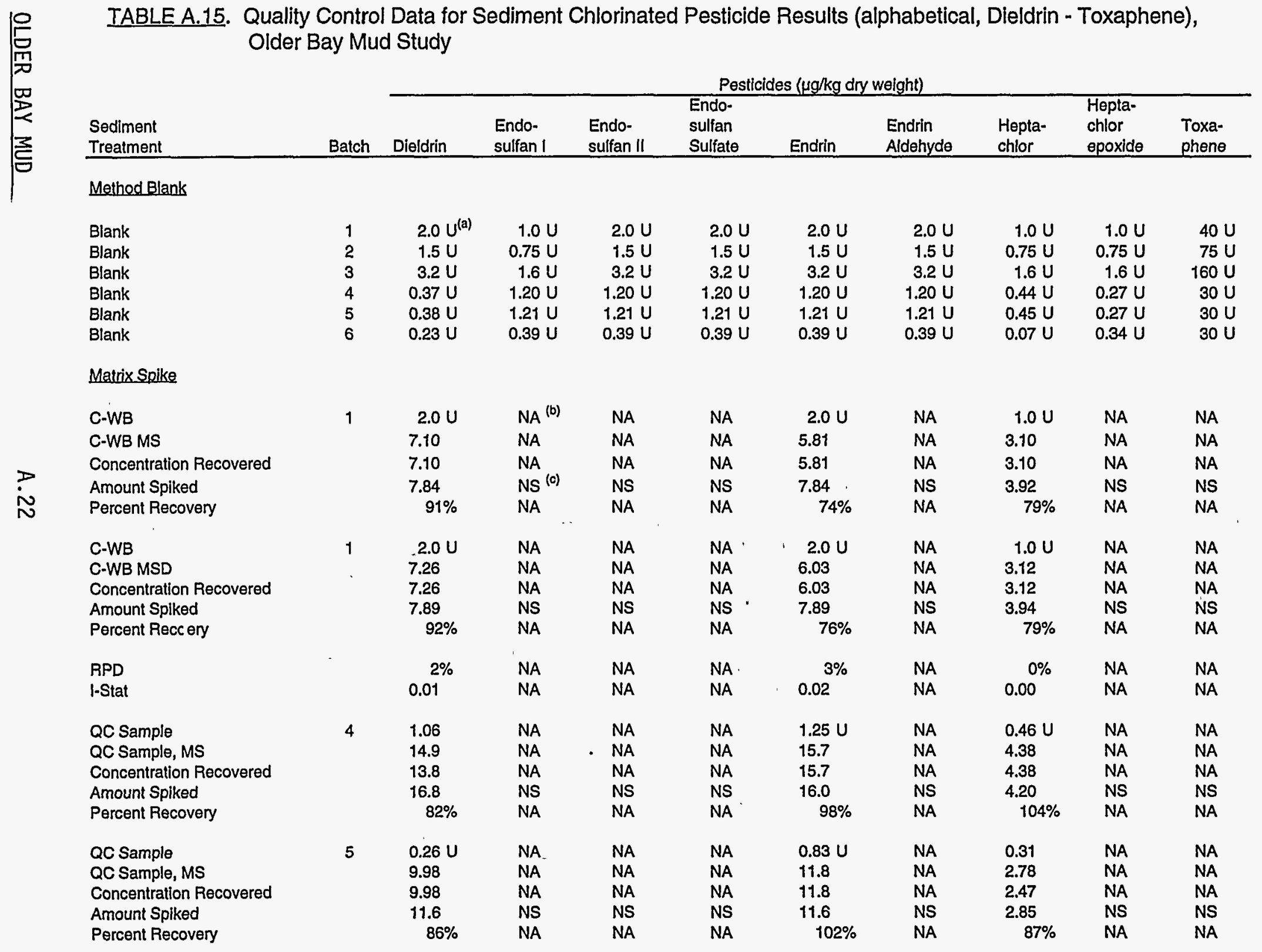




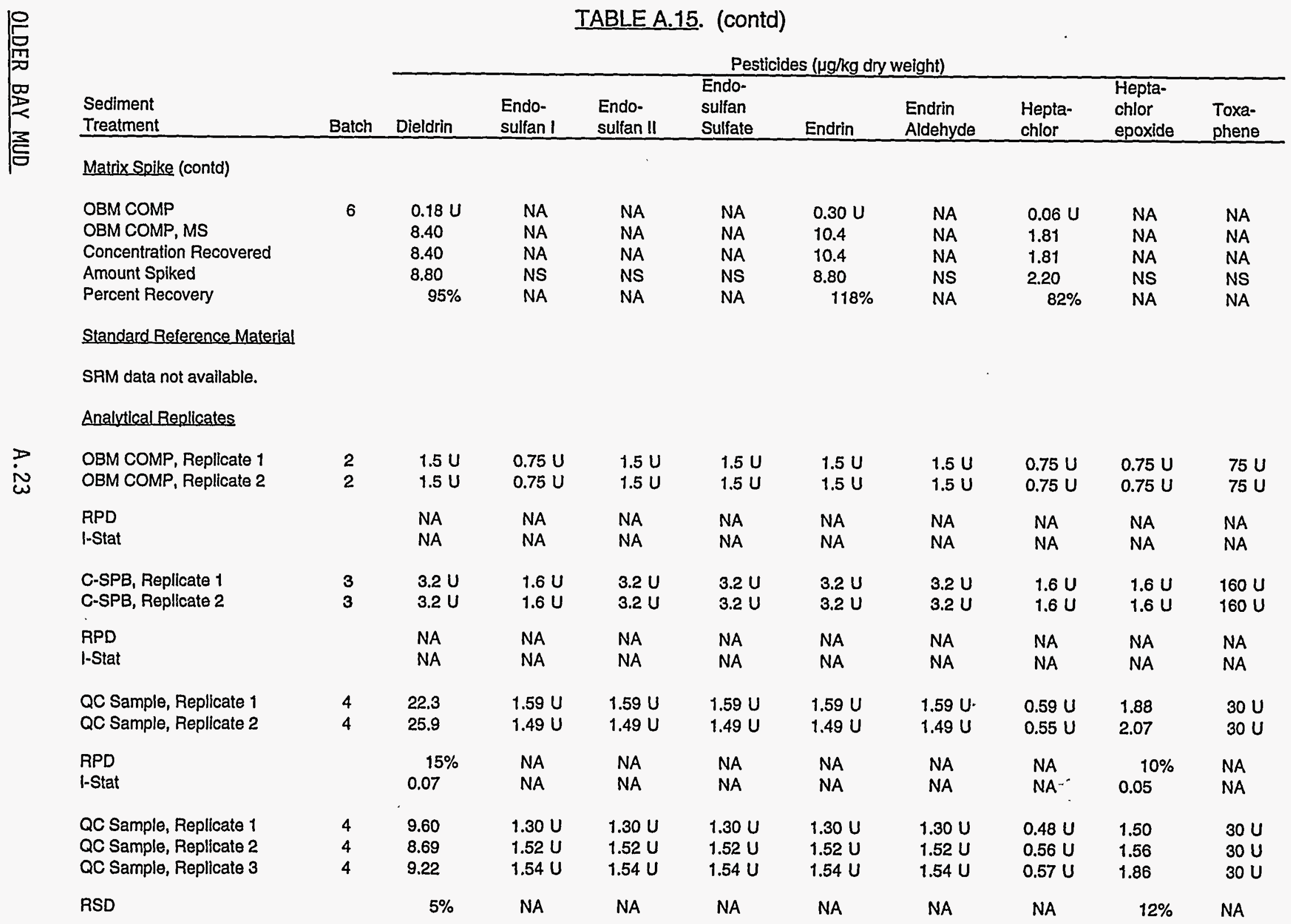


TABLEA.15. (contd)

\begin{tabular}{|c|c|c|c|c|c|c|c|c|c|c|}
\hline \multirow[b]{2}{*}{$\begin{array}{l}\text { Sediment } \\
\text { Treatment }\end{array}$} & \multirow[b]{2}{*}{ Batch } & \multicolumn{9}{|c|}{ Pesticides ( $\mu \mathrm{g} / \mathrm{kg}$ dry welght) } \\
\hline & & Dieldrin & $\begin{array}{l}\text { Endo- } \\
\text { sulfan I }\end{array}$ & $\begin{array}{l}\text { Endo- } \\
\text { sulfan II }\end{array}$ & $\begin{array}{l}\text { Endo- } \\
\text { sulfan } \\
\text { Sulfate } \\
\end{array}$ & Endrin & $\begin{array}{l}\text { Endrin } \\
\text { Aldehyde } \\
\end{array}$ & $\begin{array}{l}\text { Hepta- } \\
\text { chlor }\end{array}$ & $\begin{array}{l}\text { Hepta- } \\
\text { chlor } \\
\text { epoxide } \\
\end{array}$ & $\begin{array}{l}\text { Toxa- } \\
\text { phene }\end{array}$ \\
\hline \multicolumn{11}{|c|}{ Analytical Replicates (contd) } \\
\hline $\begin{array}{l}\text { R-AM, Replicate } 1 \\
\text { R-AM, Replicate } 2 \\
\text { R-AM, Replicate } 3\end{array}$ & $\begin{array}{l}5 \\
5 \\
5\end{array}$ & $\begin{array}{l}0.28 U \\
0.28 U \\
0.27 U\end{array}$ & $\begin{array}{l}0.90 U \\
0.88 U \\
0.87 U\end{array}$ & $\begin{array}{l}0.90 \mathrm{U} \\
0.88 \mathrm{U} \\
0.87 \mathrm{U}\end{array}$ & $\begin{array}{l}0.90 U \\
0.88 U \\
0.87 U\end{array}$ & $\begin{array}{l}0.90 \mathrm{U} \\
0.88 \mathrm{U} \\
0.87 \mathrm{U}\end{array}$ & $\begin{array}{l}0.90 U \\
0.88 U \\
0.87 U\end{array}$ & $\begin{array}{l}0.33 U \\
0.33 U \\
0.32 U\end{array}$ & $\begin{array}{l}0.20 U \\
0.20 U \\
0.20 U\end{array}$ & $\begin{array}{l}30 \mathrm{U} \\
30 \mathrm{U} \\
30 \mathrm{U}\end{array}$ \\
\hline RSD & & NA & NA & NA & NA & NA & NA & NA & NA & NA \\
\hline $\begin{array}{l}\text { QC Sample, Replicate } 1 \\
\text { QC Sample, Replicate } 2 \\
\text { QC Sample, Replicate } 3\end{array}$ & $\begin{array}{l}6 \\
6 \\
6\end{array}$ & $\begin{array}{l}0.35 U \\
0.34 U \\
0.33 U\end{array}$ & $\begin{array}{l}0.59 U \\
0.59 U \\
0.56 U\end{array}$ & $\begin{array}{l}0.59 U \\
0.59 U \\
0.56 U\end{array}$ & $\begin{array}{l}0.59 U \\
0.59 U \\
0.56 U\end{array}$ & $\begin{array}{l}0.59 U \\
0.59 U \\
0.56 U\end{array}$ & $\begin{array}{l}0.59 U \\
0.59 U \\
0.56 U\end{array}$ & $\begin{array}{l}0.11 \mathrm{U} \\
0.11 \mathrm{U} \\
0.10 \mathrm{U}\end{array}$ & $\begin{array}{l}0.52 U \\
0.51 U \\
0.49 U\end{array}$ & $\begin{array}{l}30 \mathrm{U} \\
30 \mathrm{U} \\
30 \mathrm{U}\end{array}$ \\
\hline RSD & & NA & NA & NA & NA & NA & NA & NA & NA & NA \\
\hline
\end{tabular}

(a) U Undetected at or above detection limit.

(b) NA Not applicable.

(c) NS Not spiked. 
TABLE A.16. Sediment Polychlorinated Biphenyl (PCB) Results, 01der Bay Mud Study

Sediment

Treatment

Target $D^{(a)}$

January 1993

OBM COMP, Replicate 1

OBM COMP, Replicate 2

$\mathrm{C}-\mathrm{SB}$

$C-W B$

C-SPB, Replicate 1

C-SPB, Replicate 2

January 1994

OBM COMP

$\mathrm{R}-\mathrm{OS}$

$\mathrm{R}-\mathrm{BF}$

R-AM, Replicate 1

R-AM, Replicate 2

R-AM, Replicate 3

October 1994

OBM COMP
R-OS
R-BF
R-AM

$\begin{array}{ll}2 & 15 U^{(b)} \\ 2 & 15 \mathrm{U} \\ 1 & 29 \mathrm{U} \\ 1 & 15 \mathrm{U} \\ 3 & 32 \mathrm{U} \\ 3 & 32 \mathrm{U}\end{array}$

$20 \mathrm{U}$

$20 \mathrm{U}$

$20 \mathrm{U}$

$20 \mathrm{U}$

$20 \mathrm{U}$

$20 \mathrm{U}$

$20 \mathrm{U}$

$20 \mathrm{U}$

$20 \mathrm{U}$

$20 \mathrm{U}$

$6 \quad 20 U$

$15 \mathrm{U}$

$15 \mathrm{U}$

$60 \mathrm{U}$

$15 \mathrm{U}$

$32 \mathrm{U}$

$32 \mathrm{U}$

$20 \mathrm{U}$

$20 \mathrm{U}$

$20 \mathrm{U}$

$20 \mathrm{U}$

$20 \mathrm{U}$

$20 \mathrm{U}$

$20 \mathrm{U}$

$20 \mathrm{U}$

$20 \mathrm{U}$

$20 \mathrm{U}$
$15 U$

$15 U$

$29 \mathrm{U}$

$15 \mathrm{U}$

$32 \mathrm{U}$

$32 \mathrm{U}$
$15 U$

$15 \mathrm{U}$

$29 \mathrm{U}$

$15 \mathrm{U}$

$32 \mathrm{U}$

$32 \mathrm{U}$

(a) DL Detection Timit.

(b) $U$ Undetected at or above detection limit.

$20 \mathrm{U}$

$20 \mathrm{U}$

23.3

$20 \mathrm{U}$

$20 \mathrm{U}$

$20 \mathrm{U}$

$20 \mathrm{U}$

$20 \mathrm{U}$

$20 \mathrm{U}$

$20 \mathrm{U}$

$20 \mathrm{U}$

$20 \mathrm{U}$

$20 \mathrm{U}$

$20 \mathrm{U}$

$20 \mathrm{U}$

46.8

$20 \mathrm{U}$

$20 \mathrm{U}$

$20 \mathrm{U}$

$20 \mathrm{U}$ 
TABLE A.17. Quality Control Data for Sediment Polychlorinated Biphenyl (PCB) Results, 01der Bay Mud Study

Sediment

Treatment

Method BTank
Blank

Blank

Blank

B] ank

Blank

Blank

\begin{tabular}{cccc}
\multicolumn{4}{c}{ PCBs $(\mu \mathrm{g} / \mathrm{kg}$ dry weight) } \\
\hline Aroclor & Aroclor & Aroclor & Aroclor \\
$1242 / 1016$ & 1248 & 1254 & 1260 \\
\cline { 3 - 4 }
\end{tabular}

1
2
3
4
5
6

$15 U^{(a)}$
$15 U$
$32 U$
$20 U$
$20 U$
$20 U$

$15 U$

$15 \mathrm{U}$

$32 \mathrm{U}$

$20 \mathrm{U}$

$20 \mathrm{U}$

$20 \mathrm{U}$
$15 U$

$15 \mathrm{U}$

$32 \mathrm{U}$

$20 \mathrm{U}$

$20 \mathrm{U}$

$20 \mathrm{U}$

\section{Matrix Spike}

QC Sample

QC Sample, MS

Concentration Recovered

Amount Spiked

Percent Recovery

QC Sample

QC sample, MS

Concentration Recovered

Amount Spiked

Percent Recovery

OBM COMP

OBM COMP, MS

Concentration Recovered

Amount Spiked

Percent Recovery
4

$\begin{array}{ll}N A^{(b)} & N A \\ N A & N A \\ N A & N A \\ N S^{(c)} & N S \\ N A & N A\end{array}$

5

NA

NA

NA

NS

NA

NA

NA

NA

NS

NA
NA
NA
NA
NS
NA

NA

NA

NA

NS

NA

NA

NA

NA

NS

NA
$20 \mathrm{U}$

92.1

92.1

84.0

$110 \%$

$20 \mathrm{U}$

55.8

55.8

57.0

98\%

$20 \mathrm{U}$

44.5

44.5

44.0

$101 \%$
NA

NA

NA

NS

NA

NA

NA

NA

NS

NA

NA

NA

NA

NS

NA

Standard Reference Material

SRM data not available for PCBs.

Analytical Replicates

OBM COMP, Replicate 1

OBM COMP, Replicate 2

RPD

I-Stat
2

NA
NA

$15 \mathrm{U}$

$15 \mathrm{U}$

A

$15 U$

$15 \mathrm{U}$

NA

NA

NA
NA

$15 \mathrm{U}$

$15 \mathrm{U}$

$15 U$

$15 \mathrm{U}$

NA

NA 
TABLE A.17. (contd)

Sediment

Treatment

C-SPB, Replicate 1

C-SPB, Replicate 2

RPD

I-Stat

QC Sample, Replicate 1

QC Sample, Replicate 2

RPD

I-Stat

QC Sample, Replicate 1

QC Sample, Replicate 2

QC Sample, Replicate 3

RSD

R-AM, Replicate 1

R-AM, Replicate 2

R-AM, Replicate 3

RSD

QC Sample, Replicate 1

QC Sample, Replicate 2

QC Sample, Replicate 3

RSD

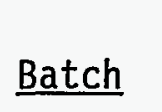

3
3

$32 U$

$32 \mathrm{U}$

NA

NA

$420 \mathrm{U}$

$20 \mathrm{U}$

NA

NA

$\begin{array}{ll}4 & 20 U \\ 4 & 20 U \\ 4 & 20 \mathrm{U}\end{array}$

NA

$\begin{array}{ll}5 & 20 \mathrm{U} \\ 5 & 20 \mathrm{U} \\ 5 & 20 \mathrm{U}\end{array}$

NA

$20 \mathrm{U}$

$20 \mathrm{U}$

$20 \mathrm{U}$

NA
PCBs $(\mu \mathrm{g} / \mathrm{kg}$ dry weight)

Arocior Aroclor Aroclor

$1248 \quad 1254 \quad 1260$

$32 \mathrm{U}$

$32 U$

$32 \mathrm{U}$

$32 \mathrm{U} \quad 32 \mathrm{U} . \quad 32 \mathrm{U}$

NA

NA

NA

NA

NA

NA

$20 \mathrm{U}$

155

210

$20 \mathrm{U}$

$20 \mathrm{U}$

NA

NA

$30 \%$

0.15

NA

NA

$20 \mathrm{U}$

93.8

$20 \mathrm{U}$

$20 \mathrm{U}$

$20 \mathrm{U}$

82.7

101

$20 \mathrm{U}$

$20 \mathrm{U}$

NA.

$10 \%$

NA

$20 \mathrm{U}$

$20 \mathrm{U}$

$20 \mathrm{U}$

$20 \mathrm{U}$

$20 \mathrm{U}$

$20 \mathrm{U}$

$20 \mathrm{U}$

$20 \mathrm{U}$

$20 \mathrm{U}$

NA

NA

NA

$20 \mathrm{U}$

$20 \mathrm{U}$

$20 \mathrm{U}$

$20 \mathrm{U}$

$20 \mathrm{U}$

$20 \mathrm{U}$

$20 \mathrm{U}$

$20 \mathrm{U}$

$20 \mathrm{U}$

NA

NA

NA

(a) U Undetected at or above detection 7 imit.

(b) NA Not applicable.

(c) NS Not spiked. 
TABLE A.18. Surrogate Percent Recoveries and Quality Control Data for Chlorinated Pesticides and Polychlorinated Biphenyls (PCBs) in Sediment, OTder Bay Mud Study

Sediment

Treatment

January 1993

OBM COMP, Replicate 1

OBM COMP, Replicate 2

$\mathrm{C}-\mathrm{SB}$

$C-W B$

C-SPB, Replicate 1

C-SPB, Rep Ticate 2

January 1994

OBM COMP

R-OS

$\mathrm{R}-\mathrm{BF}$

R-AM, Replicate 1

R-AM, Replicate 2

R-AM, Replicate 3

October 1994

OBM COMP

$\mathrm{R}-0 \mathrm{~S}$

$\mathrm{R}-\mathrm{BF}$

R-AM

Quality Control Data

Method Blank

Blank

Blank

Blank

Blank

Blank

Blank

Matrix Spike

C-WB MS

C-WB MSD
Surrogate Percent Recoveries

Decachloro- Tetrachlorobipheny7 Metaxylene PCB PCB

Batch $\underline{\text { (DCBP) }} \quad$ (TCMX) $\quad \underline{103} \underline{198}$

$\begin{array}{lllll}2 & 110 & 81 & N A^{(a)} & N A \\ 2 & 113 & 80 & N A & N A \\ 1 & 80 & 84 & N A & N A \\ 1 & 92 & 85 & N A & N A \\ 3 & 13^{(b)} & 10^{(b)} & N A & N A \\ 3 & 69 & 77 & N A & N A\end{array}$

NA

NA

NA

NA

NA

NA

NA

NA

NA

NA

NA

NA

$70 \quad 72$

$68 \quad 70$

$65 \quad 94$

$65 \quad 76$

$61 \quad 70$

$65 \quad 73$

NA

NA

NA

NA

NA

70

63

NA

81

77

67

NA

81

58
91

114

$13^{(b)}$

NA

$\mathrm{NA}$

NA

96

97
88

81

$10^{\text {(b) }}$

NA

NA

NA

90

87
NA NA

NA NA

NA NA

$76 \quad 78$

$74 \quad 75$

$64 \quad 62$

A
A
A
A


IABLE A.18. (contd)

Sediment

Treatment

Batch

Surrogate Percent Recoveries

Decáchloro- Tetrachioro-

biphenyl. Metaxylene PCB PCB

Matrix Spike (contd)

QC Sample

QC Sample, MS

$4 \quad N A$

NA

$65 \quad 71$

QC Sample

$5 \quad N A$

(TCMX)

$\underline{103 \quad \underline{198}}$

QC Sample, MS

$5 \quad N A$

NA

$65 \quad 71$

OBM COMP

OBM COMP, MS

$6 \quad$ NA

NA

$66 \quad 67$

$6 \quad N A$

NA

$66 \quad 71$

Standard Reference Material

SRM data not available for PCBs.

Analytical Replicates

QC Sample, Replicate 1

QC Sample, Replicate 2

QC Sample, Replicate 1

QC Sample, Replicate 2

QC Sample, Replicate 3

R-AM, Replicate 1

R-AM, Replicate 2

R-AM, Replicate 3

NA

NA

$65 \quad 83$

$4 \quad N A$

NA

$59 \quad 75$

QC Sample, Replicate 1

QC Sample, Replicate 2

QC Sample, Replicate 3

$\begin{array}{lllll}4 & \text { NA } & \text { NA } & 60 & 81 \\ 4 & \text { NA } & \text { NA } & 55 & 70 \\ 4 & \text { NA } & \text { NA } & 62 & 78\end{array}$

$\begin{array}{lllll}5 & \text { NA } & \text { NA } & 65 & 76\end{array}$

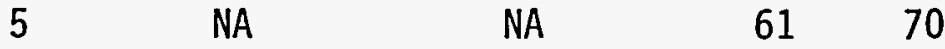

$\begin{array}{llll}5 & N A & N A & 65\end{array}$

$6 \quad$ NA $\quad$ NA $\quad 79 \quad 64$

$6 \quad$ NA $\quad N A \quad 7501$

$\begin{array}{llll}6 & N A & N A & 78\end{array}$

(a) NA Not applicable.

(b) Recovery outside of quality control range (40\%-120\%). 
TABLE A.19. Sediment Metal Results, Dry Weight, 01der Bay Mud Study

Sediment

Treatment

Target $D L^{(0)}$

January 1993

OBM COMP

C-SB

C-SPB, Replicate 1

C-SPB, Replicate 2

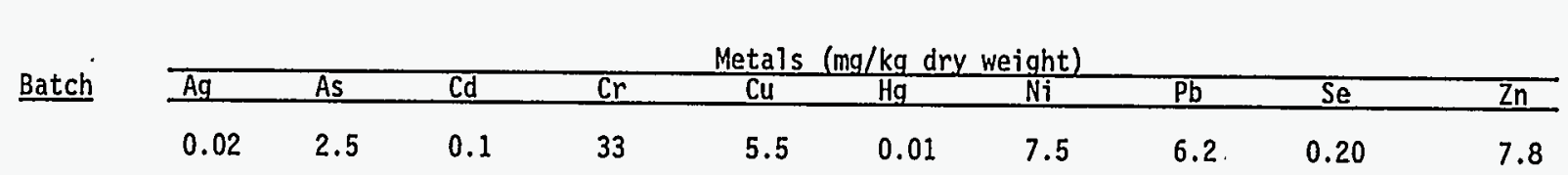

October 1994

OBM COMP

$R-O S$

$R-B F$

R-AM

$\begin{array}{lllll}2 & 0.11 & 3.28 & 0.56 & 142 \\ 2 & 0.44 & 5.39 & 0.35 & 186 \\ 2 & 0.44 & 9.4 & 0.14 & 178 \\ 2 & 0.026 & 5.88 & 0.015 & 95.4\end{array}$

$\begin{array}{lcll}0.11 & 3.30 & 0.84 & 148 \\ 0.18 & 10.4 & 0.93 & 96.0 \\ 0.01 & 2.15 & 0.11 & 234 \\ 0.29 & 12.0 & 0.24 & 160 \\ 0.30 & 14.0 & 0.24 & 173\end{array}$

32.9

29.9
10.6

10.6
53.7

\subsection{7}

$70.0 \quad 14.6$

0.073

0.023

$40.4 \quad 6.90$

0.348

$97.3 \quad 31.4$

$99.5 \quad 24.8$

0.30

$0.13 U^{(b)}$

$0.13 \mathrm{U}$

0.22

72.4

43.3
119

125

(a) OL Detection limit.

w

(b) U Undetected at or above detection limit. 


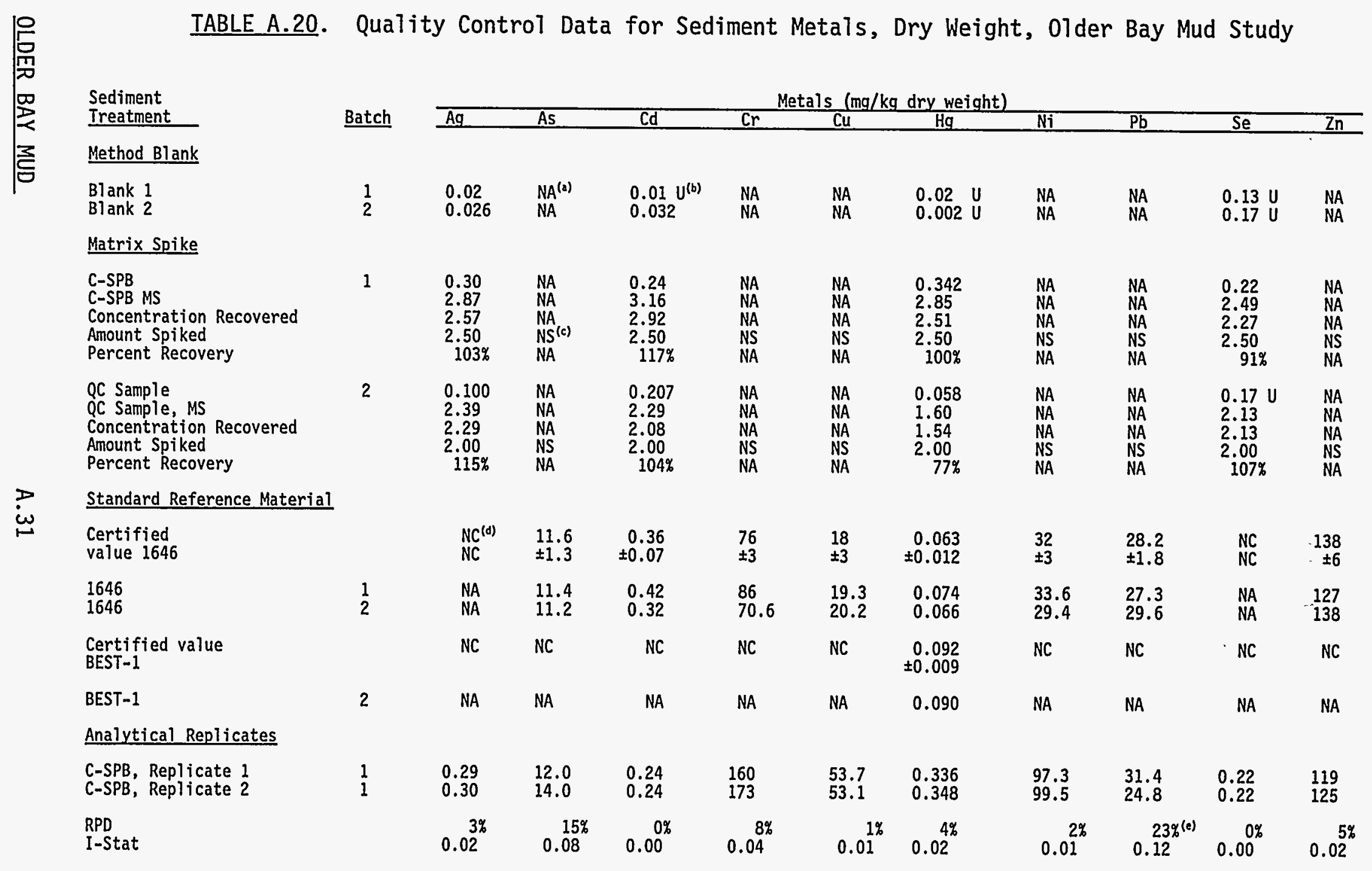


TABLE A.20. (contd)

\section{Analytical Replicates}

QC Sample, Replicate

C Sample, Replicate

C Sample, Replicate

RSD

Batch

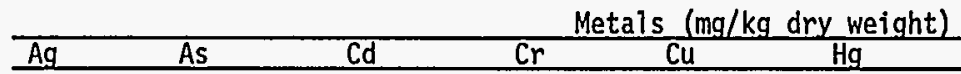

$\mathrm{Pb}$

Se

$\begin{array}{rrr}0.10 & 10.0 & 0.21 \\ 0.10 & 9.0 & 0.20 \\ 0.10 & 11.2 & 0.21 \\ & & \\ 0 \% & 11 \% & \end{array}$

$\begin{array}{rr}0.21 & 202 \\ 0.20 & 174 \\ 0.21 & 201 \\ & \\ 3 \% & 8 \%\end{array}$

$43.2 \quad 0.029$

0.029
0.073
0.071

94.7

41.1

99.9

11.9

$8 \%$

$5 \%$

$43 \%(e)$

$3 \%$

$13 \%$

$2 \%$

(a) NA Not applicable.

b) Undetected at or above detection limit

c) NS Not spiked.

e) Value exceeds relative precision goal of $\leq 20 \%$.

i 
TABLE A.21. Sediment Butyltin Results, 01der Bay Mud Study

Sediment

Treatment

Target $D L^{(a)}$

January 1993

OBM COMP

C-SB

C-WB

C-SPB, Replicate 1

C-SPB, Replicate 2
Surrogate $\frac{\text { Butyltins }(\mu \mathrm{g} / \mathrm{kg} \text { dry weight) }}{\text { Pri- }}$

Batch Recovery butyltin butyltin

10

10

$2.2 B^{(c)} J^{(d)}$

$8.0 U^{(b)}$

$8.0 \mathrm{U}$

$8.0 \mathrm{U}$

$3.8 \mathrm{~J}$

$3.8 \mathrm{~J}$

$2.0 \mathrm{BJ}$

$5.0 \mathrm{U}$

$5.0 \mathrm{U}$

$5.0 \mathrm{U}$

January 1994

OBM COMP

R-OS

$\mathrm{R}-\mathrm{BF}$

R-AM

$\begin{array}{rr}2 & 80 \\ 3 & 99 \\ 3 & 102 \\ 3 & 104\end{array}$

$0.40 \mathrm{U}$

$0.40 \mathrm{U}$

$0.65 \mathrm{U}$

3.82

$0.65 \mathrm{U}$

104

$0.40 \mathrm{U}$

3.38

$0.65 \mathrm{U}$

October 1994

OBM COMP

R-OS, Rep 7 icate 1

$\mathrm{R}-0 \mathrm{~S}$, Replicate 2

$\mathrm{R}-\mathrm{OS}$, Replicate 3

$\mathrm{R}-\mathrm{BF}$

$\mathrm{R}-\mathrm{AM}$

$\begin{array}{rr}4 & 94 \\ 4 & 98 \\ 4 & 103 \\ 4 & 98 \\ 4 & 104 \\ 4 & 93\end{array}$

$0.48 \mathrm{U}$

$0.56 U$

0.67

$0.56 \mathrm{U}$

0.54

$0.56 \mathrm{U}$

0.66

$0.56 \mathrm{U}$

2.27

2.11

93

$0.48 \mathrm{U}$

$0.56 \mathrm{U}$
(a) DL Detection limit.
(b) $U$ Undetected at or above detection limit.
(c) B Analyte detected in sample at less than five times the value in
(d) J Analyte detected below method detection limit (MDL), but above instrument detection limit (IDL). 
TABLE A.22. Quality Control Data for Sediment Butyltin Results, 01der Bay Mud Study

Sediment

Treatment

Method Blank

Blank

Blank

BTank

Blank

Matrix Spike

\section{C-WB}

C-WB MS

Concentration Recovered

Amount Spiked

Percent Recovery

C-WB

C-WB MSD

Concentration Recovered

Amount Spiked

Percent Recovery

RPD

I-Stat

QC Sample

QC Sample, MS

Concentration Recovered

Amount Spiked

Percent Recovery

R-AM

R-AM, MS

Concentration Recovered

Amount Spiked

Percent Recovery

QC Sample

QC Sample, MS

Concentration Recovered

Amount Spiked

Percent Recovery
Surrogate Percent

Batch

Recovery

110

91

100

101 $\frac{\text { Butyltins }(\mu \mathrm{g} / \mathrm{kg} \text { dry weight })}{\text { Tri- }}$ butyltin

butyltin

$\begin{array}{rr}1 & 110 \\ 2 & 91 \\ 3 & 100 \\ 4 & 101\end{array}$

1

1

2

3

$3-104$

103

4
NA

104
103
NA
NS
NA

104
103
NA
NS
NA

81

98

$N A^{(c)}$

$\mathrm{NS}^{(\mathrm{d})}$

NA

81

107

NA

NS

NA

NA

NA

97

90

NA

NS

NA

92

85

NA

NS

NA
$8.0 U^{(a)}$
$0.40 \mathrm{U}$
$0.40 \mathrm{U}$
0.55

$4.3 \mathrm{~J}^{(b)}$
$0.65 \mathrm{U}$
$0.65 \mathrm{U}$
$0.56 \mathrm{U}$

$8.0 \mathrm{U}$

27.4

27.4

31.5

$87 \%$

$8.0 \mathrm{U}$

29.3

29.3

31.3

$94 \%$

$0.04 \%$

8.52

64.6

56.1

43.9

$128 \%(\mathrm{e})$

$0.40 \mathrm{U}$

31.9

31.9

30.9

$103 \%$

0.49

45.1

44.6

50.0

$89 \%$
$5.0 \mathrm{U}$

26.8

26.8

31.5 $85 \%$

$5.0 \mathrm{U}$

26.1

26.1

31.3 $83 \%$
0.01

7.48

44.0

36.5

43.9 $83 \%$

$0.65 \mathrm{U}$

31.7

31.7

30.9 $103 \%$

$0.56 \mathrm{U}$

26.6

26.6

50.0 $53 \%$

OLDER BAY MUD- 
TABLE A.22. (contd)

Surrogate

Percent

Batch
Sediment
Treatment

Standard Reference Material

Certified

Value PACS-1

PACS-1

PACS-1

PACS-1

PACS-1

$\begin{array}{lrcc} & \text { NA } & 1270 & 1160 \\ & \text { NA } & \pm 220 & \pm 180 \\ 1 & 102 & 798^{\text {(f) }} & 827 \\ 2 & 99 & 1110 & 1210 \\ 3 & 103 & 1060 & 659^{(f)} \\ 4 & 96 & 897 & 1080\end{array}$

Analytical Replicates

C-SPB, Rep Ticate 1

C-SPB, Replicate 2

$1 \quad 100$

$1 \quad 107$

$3.8 \mathrm{~J}$

$3.8 \mathrm{~J}$

$5.0 \mathrm{U}$

NA

NA

$0 \%$

$5.0 \mathrm{U}$

RPD

I-Stat

107

QC Sample, Replicate 1

QC Sample, Replicate 2

QC Sample, Replicate 3

$\begin{array}{rr}2 & 107 \\ 2 & 91\end{array}$

2100

0.00

NA

NA

RSD

NA

9.32

7.48

9.30

8.98

7.74

8.11

$11 \%$

$10 \%$

QC Sample, Replicate 1

QC Sample, Replicate 2

91

94

105

$0.40 \mathrm{U}$

$0.40 \mathrm{U}$

$0.40 \mathrm{U}$

$0.65 U$

$0.65 U$

$0.65 \mathrm{U}$

RSD

NA

NA

NA

R-OS, RepTicate 1

R-OS, Replicate 2

R-OS, Replicate 3

$\begin{array}{rr}4 & 98 \\ 4 & 103 \\ 4 & 98\end{array}$

0.67

0.54

0.66

$0.56 U$

$0.56 U$

$0.56 \mathrm{U}$

RSD

NA

$12 \%$

NA

(a) $U$ Undetected at or above detection limit.

(b) J Analyte detected below method detection limit (MDL), but above instrument detection limit (IDL).

(c) NA Not applicable.

(d) NS Not spiked.

(e) Outside quality control criteria (40\%-120\%) for matrix spike recoveries.

(f) Outside quality control criteria $( \pm 30 \%)$ for SRMs. 
APPENDIX B

BIOASSAY RESULTS FOR 10-DAY SOLID-PHASE, STATIC TEST AND 96-HOUR REFERENCE TOXICANT TEST FOR RHEPOXYNIUS abronius 
IABLE B.1. Test Results for 10-Day R. abronius Solid-Phase, Static Test, 01der Bay Mud Study

Sediment

Treatment

January 1993

OBM COMP

OBM COMP

OBM COMP

OBM COMP

OBM COMP

$C-W B$

C-WB

C-WB

C-WB

C-WB

January 1994

OBM COMP

OBM COMP

OBM COMP

OBM COMP

OBM COMP

R-OS

$R-0 S$

R-OS

$\mathrm{R}-\mathrm{OS}$

R-OS

$R-B F$

$\mathrm{R}-\mathrm{BF}$

$\mathrm{R}-\mathrm{BF}$

$R-B F$

$R-B F$

R-AM

R-AM

$R-A M$

R-AM

$R-A M$

C.WB

C-WB

$C-W B$

C-WB

$C-H B$

C-SB

C-SB

C-SB

$C-S B$

C-SB

October 1994

OBM COMP

OBM COMP

OBM COMP

OBM COMP

OBM COMP

\begin{tabular}{|c|c|c|c|c|c|}
\hline \multirow[b]{2}{*}{ Replicate } & \multicolumn{3}{|c|}{ R. abronius } & \multirow{2}{*}{$\begin{array}{c}\text { Mean } \\
\text { Proportion } \\
\text { Surviving }\end{array}$} & \multirow[b]{2}{*}{$\begin{array}{l}\text { Standard } \\
\text { Deviation }\end{array}$} \\
\hline & $\underline{\text { Live }}$ (a) & $\begin{array}{l}\text { Dead or } \\
\text { Missing }\end{array}$ & $\begin{array}{l}\text { Proportion } \\
\text { Surviving }\end{array}$ & & \\
\hline
\end{tabular}

$\begin{array}{llllll}1 & 17 & 3 & 0.85 & & \\ 2 & 18 & 2 & 0.90 & & \\ 3 & 15 & 5 & 0.75 & & \\ 4 & 17 & 3 & 0.85 & 0.85 & 0.06 \\ 5 & 18 & 2 & 0.90 & & \\ 1 & 19 & 1 & 0.95 & & \\ 2 & 20 & 0 & 1.00 & & \\ 3 & 20 & 0 & 1.00 & & \\ 4 & 20 & 0 & 1.00 & 0.03\end{array}$

$0.72 \quad 0.08$

0.65

0.75

0.85

0.95

0.95

0.80

0.90

$\begin{array}{ll}0.89 & 0.07\end{array}$

0.85

0.95

1.00

0.95
0.95

$0.94 \quad 0.05$

1.00

1.00

1.00

1.00

$0.99 \quad 0.02$

1.00

0.95

1.00

1.00

0.95

$0.98 \quad 0.03$

0.90

0.90

1.00

0.85

$0.93 \quad 0.07$

0.65

0.75

0.80

0.65

0.55

$0.68 \quad 0.10$ 
TABLE B.1. (contd)

Sediment
Treatment

R-OS

R-OS

R-OS

R-OS

R-OS

$R-B F$

$R-B F$

R-BF

R-BF

R-BF

R-AM

R-AM

R-AM

R-AM

R-AM

C-WB

C-WB

C-WB

C-HB

C-WB

C-SB

C-SB

C-SB

C-SB

C-SB

\begin{tabular}{ccc} 
& & \multicolumn{1}{c}{$R$} \\
\cline { 3 - 3 } Replicate & Live & Dea \\
& & \\
1 & 19 \\
2 & 17 \\
3 & 19 \\
4 & 20 \\
5 & 19
\end{tabular}

R. abronius

R. abronius

Surviving

Mean

Proportion Standard

Surviving Deviation

$\begin{array}{ll}1 & 0.95 \\ 3 & 0.85 \\ 1 & 0.95 \\ 0 & 1.00 \\ 1 & 0.95\end{array}$

0.94

0.05

1
3
5
1
6

0.95

0.85

0.75

0.95

0.70

0.84

0.11

0.85

1.00

1.00

1.00

0.97

0.07

0.95

0.95

1.00

1.00

1.00

0.98

0.03

0.90

0.85

0.85

1.00

0.85

0.89

0.07

(a) Survival based on initial exposure of 20 organisms per replicate. 
TABLE B.2. Water Quality Summary for 10-Day R. abronius Solid-Phase, Static Test, 01der Bay Mud Study

Sediment

Treatment

Temperature

Acceptable

Range

$\frac{\left({ }^{\circ} \mathrm{C}\right)}{\operatorname{Min} \quad \underline{M a x}}$

$\underline{\text { Min }} \underline{\mathrm{Max}}$

Dissolved

January 1993

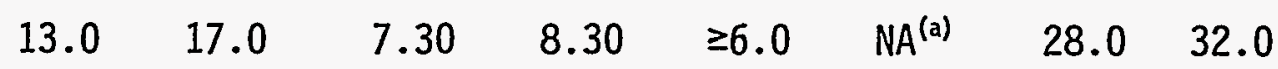

OBM COMP

C-WB

$15.4 \quad 16.2 \quad 7.98$

8.13

8.17

7.2

8.2

$30.5 \quad 31.0$

$\begin{array}{lll}15.4 & 16.2 & 7.88\end{array}$

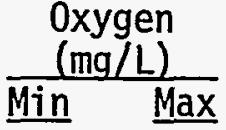

Salinity

$\frac{(0 / 00)}{\operatorname{Max}}$

January 1994

$\begin{array}{lllllllll}\text { OBM COMP } & 14.6 & 16.1 & 7.89 & 8.10 & 7.2 & 8.6 & 31.0 & 32.5^{(\text {b) }} \\ \text { R-OS } & 14.6 & 15.9 & 7.49 & 8.01 & 7.4 & 8.4 & 31.0 & 32.0 \\ \text { R-BF } & 14.7 & 15.9 & 7.49 & 7.92 & 7.5 & 8.5 & 30.0 & 32.0 \\ \text { R-AM } & 14.6 & 15.7 & 7.49 & 7.97 & 7.3 & 8.5 & 31.0 & 32.0 \\ \text { C-WB } & .14 .6 & 16.0 & 7.67 & 7.99 & 7.3 & 8.3 & 31.5 & 32.0 \\ \text { C-SB } & 14.6 & 15.9 & 7.76 & 8.40^{(\text {b) }} & 7.2 & 8.4 & 31.0 & 32.0\end{array}$

October 1994

$\begin{array}{lllllllll}\text { OBM COMP } & 15.0 & 15.8 & 7.98 & 8.18 & 7.6 & 8.0 & 31.0 & 33.0^{(b)} \\ \text { R-OS } & 15.0 & 15.9 & 7.94 & 8.11 & 7.5 & 7.9 & 31.0 & 33.0^{(b)} \\ \text { R-BF } & 15.1 & 15.8 & 7.86 & 8.09 & 7.4 & 7.8 & 31.0 & 32.5^{(b)} \\ \text { R-AM } & 15.0 & 15.9 & 7.87 & 8.10 & 7.4 & 7.9 & 30.5 & 33.0^{(b)} \\ \text { C-WB } & 15.0 & 15.9 & 7.80 & 8.09 & 7.3 & 7.9 & 31.0 & 32.5^{(b)} \\ \text { C-SB } & 15.0 & 15.9 & 7.81 & 8.19 & 7.3 & 7.9 & 31.0 & 33.0^{(b)}\end{array}$

(a) NA Not applicable.

(b) Data point out of range. 
IABLE B.3. Ammonia Measurements in Overlying Water for 10-Day R. abronius Solid-Phase, Static Test, Older Bay Mud Study

Sediment

Treatment

January 1994

OBM COMP

R-OS

R-BF

R-AM

C-WB

C-SB
1.11

0.65

0.78

0.42

0.82

0.76
1.96

1.09

1.43

0.493

0.947

1.94

Ammonia

(mg/L)

Day 3

October 1994

OBM COMP
R-OS
R-BF
R-AM
C-WB
C-SB

0.734

0.447

2.71

0.639

0.723

2.14

0.272

3.34

1.32

1.74

1.48

1.42

0.261

0.700

1.23

0.802

0.896

1.19

1.31

1.45

0.844

1.14

1.30

0.140

0.396

0.579

1.13

0.380

2.60

1.12

0.566

1.90

0.630

0.347

0.180

0.177

0.350

0.295

1.67

0.330

0.778

1.39

0.564

1.61

1.23

1.08

0.597 
TABLE B.4. Water Quality Measurements of Interstitial Water for 10-Day R. abronius Solid-Phase, Static Test, Older Bay Mud Study

Sediment

Treatment

\begin{tabular}{|c|c|c|c|c|c|}
\hline \multicolumn{2}{|c|}{$\mathrm{aH}$} & \multicolumn{2}{|c|}{$\begin{array}{l}\text { Salinity } \\
(0 / 00)\end{array}$} & \multicolumn{2}{|c|}{$\begin{array}{l}\text { Porewater } \\
\text { Ammonia } \\
\text { (mg/L) }\end{array}$} \\
\hline Min & Max & Min & Max & Day 0 & Day 10 \\
\hline
\end{tabular}

January 1994

OBM COMP

R-OS

R-BF

R-AM

C-WB

C-SB
8.08

7.87

7.61

7.92

7.71

7.82
8.30

8.00

7.96

7.93

7.71

7.85
$32.0 \quad 32.0$

$32.0 \quad 32.0$

$32.0 \quad 32.0$

$32.0 \quad 32.0$

$32.0 \quad 32.0$

$32.0 \quad 32.0$
2.53

3.61

3.38

3.25

4.99

4.22
2.49

1.05

0.66

1.03

$\mathrm{NI}^{\text {(a) }}$

1.07

October 1994

\begin{tabular}{|c|c|c|c|c|}
\hline $\mathrm{pH}$ & & & & $\begin{array}{l}\text { ater } \\
\text { nia } \\
g / L)\end{array}$ \\
\hline Day 10 & Day 0 & Day 10 & Day 0 & Day 10 \\
\hline
\end{tabular}

OBM COMP

\subsection{1}

8.25

32.0

31.5

1.14

0.637

R-OS

7.95

32.0

32.5

7.45

31.5

32.0

1.18

1.01

$\begin{array}{ll}7.84 & 7.47\end{array}$

32.0

32.0

6.98

2.11

R-AM

7.79

31.0

0.476

0.156

C-SB

$7.71 \quad 7.30$

32.0

32.0

2.20

2.71

2.46

1.08

(a) NI Not initiated; not enough water in sediment sample. 
TABLE B.5. Test Results for 96-Hour R. abronius Cadmium Reference Toxicant Test, 01der Bay Mud Study

Joncenc
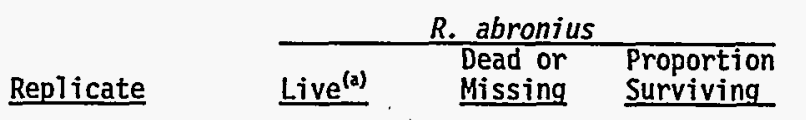

Mean

Proportion Standard

Cadmium

(mg/L)

Replicate

Missing Surviving

Surviving

Deviation

January 1993

0
0
0

$\begin{array}{ll}1 & 18 \\ 2 & 18 \\ 3 & 19\end{array}$

$\begin{array}{lll}18 & 2 & 0.90 \\ 18 & 2 & 0.90 \\ 19 & 1 & 0.95\end{array}$

0.92

0.03

0.5

0.5

1
2
3

13

11

7
8
9

0.65

0.60

0.55

0.60

0.05

$\begin{array}{ll}1 & 1 \\ 1 & 2 \\ 1 & 3\end{array}$

$\begin{array}{ll}3 & 17 \\ 5 & 15 \\ 5 & 15\end{array}$

0.15

0.25
0.25

0.22

0.06

$\begin{array}{ll}2 & 1 \\ 2 & 2 \\ 2 & 3\end{array}$

3
0
0

0.15

0.00

0.00

$0.05 \quad 0.09$

$\begin{array}{ll}4 & 1 \\ 4 & 2 \\ 4 & 3\end{array}$

0
0
0

0.00

0.00

0.00

0.00

0.00

January 1994

\begin{tabular}{|c|c|c|c|c|c|c|}
\hline $\begin{array}{l}0.00 \\
0.00 \\
0.00\end{array}$ & $\begin{array}{l}1 \\
2 \\
3\end{array}$ & $\begin{array}{l}19 \\
17 \\
20\end{array}$ & $\begin{array}{l}1 \\
3 \\
0\end{array}$ & $\begin{array}{l}0.95 \\
0.85 \\
1.00\end{array}$ & 0.93 & 0.08 \\
\hline $\begin{array}{l}0.38 \\
0.38 \\
0.38\end{array}$ & $\begin{array}{l}1 \\
2 \\
3\end{array}$ & $\begin{array}{r}15 \\
10 \\
5\end{array}$ & $\begin{array}{r}5 \\
10 \\
15\end{array}$ & $\begin{array}{l}0.75 \\
0.50 \\
0.25\end{array}$ & 0.50 & 0.25 \\
\hline $\begin{array}{l}0.75 \\
0.75 \\
0.75\end{array}$ & $\begin{array}{l}1 \\
2 \\
3\end{array}$ & $\begin{array}{l}11 \\
12 \\
15\end{array}$ & $\begin{array}{r}9 \\
8 \\
5\end{array}$ & $\begin{array}{l}0.55 \\
0.60 \\
0.75\end{array}$ & 0.63 & 0.10 \\
\hline $\begin{array}{l}1.50 \\
1.50 \\
1.50\end{array}$ & $\begin{array}{l}1 \\
2 \\
3\end{array}$ & $\begin{array}{l}5 \\
3 \\
3\end{array}$ & $\begin{array}{l}15 \\
17 \\
17\end{array}$ & $\begin{array}{l}0.25 \\
0.15 \\
0.15\end{array}$ & 0.18 & 0.06 \\
\hline $\begin{array}{l}3.00 \\
3.00 \\
3.00\end{array}$ & $\begin{array}{l}1 \\
2 \\
3\end{array}$ & $\begin{array}{l}0 \\
0 \\
0\end{array}$ & $\begin{array}{l}20 \\
20 \\
20\end{array}$ & $\begin{array}{l}0.00 \\
0.00 \\
0.00\end{array}$ & 0.00 & 0.00 \\
\hline
\end{tabular}

October 1994

$\begin{array}{lrrrr}0.00 & 1 & 19 & 1 & 0.95 \\ 0.25 & 1 & 15 & 5 & 0.75 \\ 0.50 & 1 & 12 & 8 & 0.60 \\ 1.00 & 1 & 10 & 10 & 0.50 \\ 1.50 & 1 & 5 & 15 & 0.25 \\ 2.00 & 1 & 2 & 18 & 0.10 \\ 4.00 & 1 & 0 & 20 & 0.00\end{array}$

0.75

0.60

0.50

0.10

4.00

1

(a) Survival based on initial exposure of 20 organisms per replicate. 
TABLE B.6. Water Quality Summary for 96-Hour R. abronius Cadmium Reference Toxicant Test, 01der Bay Mud Study

\begin{tabular}{|c|c|c|c|c|c|c|c|c|}
\hline \multirow{2}{*}{$\begin{array}{l}\text { Cadmium } \\
\text { Concentration } \\
\text { (mg/L) }\end{array}$} & \multicolumn{2}{|c|}{$\begin{array}{c}\text { Temperature } \\
\left({ }^{\circ} \mathrm{C}\right)\end{array}$} & \multicolumn{2}{|c|}{$\mathrm{pH}$} & \multicolumn{2}{|c|}{$\begin{array}{l}\text { Dissolved } \\
\text { oxygen } \\
\text { (mg/L) } \\
\end{array}$} & \multicolumn{2}{|c|}{$\begin{array}{c}\text { Salinity } \\
(0 / 00)\end{array}$} \\
\hline & $\underline{\text { Min }}$ & $\underline{\text { Max }}$ & Min & $\underline{\operatorname{Max}}$ & $\underline{\text { Min }}$ & Max & Min & Max \\
\hline $\begin{array}{l}\text { Acceptable } \\
\text { Range }\end{array}$ & 13.0 & 17.0 & 7.30 & 8.30 & $\geq 6.0$ & $N A^{(a)}$ & 28.0 & 32.0 \\
\hline \multicolumn{9}{|l|}{ January 1993} \\
\hline 0 & 15.6 & 16.2 & 7.92 & 8.08 & 7.1 & 8.0 & 30.5 & 30.5 \\
\hline 0.5 & 15.6 & 16.1 & 7.93 & 8.07 & 7.1 & 7.9 & 30.5 & 30.5 \\
\hline 1 & 15.6 & 15.9 & 7.82 & 8.04 & 7.1 & 8.0 & 30.5 & 30.5 \\
\hline 2 & 15.6 & 16.1 & 7.87 & 8.01 & 7.2 & 7.9 & 30.5 & 30.5 \\
\hline 4 & 15.6 & 16.1 & 7.80 & 7.93 & 7.2 & 8.0 & 30.5 & 30.5 \\
\hline \multicolumn{9}{|l|}{ January 1994} \\
\hline 0.00 & 15.1 & 15.5 & 7.83 & 7.96 & 7.4 & 8.4 & 31.5 & 32.0 \\
\hline 0.38 & 15.1 & 15.5 & 7.83 & 7.92 & 7.3 & 8.6 & 31.5 & 32.0 \\
\hline 0.75 & 15.1 & 15.5 & 7.84 & $7.93 \$$ & 7.6 & 8.6 & 31.0 & 32.0 \\
\hline 1.50 & 15.1 & 15.4 & 7.79 & 7.91 & 7.7 & 8.7 & 31.5 & 32.0 \\
\hline 3.00 & 15.2 & 15.5 & 7.79 & 7.85 & 7.4 & 8.7 & 31.5 & 32.0 \\
\hline
\end{tabular}

October 1994

$\begin{array}{lllllllll}0.00 & 15.1 & 15.5 & 7.78 & 8.09 & 7.7 & 7.8 & 31.5 & 32.0 \\ 0.25 & 15.2 & 15.5 & 7.73 & 8.09 & 7.7 & 8.0 & 31.5 & 32.0 \\ 0.50 & 15.2 & 15.4 & 7.78 & 8.08 & 7.8 & 8.1 & 31.5 & 32.0 \\ 1.00 & 15.1 & 15.5 & 7.77 & 8.05 & 7.8 & 8.0 & 31.5 & 32.0 \\ 1.50 & 15.2 & 15.5 & 7.71 & 8.04 & 7.9 & 8.1 & 31.5 & 32.0 \\ 2.00 & 15.1 & 15.5 & 7.62 & 8.01 & 7.8 & 8.0 & 31.5 & 32.0 \\ 4.00 & 15.1 & 15.5 & 7.60 & 7.96 & 7.9 & 8.0 & 31.5 & 32.0\end{array}$

(a) NA Not applicable. 
IABLE B.7. Test Results for 96-Hour $R$. abronius Ammonia Reference Toxicant Test, Older Bay Mud Study

\begin{tabular}{cccc}
$\begin{array}{c}\text { Ammonia } \\
\begin{array}{c}\text { Concentration } \\
\text { mg/L }\end{array}\end{array}$ & Live $^{\text {(a) }}$ & $\begin{array}{c}\text { Dead or } \\
\text { Missing }\end{array}$ & $\begin{array}{c}\text { Proportion } \\
\text { Surviving }\end{array}$ \\
\hline 0 & 20 & 0 & \\
10 & 20 & 0 & 1.00 \\
20 & 20 & 0 & 1.00 \\
40 & 19 & 1 & 1.00 \\
80 & 13 & 7 & 0.95 \\
120 & 5 & 15 & 0.65 \\
160 & 0 & 20 & 0.25 \\
& & & 0.00
\end{tabular}

(a) Survival based on initial exposure of 20 organisms per replicate. 
TABLE B.8. Water Quality Summary for 96-Hour R. abronius Ammonia Reference Toxicant Test, Older Bay Mud Study

\begin{tabular}{|c|c|c|c|c|c|c|c|c|c|c|}
\hline \multirow{2}{*}{$\begin{array}{c}\text { Ammonia } \\
\text { Concentration } \\
\mathrm{mg} / \mathrm{L}\end{array}$} & \multicolumn{2}{|c|}{$\begin{array}{c}\text { Temperature } \\
\left({ }^{\circ} \mathrm{C}\right) \\
\end{array}$} & \multicolumn{4}{|c|}{$\begin{array}{c}\text { Dissolved } \\
\text { Oxygen } \\
\text { (mg/L) }\end{array}$} & \multicolumn{2}{|c|}{$\begin{array}{c}\text { Salinity } \\
(0 / 00)\end{array}$} & \multicolumn{2}{|c|}{$\begin{array}{c}\text { Ammonia } \\
(\mathrm{mg} / \mathrm{L})\end{array}$} \\
\hline & Min & $\operatorname{Max}$ & Min & $\operatorname{Max}$ & Min & Max & Min & Max & Min & Max \\
\hline \multicolumn{11}{|l|}{ Acceptable } \\
\hline Range & 13.0 & 17.0 & 7.30 & 8.30 & 6.0 & $N A^{(a)}$ & 28.0 & 32.0 & $N E^{(b)}$ & NE \\
\hline 0 & 15.0 & 15.6 & 7.71 & 8.05 & 7.7 & 7.8 & 31.5 & 32.0 & 0.212 & 0.419 \\
\hline 10 & 15.0 & 15.6 & 7.65 & 8.04 & 7.8 & 8.0 & 31.5 & 32.0 & 9.15 & 10.5 \\
\hline 20 & 14.9 & 15.6 & 7.65 & 8.05 & 7.7 & 8.0 & 31.0 & 32.0 & 17.3 & 21.7 \\
\hline 40 & 14.9 & 15.5 & 7.60 & 8.08 & 7.8 & 8.1 & 31.0 & 32.0 & 34.7 & 40.0 \\
\hline 80 & 14.9 & 15.5 & 7.59 & 8.06 & 7.8 & 8.0 & 31.5 & 32.0 & 66.2 & 78.6 \\
\hline 120 & 15.0 & 15.5 & 7.60 & 8.03 & 7.8 & 8.1 & 31.5 & 32.0 & 99.5 & 126 \\
\hline 160 & 15.0 & 15.5 & 7.45 & 8.01 & 7.8 & 8.1 & 31.5 & 32.0 & 132 & 179 \\
\hline
\end{tabular}

(a) NA Not applicable.

(b) NE Not established. 


\section{APPENDIX C}

BIOASSAY RESULTS FOR 10-DAY SOLID-PHASE, FLOW-THROUGH TEST WITH MACOMA nasuta AND NEPHTYS caecoides 
TABLE C.1. Test Results for 10-Day M. nasuta Solid-Phase, Flow-Through Test, Older Bay Mud Study

\begin{tabular}{llllll} 
& & \multicolumn{2}{c}{ M. nasuta } & & \multicolumn{2}{c}{ Mean } \\
\cline { 3 - 4 } Sediment & & Dead or & Proportion & Proportion Standard \\
Treatment & Replicate & Live $^{(a)}$ & Missing & Surviving & Surviving Deviation \\
\hline
\end{tabular}

January 1994

\begin{tabular}{|c|c|c|c|c|c|c|}
\hline OBM COMP & 1 & 25 & 0 & 1.00 & & \\
\hline OBM COMP & 2 & 25 & 0 & 1.00 & & \\
\hline OBM COMP & 3 & 24 & 1 & 0.96 & & \\
\hline OBM COMP & 4 & 25 & 0 & 1.00 & & \\
\hline OBM COMP & 5 & 24 & 1 & 0.96 & 0.98 & 0.02 \\
\hline R-OS & 1 & 25 & 0 & 1.00 & & \\
\hline R-OS & 2 & 25 & 0 & 1.00 & & \\
\hline R-OS & 3 & 25 & 0 & 1.00 & & \\
\hline R-OS & 4 & 25 & 0 & 1.00 & & \\
\hline R-OS & 5 & 25 & 0 & 1.00 & 1.00 & 0.00 \\
\hline $\mathrm{R}-\mathrm{BF}$ & 1 & 25 & 0 & 1.00 & & \\
\hline R-BF & 2 & 25 & 0 & 1.00 & & \\
\hline R-BF & 3 & 25 & 0 & 1.00 & & \\
\hline R-BF & 4 & 25 & 0 & 1.00 & & \\
\hline R-BF & 5 & 25 & 0 & 1.00 & 1.00 & 0.00 \\
\hline R-AM & 1 & 25 & 0 & 1.00 & & \\
\hline R-AM & 2 & 25 & 0 & 1.00 & & \\
\hline R-AM & 3 & 25 & 0 & 1.00 & & \\
\hline R-AM & 4 & $\mathrm{NI}^{(\mathrm{s})}$ & NI & $N A^{(c)}$ & & \\
\hline R-AM & 5 & 25 & 0 & 1.00 & 1.00 & 0.00 \\
\hline C-SB & 1 & 20 & 0 & 1.00 & & \\
\hline C-SB & 2 & 20 & 0 & 1.00 & & \\
\hline C-SB & 3 & 20 & 0 & 1.00 & & - \\
\hline C-SB & 4 & 20 & 0 & 1.00 & & \\
\hline C-SB & 5 & 20 & 0 & 1.00 & 1.00 & 0.00 \\
\hline C-NE & 1 & 20 & 0 & 1.00 & & \\
\hline C-NE & 2 & 20 & 0 & 1.00 & & \\
\hline C-NE & 3 & 20 & 0 & 1.00 & & \\
\hline C-NE & 4 & 20 & 0 & 1.00 & & \\
\hline C-NE & 5 & 20 & 0 & 1.00 & 1.00 & 0.00 \\
\hline
\end{tabular}

(a) Survival based on initial exposure of either 20 or 25 organisms per replicate.

(b) NI Not initiated; insufficient organisms to test all five replicates.

(c) NA Not applicable. 
TABLE C.2. Test Results for 10-Day N. caecoides Solid-Phase, Flow-Through Test, Older Bay Mud Study

\begin{tabular}{|c|c|c|c|c|c|c|}
\hline \multirow{2}{*}{$\begin{array}{l}\text { Sediment } \\
\text { Treatment }\end{array}$} & \multirow[b]{2}{*}{ Replicate } & \multicolumn{2}{|c|}{ N. caecoides } & \multirow[b]{2}{*}{$\begin{array}{l}\text { Proportion } \\
\text { Surviving }\end{array}$} & \multirow{2}{*}{\begin{tabular}{l}
\multicolumn{1}{c}{ Mean } \\
Proportion \\
Surviving
\end{tabular}} & \multirow[b]{2}{*}{$\begin{array}{l}\text { Standard } \\
\text { Deviation }\end{array}$} \\
\hline & & Live $^{(a)}$ & $\begin{array}{l}\text { Dead or } \\
\text { Missing }\end{array}$ & & & \\
\hline \multicolumn{7}{|l|}{ January 1994} \\
\hline OBM COMP & 1 & 6 & 14 & 0.30 & ' & \\
\hline OBM COMP & 2 & 11 & 9 & 0.55 & & \\
\hline OBM COMP & 3 & 4 & 16 & 0.20 & & \\
\hline OBM COMP & 4 & 11 & 9 & 0.55 & & \\
\hline OBM COMP & 5 & 6 & 14 & 0.30 & 0.38 & 0.16 \\
\hline R-OS & 1 & 19 & 1 & 0.95 & & \\
\hline R-OS & 2 & 20 & 0 & 1.00 & & \\
\hline R-OS & 3 & 19 & 1 & 0.95 & & \\
\hline R-OS & 4 & 18 & 2 & 0.90 & & \\
\hline R-OS & 5 & 20 & 0 & 1.00 & 0.96 & 0.04 \\
\hline R-BF & 1 & 17 & 3 & 0.85 & & \\
\hline R-BF & 2 & 19 & 1 & 0.95 & & \\
\hline R-BF & 3 & 17 & 3 & 0.85 & & \\
\hline$R-B F$ & $: 4$ & 18 & 2 & 0.90 & & \\
\hline $\mathrm{R}-\mathrm{BF}$ & 5 & 20 & 0 & 1.00 & 0.91 & 0.07 \\
\hline R-AM & 1 & 19 & 1 & 0.95 & & \\
\hline R-AM & 2 & 20 & 0 & 1.00 & & \\
\hline R-AM & 3 & 19 & 1 & 0.95 & & \\
\hline R-AM & 4 & $\mathrm{Nl}^{(\mathrm{b})}$ & NI & $N A^{(c)}$ & & \\
\hline R-AM & 5 & 19 & 1 & 0.95 & 0.96 & 0.03 \\
\hline $\mathrm{C}-\mathrm{NE}$ & 1 & 18 & 2 & 0.90 & & \\
\hline C-NE & 2 & 20 & 0 & 1.00 & & - \\
\hline C-NE & 3 & 18 & 2 & 0.90 & & \\
\hline C-NE & 4 & 18 & 2 & 0.90 & & \\
\hline C-NE & 5 & 20 & 0 & 1.00 & 0.94 & 0.05 \\
\hline C-SB & 1 & 20 & 0 & 1.00 & & \\
\hline C-SB & 2 & 19 & 1 & 0.95 & & \\
\hline C-SB & 3 & 19 & 1 & 0.95 & & \\
\hline C-SB & 4 & 19 & 1 & 0.95 & & \\
\hline C-SB & 5 & 19 & 1 & 0.95 & 0.96 & 0.02 \\
\hline
\end{tabular}

(a) Survival based on initial exposure of 20 organisms per replicate.

(b) NI Not initiated; insufficient organisms for all five replicates.

(c) NA Not applicable. 
TABLE C.3. Water Quality Summary for 10-Day M. nasuta/N. caecoides Solid-Phase, Flow-Through Test, Older Bay Mud Study

\begin{tabular}{|c|c|c|c|c|c|c|c|c|}
\hline \multirow{2}{*}{$\begin{array}{l}\text { Sediment } \\
\text { Treatment }\end{array}$} & \multicolumn{2}{|c|}{$\begin{array}{c}\text { Temperature } \\
\left({ }^{\circ} \mathrm{C}\right) \\
\end{array}$} & \multicolumn{2}{|c|}{$\mathrm{pH}$} & \multicolumn{2}{|c|}{$\begin{array}{c}\text { Dissolved } \\
\text { Oxygen } \\
\text { (mg/L) }\end{array}$} & \multicolumn{2}{|c|}{$\begin{array}{l}\text { Salinity } \\
(0 / 00)\end{array}$} \\
\hline & Min & $\operatorname{Max}$ & Min & Max & Min & Max & Min & Max \\
\hline $\begin{array}{l}\text { Acceptable } \\
\text { Range }\end{array}$ & 13.0 & 17.0 & 7.30 & 8.30 & 5.0 & NA (a) & 28.0 & 32.0 \\
\hline January 1994 & & & & & & & & \\
\hline OBM COMP & 14.3 & 15.6 & 7.32 & 7.87 & 7.4 & 8.6 & 30.5 & 32.0 \\
\hline R-OS & 14.2 & 15.5 & 7.40 & 7.90 & 7.4 & 8.5 & 30.5 & 32.0 \\
\hline R-BF & 14.2 & 15.5 & 7.32 & 7.89 & 7.3 & 8.5 & 30.5 & 32.0 \\
\hline R-AM & 14.3 & 15.6 & 7.43 & 8.00 & 7.5 & 8.5 & 31.0 & 32.0 \\
\hline C-NE & 14.3 & 15.6 & 7.34 & 8.20 & 7.1 & 8.5 & 30.5 & 32.0 \\
\hline C-SB & 14.2 & 15.6 & 7.42 & 7.89 & 7.2 & 8.4 & 30.5 & 32.0 \\
\hline
\end{tabular}

(a) NA Not applicable. 
TABLE C.4. Ammonia Measurements in Overlying Water for 10-Day M. nasuta/ N. caecoides Solid-Phase, Flow-Through Test, Older Bay Mud Study

Sediment

Ammonia

Treatment

(mg/L)

January 1994

OBM COMP

0.134

0.159

0.372

0.177

R-OS

R-BF

0.149

0.177

0.348

0.143

0.352

0.232

R-AM

0.118

0.300

0.352

0.178

C-NE

0.137

0.127

0.150

0.358

0.364

0.125

C-SB

0.127

0.358

0.361

0.373

0.133

0.144 
APPENDIX D

BIOASSAY RESULTS FOR 28-DAY SOLID-PHASE, FLOW-THROUGH TEST WITH MACOMA nasuta 
TABLED.1. Test Results for 28-Day $M$. nasuta Solid-Phase, Flow-Through Test, Older Bay Mud Study

\begin{tabular}{|c|c|c|c|c|c|c|}
\hline \multirow[b]{2}{*}{$\begin{array}{l}\text { Sediment } \\
\text { Treatment }\end{array}$} & \multirow[b]{2}{*}{ Replicate } & \multicolumn{2}{|c|}{ M. nasuta } & \multirow[b]{2}{*}{$\begin{array}{l}\text { Proportion } \\
\text { Surviving }\end{array}$} & \multirow{2}{*}{$\begin{array}{l}\quad \text { Mean } \\
\text { Proportion } \\
\text { Surviving }\end{array}$} & \multirow[b]{2}{*}{$\begin{array}{l}\text { Standarc } \\
\text { Deviatior }\end{array}$} \\
\hline & & $\operatorname{Live}^{(a)}$ & $\begin{array}{l}\text { Dead or } \\
\text { Missing }\end{array}$ & & & \\
\hline \multicolumn{7}{|l|}{ January 1993} \\
\hline OBM COMP & 1 & 29 & 1 & 0.97 & & \\
\hline OBM COMP & 2 & 30 & 0 & 1.00 & & \\
\hline OBM COMP & 3 & 28 & 2 & 0.93 & & \\
\hline OBM COMP & 4 & 30 & 0 & 1.00 & & \\
\hline OBM COMP & 5 & 29 & 1 & 0.97 & 0.97 & 0.03 \\
\hline C-SB & 1 & 30 & 0 & 1.00 & & \\
\hline C-SB & 2 & 30 & 0 & 1.00 & & \\
\hline C-SB & 3 & 28 & 2 & 0.93 & & \\
\hline C-SB & 4 & 30 & 0 & 1.00 & & \\
\hline C-SB & 5 & 30 & 0 & 1.00 & 0.99 & 0.03 \\
\hline
\end{tabular}

$\underline{\text { January } 1994}$

$\begin{array}{lllllll}\text { OBM COMP } & 1 & 25 & 0 & 1.00 & & \\ \text { OBM COMP } & 2 & 22 & 3 & 0.88 & & \\ \text { OBM COMP } & 3 & 25 & 0 & 1.00 & \\ \text { OBM COMP } & 4 & 22 & 3 & 0.88 & 0.06 \\ \text { OBM COMP } & 5 & 24 & 1 & 0.96 & & \\ \text { R-OS } & 1 & 25 & 0 & 1.00 & & \\ \text { R-OS } & 2 & 23 & 2 & 0.92 & \\ \text { R-OS } & 3 & 22 & 3 & 0.88 & & \\ \text { R-OS } & 4 & 25 & 0 & 1.00 & \\ \text { R-OS } & 5 & 25 & 0 & 1.00 & \\ \text { R-BF } & 1 & 25 & 0 & 1.00 & \\ \text { R-BF } & 2 & 25 & 0 & 1.00 & & \\ \text { R-BF } & 3 & 23 & 2 & 0.92 & & \\ \text { R-BF } & 4 & 22 & 3 & 0.88 & \\ \text { R-BF } & 5 & 23 & 2 & 0.92 & 0.94 \\ \text { R-AM } & & & & & & \\ \text { R-AM } & 1 & 23 & 2 & 0.92 & & \\ \text { R-AM } & 2 & 24 & 1 & 0.96 & & \\ \text { R-AM } & 3 & 23 & 2 & 0.92 & & \\ \text { R-AM } & 4 & 25 & 0 & 1.00 & & \\ & 5 & 23 & 2 & 0.92 & 0.94\end{array}$


TABLED.1. (contd)

\begin{tabular}{|c|c|c|c|c|c|c|}
\hline \multirow[b]{2}{*}{$\begin{array}{l}\text { Sediment } \\
\text { Treatment }\end{array}$} & \multirow[b]{2}{*}{ Replicate } & \multicolumn{2}{|c|}{ M. nasuta } & \multirow[b]{2}{*}{$\begin{array}{l}\text { Proportion } \\
\text { Surviving }\end{array}$} & \multirow{2}{*}{$\begin{array}{l}\text { Mean } \\
\text { Proportion } \\
\text { Surviving }\end{array}$} & \multirow[b]{2}{*}{$\begin{array}{l}\text { Standard } \\
\text { Deviation }\end{array}$} \\
\hline & & Live $^{(a)}$ & $\begin{array}{l}\text { Dead or } \\
\text { Missing }\end{array}$ & & & \\
\hline C-SB & $1^{-}$ & 23 & 2 & 0.92 & & \\
\hline C-SB & 2 & 22 & 3 & 0.88 & & \\
\hline C-SB & 3 & 24 & 1 & 0.96 & & \\
\hline C-SB & 4 & 24 & 1 & 0.96 & & \\
\hline $\mathrm{C}-\mathrm{SB}$ & 5 & 21 & 4 & 0.84 & 0.91 & 0.05 \\
\hline
\end{tabular}

(a) Survival based on initial exposure of 25 organisms per replicate. 
TABLE D.2. Water QuaTity Summary for 28-Day M. nasuta Solid-Phase FlowThrough Test, 01der Bay Mud Study

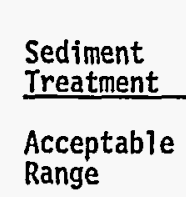

January 1993

OBM COMP

C-SB

January 1994

OBM COMP

R-OS

$R-B F$

R-AM

C-SB

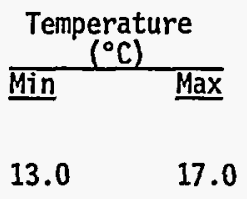

15.1

15.1

$17.3^{(b)}$

$17.2^{\text {(b) }}$

$11.0^{(b)}$

$10.9^{(b)}$

$11.0^{(b)}$

$11.0^{(b)}$

16.4

16.5

16.5

16.5

$10.9^{(b)}$

16.5

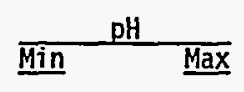

7.30

7.73

7.92

7.62

7.91

8.30

7.56

7.93

7.56

7.53

7.52

7.51

7.93

7.93

7.90

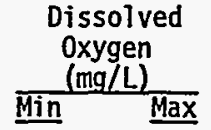

$\geq 6.0 \quad N A^{(a)}$

$7.4 \quad 9.7$

$7.1 \quad 9.2$

$7.4 \quad 8.9$

$7.4 \quad 8.9$

$7.3 \quad 8.8$

$7.4 \quad 8.8$

$\begin{array}{ll}7.3 & 8.8\end{array}$

$\frac{\begin{array}{c}\text { Salinity } \\ (0 / 00)\end{array}}{\text { Min Max }}$

$28.0 \quad 32.0$

$30.0 \quad 31.0$

$30.0 \quad 31.0$

30.0

32.0

(a) NA Not applicable.

(b) Data point out of range.

D. 3 


\section{APPENDIX E}

BIOASSAY RESULTS FOR 48-HOUR SUSPENDED-PARTICULATE-PHASE TEST AND 48-HOUR REFERENCE TOXICANT TEST

FOR MYTILUS galloprovincialis 


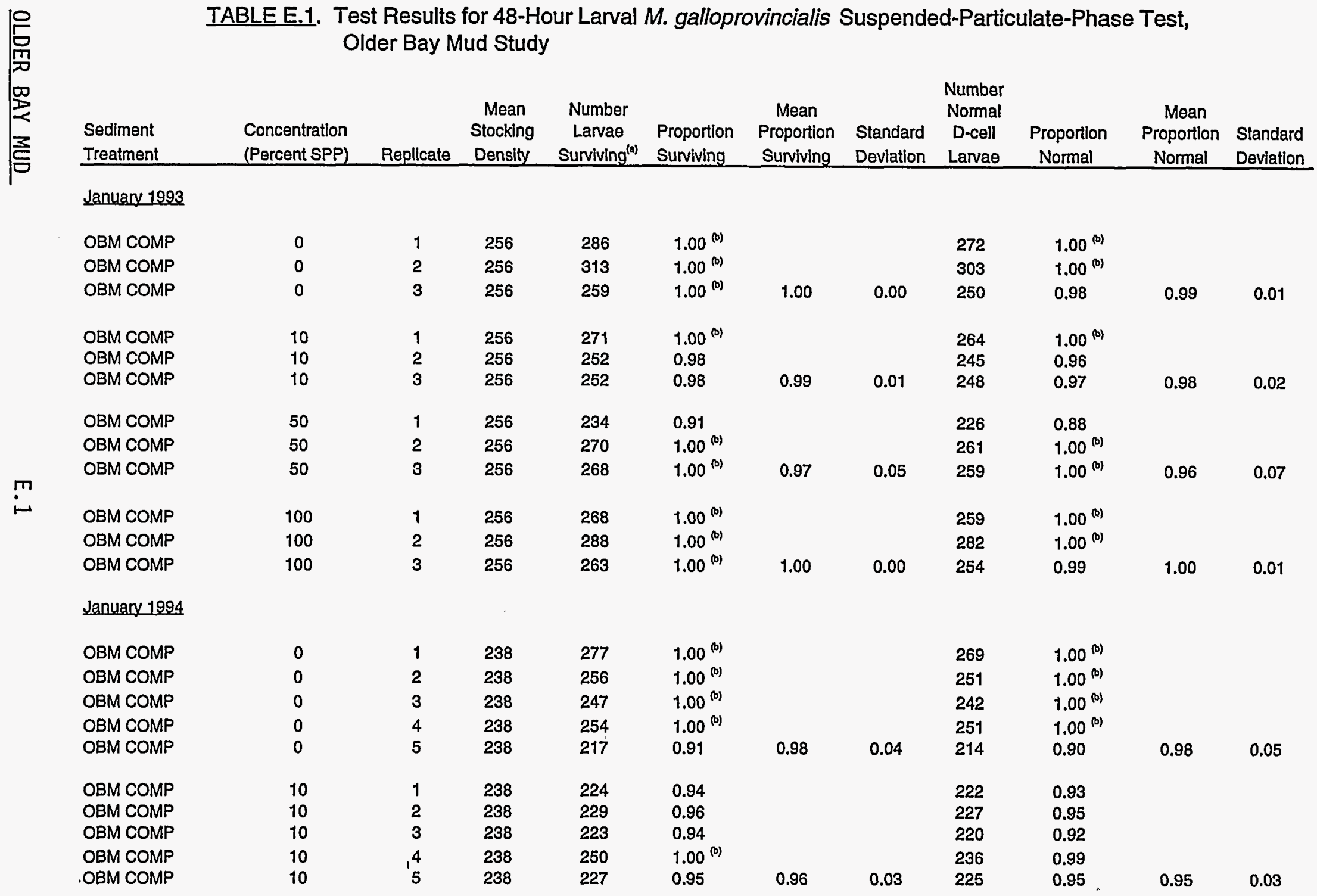




\begin{tabular}{|c|c|c|c|c|c|c|c|c|c|c|c|}
\hline \multirow[b]{2}{*}{$\begin{array}{l}\text { Sediment } \\
\text { Treatment }\end{array}$} & \multicolumn{7}{|c|}{ TABLE E.1. (contd) } & \multirow[b]{2}{*}{$\begin{array}{c}\text { Number } \\
\text { Normal } \\
\text { D-cell } \\
\text { Larvae } \\
\end{array}$} & \multirow[b]{2}{*}{$\begin{array}{c}\text { Proportion } \\
\text { Normal }\end{array}$} & \multirow[b]{2}{*}{$\begin{array}{c}\text { Mean } \\
\text { Proportion } \\
\text { Normal }\end{array}$} & \multirow[b]{2}{*}{$\begin{array}{l}\text { Standard } \\
\text { Devlation }\end{array}$} \\
\hline & $\begin{array}{l}\text { Concentratlon } \\
\text { (Percent SPP) }\end{array}$ & Repllicate & $\begin{array}{c}\text { Mean } \\
\text { Stocking } \\
\text { Density }\end{array}$ & $\begin{array}{c}\text { Number } \\
\text { Larvae } \\
\text { Surviving } \\
\end{array}$ & $\begin{array}{l}\text { Proportion } \\
\text { Surviving }\end{array}$ & $\begin{array}{c}\text { Mean } \\
\text { Proportion } \\
\text { Surviving } \\
\end{array}$ & $\begin{array}{l}\text { Standard } \\
\text { Deviation }\end{array}$ & & & & \\
\hline OBM COMP & 50 & 1 & 238 & 196 & 0.82 & & & 194 & 0.82 & & \\
\hline OBM COMP & 50 & 2 & 238 & 232 & 0.97 & & & 230 & 0.97 & & \\
\hline OBM COMP & 50 & 3 & 238 & 214 & 0.90 & & & 212 & 0.89 & & \\
\hline OBM COMP & 50 & 4 & 238 & 204 & 0.86 & & & 203 & 0.85 & & \\
\hline OBM COMP & 50 & 5 & 238 & 260 & $1.00^{(0)}$ & 0.91 & 0.08 & 253 & $1.00^{(0)}$ & 0.91 & 0.08 \\
\hline OBM COMP & 100 & 1 & 238 & 233 & 0.98 & & & 227 & 0.95 & & \\
\hline OBM COMP & 100 & 2 & 238 & 228 & 0.96 & & & 220 & 0.92 & & \\
\hline OBM COMP & 100 & 3 & 238 & 248 & $1.00^{(0)}$ & & & 239 & 1.00 & & \\
\hline OBM COMP & 100 & 4 & 238 & 244 & $1.00^{(0)}$ & & & 240 & $1.00^{(0)}$ & & \\
\hline OBM COMP & 100 & 5 & 238 & 226 & 0.95 & 0.98 & 0.02 & 221 & 0.93 & 0.96 & 0.04 \\
\hline
\end{tabular}

(a) Sum total of normal D-cell, abnormal D-cell, and developmentally delayed larvae.

(b) When number normal or number surviving exceeded the stocking density, a proportion normal and/or proportion survival of 1.00 was used for mean calculation and statlstical analysis. 


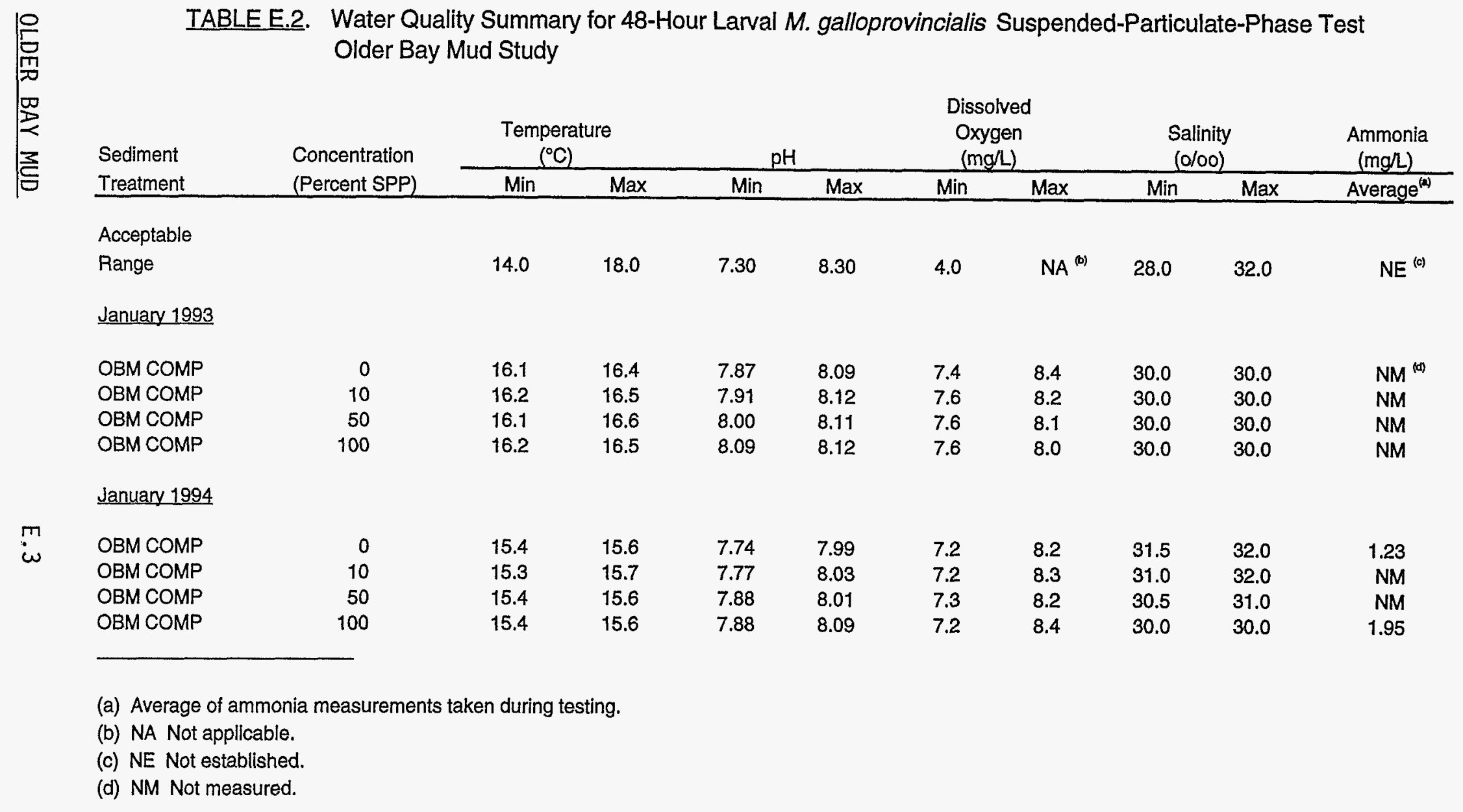


TABLEE.3. Test Results for 48-Hour Larval M. galloprovincialis Copper Reference Toxicant Test, Older Bay Mud Study

\begin{tabular}{|c|c|c|c|c|c|c|c|c|c|c|}
\hline Copper & & Mean & Number & & Mean & & $\begin{array}{l}\text { Number } \\
\text { Normal }\end{array}$ & & Mean & \\
\hline $\begin{array}{c}\text { Concentration } \\
(\mu \mathrm{g} / \mathrm{L})\end{array}$ & Replicate & $\begin{array}{l}\text { Stocking } \\
\text { Density }\end{array}$ & $\begin{array}{c}\text { Larvae } \\
\text { Surviving } \\
\end{array}$ & $\begin{array}{l}\text { Proportion } \\
\text { Surviving }\end{array}$ & $\begin{array}{l}\text { Proportion } \\
\text { Surviving }\end{array}$ & $\begin{array}{l}\text { Standard } \\
\text { Deviation }\end{array}$ & $\begin{array}{l}\text { D-cell } \\
\text { Larvae }\end{array}$ & $\begin{array}{l}\text { Proportion } \\
\text { Normal }\end{array}$ & $\begin{array}{l}\text { Proportion } \\
\text { Normal }\end{array}$ & $\begin{array}{l}\text { Standard } \\
\text { Deviation }\end{array}$ \\
\hline
\end{tabular}

Januerv 1993

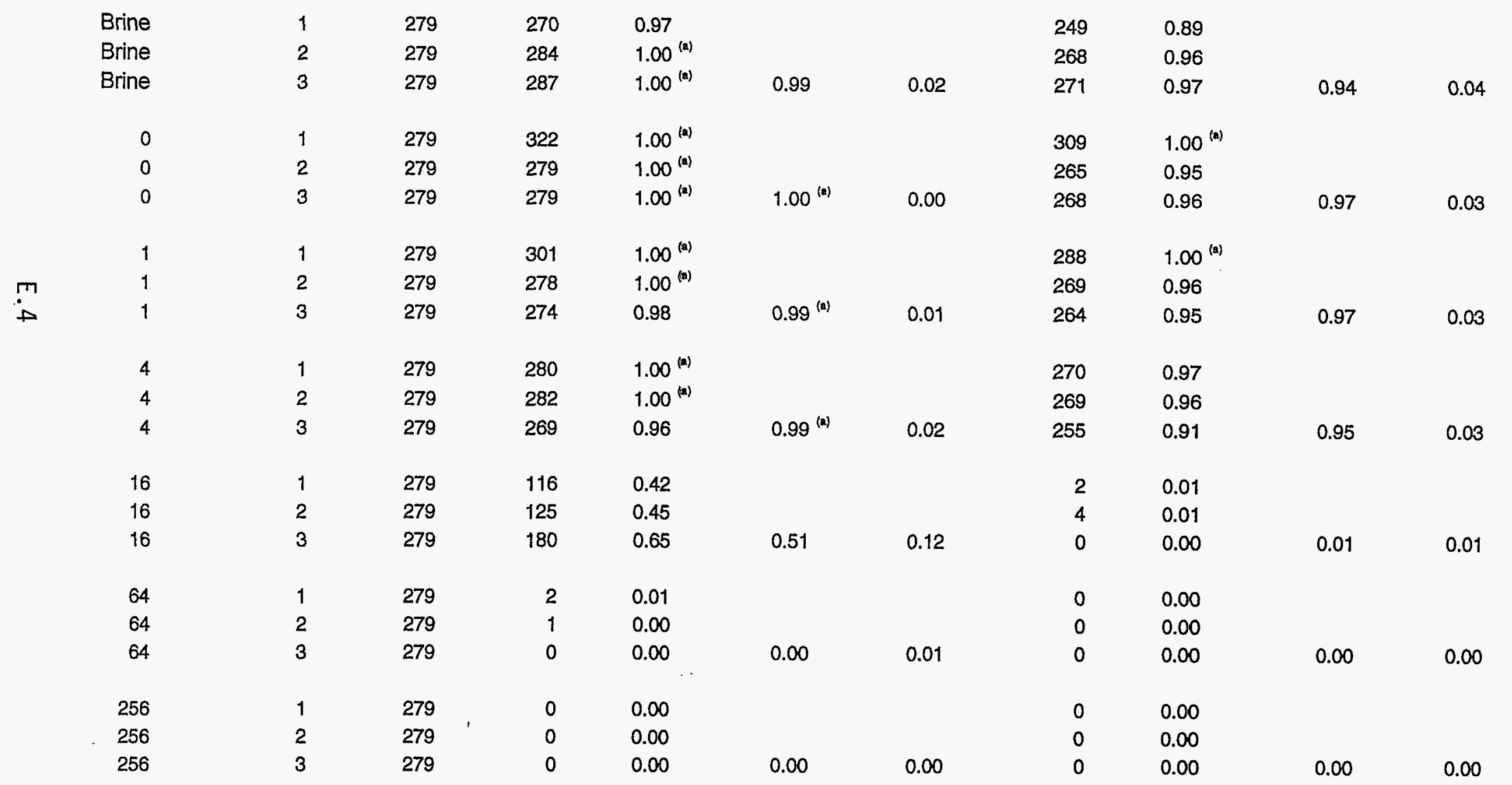


TABLEE.3. (contd)

\begin{tabular}{|c|c|c|c|c|c|c|c|c|c|c|}
\hline $\begin{array}{c}\text { Copper } \\
\text { Concentration } \\
(\mu g /)\end{array}$ & Replicate & $\begin{array}{l}\text { Mean } \\
\text { Stocking } \\
\text { Density }\end{array}$ & $\begin{array}{c}\text { Number } \\
\text { Larvae } \\
\text { Surviving }\end{array}$ & $\begin{array}{l}\text { Proportion } \\
\text { Surviving }\end{array}$ & $\begin{array}{c}\text { Mean } \\
\text { Proportion } \\
\text { Surviving } \\
\end{array}$ & $\begin{array}{l}\text { Standard } \\
\text { Deviation } \\
\end{array}$ & $\begin{array}{l}\text { Number } \\
\text { Normal } \\
\text { D-cell } \\
\text { Larvae } \\
\end{array}$ & $\begin{array}{c}\text { Proportion } \\
\text { Normal }\end{array}$ & $\begin{array}{c}\text { Mean } \\
\text { Proportion } \\
\text { Normal } \\
\end{array}$ & $\begin{array}{l}\text { Standard } \\
\text { Deviation }\end{array}$ \\
\hline \multicolumn{11}{|l|}{ January 1994} \\
\hline Site water & 1 & 238 & 269 & $1.00^{\text {(a) }}$ & & & 266 & $1.00^{(1)}$ & & \\
\hline Site water & 2 & 238 & 287 & $1.00^{\text {(a) }}$ & & & 283 & $1.00^{(9)}$ & & \\
\hline Site water & 3 & 238 & 285 & $1.00^{(a)}$ & 1.00 & 0.00 & 279 & 1.00 & 1.00 & 0.00 \\
\hline Brine & 1 & 238 & 303 & $1.00^{\text {(a) }}$ & & & 297 & $1.00^{(4)}$ & & \\
\hline Brine & 2 & 238 & 235 & 0.99 & & & 231 & 0.97 & & \\
\hline Brine & 3 & 238 & 263 & $1.00^{(a)}$ & 1.00 & 0.01 & 259 & 1.00 & 0.99 & 0.02 \\
\hline 0.00 & 1 & 238 & 238 & 1.00 & & & 232 & 0.97 & & \\
\hline 0.00 & 2 & 238 & 242 & $1.00^{\text {(a) }}$ & & & 241 & $1.00^{(m)}$ & & \\
\hline 0.00 & 3 & 238 & 280 & $1.00^{(n)}$ & 1.00 & 0.00 & 277 & $1.00^{(6)}$ & 0.99 & 0.01 \\
\hline 1.00 & 1 & 238 & 244 & $1.00^{(2)}$ & & & 240 & $1.00^{(n)}$ & & \\
\hline 1.00 & 2 & 238 & 321 & $1.00^{\text {(a) }}$ & & & 318 & $1.00^{(a)}$ & & \\
\hline 1.00 & 3 & 238 & 272 & $1.00^{(4)}$ & 1.00 & 0.00 & 271 & $1.00^{(0)}$ & 1.00 & 0.00 \\
\hline 4.00 & 1 & 238 & 241 & $1.00^{(a)}$ & & & 236 & 0.99 & & \\
\hline 4.00 & 2 & 238 & 268 & $1.00^{\text {(a) }}$ & & & 265 & $1.00^{(2)}$ & & \\
\hline 4.00 & 3 & 238 & 257 & $1.00^{(a)}$ & 1.00 & 0.00 & 247 & $1.00^{(a)}$ & 1.00 & 0.00 \\
\hline 16.0 & 1 & 238 & 88 & 0.37 & & & 0 & 0.00 & & \\
\hline 16.0 & 2 & 238 & 69 & 0.29 & & & 0 & 0.00 & & \\
\hline 16.0 & 3 & 238 & 54 & 0.23 & 0.30 & 0.07 & 0 & 0.00 & 0.00 & 0.00 \\
\hline 64.0 & 1 & 238 & 6 & 0.03 & & & 0 & 0.00 & & \\
\hline 64.0 & 2 & 238 & 12 & 0.05 & & & 0 & 0.00 & & \\
\hline 64.0 & 3 & 238 & 15 & 0.06 & 0.05 & 0.02 & 0 & 0.00 & 0.00 & 0.00 \\
\hline
\end{tabular}

(a) When number normal or number surviving exeeded the stocking density, a proportion normal and/or proportion surviving of 1.00 was used for mean calculations and statistical analysis. 
TABLE E.4. Water Quality Summary for 48-Hour M. galloprovincial is Reference Toxicant Test, OIder Bay Mud Study

\begin{tabular}{|c|c|c|c|c|c|c|c|c|}
\hline \multirow{2}{*}{$\begin{array}{c}\text { Copper } \\
\text { Concentration } \\
(\mu \mathrm{g} / \mathrm{L}) \\
\end{array}$} & \multicolumn{2}{|c|}{$\begin{array}{c}\text { Temperature } \\
\left({ }^{\circ} \mathrm{C}\right)\end{array}$} & \multicolumn{2}{|c|}{$\mathrm{pH}$} & \multicolumn{2}{|c|}{$\begin{array}{l}\text { Dissolved } \\
\text { Oxygen } \\
(\mathrm{mg} / \mathrm{L}) \\
\end{array}$} & \multicolumn{2}{|c|}{$\begin{array}{l}\text { Salinity } \\
(0 / 00)\end{array}$} \\
\hline & Min & $\underline{\operatorname{Max}}$ & Min & $\underline{\operatorname{Max}}$ & Min & Max & Min & $\underline{\operatorname{Max}}$ \\
\hline $\begin{array}{l}\text { Acceptable } \\
\text { Range }\end{array}$ & 14.0 & 18.0 & 7.30 & 8.30 & $\geq 4.0$ & $N A^{(u)}$ & 28.0 & 32.0 \\
\hline \multicolumn{9}{|l|}{ January 1993} \\
\hline Brine & 16.2 & 16.5 & 7.53 & 8.08 & 6.4 & 8.0 & 30.0 & 30.5 \\
\hline 0 & 16.2 & 16.5 & 7.83 & 8.13 & 7.6 & 8.4 & 30.0 & 30.0 \\
\hline 1 & 16.2 & 16.5 & 7.87 & 8.12 & 7.5 & 8.5 & 30.0 & 30.0 \\
\hline 4 & 16.2 & 16.5 & 7.89 & 8.13 & 7.5 & 8.2 & 30.0 & 30.0 \\
\hline 16 & 16.2 & 16.6 & 7.88 & 8.14 & 7.4 & 8.5 & 30.0 & 30.0 \\
\hline 64 & 16.2 & 16.5 & 7.87 & 8.12 & 7.4 & 8.4 & 30.0 & 30.0 \\
\hline 256 & 16.2 & 16.6 & 7.87 & 8.11 & 7.4 & 8.3 & 30.0 & 30.0 \\
\hline \multicolumn{9}{|l|}{ January 1994} \\
\hline Site water & 15.4 & 15.5 & 7.75 & 7.83 & 7.2 & 7.9 & 30.0 & 30.0 \\
\hline Brine & 15.4 & 15.7 & 7.75 & 7.79 & 6.9 & 7.5 & 30.0 & 31.5 \\
\hline 0 & 15.4 & 15.5 & 7.72 & 7.89 & 6.9 & 7.5 & 31.5 & 32.0 \\
\hline 1 & 15.4 & 15.5 & 7.72 & 7.94 & 7.0 & 7.6 & 31.5 & 32.0 \\
\hline 4 & 15.4 & 15.5 & 7.71 & 7.95 & 7.1 & 7.6 & 31.5 & 32.0 \\
\hline 16 & 15.4 & 15.5 & 7.71 & 7.96 & 7.0 & 7.5 & 31.5 & 32.0 \\
\hline 64 & 15.4 & 15.5 & 7.70 & 7.97 & 7.0 & 7.5 & 31.5 & 32.0 \\
\hline
\end{tabular}

(a) NA Not applicable. 
TABLE E.5. Test Results for 48-Hour Larval M. galloprovincialis Ammonia Reference Toxicant Test, Older Bay Mud Study

\begin{tabular}{|c|c|c|c|c|c|c|c|c|c|c|}
\hline $\begin{array}{c}\text { Ammonia } \\
\text { Concentration } \\
\text { (mg/L) }\end{array}$ & Replicate & $\begin{array}{l}\text { Mean } \\
\text { Stocking } \\
\text { Density }\end{array}$ & $\begin{array}{c}\text { Number } \\
\text { Larvae } \\
\text { Surviving }\end{array}$ & $\begin{array}{l}\text { Proportion } \\
\text { Surviving }\end{array}$ & $\begin{array}{l}\text { Mean } \\
\text { Proportion } \\
\text { Surviving } \\
\end{array}$ & $\begin{array}{l}\text { Standard } \\
\text { Deviation }\end{array}$ & $\begin{array}{l}\text { Number } \\
\text { Normal } \\
\text { D-cell } \\
\text { Larvae } \\
\end{array}$ & $\begin{array}{c}\text { Proportion } \\
\text { Normal }\end{array}$ & $\begin{array}{c}\text { Mean } \\
\text { Proportion } \\
\text { Normal } \\
\end{array}$ & $\begin{array}{l}\text { Standard } \\
\text { Deviation }\end{array}$ \\
\hline \multicolumn{11}{|l|}{ January 1994} \\
\hline Site water & 1 & 238 & 269 & $1.00^{(4)}$ & & & 266 & $1.00^{(4)}$ & & \\
\hline Site water & 2 & 238 & 287 & $1.00^{(0)}$ & & & 283 & $1.00^{(a)}$ & & \\
\hline Site water & 3 & 238 & 285 & $1.00^{(a)}$ & 1.00 & 0.00 & 279 & $1.00^{(a)}$ & 1.00 & 0.00 \\
\hline brine & 1 & 238 & 303 & $1.00^{(a)}$ & & & 297 & $1.00^{(a)}$ & & \\
\hline brine & 2 & 238 & 235 & 0.99 & & & 231 & 0.97 & & \\
\hline brine & 3 & 238 & 263 & $1.00^{(n)}$ & 1.00 & 0.01 & 259 & $1.00^{(n)}$ & 0.99 & 0.02 \\
\hline 0.0 & 1 & 238 & 238 & 1.00 & & & 232 & 0.97 & & \\
\hline 0.0 & 2 & 238 & 242 & $1.00^{(4)}$ & & & 241 & $1.00^{(a)}$ & & \\
\hline 0.0 & 3 & 238 & 280 & $1.00^{(a)}$ & 1.00 & 0.00 & 277 & $1.00^{(8)}$ & 0.99 & 0.01 \\
\hline 1.05 & 1 & 238 & 251 & $1.00^{(0)}$ & & & 246 & $1.00^{(4)}$ & & \\
\hline 1.05 & 2 & 238 & 282 & $1.00^{(a)}$ & & & 280 & $1.00^{(4)}$ & & \\
\hline 1.05 & 3 & 238 & 224 & 0.94 & 0.98 & 0.03 & 220 & 0.92 & 0.97 & 0.04 \\
\hline 7.48 & 1 & 238 & 253 & $1.00^{(a)}$ & & & 1 & 0.00 & & \\
\hline 7.48 & 2 & 238 & 211 & 0.89 & & & 0 & 0.00 & & \\
\hline 7.48 & 3 & 238 & 255 & $1.00^{(0)}$ & 0.96 & 0.07 & 0 & 0.00 & 0.00 & 0.00 \\
\hline 16.64 & 1 & 238 & 296 & $1.00^{(4)}$ & & & 0 & 0.00 & & \\
\hline 16.64 & 2 & 238 & 251 & $1.00^{(a)}$ & & & 0 & 0.00 & & \\
\hline 16.64 & 3 & 238 & 264 & $1.00^{(a)}$ & 1.00 & 0.00 & 0 & 0.00 & 0.00 & 0.00 \\
\hline 60.56 & 1 & 238 & 87 & 0.37 & & & 0 & 0.00 & & \\
\hline 60.56 & 2 & 238 & 113 & 0.47 & & & 0 & 0.00 & & \\
\hline 60.56 & 3 & 238 & 46 & 0.19 & 0.34 & 0.14 & 0 & 0.00 & 0.00 & 0.00 \\
\hline 105.4 & 1 & 238 & 9 & 0.04 & & & 0 & 0.00 & & \\
\hline 105.4 & 2 & 238 & 0 & 0.00 & & & 0 & 0.00 & & \\
\hline 105.4 & 3 & 238 & 0 & 0.00 & 0.01 & 0.02 & 0 & 0.00 & 0.00 & 0.00 \\
\hline
\end{tabular}

(a) When number normal or number surviving exeeded the stocking density, a proportion normal and/or proportion surviving of 1.00 was used for mean calculations and statistical analysis. 
TABLE E.6. Water Quality Summary for 48-Hour Larval M. galloprovincialis Ammonia Toxicant Test, Older Bay Mud Study

\begin{tabular}{|c|c|c|c|c|c|c|c|c|c|c|}
\hline \multirow{2}{*}{$\begin{array}{c}\text { Ammonia } \\
\text { Concentration } \\
\text { (mg/L) }\end{array}$} & \multicolumn{2}{|c|}{$\begin{array}{c}\text { Temperature } \\
\left({ }^{\circ} \mathrm{C}\right)\end{array}$} & \multicolumn{2}{|c|}{$\mathrm{pH}$} & \multicolumn{2}{|c|}{$\begin{array}{l}\text { Dissolved } \\
\text { Oxygen } \\
\text { (mg/L) }\end{array}$} & \multicolumn{2}{|c|}{$\begin{array}{l}\text { Salinity } \\
(0 / 00)\end{array}$} & \multicolumn{2}{|c|}{$\begin{array}{c}\text { Ammonia } \\
(\mathrm{mg} / \mathrm{L})\end{array}$} \\
\hline & Min & $\operatorname{Max}$ & Min & Max & Min & Max & Min & $\operatorname{Max}$ & Min & $\operatorname{Max}$ \\
\hline \multicolumn{11}{|l|}{ Acceptable } \\
\hline Range & 14.0 & 18.0 & 7.30 & 8.30 & 4.0 & $N A^{(a)}$ & 28.0 & 32.0 & $N E^{(b)}$ & NE \\
\hline \multicolumn{11}{|l|}{ January 1994} \\
\hline Site water & 15.4 & 15.5 & 7.75 & 7.83 & 7.2 & 7.9 & 30.0 & 30.0 & $N M^{(c)}$ & NM \\
\hline Brine & 15.4 & 15.8 & 7.83 & 7.97 & 6.9 & 7.9 & 30.0 & 32.0 & NM & NM \\
\hline 0.0 & 15.5 & 15.8 & 7.70 & 7.86 & 6.8 & 7.9 & 31.0 & 32.0 & NM & NM \\
\hline 1.05 & 15.4 & 15.5 & 7.68 & 7.84 & 7.2 & 8.0 & 31.5 & 32.0 & 0.80 & 1.90 \\
\hline 7.48 & 15.4 & 15.4 & 7.64 & 7.85 & 7.2 & 8.0 & 31.0 & 32.0 & 6.6 & 9.7 \\
\hline 16.64 & 15.3 & 15.5 & 7.65 & 7.86 & 7.2 & 7.9 & 30.0 & 31.0 & 14 & 21 \\
\hline 60.56 & 15.4 & 15.5 & 7.57 & 7.85 & 7.2 & 8.0 & 28.5 & 30.0 & 46 & 81 \\
\hline 105.4 & 15.4 & 15.5 & 7.48 & 7.78 & 7.2 & 8.0 & 28.0 & 28.0 & $89^{\circ}$ & 123 \\
\hline
\end{tabular}
(a) NA Not applicable.
(b) NE Not established.
(c) NM Not measured. 


\section{APPENDIX F}

BIOASSAY RESULTS FOR 96-HOUR SUSPENDED-PARTICULATE-PHASE TEST AND 96-HOUR REFERENCE TOXICANT TEST FOR CITHARICHTHYS stigmaeus 
TABLE F.1. Test Results for 96-Hour C. stigmaeus Suspended-Particulate-Phase Test, Older Bay Mud Study

\begin{tabular}{|c|c|c|c|c|c|c|c|}
\hline \multirow[b]{2}{*}{$\begin{array}{l}\text { Sediment } \\
\text { Treatment }\end{array}$} & \multirow[b]{2}{*}{$\begin{array}{l}\text { Concentration } \\
\text { (Percent SPP) }\end{array}$} & \multirow[b]{2}{*}{ Replicate } & \multicolumn{2}{|c|}{ C. stigmaeus } & \multirow[b]{2}{*}{$\begin{array}{c}\text { Proportion } \\
\text { Surviving }\end{array}$} & \multirow{2}{*}{$\begin{array}{c}\text { Mean } \\
\text { Proportion } \\
\text { Surviving }\end{array}$} & \multirow[b]{2}{*}{$\begin{array}{l}\text { Standard } \\
\text { Deviation }\end{array}$} \\
\hline & & & Live $^{(a)}$ & $\begin{array}{l}\text { Dead or } \\
\text { Missing }\end{array}$ & & & \\
\hline \multicolumn{8}{|l|}{ January 1994} \\
\hline OBM COMP & 0 & 1 & 10 & 0 & 1.00 & & \\
\hline OBM COMP & 0 & 2 & 10 & 0 & 1.00 & & \\
\hline OBM COMP & 0 & 3 & 10 & 0 & 1.00 & & \\
\hline OBM COMP & 0 & 4 & 10 & 0 & 1.00 & & \\
\hline OBM COMP & 0 & 5 & 10 & 0 & 1.00 & 1.00 & 0.00 \\
\hline OBM COMP & 10 & 1 & 10 & 0 & 1.00 & & \\
\hline OBM COMP & 10 & 2 & 10 & 0 & 1.00 & & \\
\hline OBM COMP & 10 & 3 & 10 & 0 & 1.00 & & \\
\hline OBM COMP & 10 & 4 & 10 & 0 & 1.00 & & \\
\hline OBM COMP & 10 & 5 & 10 & 0 & 1.00 & 1.00 & 0.00 \\
\hline OBM COMP & 50 & 1 & 10 & 0 & 1.00 & & \\
\hline OBM COMP & 50 & 2 & 10 & 0 & 1.00 & & \\
\hline OBM COMP & 50 & 3 & 10 & 0 & 1.00 & & \\
\hline OBM COMP & 50 & 4 & 9 & 1 & 0.90 & & \\
\hline OBM COMP & 50 & 5 & 10 & 0 & 1.00 & 0.98 & 0.04 \\
\hline OBM COMP & 100 & 1 & 10 & 0 & 1.00 & & \\
\hline OBM COMP & 100 & 2 & 10 & 0 & 1.00 & & \\
\hline OBM COMP & 100 & 3 & 10 & 0 & 1.00 & & \\
\hline OBM COMP & 100 & 4 & 10 & 0 & 1.00 & & \\
\hline OBM COMP & 100 & 5 & 10 & 0 & 1.00 & 1.00 & 0.00 \\
\hline
\end{tabular}

(a) Survival based on initial exposure of 10 organisms per replicate. 
TABLE F.2. Summary of Mean Proportion Surviving 96-Hour C. stigmaeus Suspended-Particulate-Phase Test, Older Bay Mud Study

Sediment

Treatment

$\underline{\text { January } 1994}$

OBM COMP

OBM COMP

OBM COMP

OBM COMP
Mean

Concentration . Proportion

(Percent SPP) - Surviving
0

10

50

100
1.00

1.00

0.98

1.00 
IABLE F.3. Water Quality Summary for 96-Hour C. stigmaeus Suspended-ParticulatePhase Test, Older Bay Mud Study

\begin{tabular}{|c|c|c|c|c|c|c|c|c|c|c|}
\hline \multirow{2}{*}{$\begin{array}{l}\text { Sediment } \\
\text { Treatment }\end{array}$} & \multirow{2}{*}{$\begin{array}{l}\text { Concentration } \\
\text { (Percent SPP) }\end{array}$} & \multicolumn{2}{|c|}{$\begin{array}{c}\text { Temperature } \\
\left({ }^{\circ} \mathrm{C}\right)\end{array}$} & \multicolumn{2}{|c|}{$\mathrm{pH}$} & \multicolumn{2}{|c|}{$\begin{array}{c}\text { Dissolved } \\
\text { Oxygen } \\
\text { (mg/L) }\end{array}$} & \multicolumn{2}{|c|}{$\begin{array}{l}\text { Salinity } \\
(0 / 00)\end{array}$} & \multirow{2}{*}{$\begin{array}{l}\text { Ammonia } \\
\text { (mg/L) } \\
\text { Average }^{(\mathrm{a})}\end{array}$} \\
\hline & & Min & Max & Min & $\operatorname{Max}$ & Min & Max & Min & Max & \\
\hline \multicolumn{11}{|l|}{ Acceptable } \\
\hline Range & & 13.0 & 17.0 & 7.30 & 8.30 & 6.0 & $N A^{(p)}$ & 28.0 & 32.0 & $N E^{(c)}$ \\
\hline \multicolumn{11}{|l|}{ January 1994} \\
\hline OBM COMP & 0 & 13.9 & 14.9 & 7.68 & 7.96 & 7.8 & 8.6 & 31.0 & 31.5 & $N M^{(n)}$ \\
\hline OBM COMP & 10 & 13.9 & 14.8 & 7.73 & 7.98 & 7.9 & 8.6 & 30.0 & 31.5 & NM \\
\hline OBM COMP & 50 & 14.3 & 14.8 & 7.78 & 7.99 & 7.7 & 8.6 & 30.0 & 31.0 & NM \\
\hline OBM COMP & 100 & 14.5 & 15.1 & 7.81 & 8.07 & 7.7 & 8.7 & 29.5 & 30.0 & 1.00 \\
\hline
\end{tabular}
(a) Average of Day 4 measurements.
(b) NA Not applicable.
(c) NE Not established.
(d) NM Not measured. 
TABLE F.4. Test Results for 96-Hour C. stigmaeus Copper Reference Toxicant Test, Older Bay Mud Study

\begin{tabular}{|c|c|c|c|c|c|c|}
\hline \multirow{2}{*}{$\begin{array}{c}\text { Copper } \\
\text { Concentration } \\
\text { (mg/L) }\end{array}$} & \multirow[b]{2}{*}{ Replicate } & \multicolumn{2}{|c|}{ C. stigmaeus } & \multirow[b]{2}{*}{$\begin{array}{l}\text { Proportion } \\
\text { Surviving }\end{array}$} & \multirow{2}{*}{$\begin{array}{c}\text { Mean } \\
\text { Proportion } \\
\text { Survival } \\
\end{array}$} & \multirow[b]{2}{*}{$\begin{array}{l}\text { Standard } \\
\text { Deviation }\end{array}$} \\
\hline & & Live $^{(a)}$ & $\begin{array}{l}\text { Dead or } \\
\text { Missing. }\end{array}$ & & & \\
\hline January 1994 & & & & & & \\
\hline 0.00 & 1 & 10 & 0 & 1.00 & & \\
\hline 0.00 & 2 & 10 & 0 & 1.00 & & \\
\hline 0.00 & 3 & 10 & 0 & 1.00 & 1.00 & 0.00 \\
\hline 0.50 & 1 & 10 & 0 & 1.00 & & \\
\hline 0.50 & 2 & 10 & 0 & 1.00 & & \\
\hline 0.50 & 3 & 9 & 1 & 0.90 & 0.97 & 0.06 \\
\hline 1.00 & 1 & 0 & 10 & 0.00 & & \\
\hline 1.00 & 2 & 1 & 9 & 0.10 & & \\
\hline 1.00 & 3 & 10 & 0 & 1.00 & 0.37 & 0.55 \\
\hline 1.50 & 1 & 0 & 10 & 0.00 & & \\
\hline 1.50 & 2 & 0 & 10 & 0.00 & & \\
\hline 1.50 & 3 & 4 & 6 & 0.40 & 0.13 & 0.23 \\
\hline 2.00 & 1 & 0 & 10 & 0.00 & & \\
\hline 2.00 & 2 & 1 & 9 & 0.10 & & \\
\hline 2.00 & 3 & 0 & 10 & 0.00 & 0.03 & 0.06 \\
\hline
\end{tabular}

(a) Survival based on initial exposure of 10 organisms per replicate. 
TABLEF.5. Water Quality Summary for 96-Hour C. stigmaeus Copper Reference Toxicant Test, Older Bay Mud Study

\begin{tabular}{|c|c|c|c|c|c|c|c|c|}
\hline \multirow{2}{*}{$\begin{array}{c}\text { Copper } \\
\text { Concentration } \\
\text { (mg/L) }\end{array}$} & \multicolumn{2}{|c|}{$\begin{array}{c}\text { Temperature } \\
\left({ }^{\circ} \mathrm{C}\right)\end{array}$} & \multicolumn{2}{|c|}{$\mathrm{pH}$} & \multicolumn{2}{|c|}{$\begin{array}{c}\text { Dissolved } \\
\text { Oxygen } \\
\text { (mg/L) }\end{array}$} & \multicolumn{2}{|c|}{$\begin{array}{l}\text { Salinity } \\
(\mathrm{o} / 00)\end{array}$} \\
\hline & Min & Max & Min & $\operatorname{Max}$ & Min & Max & Min & $\operatorname{Max}$ \\
\hline \multicolumn{9}{|l|}{ Acceptable } \\
\hline Range & 13.0 & 17.0 & 7.30 & 8.30 & 6.0 & $N A^{(a)}$ & 28.0 & 32.0 \\
\hline \multicolumn{9}{|l|}{ January 1994} \\
\hline 0.00 & 14.2 & 15.4 & 7.72 & 7.90 & 7.7 & 8.4 & 30.5 & 32.0 \\
\hline 0.50 & 14.0 & 15.0 & 7.78 & 7.93 & 8.1 & 8.5 & 30.5 & 31.5 \\
\hline 1.00 & 14.0 & 15.4 & 7.68 & 7.95 & 8.0 & 8.4 & 30.5 & 32.0 \\
\hline 1.50 & 14.1 & 15.3 & 7.67 & 7.96 & 8.2 & 8.5 & 30.5 & 31.5 \\
\hline 2.00 & 14.1 & 15.4 & 7.63 & 7.91 & 8.0 & 8.4 & 30.5 & 32.0 \\
\hline
\end{tabular}

(a) NA Not applicable. 
TABLEF.6. Test Results for 96-Hour C. stigmaeus Ammonia Reference Toxicant Test, Older Bay Mud Study

\begin{tabular}{|c|c|c|c|c|c|c|}
\hline \multirow{2}{*}{$\begin{array}{c}\text { Ammonia } \\
\text { Concentration } \\
(\mathrm{mg} / \mathrm{L}) \\
\end{array}$} & \multirow[b]{2}{*}{ Replicate } & \multicolumn{2}{|c|}{ C. stigmaeus } & \multirow[b]{2}{*}{$\begin{array}{c}\text { Proportion } \\
\text { Surviving } \\
\end{array}$} & \multirow{2}{*}{$\begin{array}{c}\text { Mean } \\
\text { Proportion } \\
\text { Survival } \\
\end{array}$} & \multirow[b]{2}{*}{$\begin{array}{l}\text { Standard } \\
\text { Deviation }\end{array}$} \\
\hline & & Live $^{(a)}$ & $\begin{array}{l}\text { Dead or } \\
\text { Missing }\end{array}$ & & & \\
\hline \multicolumn{7}{|l|}{ January 1994} \\
\hline 0.350 & 1 & 10 & 0 & 1.00 & & \\
\hline 0.350 & 2 & 10 & 0 & 1.00 & & \\
\hline 0.350 & 3 & 10 & 0 & 1.00 & 1.00 & 0.00 \\
\hline 12.9 & 1 & 10 & 0 & 1.00 & & \\
\hline 12.9 & 2 & 10 & 0 & 1.00 & & \\
\hline 12.9 & 3 & 10 & 0 & 1.00 & 1.00 & 0.00 \\
\hline 17.1 & 1 & 10 & 0 & 1.00 & & \\
\hline 17.1 & 2 & 10 & 0 & 1.00 & & \\
\hline 17.1 & 3 & 10 & 0 & 1.00 & 1.00 & 0.00 \\
\hline 21.7 & 1 & 9 & 1 & 0.90 & & \\
\hline 21.7 & 2 & 7 & 3 & 0.70 & & \\
\hline 21.7 & 3 & 8 & 2 & 0.80 & 0.80 & 0.10 \\
\hline 25.8 & 1 & 2 & 8 & 0.20 & & \\
\hline 25.8 & 2 & 1 & 9 & 0.10 & & \\
\hline 25.8 & 3 & 5 & 5 & 0.50 & 0.27 & 0.21 \\
\hline
\end{tabular}

(a) Survival based on initial exposure of 10 organisms per replicate. 
TABLE F.7. Water Quality Summary for 96-Hour C. stigmaeus Ammonia Reference Toxicant Test, Older Bay Mud Study

\begin{tabular}{|c|c|c|c|c|c|c|c|c|c|c|}
\hline \multirow{2}{*}{$\begin{array}{l}\text { Ammonia } \\
\text { Concentration } \\
(\mathrm{mg} / \mathrm{L})\end{array}$} & \multicolumn{2}{|c|}{$\begin{array}{l}\text { Temperature } \\
\left({ }^{\circ} \mathrm{C}\right)\end{array}$} & \multicolumn{2}{|c|}{$\mathrm{pH}$} & \multicolumn{2}{|c|}{$\begin{array}{c}\text { Dissolved } \\
\text { Oxygen } \\
\text { (mg/L) }\end{array}$} & \multicolumn{2}{|c|}{$\begin{array}{c}\text { Salinity } \\
(0 / 00)\end{array}$} & \multicolumn{2}{|c|}{$\begin{array}{c}\text { Ammonia } \\
\text { (mg/L) }\end{array}$} \\
\hline & Min & $\operatorname{Max}$ & Min & $\operatorname{Max}$ & Min & Max & Min & Max & Min & Max \\
\hline \multicolumn{11}{|l|}{ Acceptable } \\
\hline Range & 13.0 & 17.0 & 7.30 & 8.30 & 6.0 & $N A^{(a)}$ & 28.0 & 32.0 & $N E^{(0)}$ & NE \\
\hline \multicolumn{11}{|l|}{ January 1994} \\
\hline 0.350 & 14.1 & 14.7 & 7.68 & 7.93 & 7.8 & 8.3 & 31.0 & 32.0 & 0.234 & 0.548 \\
\hline 12.9 & 14.0 & 14.4 & 7.70 & 7.88 & 8.0 & 8.4 & 31.0 & 32.0 & 11.2 & 17.5 \\
\hline 17.1 & 14.1 & 14.3 & 7.78 & 7.89 & 8.0 & 8.4 & 31.0 & 32.0 & 14.6 & 20.8 \\
\hline 21.7 & 14.1 & 14.3 & 7.77 & 7.92 & 7.9 & 8.4 & 31.0 & 31.5 & 18.4 & 24.5 \\
\hline 25.8 & 14.1 & 14.6 & 7.82 & 7.95 & 7.8 & 8.4 & 31.5 & 32.0 & 21.3 & 28.5 \\
\hline
\end{tabular}

(a) NA Not applicable.

(b) NE Not established. 


\section{APPENDIX G}

BIOASSAY RESULTS FOR 96-HOUR SUSPENDED-PARTICULATE-PHASE TEST AND 96-HOUR REFERENCE TOXICANT TEST FOR HOLMESIMYSIS costata 


\section{TABLE G.1. Test Results for 96-Hour H. costata Suspended-Particulate-Phase}

Test, 01der Bay Mud Study

Sediment Treatment

January 1993

OBM COMP

OBM COMP

OBM COMP

OBM COMP

OBM COMP

OBM COMP

OBM COMP

OBM COMP

OBM COMP

OBM COMP

OBM COMP

OBM COMP

January 1994

OBM COMP

OBM COMP

OBM COMP

OBM COMP

OBM COMP

OBM COMP

OBM COMP

OBM COMP

OBM COMP

OBM COMP

OBM COMP

OBM СOMP

OBM COMP

OBM COMP

OBM COMP

OBM COMP

OBM COMP

OBM СOMP

OBM COMP

OBM COMP
Concentration

(Percent SPP) Replicate Live ${ }^{(a)}$ Missing

Mean

Proportion Proportion Surviving Surviving

1.00

0.90

0.90

0.93

0.06

0.90

1.00

0.90

0.93

0.06

0.90

0.90

1.00

0.93

0.06

1.00

0.90

0.93

0.06

0.90

1
2
3

10
9
9

1.00

0.90

1.00

1.00

0.98

0.04

0.90

1.00

0.90

1.00

$0.94 \quad 0.05$

1.00

0.90

1.00

1.00

1.00

0.98

0.04

1.00

1.00

0.90

1.00

0.90

0.96

0.05

(a) Survival based on initial exposure of 10 organisms per replicate. 
TABLE G.2. Summary of Mean Proportion Surviving 96-Hour H. costata SuspendedParticulate-Phase Test, Older Bay Mud Study

Sediment

Treatment

January 1993

OBM COMP

OBM COMP

OBM COMP

OBM COMP

January 1994

OBM COMP

OBM COMP

OBM COMP

OBM COMP
Concentration

(Percent SPP)
Mean

Proportion

Surviving ${ }^{(a)}$

(a) Survival based on initial exposure of 10 organisms per replicate.

0.93

0.93

0.93

0.93

0.98

0.94

0.98

100

0.96 
TABLE G.3. Water Quality Summary for 96-Hour H. costata SuspendedParticulate-Phase Test, 01der Bay Mud Study

\begin{tabular}{|c|c|c|c|c|c|c|c|c|c|c|}
\hline \multirow{2}{*}{$\begin{array}{l}\text { Sediment } \\
\text { Ireatment } \\
\end{array}$} & \multirow{2}{*}{$\begin{array}{l}\text { Percent } \\
\text { SPP } \\
\end{array}$} & \multicolumn{2}{|c|}{$\begin{array}{l}\text { Temperature } \\
\left({ }^{\circ} \mathrm{C}\right)\end{array}$} & \multicolumn{2}{|c|}{$\mathrm{pH}$} & \multicolumn{2}{|c|}{$\begin{array}{c}\text { Dissolved } \\
\text { Oxygen } \\
\text { (mg/L) } \\
\end{array}$} & \multicolumn{2}{|c|}{$\begin{array}{c}\text { Salinity } \\
(0 / 00)\end{array}$} & \multirow[t]{2}{*}{$\begin{array}{l}\text { Anmonia } \\
\text { (mg/L) }\end{array}$} \\
\hline & & & Max & $\underline{\operatorname{Min}}$ & Max & $\underline{\text { Min }}$ & Max & Min & Max & \\
\hline $\begin{array}{l}\text { Acceptable } \\
\text { Range }\end{array}$ & & 13.0 & 17.0 & 7.30 & 8.30 & $\geq 4.0$ & $N A^{(s)}$ & 28.0 & 32.0 & $\mathrm{NE}^{(\mathrm{b})}$ \\
\hline \multicolumn{11}{|c|}{ January 1993} \\
\hline OBM СOMP & 0 & 15.5 & 16.0 & 7.45 & 7.84 & 6.6 & 8.7 & 29.0 & 30.0 & $N M^{(c)}$ \\
\hline OBM COMP & 10 & 15.6 & 16.0 & 7.63 & 7.89 & 6.7 & 8.7 & 29.0 & 30.0 & NM \\
\hline OBM СОMP & 50 & 15.6 & 15.9 & 7.60 & 7.99 & 6.6 & 8.6 & 29.0 & 30.0 & NM \\
\hline OBM COMP & 100 & 15.6 & 16.0 & 7.51 & 8.11 & 6.6 & 8.6 & 29.0 & 30.0 & NM \\
\hline \multicolumn{11}{|c|}{ January 1994} \\
\hline OBM СOMP & 0 & 14.9 & 15.9 & 7.69 & 8.05 & 7.5 & 8.3 & 31.0 & 32.0 & NM \\
\hline OBM COMP & 10 & 14.9 & 15.9 & 7.62 & 8.07 & 7.7 & 8.3 & 30.5 & 32.0 & NM \\
\hline OBM COMP & 50 & 15.0 & 15.8 & 7.62 & 8.12 & 7.7 & 8.3 & 30.0 & 31.5 & NM \\
\hline OBM COMP & 100 & 15.0 & 15.9 & 7.66 & 8.17 & 7.7 & 8.4 & 30.0 & 30.5 & 2.22 \\
\hline $\begin{array}{lll}\text { (a) } & N A & N o \\
\text { b) } & N E & N o \\
\text { (c) } & N M & N o\end{array}$ & $\begin{array}{l}\text { able. } \\
\text { ished. } \\
\text { ed. }\end{array}$ & & & & & & & & & \\
\hline
\end{tabular}


TABLE G.4. Test Results for 96-Hour H. costata Copper Reference Toxicant Test, 01der Bay Mud Study

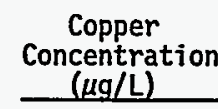

January 1993

$\begin{array}{ll}0 & 1 \\ 0 & 2 \\ 0 & 3\end{array}$

$\begin{array}{ll}50 & 1 \\ 50 & 2 \\ 50 & 3\end{array}$

100

100

100

200

200

400

400

400

$\underline{\text { January } 1994}$

0
0
0
50
50
50
100
100
100
150
150
150
200
200
200

1
2
3

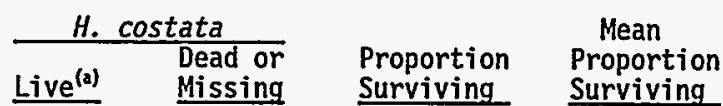

Standard Replicate Live La $^{(2)} \begin{aligned} & \text { Dead or } \\ & \text { Missing }\end{aligned} \quad \begin{aligned} & \text { Proportion } \\ & \text { Surviving }\end{aligned} \quad \begin{aligned} & \text { Proportion } \\ & \text { Surviving }\end{aligned}$

1
2
3
1
2
3
1
2
3
1
2
3
1
2
3

$\begin{array}{ll}1 & 0.90 \\ 0 & 1.00\end{array}$

0.90

0.90

0.80

0.80

0.83

0.06

0.50

0.70

0.50

0.57

0.12

0.00

0.00

0.00

0.00

0.00

0.00

0.00

0.00

0.00

0.00

1.00

0.90

0.93

0.06

$\begin{array}{ll}1 & 9 \\ 2 & 8 \\ 3 & 9\end{array}$

0.90

0.80

0.90

0.87

0.06

$\begin{array}{ll}1 & 1 \\ 2 & 1 \\ 3 & 0\end{array}$

0.10

0.10

0.00

0.07

0.06

100

0.00

0.00

0.00

0.00

0.00

0.00

0.00

0.00

0.00

0.00

(a) Survival based on initial exposure of 10 organisms per replicate. 
TABLE G.5. Water Quality Summary for 96-Hour H. costata Copper Reference Toxicant Test, 01der Bay Mud Study

\begin{tabular}{|c|c|c|c|c|c|c|c|c|}
\hline \multirow{2}{*}{$\begin{array}{c}\text { Copper } \\
\text { Concentration } \\
(\mu \mathrm{g} / \mathrm{L})\end{array}$} & \multicolumn{2}{|c|}{$\begin{array}{c}\text { Temperature } \\
\left({ }^{\circ} \mathrm{C}\right) \\
\end{array}$} & \multicolumn{2}{|c|}{$\mathrm{pH}$} & \multicolumn{2}{|c|}{$\begin{array}{c}\text { Dissolved } \\
\text { Oxygen } \\
(\mathrm{mg} / \mathrm{L}) \\
\end{array}$} & \multicolumn{2}{|c|}{$\begin{array}{c}\text { Salinity } \\
(0 / 00)\end{array}$} \\
\hline & Min & Max & $\underline{\text { Min }}$ & Max & Min & Max & $\underline{M i n}$ & Max \\
\hline $\begin{array}{l}\text { Acceptable } \\
\text { Range }\end{array}$ & 13.0 & 17.0 & 7.30 & 8.30 & $\geq 4.0$ & $N A^{(a)}$ & 28.0 & 32.0 \\
\hline \multicolumn{9}{|l|}{ January 1993} \\
\hline 0 & 16.1 & 16.5 & 7.44 & 7.82 & 6.2 & 8.2 & 30.5 & 31.0 \\
\hline 50 & 16.0 & 16.4 & 7.54 & 7.83 & 6.6 & 8.3 & 30.5 & 31.0 \\
\hline 100 & 16.1 & 16.5 & 7.66 & 7.95 & 7.1 & 8.2 & 30.5 & 31.0 \\
\hline 200 & 16.2 & 16.6 & 7.77 & 7.96 & 7.2 & 8.3 & 30.0 & 31.0 \\
\hline 400 & 16.3 & 16.6 & 7.80 & 7.89 & 7.8 & 8.2 & 30.0 & 31.0 \\
\hline \multicolumn{9}{|l|}{ January 1994} \\
\hline 0 & 14.7 & 15.7 & 7.62 & 7.91 & 7.8 & 8.7 & 30.5 & 32.0 \\
\hline 50 & 14.8 & 15.8 & 7.69 & 7.88 & 7.7 & 8.4 & 30.5 & 32.0 \\
\hline 100 & 14.7 & 15.9 & 7.72 & 8.01 & 7.8 & 8.5 & 30.5 & 32.0 \\
\hline $150^{(b)}$ & 15.1 & 15.5 & 7.75 & 7.77 & 7.8 & 8.5 & 30.0 & 31.5 \\
\hline $200^{(b)}$ & 15.1 & 15.9 & 7.75 & 7.79 & 8.0 & 8.1 & 30.5 & 31.5 \\
\hline
\end{tabular}

(a) NA Not applicable. 
TABLE G.6. Test Results for 96-Hour H. costata Ammonia Reference Toxicant Test, Older Bay Mud Study

\begin{tabular}{|c|c|c|c|c|c|c|}
\hline \multirow{2}{*}{$\begin{array}{c}\text { Ammonia } \\
\text { Concentration } \\
\text { (mg/L) }\end{array}$} & \multirow[b]{2}{*}{ Replicate } & \multicolumn{2}{|c|}{ H. costata } & \multirow[b]{2}{*}{$\begin{array}{l}\text { Proportion } \\
\text { Surviving }\end{array}$} & \multirow{2}{*}{$\begin{array}{l}\text { Mean } \\
\text { Proportion } \\
\text { Surviving } \\
\end{array}$} & \multirow[b]{2}{*}{$\begin{array}{l}\text { Standard } \\
\text { Deviation }\end{array}$} \\
\hline & & $\operatorname{Live}^{(e)}$ & $\begin{array}{l}\text { Dead or } \\
\text { Missing }\end{array}$ & & & \\
\hline \multicolumn{7}{|l|}{ Jảnuary 1994} \\
\hline \multicolumn{7}{|l|}{ Test 1} \\
\hline 0.68 & 1 & 9 & 1 & 0.90 & & \\
\hline 0.68 & 2 & 10 & 0 & 1.00 & & \\
\hline 0.68 & 3 & 10 & 0 & 1.00 & 0.97 & 0.06 \\
\hline 0.71 & 1 & 8 & 2 & 0.80 & & \\
\hline 0.71 & 2 & 10 & 0 & 1.00 & & \\
\hline 0.71 & 3 & 9 & 1 & 0.90 & 0.90 & 0.10 \\
\hline 0.79 & 1 & 9 & 1 & 0.90 & & \\
\hline 0.79 & 2 & 9 & 1 & 0.90 & & \\
\hline 0.79 & 3 & 10 & 0 & 1.00 & 0.93 & 0.06 \\
\hline 0.87 & 1 & 9 & 1 & 0.90 & & \\
\hline 0.87 & 2 & 9 & 1 & 0.90 & & \\
\hline 0.87 & 3 & 9 & 1 & 0.90 & 0.90 & 0.00 \\
\hline 1.32 & 1 & 9 & 1 & 0.90 & & \\
\hline 1.32 & 2 & 10 & 0 & 1.00 & & \\
\hline 1.32 & 3 & 8 & 2 & 0.80 & 0.90 & 0.10 \\
\hline \multicolumn{7}{|l|}{ Test 2} \\
\hline 1.64 & 1 & 9 & 1 & 0.90 & & \\
\hline 1.64 & 2 & 10 & 0 & 1.00 & & \\
\hline 1.64 & 3 & 9 & 1 & 0.90 & 0.93 & 0.06 \\
\hline 3.03 & 1 & 10 & 0 & 1.00 & & \\
\hline 3.03 & 2 & 8 & 2 & 0.80 & & \\
\hline 3.03 & 3 & 9 & 1 & 0.90 & 0.90 & 0.10 \\
\hline 6.66 & 1 & 9 & 1 & 0.90 & & \\
\hline 6.66 & 2 & 9 & 1 & 0.90 & & \\
\hline 6.66 & 3 & 8 & 2 & 0.80 & 0.87 & 0.06 \\
\hline 14.8 & 1 & 8 & 2 & 0.80 & & \\
\hline 14.8 & 2 & 8 & 2 & 0.80 & & \\
\hline 14.8 & 3 & 8 & 2 & 0.80 & 0.80 & 0.00 \\
\hline 29.96 & 1 & 9 & 1 & 0.90 & & \\
\hline 29.96 & 2 & 9 & 1 & 0.90 & & \\
\hline 29.96 & 3 & 7 & 3 & 0.70 & 0.83 & 0.12 \\
\hline
\end{tabular}


TABLE G.6. (contd)

\begin{tabular}{|c|c|c|c|c|c|c|}
\hline \multirow{2}{*}{$\begin{array}{c}\text { Ammonia } \\
\text { Concentration } \\
\text { (mg/L) }\end{array}$} & \multirow[b]{2}{*}{ Replicate } & \multicolumn{2}{|c|}{ H. costata } & \multirow[b]{2}{*}{$\begin{array}{l}\text { Proportion } \\
\text { Surviving }\end{array}$} & \multirow{2}{*}{$\begin{array}{l}\text { Mean } \\
\text { Proportion } \\
\text { Surviving } \\
\end{array}$} & \multirow[b]{2}{*}{$\begin{array}{l}\text { Standard } \\
\text { Deviation }\end{array}$} \\
\hline & & Live $^{(a)}$ & $\begin{array}{l}\text { Dead or } \\
\text { Missing }\end{array}$ & & & \\
\hline \multicolumn{7}{|l|}{ Test 3} \\
\hline 2.37 & 1 & 10 & 0 & 1.00 & & \\
\hline 2.37 & 2 & 10 & 0 & 1.00 & & \\
\hline 2.37 & 3 & 9 & 1 & 0.90 & 0.97 & 0.06 \\
\hline 57.99 & 1 & 3 & 7 & 0.30 & & \\
\hline 57.99 & 2 & 5 & 5 & 0.50 & & \\
\hline 57.99 & 3 & 6 & 4 & 0.60 & 0.47 & 0.15 \\
\hline 79.11 & 1 & 0 & 10 & 0.00 & & \\
\hline 79.11 & 2 & 0 & 10 & 0.00 & & \\
\hline 79.11 & 3 & 0 & 10 & 0.00 & 0.00 & 0.00 \\
\hline 96.8 & 1 & 0 & 10 & 0.00 & & \\
\hline 96.8 & 2 & 0 & 10 & 0.00 & & \\
\hline 96.8 & 3 & 0 & 10 & 0.00 & 0.00 & 0.00 \\
\hline
\end{tabular}

(a) Survival based on initial exposure of 10 organisms per replicate. 
TABLE G.7. Water Quality Summary for 96-Hour H. costata Ammonia Reference Toxicant Test, Older Bay Mud Study

\begin{tabular}{|c|c|c|c|c|c|c|c|c|c|c|}
\hline \multirow{2}{*}{$\begin{array}{l}\text { Ammonia } \\
\text { Concentration } \\
\text { (mg/L) }\end{array}$} & \multicolumn{2}{|c|}{$\begin{array}{c}\text { Temperature } \\
\left({ }^{\circ} \mathrm{C}\right)\end{array}$} & $\mathrm{pl}$ & & \multicolumn{2}{|c|}{$\begin{array}{l}\text { Dissolved } \\
\text { Oxygen } \\
\text { (mg/L) }\end{array}$} & \multicolumn{2}{|c|}{$\begin{array}{c}\text { Salinity } \\
(0 / 00)\end{array}$} & \multicolumn{2}{|c|}{$\begin{array}{c}\text { Ammonia } \\
\text { (mg/L) }\end{array}$} \\
\hline & Min & $\operatorname{Max}$ & Min & $\operatorname{Max}$ & Min & $\operatorname{Max}$ & Min & Max & Min & $\operatorname{Max}$ \\
\hline \multicolumn{11}{|l|}{ Acceptable } \\
\hline Range & 13.0 & 17.0 & 7.30 & 8.30 & 4.0 & $N A^{(a)}$ & 28.0 & 32.0 & NE & $\mathrm{NE}$ \\
\hline
\end{tabular}

January 1994

Test 1

\begin{tabular}{|c|c|c|c|c|c|c|c|c|c|c|}
\hline 0.68 & 14.6 & 15.1 & 7.73 & 7.94 & 7.7 & 8.4 & 31.5 & 32.0 & 0.212 & 1.04 \\
\hline 0.71 & 14.7 & 15.3 & 7.78 & 7.93 & 7.7 & 8.5 & 31.5 & 32.0 & 0.246 & 1.20 \\
\hline 0.79 & 14.7 & 15.3 & 7.80 & 7.96 & 8.0 & 8.5 & 31.0 & 32.0 & 0.289 & 1.27 \\
\hline 0.87 & 14.6 & 15.3 & 7.78 & 7.99 & 7.8 & 8.5 & 31.0 & $32.5^{(0)}$ & 0.406 & 1.31 \\
\hline 1.32 & 14.7 & 15.4 & 7.76 & 8.01 & 7.9 & 8.4 & 31.0 & 32.0 & 0.785 & 1.87 \\
\hline
\end{tabular}

Test 2

$\begin{array}{lrlllllllll}1.64 & 14.7 & 14.9 & 7.60 & 7.98 & 7.0 & 8.3 & 30.5 & 31.5 & 0.286 & 4.18 \\ 3.03 & 14.7 & 14.8 & 7.59 & 7.98 & 7.4 & 8.4 & 30.5 & 31.5 & 1.73 & 5.25 \\ 6.66 & 14.7 & 14.9 & 7.69 & 7.97 & 7.7 & 8.4 & 30.5 & 31.5 & 4.79 & 7.81 \\ 14.8 & 14.7 & 14.8 & 7.68 & 7.95 & 7.6 & 8.5 & 31.0 & 31.5 & 11.9 & 17.6 \\ 29.96 & 14.7 & 14.9 & 7.69 & 7.90 & 7.8 & 8.4 & 30.5 & 31.5 & 18.7 & 37.7\end{array}$

$\underline{\text { Test } 3}$

$\begin{array}{rrrrrrrrrrr}2.37 & 14.8 & 15.6 & 7.46 & 7.84 & 7.4 & 8.3 & 30.5 & 31.0 & 0.556 & 3.93 \\ 57.99 & 14.7 & 15.5 & 7.65 & 7.78 & 7.7 & 8.2 & 30.5 & 31.0 & 51.2 & 68.9 \\ 79.11 & 14.6 & 15.6 & 7.54 & 7.84 & 7.1 & 8.2 & 30.5 & 31.0 & 63.7 & 96.4 \\ 96.8 & 14.6 & 15.4 & 7.48 & 7.88 & 7.6 & 8.3 & 30.5 & 31.0 & 75.4 & 120\end{array}$
(a) NA Not applicable.
(b) NE Not established.
(c) Data point out of range. 


\section{APPENDIX H}

BIOASSAY RESULTS FOR 10-DAY SOLID-PHASE, FLOW-THROUGH TEST WITH NEPHTYS caecoides FOR FEEDING STUDY 
TABLEH.1. Test Results for 10-Day N. caecoides Solid-Phase, Flow-Through Preliminary Test with Different Concentrations of TOC and Food Sources, Older Bay Mud Study

\begin{tabular}{|c|c|c|c|c|c|c|}
\hline $\begin{array}{l}\text { Sediment } \\
\text { Treatment }\end{array}$ & Replicate & Live ${ }^{(a)}$ & $\begin{array}{l}\text { Dead or } \\
\text { Missing }\end{array}$ & $\begin{array}{l}\text { Proportion } \\
\text { Surviving }\end{array}$ & $\begin{array}{c}\text { Mean } \\
\text { Proportion } \\
\text { Surviving } \\
\end{array}$ & $\begin{array}{l}\text { Standard } \\
\text { Deviation }\end{array}$ \\
\hline OBM & 1 & 8 & 12 & 0.40 & & \\
\hline OBM & 2 & 6 & 14 & 0.30 & & \\
\hline OBM & 3 & 5 & 15 & 0.25 & 0.32 & 0.08 \\
\hline OBM with water & 1 & 18 & 2 & 0.90 & & \\
\hline OBM with water & 2 & 13 & 7 & 0.65 & & \\
\hline OBM with water & 3 & 15 & 5 & 0.75 & 0.77 & 0.13 \\
\hline OBM-0.4\% TOC (mixed with alfalfa) & 1 & 11 & 9 & 0.55 & & \\
\hline OBM- $0.4 \%$ TOC (mixed with alfalfa) & 2 & 18 & 2 & 0.90 & & \\
\hline OBM-0.4\% TOC (mixed with alfalfa) & 3 & 17 & 3 & 0.85 & & \\
\hline OBM-0.4\% TOC (mixed with alfalfa) & 4 & 17 & 3 & 0.85 & & \\
\hline OBM-0.4\% TOC (mixed with alfalfa) & 5 & 18 & 2 & 0.90 & 0.81 & 0.15 \\
\hline OBM- $0.8 \%$ TOC (mixed with alfalfa) & 1 & 16 & 4 & 0.80 & & \\
\hline OBM-0.8\% TOC (mixed with alfalfa) & 2 & 17 & 3 & 0.85 & & \\
\hline OBM- $0.8 \%$ TOC (mixed with alfalfa) & 3 & 18 & 2 & 0.90 & & \\
\hline OBM-0.8\% TOC (mixed with alfalfa) & 4 & 18 & 3 & 0.90 & & \\
\hline OBM- $0.8 \%$ TOC (mixed with alfalfa) & 5 & 18 & 2 & 0.90 & 0.87 & 0.04 \\
\hline OBM- $0.8 \%$ TOC (sprinkled with alfalfa) & 1 & 15 & 5 & 0.75 & & \\
\hline OBM-0.8\% TOC (sprinkled with alfalfa) & 2 & 19 & 1 & 0.95 & & \\
\hline OBM-0.8\% TOC (sprinkled with alfalfa) & 3 & 16 & 4 & 0.80 & & \\
\hline OBM-0.8\% TOC (sprinkled with alfalfa) & 4 & 19 & 1 & 0.95 & & \\
\hline OBM-0.8\% TOC (sprinkled with alfalfa) & 5 & 18 & 2 & 0.90 & 0.87 & 0.09 \\
\hline OBM-0.8\% TOC (mixed with Enteromorpha) & 1 & 18 & 2 & 0.90 & & \\
\hline OBM-0.8\% TOC (mixed with Enteromorpha) & 2 & 17 & 3 & 0.85 & & \\
\hline OBM-0.8\% TOC (mixed with Enteromorpha) & 3 & 18 & 2 & 0.90 & & \\
\hline OBM-0.8\% TOC (mixed with Enteromorpha) & 4 & 18 & 2 & 0.90 & & \\
\hline OBM-0.8\% TOC (mixed with Enteromorpha) & 5 & 16 & 4 & 0.80 & 0.87 & 0.04 \\
\hline OBM-0.8\% TOC (sprinkled with Enteromorpha) & 1 & 18 & 2 & 0.90 & & \\
\hline OBM-0.8\% TOC (sprinkled with Enteromorpha) & 2 & 19 & 1 & 0.95 & & \\
\hline OBM-0.8\% TOC (sprinkled with Enteromorpha) & 3 & 20 & 0 & 1.00 & & \\
\hline OBM-0.8\% TOC (sprinkled with Enteromorpha) & 4 & 14 & 6 & 0.70 & & \\
\hline OBM-0.8\% TOC (sprinkled with Enteromorpha) & 5 & 14 & 6 & 0.70 & 0.85 & 0.14 \\
\hline OBM-0.8\% TOC (mixed with tetramin) & 1 & 18 & 2 & 0.90 & & \\
\hline OBM-0.8\% TOC (mixed with tetramin) & 2 & 17 & 3 & 0.85 & & \\
\hline OBM-0.8\% TOC (mixed with tetramin) & 3 & 16 & 4 & 0.80 & & \\
\hline OBM-0.8\% TOC (mixed with tetramin) & 4 & 18 & 2 & 0.90 & & \\
\hline OBM-0.8\% TOC (mixed with tetramin) & 5 & 16 & 4 & 0.80 & 0.85 & 0.05 \\
\hline
\end{tabular}


TABLEH.1. (contd)

\begin{tabular}{|c|c|c|c|c|c|c|}
\hline $\begin{array}{l}\text { Sediment } \\
\text { Treatment }\end{array}$ & Replicate & Live $^{(a)}$ & $\begin{array}{l}\text { Dead or } \\
\text { Missing }\end{array}$ & $\begin{array}{c}\text { Proportion } \\
\text { Surviving } \\
\end{array}$ & $\begin{array}{c}\text { Mean } \\
\text { Proportion } \\
\text { Surviving }\end{array}$ & $\begin{array}{l}\text { Standard } \\
\text { Deviation }\end{array}$ \\
\hline OBM- $0.8 \%$ TOC (sprinkled with tetramin) & 1 & 14 & 6 & 0.70 & & \\
\hline OBM- $0.8 \%$ TOC (sprinkled with tetramin) & 2 & 9 & 11 & 0.45 & & \\
\hline OBM-0.8\% TOC (sprinkled with tetramin) & 3 & 10 & 10 & 0.50 & & \\
\hline OBM-0.8\% TOC (sprinkled with tetramin) & 4 & 16 & 4 & 0.80 & & \\
\hline OBM-0.8\% TOC (sprinkled with tetramin) & 5 & 14 & 6 & 0.70 & 0.63 & 0.15 \\
\hline OBM-1.2\% TOC (mixed with alfalfa) & 1 & 17 & 3 & 0.85 & & \\
\hline OBM-1.2\% TOC (mixed with alfalfa) & 2 & 13 & 7 & 0.65 & & \\
\hline OBM-1.2\% TOC (mixed with alfalfa) & 3 & 9 & 11 & 0.45 & & \\
\hline OBM-1.2\% TOC (mixed with alfalfa) & 4 & 11 & 9 & 0.55 & & \\
\hline OBM-1.2\% TOC (mixed with alfalfa) & 5 & 17 & 3 & 0.85 & 0.67 & 0.18 \\
\hline C-NE & 1 & 20 & 0 & 1.00 & & \\
\hline C-NE & 2 & 20 & 0 & 1.00 & & \\
\hline C-NE & 3 & 19 & 1 & 0.95 & & \\
\hline C-NE & 4 & 20 & 0 & 1.00 & & \\
\hline C-NE & 5 & 20 & 0 & 1.00 & 0.99 & 0.02 \\
\hline
\end{tabular}

(a) Survival based on initial exposure of 20 organisms per replicate. 
TABLE H.2. Water Quality Summary for 10-Day N. caecoides Solid-Phase, Flow-Through Preliminary Test, Older Bay Mud Study

\begin{tabular}{|c|c|c|c|c|c|c|c|c|}
\hline \multirow{2}{*}{$\begin{array}{l}\text { Sediment } \\
\text { Treatment }\end{array}$} & \multicolumn{2}{|c|}{$\begin{array}{c}\text { Temperature } \\
\left({ }^{\circ} \mathrm{C}\right)\end{array}$} & \multicolumn{2}{|c|}{$\mathrm{pH}$} & \multicolumn{2}{|c|}{$\begin{array}{c}\text { Dissolved } \\
\text { Oxygen } \\
\text { (mg/L) } \\
\end{array}$} & \multicolumn{2}{|c|}{$\begin{array}{l}\text { Salinity } \\
\text { (o/oo) }\end{array}$} \\
\hline & Min & Max & Min & $\operatorname{Max}$ & Min & $\operatorname{Max}$ & Min & Max \\
\hline \multicolumn{9}{|l|}{ Acceptable } \\
\hline Range & 13.0 & 17.0 & 7.30 & 8.30 & 6.0 & $N A^{(a)}$ & 28.0 & 32.0 \\
\hline OBM & 14.2 & 15.7 & 7.78 & 7.92 & 7.5 & 8.0 & 31.5 & 32.0 \\
\hline OBM with water & 14.0 & 16.0 & 7.65 & 7.93 & 7.5 & 8.0 & 31.5 & 32.0 \\
\hline OBM- $0.4 \%$ TOC (mixed with alfalfa) & 15.0 & 16.0 & 7.70 & 7.89 & 7.3 & 7.8 & 31.5 & 32.0 \\
\hline OBM- $0.8 \%$ TOC (mixed with alfalfa) & 15.0 & 15.8 & 7.71 & 7.87 & 7.0 & 7.6 & 31.5 & 32.0 \\
\hline OBM-0.8\% TOC (sprinkled with alfalfa) & 15.1 & 15.8 & 7.73 & 7.93 & 7.4 & 7.8 & 31.5 & 32.0 \\
\hline OBM-0.8\% TOC (mixed with Enteromorpha) & 15.1 & 16.0 & 7.68 & 7.91 & 7.0 & 7.7 & 31.5 & 32.0 \\
\hline OBM- $0.8 \%$ TOC (sprinkled with Enteromorpha) & 15.0 & 15.8 & 7.72 & 7.88 & 7.3 & 7.8 & 31.5 & 32.0 \\
\hline OBM- $0.8 \%$ TOC (mixed with tetramin) & 15.0 & 15.8 & 7.68 & 7.89 & 7.0 & 7.6 & 31.5 & 32.0 \\
\hline OBM-0.8\% TOC (sprinkled with tetramin) & 15.0 & 15.8 & 7.71 & 7.89 & 7.2 & 7.8 & 31.5 & 32.0 \\
\hline OBM-1.2\% TOC (mixed with alfalfa) & 15.2 & 15.9 & 7.62 & 7.89 & 6.8 & 7.6 & 31.5 & 32.0 \\
\hline C-NE & 15.0 & 15.9 & 7.73 & 7.87 & 7.4 & 7.8 & 31.5 & 32.0 \\
\hline
\end{tabular}

(a) NA Not applicable. 
TABLE H.3. Ammonia Measurements in the Overlying and Porewater from Day 10 of the N. caecoides, Preliminary Test, Older Bay Mud Study

\begin{tabular}{lccccc} 
& \multicolumn{5}{c}{ Overlying Day 10 } \\
\cline { 2 - 6 } $\begin{array}{l}\text { Sediment } \\
\text { Treatment }\end{array}$ & $\begin{array}{c}\text { Ammonia } \\
\text { Concentration } \\
(\mathrm{mg} / \mathrm{L})\end{array}$ & $\begin{array}{c}\text { Temperature } \\
\left({ }^{\circ} \mathrm{C}\right)\end{array}$ & $\begin{array}{c}\text { Dissolved } \\
\text { Oxygen } \\
(\mathrm{mg} / \mathrm{L})\end{array}$ & $\begin{array}{c}\text { Salinity } \\
(\mathrm{O} / 00)\end{array}$ \\
\hline OBM & & & & & \\
OBM with water & 0.082 & 15.1 & 7.85 & 7.6 & 32.0 \\
OBM-0.4\% TOC (mixed with alfalfa) & 0.034 & 15.2 & 7.83 & 7.6 & 32.0 \\
OBM-0.8\% TOC (mixed with alfalfa) & 0.081 & 15.2 & 7.85 & 7.6 & 31.5 \\
OBM-0.8\% TOC (sprinkled with alfalfa) & 0.057 & 15.2 & 7.79 & 7.3 & 32.0 \\
OBM-0.8\% TOC (mixed with Enteromorpha) & 0.050 & 15.3 & 7.79 & 7.4 & 32.0 \\
OBM-0.8\% TOC (sprinkled with Enteromorpha) & 0.054 & 15.2 & 7.80 & 7.5 & 31.5 \\
OBM-0.8\% TOC (mixed with tetramin) & 0.071 & 15.3 & 7.83 & 7.5 & 32.0 \\
OBM-0.8\% TOC (sprinkled with tetramin) & 0.119 & 15.2 & 7.78 & 7.3 & 32.0 \\
OBM-1.2\% TOC (mixed with alfalfa) & 0.084 & 15.2 & 7.87 & 7.5 & 32.0 \\
C-NE & 0.045 & 15.2 & 7.82 & 7.4 & 32.0 \\
& 0.176 & 15.1 & 7.85 & 7.8 & 32.0
\end{tabular}

Sediment

Porewater Day $10^{(a)}$

Treatment

\begin{tabular}{|c|c|c|c|c|}
\hline \multirow[b]{2}{*}{$\begin{array}{c}\text { Ammonia } \\
\text { Concentration } \\
\text { (mg/L) }\end{array}$} & \multicolumn{3}{|c|}{ Porewater Day 1} & \multirow[b]{2}{*}{$\begin{array}{c}\text { Salinity } \\
(0 / 00)\end{array}$} \\
\hline & $\begin{array}{c}\text { Temperature } \\
\left({ }^{\circ} \mathrm{C}\right) \\
\end{array}$ & $\mathrm{pH}$ & $\begin{array}{c}\text { Dissolved } \\
\text { Oxygen } \\
\text { (mg/L) }\end{array}$ & \\
\hline
\end{tabular}

OBM

0.601

0.463

15.4

8.09

6.0

32.0

OBM with water

1.65

15.4

8.12

7.1

32.0

OBM-0.8\% TOC (mixed with alfalfa)

1.98

15.3

7.67

5.9

31.5

OBM- $0.8 \%$ TOC (sprinkled with alfalfa)

0.287

15.4

7.40

6.1

32.0

OBM-0.8\% TOC (mixed with Enteromorpha)

1.03

7.72

5.4

32.5

OBM- $0.8 \%$ TOC (sprinkled with Enteromorpha)

0.701

15.4

7.48

5.5

32.0

OBM- $0.8 \%$ TOC (mixed with tetramin)

5.90

15.5

7.82

6.1

32.5

OBM- $0.8 \%$ TOC (sprinkled with tetramin)

2.63

15.4

7.32

4.1

32.5

3.84

15.5

7.88

6.2

32.0

OBM-1.2\% TOC (mixed with alfalfa)

0.401

15.4

7.07

4.2

33.5

C-NE

15.4

7.78

6.2

32.0

(a) The temperature, $\mathrm{pH}$, dissolved oxygen, and salinity values are an average of the five replicates. 
TABLE H.4. Test Results for 10-day N. caecoides Solid-Phase, Flow-Through Definitive with Different Concentrations of TOC and Enteromorpha, Older Bay Mud Study

\begin{tabular}{|c|c|c|c|c|c|c|}
\hline $\begin{array}{l}\text { Sediment } \\
\text { Treatment }^{(\mathrm{a})} \\
\end{array}$ & Replicate & Live $^{(b)}$ & $\begin{array}{l}\text { Dead or } \\
\text { Missing }\end{array}$ & $\begin{array}{l}\text { Proportion } \\
\text { Surviving }\end{array}$ & $\begin{array}{c}\text { Mean } \\
\text { Proportion } \\
\text { Surviving } \\
\end{array}$ & $\begin{array}{l}\text { Standard } \\
\text { Deviation }\end{array}$ \\
\hline OBM & 1 & 2 & 18 & 0.10 & & \\
\hline OBM & 2 & 6 & 14 & 0.30 & & \\
\hline OBM & 3 & 4 & 16 & 0.20 & 0.20 & 0.10 \\
\hline OBM & 4 & $N A^{(c)}$ & NA & NA & & \\
\hline OBM & 5 & NA & NA & NA & & \\
\hline OBM with water & 1 & 13 & 7 & 0.65 & & \\
\hline OBM with water & 2 & 13 & 7 & 0.65 & & \\
\hline OBM with water & 3 & 13 & 7 & 0.65 & 0.65 & 0.00 \\
\hline OBM with water & 4 & NA & NA & NA & & \\
\hline OBM with water & 5 & NA & NA & NA & & \\
\hline OBM with $0.24 \%$ TOC & 1 & 18 & 2 & 0.90 & & \\
\hline OBM with $0.24 \%$ TOC & 2 & 16 & 4 & 0.80 & & \\
\hline OBM with $0.24 \%$ TOC & 3 & 19 & 1 & 0.95 & & \\
\hline OBM with $0.24 \%$ TOC & 4 & 18 & 2 & 0.90 & & \\
\hline OBM with $0.24 \%$ TOC & 5 & 18 & 2 & 0.90 & 0.89 & 0.06 \\
\hline OBM with $0.27 \%$ TOC & 1 & 13 & 7 & 0.65 & & \\
\hline OBM with $0.27 \%$ TOC & 2 & 17 & 3 & 0.85 & & \\
\hline OBM with $0.27 \%$ TOC & 3 & 20 & 0 & 1.00 & & \\
\hline OBM with $0.27 \%$ TOC & 4 & 16 & 4 & 0.80 & & \\
\hline OBM with $0.27 \%$ TOC & 5 & 14 & 6 & 0.70 & 0.80 & 0.14 \\
\hline OBM with $0.39 \%$ TOC & 1 & 18 & 2 & 0.90 & & - \\
\hline OBM with $0.39 \%$ TOC & 2 & 17 & 3 & 0.85 & & \\
\hline OBM with $0.39 \%$ TOC & 3 & 17 & 3 & 0.85 & & \\
\hline OBM with $0.39 \%$ TOC & 4 & 18 & 2 & 0.90 & & \\
\hline OBM with $0.39 \%$ TOC & 5 & 17 & 3 & 0.85 & 0.87 & 0.03 \\
\hline OBM with $0.44 \%$ TOC & 1 & 17 & 3 & 0.85 & & \\
\hline OBM with $0.44 \%$ TOC & 2 & 14 & 6 & 0.70 & & \\
\hline OBM with $0.44 \%$ TOC & 3 & 17 & 3 & 0.85 & & \\
\hline OBM with $0.44 \%$ TOC & 4 & 12 & 8 & 0.60 & & \\
\hline OBM with $0.44 \%$ TOC & 5 & 18 & 2 & 0.90 & 0.78 & 0.13 \\
\hline
\end{tabular}


TABLE H.4. (contd)

\begin{tabular}{lcccccc}
$\begin{array}{l}\text { Sediment } \\
\text { Treatment }\end{array}$ & Replicate & Live & $\begin{array}{c}\text { Dead or } \\
\text { Missing }\end{array}$ & $\begin{array}{c}\text { Mean } \\
\text { Proportion } \\
\text { Surviving }\end{array}$ & $\begin{array}{c}\text { Proportion } \\
\text { Surviving }\end{array}$ & $\begin{array}{c}\text { Standard } \\
\text { Deviation }\end{array}$ \\
\hline C-NE & 1 & 20 & 0 & 1.00 & & \\
C-NE & 2 & 20 & 0 & 1.00 & & \\
C-NE & 3 & 20 & 0 & 1.00 & & \\
C-NE & 4 & 20 & 0 & 1.00 & & 0.00 \\
C-NE & 5 & 20 & 0 & 1.00 & 1.00 & \\
\hline
\end{tabular}

(a) The percentages of TOC are actual measurements determined by analysis of sediment at Global Geochemistry.

(b) Survival based on initial exposure of 20 organisms per replicate.

(c) NA Not applicable. 
TABLE H.5. Water Quality Summary for 10-day N. caecoides Solid-Phase, FlowThrough Definitive Test with Different Concentrations of TOC and Enteromorpha, Older Bay Mud Study

\begin{tabular}{|c|c|c|c|c|c|c|c|c|}
\hline \multirow{2}{*}{$\begin{array}{l}\text { Sediment } \\
\text { Treatment }^{(a)}\end{array}$} & \multicolumn{2}{|c|}{$\begin{array}{c}\text { Temperature } \\
\left({ }^{\circ} \mathrm{C}\right)\end{array}$} & \multicolumn{2}{|c|}{$\mathrm{pH}$} & \multicolumn{2}{|c|}{$\begin{array}{c}\text { Dissolved } \\
\text { Oxygen } \\
\text { (mg/L) }\end{array}$} & \multicolumn{2}{|c|}{$\begin{array}{l}\text { Salinity } \\
(0 / 00)\end{array}$} \\
\hline & Min & Max & Min & Max & Min & Max & Min & $\operatorname{Max}$ \\
\hline \multicolumn{9}{|l|}{ Acceptable } \\
\hline Range & 13.0 & 17.0 & 7.30 & 8.30 & 6.0 & $N A^{(b)}$ & 28.0 & 32.0 \\
\hline OBM & 14.7 & 15.7 & 7.78 & 7.87 & 6.5 & 8.0 & 30.5 & 32.0 \\
\hline OBM with water & 14.7 & 15.8 & 7.76 & 7.90 & 6.6 & 8.0 & 30.5 & 32.0 \\
\hline OBM with $0.24 \%$ TOC & 14.7 & 15.8 & 7.79 & 7.89 & 6.3 & 8.0 & 30.5 & 32.0 \\
\hline OBM with $0.27 \%$ TOC & 14.7 & 15.8 & 7.76 & 7.89 & 6.2 & 7.9 & 30.5 & 32.0 \\
\hline OBM with $0.39 \%$ TOC & 14.7 & 15.8 & 7.71 & 7.86 & 6.0 & 7.8 & 30.5 & 32.0 \\
\hline OBM with $0.44 \%$ TOC & 14.6 & 15.7 & 7.66 & 7.87 & 6.0 & 7.8 & 30.5 & 32.0 \\
\hline C-NE & 14.7 & 15.8 & 7.78 & 8.00 & 6.3 & 8.0 & 30.5 & 32.0 \\
\hline
\end{tabular}

(a) The percentages of TOC are actual measurements determined by analysis of sediment at Global Chemistry.

(b) NA Not applicable. 
TABLE H.6. Ammonia Measurements in the Overlying and Porewater from Day 10 of $N$. caecoides Definitive Test, Older Bay Mud Study

\begin{tabular}{|c|c|c|c|c|c|}
\hline \multirow[b]{2}{*}{$\begin{array}{l}\text { Sediment } \\
\text { Treatment }^{(a)}\end{array}$} & \multicolumn{5}{|c|}{ Overlying Day 10} \\
\hline & $\begin{array}{c}\text { Ammonia } \\
\text { Concentration } \\
(\mathrm{mg} / \mathrm{L})\end{array}$ & $\begin{array}{c}\text { Temperature } \\
\left({ }^{\circ} \mathrm{C}\right)\end{array}$ & $\mathrm{pH}$ & $\begin{array}{l}\text { Dissolved } \\
\text { Oxygen } \\
\text { (mg/L) }\end{array}$ & $\begin{array}{l}\text { Salinity } \\
\text { (o/oo) }\end{array}$ \\
\hline OBM & 0.031 & 15.6 & 7.85 & 8.0 & 32.0 \\
\hline OBM with water & 0.073 & 15.8 & 7.86 & 7.9 & 32.0 \\
\hline OBM with $0.24 \%$ TOC & 0.062 & 15.7 & 7.83 & 7.8 & 32.0 \\
\hline OBM with $0.27 \%$ TOC & 0.179 & 15.7 & 7.86 & 7.9 & 32.0 \\
\hline OBM with $0.39 \%$ TOC & 0.153 & 15.8 & 7.81 & 7.6 & 32.0 \\
\hline OBM with $0.44 \%$ TOC & 0.073 & 15.7 & 7.77 & 7.6 & 32.0 \\
\hline C-NE & 0.027 & 15.8 & 7.83 & 7.9 & 32.0 \\
\hline
\end{tabular}

\begin{tabular}{lccccr} 
& \multicolumn{5}{c}{ Porewater Day 10 } \\
\cline { 2 - 6 } $\begin{array}{l}\text { Sediment } \\
\text { Treatment }\end{array}$ & $\begin{array}{c}\text { Ammonia } \\
\text { Concentration } \\
(\mathrm{mg} / \mathrm{L})\end{array}$ & $\begin{array}{c}\text { Temperature } \\
\left({ }^{\circ} \mathrm{C}\right)\end{array}$ & $\begin{array}{c}\text { Dissolved } \\
\text { Oxygen } \\
(\mathrm{mg} / \mathrm{L})\end{array}$ & $\begin{array}{r}\text { Salinity } \\
(\mathrm{O} / \mathrm{OO})\end{array}$ \\
\hline & & & & & \\
OBM & 3.24 & 14.8 & 7.87 & 7.0 & 32.0 \\
OBM with water & 1.28 & 14.7 & 8.13 & 6.6 & 32.0 \\
OBM with 0.24\% TOC & 0.507 & 14.9 & 7.73 & 6.0 & 32.0 \\
OBM with 0.27\% TOC & 2.76 & 14.9 & 7.67 & 6.3 & 32.5 \\
OBM with 0.39\% TOC & 1.96 & 14.8 & 7.45 & 5.3 & 32.0 \\
OBM with 0.44\% TOC & 3.35 & 14.9 & 7.29 & 5.3 & 32.0 \\
C-NE & 0.86 & 14.8 & 7.80 & 6.3 & 32.0
\end{tabular}

(a) The percentages of TOC are actual measurements determined by analysis of sediment at Global Geochemistry. 


\section{APPENDIX I}

TISSUE CHEMISTRY AND QUALITY ASSURANCE DATA FOR MACOMA nasuta 


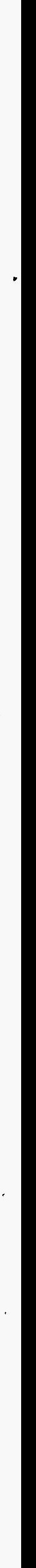




\section{QA/QC SUMMARY}

\section{PROGRAM \\ LABORATORY: MATRIX:}

PARAMETER:

METHOD

HOLDING TIMES

DETECTION LIMITS

METHOD BLANKS

MATRIX SPIKES

REPLICATES

\author{
Older Bay Mud Study \\ Battelle Marine Sciences Laboratory, Sequim, Washington \\ M. nasuta Tissue \\ Polynuclear Aromatic Hydrocarbons (PAH)
}

Tissue samples were homogenized using a Tekmar tissuemizer. Approximately 5 grams of homogenized tissue were extracted with methylene chloride using a roller under ambient conditions following methods used by the National Oceanic and Atmospheric

Administration for their Status and Trends Program (Krahn et al, 1988). Samples were then cleaned using silica/alumina ( $5 \%$ deactivated) chromatography followed by HPLC cleanup (Krahn et al. 1988). Extracts were quantified using gas chromatography/mass spectrometry (GC/MS) in the selected ion mode (SIM) following EPA Method 8270 (EPA 1986).

Samples were received on $3 / 18 / 93$ in good condition. Samples were placed into Battelle's log-in system and stored at approximately $-20^{\circ} \mathrm{C}$ until extraction. Samples were extracted in one batch on 3/23/93 and analyzed by GC/MS on $3 / 29 / 93$, which is within the established holding time of 40 days.

Target detection limits of $20 \mu \mathrm{g} / \mathrm{kg}$ wet weight were met for all PAH compounds.

Four method blanks were analyzed with the sediment samples. Nine PAHs were detected in the sediment samples at values less than five times those in the method blank and have been flagged with a " $\mathrm{B}$ " to indicate possible blank contamination.

One sample, OBM COMP, was spiked in duplicate with all $\mathrm{PAH}$ compounds. Matrix spike recoveries ranged from $92 \%$ to $108 \%$ which is within the laboratory QAVQC recovery limit (40\%-120\%). Relative percent differences between MS and MSD recoveries were within the $\pm 30 \%$ QAVQC limit ranging from $0 \%$ to $6 \%$ which indicates good precision. Three samples, $M$. nasuta background, QC sample, and QC sample, were spiked with PAHs. Percent recoveries ranged from $69 \%$ to $125 \%$; three recoveries were outside the acceptable QAVQC range $(40 \%$ to $120 \%)$.

One sample, OBM COMP, was extracted in duplicate. Precision was measured by calculating the relative percent difference (RPD) between the replicate results. No PAHs were detected in either replicate above the target detection limits of $20 \mu \mathrm{g} / \mathrm{kg}$; therefore, no calculations were performed.

Three samples, $M$. nasuta background, QC sample, and R-OS, were analyzed in triplicate. Precision was measured by calculating the relative standard deviation (RSD) among replicate results. The RSDs ranged from $1 \%$ to $36 \%$ with only one value outside of the $\pm 30 \%$ QAJQC limit. 
SRMs

SURROGATES
One SRM was analyzed, NIST 1974, a marine mussel tissue obtained by the National Institute for Standards and Technology.

Eight of the sixteen PAH compounds analyzed are certified. Of these, only two are certified at levels above the target detection limit of $20 \mu \mathrm{g} / \mathrm{kg}$. One compound, pyrene, was detected within the $30 \%$ target for accuracy. The other compound, fluoranthene, slightly exceeded the $30 \%$ limit.

Up to six isotopically labelled compounds, d8-Naphthalene, d8-Acenaphthalene, d10-Acenaphthene, d10-Pyrene, d12Benzo(a)pyrene, d12-Chrysene, and d14-dibenzo(a,h,i)anthracene, were added to the sediment samples prior to extraction to assess the efficiency of the method. Recoveries of all surrogates ranged from $62 \%$ to $95 \%$ which is within the quality control limits of $40 \%$ to $120 \%$.

\section{REFERENCES}

EPA (U.S. Environmental Protection Agency). 1986. Test Methods for Evaluating Solid Waste: Physical/Chemical Methods. SWP-846 Method 8270. EPA-955-001-00000, U.S. Government Printing Office, Washington D.C.

Krahn, M. M., C. A. Wigren, R. W. Pearch, L. K. Moore, R. G. Bogar, W. D. MacLeod, Jr., S. L. Chan, and D. W. Brown. 1988. "A Rapid High-Performance Liquid Chromatographic Method for Isolating Organic Contaminants from Tissue and Sediment Extracts." NOAA Technical Memorandum NMFS F/NWC-153, Silver Spring, Maryland. 
PROGRAM

LABORATORY: MATRIX:

PARAMETER:

METHOD

HOLDING TIMES

DETECTION LIMITS

METHOD BLANKS

\author{
Older Bay Mud Study \\ Battelle Marine Sciences Laboratory, Sequim, Washington \\ M. nasuta Tissue \\ Chlorinated Pesticides
}

Tissue samples were homogenized using a Tekmar tissuemizer. Approximately 5 grams of homogenized tissue were extracted with methylene chloride using a roller under ambient conditions following methods used by the National Oceanic and Atmospheric

Administration for their Status and Trends Program (Krahn et al, 1988). Samples were then cleaned using silica/alumina ( $5 \%$ deactivated) chromatography followed by HPLC cleanup. Extracts were analyzed using Gas Chromatography/Electron Capture Detection (GC/ECD). Extracts were exchanged to methyl-t-butylether (MTBE) and analyzed by capillary column gas chromatography/electron capture detection (GC/ECD) following EPA method 8080 (1986). A second, confirmatory column (DB1701) was be used to confirm the presence of pesticide compounds. Values between primary and confirmatory columns must be within a factor of two of one another to qualify as a confirmed detection. The primary column used was a J\&W DB-5 capillary column ( $30 \mathrm{~m} \times 0.25 \mathrm{~mm}$ I.D.). Samples were analyzed for a total of 22 chlorinated pesticide compounds.

Samples were received on $3 / 18 / 93$ in good condition. Samples were placed into Battelle's log-in system and stored at approximately $-20^{\circ} \mathrm{C}$ until extraction. Samples were extracted in one batch on 3/23/93. Extracts were analyzed by GC/ECD 4/1/93, within the required holding time of 40 days.

For the January 1994 study, samples were received on 3/21/94 in good condition. Samples were logged in and stored at approximately $-20^{\circ} \mathrm{C}$ until extraction. Extracts were analyzed by GC/ECD in three batches from $5 / 10 / 94$ to $6 / 6 / 94$.

Target detection limits of $2 \mu \mathrm{g} / \mathrm{kg}$ wet weight were met for all samples. Toxaphene and chlordane detection limits of $30 \mu \mathrm{g} / \mathrm{kg}$ were also met. Detection limits reported are based on an MDL study involving low level spikes of 7 replicate extractions. The MDLs, defined as 3 times the standard deviation of the mean recovery, were all below $2 \mu \mathrm{g} / \mathrm{kg}$.

Four method blanks were analyzed with the sediment samples. One pesticide, tech-chlordane, was detected in Blank 1 at $13.0 \mu \mathrm{g} / \mathrm{kg}$. None of the sediment samples had detectable concentrations of tech-chlordane above the target detection limit of $30 \mu \mathrm{g} / \mathrm{kg}$. 
MATRIX SPIKES

\section{REPLICATES}

SRMs

SURROGATES

\section{QA/QC SUMMARY PESTICIDES (contd)}

One sample, OBM COMP, was spiked in duplicate with a subset of six pesticides. Matrix spike recoveries ranged from $103 \%$ to $119 \%$, which is within the laboratory QA/QC recovery limit (40\% to $120 \%$ ). Precision was measured by comparing the relative percent difference (RPD) between spike recoveries. The RPDs ranged from $0 \%$ to $9 \%$, which were below the precision goal of $\leq 30 \%$, indicating acceptable precision.

Three samples, $M$. nasuta background, QC sample, and QC sample, were spiked with a subset of six pesticides. Matrix spike recoveries ranged from $50 \%$ to $108 \%$, which is within the laboratory QA/QC recovery limit ( $40 \%$ to $120 \%$ ).

One sample, OBM COMP, was analyzed in duplicate. Precision was measured by calculating the relative percent difference (RPD) between the replicate results. Four compounds were detected in both replicates and RPD values ranged from $0 \%$ to $20 \%$ which is below the precision goal of $\leq 30 \%$, indicating acceptable precision.

Three samples, $M$. nasuta background, QC sample, and R-OS, were analyzed in triplicate. Precision was measured by calculating the relative standard deviation (RSD) among the triplicate results. Two compounds, aldrin and 4,4'-DDT, were detected in all replicates and produced RSD values of $12 \%$ and $16 \%$, respectively. These values were below the precision goal of $\leq 30 \%$, indicating acceptable precision.

One SRM, NIST 1974, a marine mussel tissue obtained from the National Institute for Standards and Technology, was analyzed for pesticides. Although this sample is not certified for pesticides, it does present consensus values for 5 pesticides. Results for 4,4'-DDD, were within $30 \%$ of the consensus mean. Results for a-chlordane, dieldrin, 4.4'-DDE, and 4,4'-DDT exceeded the upper range of the $30 \%$ difference, however, since these values are only "consensus," no further action was taken. Historically, higher values have been obtained for 4,4'-DDT. This appears to be a result of matrix interference from the sample. All other QA/QC results for 4,4'-DDT were acceptable.

Up to four compounds [PCB 103, PCB 198, tetrachlorometaxylene (TCMX), and octachloronaphthalene (OCN)] were added to all sediment samples prior to extraction to assess the efficiency of the analysis. Recoveries of PCB 103, PCB 198, and TCMX ranged from $61 \%$ to $116 \%$, which is within the QA/QC guidelines of $40 \%-120 \%$. Recoveries of OCN ranged from $117 \%$ to $162 \%$ with all but one falling outside of the QA/QC range. Since all of the other surrogates were acceptable, no corrective action was taken. 


\section{QA/QC SUMMARY PESTICIDES (contd)}

\section{REFERENCES}

EPA (U.S. Environmental Protection Agency). 1986. Test Methods for Evaluating Solid Waste: Physical/Chemical Methods. SWP-846 Method 8270. EPA-955-001-00000, U.S. Government Printing Office, Washington D.C.

Krahn, M. M., C. A. Wigren, R. W. Pearch, L. K. Moore, R. G. Bogar, W. D. MacLeod, Jr., S. L. Chan, and D. W. Brown. 1988. "A Rapid High-Performance Liquid Chromatographic Method for Isolating Organic Contaminants from Tissue and Sediment Extracts." NOAA Technical Memorandum NMFS F/NWC-153, Silver Spring, Maryland. 


\section{QA/QC SUMMARY}

PROGRAM

LABORATORY:

MATRIX:

PARAMETER:

METHOD

HOLDING TIMES

DETECTION LIMITS

METHOD BLANKS

MATRIX SPIKES

\author{
Older Bay Mud Study \\ Battelle Marine Sciences Laboratory, Sequim, Washington \\ M. nasuta Tissue \\ Polychlorinated Biphenyls (PCBs)
}

Tissue samples were homogenized using a Tekmar tissuemizer. Approximately 5 grams of homogenized tissue were extracted with methylene chloride using a roller under ambient conditions following methods used by the National Oceanic and Atmospheric

Administration for their Status and Trends Program (Krahn et al, 1988). Samples were then cleaned using silica/alumina (5\% deactivated) chromatography followed by HPLC cleanup. Extracts were analyzed using Gas Chromatography/Electron Capture Detection (GC/ECD). Extracts were exchanged to methyl-t-butylether (MTBE) and analyzed by capillary column gas chromatography/electron capture detection (GC/ECD) following EPA method 8080 (1986). The primary column used was a J\&W DB-5 capillary column (30m $\times 0.25 \mathrm{~mm}$ I.D.). Samples were analyzed for four Aroclor mixtures: 1242, 1248, 1254 and 1260.

Samples were received on $3 / 18 / 93$ in good condition. Samples were logged into Battelle log-in system and stored at approximately $-20^{\circ} \mathrm{C}$ until extraction. Samples were extracted in one batch on 3/23/93. Extracts were analyzed by GC/ECD 4/1/93, within the required holding time of 40 days.

Target detection limits of $20 \mu \mathrm{g} / \mathrm{kg}$ wet weight were met for all samples. Detection limits reported are based on an MDL study involving low level spikes of 7 replicate extractions. The MDLs, defined as 3 times the standard deviation of the mean recovery were below $20 \mu \mathrm{g} / \mathrm{kg}$.

Four method blanks were analyzed with the sediment samples. No PCB Aroclors were detected in the blank.

One sample, OBM COMP, was spiked in duplicate with Aroclor 1254. Matrix spike recoveries ranged from $115 \%$ to $124 \%$. The recovery for the matrix spike duplicate slightly exceeded the laboratory QA/QC recovery limit $(40 \%-120 \%)$. Precision was measured by comparing the Relative Percent Difference (RPD) between spike recoveries. The RPD was $7 \%$, which is below the precision goal of $\leq 30 \%$.

Three samples, $M$. nasuta background, QC sample, and QC sample, were spiked with Aroclor 1254. Matrix spike percent recoveries ranged from $72 \%$ to $106 \%$ which is within the QAVQC recovery limits of $40 \%$ to $120 \%$. 


\section{QA/QC SUMMARY PCBs (contd)}

REPLICATES

SRMs

SURROGATES
One sample, OBM COMP, was analyzed in duplicate. Precision was measured by calculating the RPD between the replicate results. No Aroclors were detected in either replicate, RPDs were not calculated.

Three samples, M. nasuta background, QC sample, and R-OS, were analyzed in triplicate. Precision was measured by calculating the RSD among the replicate results. The RSD's could not be calculated because Aroclors were not detected in any samples.

Not applicable.

Up to four compounds [PCB 103, PCB 198, tetrachlorometaxylene (TCMX), and octachloronaphthalene (OCN)] were added to all sediment samples prior to extraction to assess the efficiency of the analysis. Recoveries of PCB 103, PCB 198, and TCMX ranged from $61 \%$ to $116 \%$, which is within the QA/QC guidelines of $40 \%-120 \%$. Recoveries of OCN ranged from $117 \%$ to $162 \%$ with all but one falling outside of the QAVQC range. Since all of the other surrogates were acceptable, no corrective action was taken.

\section{REFERENCES}

EPA (U.S. Environmental Protection Agency). 1986. 'Test Methods for Evaluating Solid Waste: Physical/Chemical Methods. SWP-846 Method 8270. EPA-955-001-00000, U.S. Government Printing Office, Washington D.C.

Krahn, M. M., C. A. Wigren, R. W. Pearch, L. K. Moore, R. G. Bogar, W. D. MacLeod, Jr., S. L. Chan, and D. W. Brown. 1988. "A Rapid High-Performance Liquid Chromatographic Method for Isolating Organic Contaminants from Tissue and Sediment Extracts." NOAA Technical Memorandum NMFS FINWC-153, Silver Spring, Maryland. 


\section{QA/QC SUMMARY}

PROGRAM

LABORATORY:

MATRIX:

PARAMETER:

\section{METHOD}

HOLDING TIMES

DETECTION LIMITS

METHOD BLANKS

MATRIX SPIKES

REPLICATES

\author{
Older Bay Mud Study \\ Battelle Marine Sciences Laboratory, Sequim, Washington \\ M. nasuta Tissue \\ Metals
}

\begin{abstract}
A total of 10 metals was analyzed for: silver (Ag), arsenic (As), cadmium (Cd), chromium (Cr), copper (Cu), mercury ( $\mathrm{Hg})$, nickel ( $\mathrm{Ni})$, lead $(\mathrm{Pb})$, selenium (Se) and zinc ( $\mathrm{Zn}$ ). Five metals, $\mathrm{As}, \mathrm{Cu}, \mathrm{Ni}, \mathrm{Se}$ and $\mathrm{Zn}$ were analyzed by energy diffusive $\mathrm{x}$-ray fluorescence (XRF) and four metals, $\mathrm{Ag}, \mathrm{Cd}, \mathrm{Cr}$ and $\mathrm{Pb}$ were analyzed using Zeeman Graphite Furnace Atomic Absorption (GFAA) spectrometry following EPA Method 200.9 for the January 1993 study. Mercury was analyzed using cold-vapor atomic absorption spectroscopy (CVAA) according to the method of Bloom and Crecelius (1983). For the 1994 study, $\mathrm{Ag}, \mathrm{As}, \mathrm{Cd}, \mathrm{Cr}, \mathrm{Cu}, \mathrm{Ni}, \mathrm{Pb}$, and $\mathrm{Zn}$ were analyzed by ICP/Mass Spectrometry, Se was analyzed by GFAA, and $\mathrm{Hg}$ was analyzed by CVAA.
\end{abstract}

To prepare tissue for analysis, samples were freeze-dried and blended in a Spex mixer-mill. Approximately $5 \mathrm{~g}$ of mixed sample was ground in a ceramic ball mill. The XRF analysis was performed on a 0.5-g aliquot of dried, ground material pressed into a pellet with a diameter of $2 \mathrm{~cm}$. For GFAA, ICP/MS and CVAA analyses, $0.2-$ to $0.5-\mathrm{g}$ aliquots of dried homogenous sample were digested using a mixture of nitric/perchloric acids.

Samples were received on $3 / 18 / 93$ in good condition. Samples were . placed into Battelle log-in system, frozen to $-80^{\circ} \mathrm{C}$ and subsequently freeze dried within approximately 7 days of sample receipt. Samples were all analyzed within 180 days of collection. Mercury was analyzed within the 28 day holding time.

Target detection limits were met for all metals.

Method blanks were analyzed for five metals $(\mathrm{Ag}, \mathrm{Cd}, \mathrm{Cr}, \mathrm{Hg}$, and $\mathrm{Pb}$ ) during January 1993 study and for ten metals in January 1994 study. Method blanks are not analyzed by XRF. Arsenic was detected in the blanks, however, these levels were well below the detection limits; therefore, the data was not flagged to indicate blank contamination. All other metals were undetected in the blanks.

OBM COMP was spiked with four metals ( $\mathrm{Ag}, \mathrm{Cd}, \mathrm{Cr}, \mathrm{Hg}$, and $\mathrm{Pb}$ ) during the January 1993 study. QC sample, QC sample, and R-AM, were spiked with all ten metals during the January 1994 study. Matrix spike recoveries ranged from $74 \%$ to $117 \%$, with all but one percent recovery within the QA/QC limits of $75 \%$ to $125 \%$. Samples for XRF are analyzed whole and cannot be spiked.

One sample, OBM COMP, was analyzed in duplicate. Precision was measured by calculating the relative percent difference (RPD)

between the replicate results. The RPDs ranged from $1 \%$ to $36 \%$. All metals were within the QAVQ limits of $+20 \%$ indicating acceptable precision, with the exception of $\mathrm{Ni}$ which had an RPD of $36 \%$. 


\section{QA/QC SUMMARY METALS (contd)}

Three samples, QC sample, QC sample, and R-BF, were analyzed in triplicate. Precision was measured by calculating the relative standard deviation. The RSDs ranged from $0 \%$ to $11 \%$, indicating acceptable precision.

SRMs

The SRM, 1566a (Oyster tissue from the National Institute of Standards and Technology, NIST), was analyzed for each batch of metals. Results for all metals except one were within $\pm 30 \%$ of mean certified value, indicating acceptable accuracy.

\section{REFERENCES}

Bloom, N.S., and E.A. Crecelius. 1983. "Determination of Mercury in Seawater at Sub-Nanogram per Liter Levels." Marine Chemistry 21:337-390:

EPA (U.S. Environmental Protection Agency). 1991. Methods for the Determination of Metals in Environmental Samples. EPA-600/4-91-010 Methods 200.8, 200.9, Environmental Services Division, Monitoring Management Branch, Cincinnati, Ohio. 


\section{PROGRAM LABORATORY: MATRIX: PARAMETER:}

METHOD

HOLDING TIMES

DETECTION LIMITS

METHOD BLANKS

MATRIX SPIKES

REPLICATES

\author{
Older Bay Mud Study \\ Battelle Marine Sciences Laboratory, Sequim, Washington \\ M. nasuta Tissue \\ Butyltins
}

Butyltin analyses were performed following the method of Unger et al. (1986).

Samples were received on $3 / 18 / 93$ in good condition. Samples were placed into Battelle's log-in system and stored at approximately $-20^{\circ} \mathrm{C}$ until extraction. Samples were extracted in one batch on 3/23/93. Extracts were analyzed by GC/FPD on 3/25/93, which is within the established holding time of 40 days.

For the January 1994 study, samples were received on 3/21/94 in good condition. Samples were logged in and stored at approximately $-20^{\circ} \mathrm{C}$ until extraction. Extracts were analyzed in two batches from $5 / 12 / 94$ to $5 / 13 / 94$.

Target detection limits of $1.0 \mu \mathrm{g} / \mathrm{kg}$ on a wet weight basis were not met for all tissues. The actual detection limits ranged from undetected at $0.48 \mu \mathrm{g} / \mathrm{kg}$ to undetected at $1.39 \mu \mathrm{g} / \mathrm{kg}$. Detection limits reported are defined as Limits of Quantitation (LOQ) which are determined as 10 times the standard deviation of results from 7 replicate low level matrix spikes. Values detected between the LOQ and the MDL (defined as 3 times the standard deviation) are flagged with a "J" flag.

One method blank was analyzed with each batch of sediment samples. Tributyltins were not detected in the blank. Dibutyltin was detected in Blank 1 at $3.9 \mu \mathrm{g} / \mathrm{kg}$, which is below the LOQ; therefore, no associated data were flagged.

One sample, OBM COMP, was spiked in duplicate with di- and tributyltin. Matrix spike recoveries ranged from $101 \%$ to $105 \%$ for the tri- and dibutyltins, which is within the QA/QC limits of $40 \%$ to $120 \%$. Relative percent differences between MS and MSD recoveries ranged from $1 \%$ to $10 \%$ which is within the $\pm 30 \%$ QAVQ limit for tri- and dibutyltins, indicating acceptable precision.

Three samples, QC sample, OBM Comp, and C-SB, werë spiked with di- and tri-butlytin compounds. Matrix spike recoveries ranged from $93 \%$ to $108 \%$.

One sample, OBM COMP, was analyzed in duplicate. Precision was measured by calculating the RPD between the replicate results. The RPD for tributyltin was $5 \%$ indicating acceptable precision. The RPD for dibutyltin was $33 \%$, exceeding the precision goal of $30 \%$.

Three samples, QC sample, R-OS, and QC sample, were analyzed in triplicate. Precision was measured by calculating the RSD. The $\mathrm{RSD}$ ranged from $3 \%$ to $6 \%$, indicating acceptable precision. 


\section{QA/QC SUMMARY BUTYLTINS (contd)}

SRMs

SURROGATES
Not applicable.

One compound, tripentyltin chloride, is added to the sediment samples prior to extraction to assess the efficiency of the method. This compound also is used as an internal standard since all data are corrected for the recovery of the compound. Recoveries ranged from $61 \%$ to $107 \%$ for samples, which is within the QA/QC limits of $40 \%$ to $120 \%$.

\section{REFERENCES}

Unger, M.A., W.G. Macintyre, J. Reaves and R.J. Huggett. 1986. "GC Determination of Butyltins in Natural Waters by Flame Photometric Detection of Hexyl Derivatives with Mass Spectrometric Confirmation." Chemosphere. 15(4):461-470. 
TABLE 1.1. Total Detected Polynuclear Aromatic Hydrocarbons (PAHs), Wet Weight, in Tissue of $M$. nasuta, Older Bay Mud Study

M. nasuta PAHs ( $\mu \mathrm{g} / \mathrm{kg}$ wet weight)

Total Total

Sediment

Analytical

Low Molecular

High Molecular

Total

Treatment

Replicate

Batch

Weight PAHs

Weight PAHs

PAHS

January 1993

OBM COMP
OBM COMP
OBM COMP
OBM COMP
OBM COMP, Replicate 1
OBM COMP, Replicate 2

$\begin{array}{lll}1 & 1 & 0 \\ 2 & 1 & 0 \\ 3 & 1 & 0 \\ 4 & 1 & 0 \\ 5 & 1 & 0 \\ 5 & 1 & 0\end{array}$

$\begin{array}{ll}0 & 0 \\ 0 & 0 \\ 0 & 0 \\ 0 & 0 \\ 0 & 0 \\ 0 & 0\end{array}$

January 1994

R-OS

R-OS, Replicate 1

R-OS, Replicate 2

R-OS, Replicate 3

R-OS

R-OS

R-OS

$\begin{array}{ll}1 & 4 \\ 2 & 4 \\ 2 & 4 \\ 2 & 4 \\ 3 & 4 \\ 4 & 4 \\ 5 & 4\end{array}$

2

13

42

11

17

4

3

2

3

3

R-BF

R-BF

R-BF

R-BF

R-BF

13

2

3

R-AM

R-AM

R-AM

R-AM

R-AM

3
2

3

3

3

2

$$
15
$$

11

14

10

12

10

4

7

11

4

2

65

$$
66
$$

48

49

45

C-SB

C-SB

C-SB

C-SB

C-SB

M. nasuta Background

$M$. nasuta Background

M. nasuta Background, Replicate 1

M. nasuta Background, Replicate 2

M. nasuta Background, Replicate 3

M. nasuta Background

M. nasuta Background

12

46

29

524

286

492

351

403

69

73

59

53

47

50

40

55

570

315

542

391

458

$18 \quad 21$

$39 \quad 42$

$19 \quad 23$

$19 \quad 22$

$18 \quad 21$

$5 \quad 4$

36

43

$36 \quad 44$

$39 \quad 49$

$49 \quad 60$

$49 \quad 56$

$40 \quad 48$

$25 \quad 33$

OLDER BAY MUD 
TABLE 1.2. Low Molecular Weight Polynuclear Aromatic Hydrocarbons (LPAHS), Wet Weight, in Tissue of $M$. nasuta, Older Bay Mud Study

\begin{tabular}{|c|c|c|c|c|c|c|c|c|c|c|c|c|c|c|}
\hline \multirow{2}{*}{$\begin{array}{l}\text { Sediment } \\
\text { Treatment }\end{array}$} & \multirow[b]{2}{*}{ Replicate } & \multirow[b]{2}{*}{$\begin{array}{c}\text { Analytical } \\
\text { Batch }\end{array}$} & \multicolumn{12}{|c|}{ M. nasuta LPAHs ( $\mu g / \mathrm{kg}$ wet weight) } \\
\hline & & & \multicolumn{2}{|c|}{$\begin{array}{l}\text { Naphtha- } \\
\text { lene }\end{array}$} & \multicolumn{2}{|c|}{$\begin{array}{l}\text { Acenaph- } \\
\text { thylene }\end{array}$} & \multicolumn{2}{|c|}{$\begin{array}{l}\text { Acenaph- } \\
\text { thene }\end{array}$} & \multicolumn{2}{|c|}{ Fluorene } & \multicolumn{2}{|c|}{$\begin{array}{l}\text { Phenan- } \\
\text { threne }\end{array}$} & \multicolumn{2}{|c|}{$\begin{array}{l}\text { Anthra- } \\
\text { cene }\end{array}$} \\
\hline Target $D L^{(a)}$ & & & \multicolumn{2}{|c|}{20} & \multicolumn{2}{|c|}{20} & \multicolumn{2}{|c|}{20} & \multicolumn{2}{|l|}{20} & \multicolumn{2}{|c|}{20} & \multicolumn{2}{|l|}{20} \\
\hline \multicolumn{15}{|l|}{ January 1993} \\
\hline OВМ СОМР & 1 & 1 & 20 & $u^{(b)}$ & 20 & $\mathrm{U}$ & 20 & $\mathbf{U}$ & 20 & $u$ & 20 & $u$ & 20 & $u$ \\
\hline OBM COMP & 2 & 1 & 20 & $U$ & 20 & $u$ & 20 & u & 20 & $u$ & 20 & $u$ & 20 & $U$ \\
\hline OBM COMP & 3 & 1 & 20 & $U$ & 20 & $\mathrm{U}$ & 20 & $\mathbf{U}$ & 20 & U & 20 & $u$ & 20 & $\mathrm{U}$ \\
\hline ОВМ СОМР & 4 & 1 & 20 & $\mathbf{U}$ & 20 & $\mathrm{U}$ & 20 & $\mathrm{U}$ & 20 & U & 20 & $\mathrm{U}$ & 20 & $u$ \\
\hline OBM COMP, Replicate 1 & 5 & 1 & 20 & $\mathbf{U}$ & 20 & $\mathbf{U}$ & 20 & $U$ & 20 & $\mathrm{U}$ & 20 & $\mathbf{u}$ & 20 & $\mathrm{U}$ \\
\hline OBM COMP, Replicate 2 & 5 & 1 & 20 & $\mathrm{U}$ & 20 & $\mathrm{U}$ & 20 & $\mathrm{u}$ & 20 & $\mathrm{U}$ & 20 & $\mathbf{U}$ & 20 & $U$ \\
\hline \multicolumn{15}{|l|}{ January 1994} \\
\hline R-OS & 1 & 4 & \multirow{2}{*}{\multicolumn{2}{|c|}{$\begin{array}{l}0.83 \\
2.06\end{array}$}} & \multirow{2}{*}{\multicolumn{2}{|c|}{$0.81 U$}} & \multirow{2}{*}{\multicolumn{2}{|c|}{$\begin{array}{l}0.77 \mathrm{U} \\
1.53 \mathrm{U}\end{array}$}} & \multicolumn{2}{|c|}{$1.35 \mathrm{U}$} & 0.74 & & 2.18 & \\
\hline R-OS, Replicate 1 & 2 & 4 & & & & & & & 2.70 & & 1.27 & $7 \mathrm{U}$ & 4.37 & $7 \mathrm{U}$ \\
\hline R-OS, Replicate 2 & 2 & 4 & 2.56 & $6^{\text {(c) }}$ & 1.59 & 94 & 1.5 & $2 U$ & 2.67 & & 1.26 & $6 U$ & 4.32 & 24 \\
\hline R-OS, Replicate 3 & 2 & 4 & 2.00 & & 1.61 & & 1.5 & & 2.70 & & 1.27 & $7 \mathrm{U}$ & 4.37 & $7 \mathrm{U}$ \\
\hline R-OS & 3 & 4 & 1.16 & & 0.81 & 10 & 0.7 & $7 \mathrm{U}$ & 1.48 & & 0.85 & & 2.18 & $3 U$ \\
\hline R-OS & 4 & 4 & 1.25 & & 0.82 & & 0.8 & & 1.38 & & 0.88 & & 2.23 & $3 \mathrm{U}$ \\
\hline R-OS & 5 & 4 & 0.80 & & 0.82 & & 0.78 & $3 \mathrm{U}$ & 1.38 & $3 \mathrm{U}$ & 0.95 & & 2.23 & $3 U$ \\
\hline R-BF & 1 & 3 & 2.72 & $2 B^{(d)}$ & 1.61 & & 1.5 & & 2.70 & & 1.65 & & 4.37 & $7 \mathrm{U}$ \\
\hline R-BF & 2 & 2 & 0.85 & $5 \mathrm{~B}$ & 0.82 & & 0.9 & & 1.38 & $3 \mathrm{U}$ & 2.26 & & 2.86 & $3^{\text {(c) }}$ \\
\hline R-BF & 3 & 3 & 3.42 & $2 \mathrm{~B}$ & 1.64 & & 1.5 & $6 \mathrm{U}$ & 2.88 & & 2.13 & & 2.42 & $2^{(c)}$ \\
\hline R-BF & 4 & 3 & 2.05 & $5 \mathrm{~B}^{(\mathrm{c})}$ & 1.53 & & 1.4 & $\mathrm{U}$ & 2.56 & & 1.63 & & 4.15 & $5 \mathrm{U}$ \\
\hline R.BF & 5 & 3 & 1.98 & 8 B & 1.63 & & 1.6 & $5 \mathrm{U}$ & 2.73 & $\mathrm{U}$ & 1.28 & & 4.41 & $U$ \\
\hline R-AM & 1 & 2 & 1.49 & $9 \mathrm{~B}$ & 2.02 & & 1.3 & & 2.39 & & 24.1 & & 14.9 & \\
\hline R-AM & 2 & 3 & 1.92 & $2 \mathrm{~B}$ & 1.64 & & 1.5 & & 3.46 & & 14.6 & & 9.23 & \\
\hline R-AM & 3 & 3 & 2.33 & $3 \mathrm{~B}$ & 2.26 & & 1.5 & $\mathrm{Su}$ & 3.52 & & 25.6 & & 16.1 & \\
\hline R-AM & 4 & 2 & 1.66 & & 2.14 & & 1.3 & & 2.95 & & 20.3 & & 11.6 & \\
\hline R-AM & 5 & 3 & 2.98 & $8 \mathrm{~B}$ & 1.92 & & 1.9 & & 4.72 & & 26.7 & & 16.7 & \\
\hline C-SB & 1 & 4 & 1.92 & & 0.81 & & 0.7 & & 1.35 & & 1.45 & & 2.18 & $3 \mathrm{U}$ \\
\hline C-SB & 2 & 4 & 1.47 & & 0.81 & & 1.0 & & 1.35 & & 0.92 & & 2.18 & 3 \\
\hline C-SB & 3 & 4 & 0.80 & $b^{(c)}$ & 0.82 & & 0.78 & $\mathrm{u}$ & 1.48 & & 1.40 & & 2.23 & 3 \\
\hline C-SB & 4 & 4 & 1.56 & $6^{\text {(c) }}$ & 0.81 & & 0.7 & & 1.35 & & 1.42 & & & $3 \mathrm{U}$ \\
\hline C-SB & 5 & 4 & 1.69 & & 0.82 & & $0.7 \varepsilon$ & 3 & 1.38 & $\mathrm{U}$ & 1.28 & & 2.23 & $U$ \\
\hline M. nasuta Background & 1 & 2 & 1.13 & $3 \mathrm{~B}$ & 0.82 & & $0.8 s$ & & 1.38 & & 2.86 & & 2.32 & (c) \\
\hline M. nasuta Background & 2 & 2 & 2.16 & $\mathrm{~B}^{(\mathrm{c})}$ & 1.61 & $\mathrm{U}$ & 1.8 & & 2.70 & $u$ & 3.45 & & 4.37 & $\mathrm{U}$ \\
\hline M. nasuta Background, Replicate 1 & 3 & 2 & 1.76 & $\mathrm{~B}^{(\mathrm{c})}$ & 1.59 & & 1.5 & & 2.67 & & 3.63 & & 4.39 & (c) \\
\hline M. nasuta Background, Replicate 2 & 3 & 2 & 1.55 & $5 \mathrm{~B}^{(\mathrm{c})}$ & 1.55 & & 1.6 & & 2.59 & & 3.75 & & 4.42 & \\
\hline M. nasuta Background, Replicate 3 & 3 & 2 & 1.32 & $B^{(c)}$ & 1.58 & & 1.72 & & 2.64 & & 3.68 & & 4.28 & 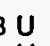 \\
\hline M. nasuta Background & 4 & 2 & 0.88 & $\mathrm{~B}^{(\mathrm{c})}$ & 0.81 & & 1.15 & & 1.35 & & 3.68 & & 2.34 & (c) \\
\hline M. nasuta Background & 5 & 2 & 0.83 & $3 B^{(c)}$ & 0.97 & & 0.8 & & 1.38 & U & 2.68 & $3 \mathrm{~B}$ & 2.38 & 3 (c) \\
\hline
\end{tabular}

(a) DL Detection limit.

(b) U Undetected at or above detection limit.

(c) Ratio of confirmation ion to primary ion is outside of the theoretical ratio of $20 \%$ established for EPA-CLP programs.

(d) $\mathrm{B}$ Analyte detected in sample at less than five times the value in associated method blank. 
TABLE 1.3. High Molecular Weight Polynuclear Aromatic Hydrocarbons (HPAHs), Wet Weight, in Tissue of M. nasuta, Older Bay Mud Study

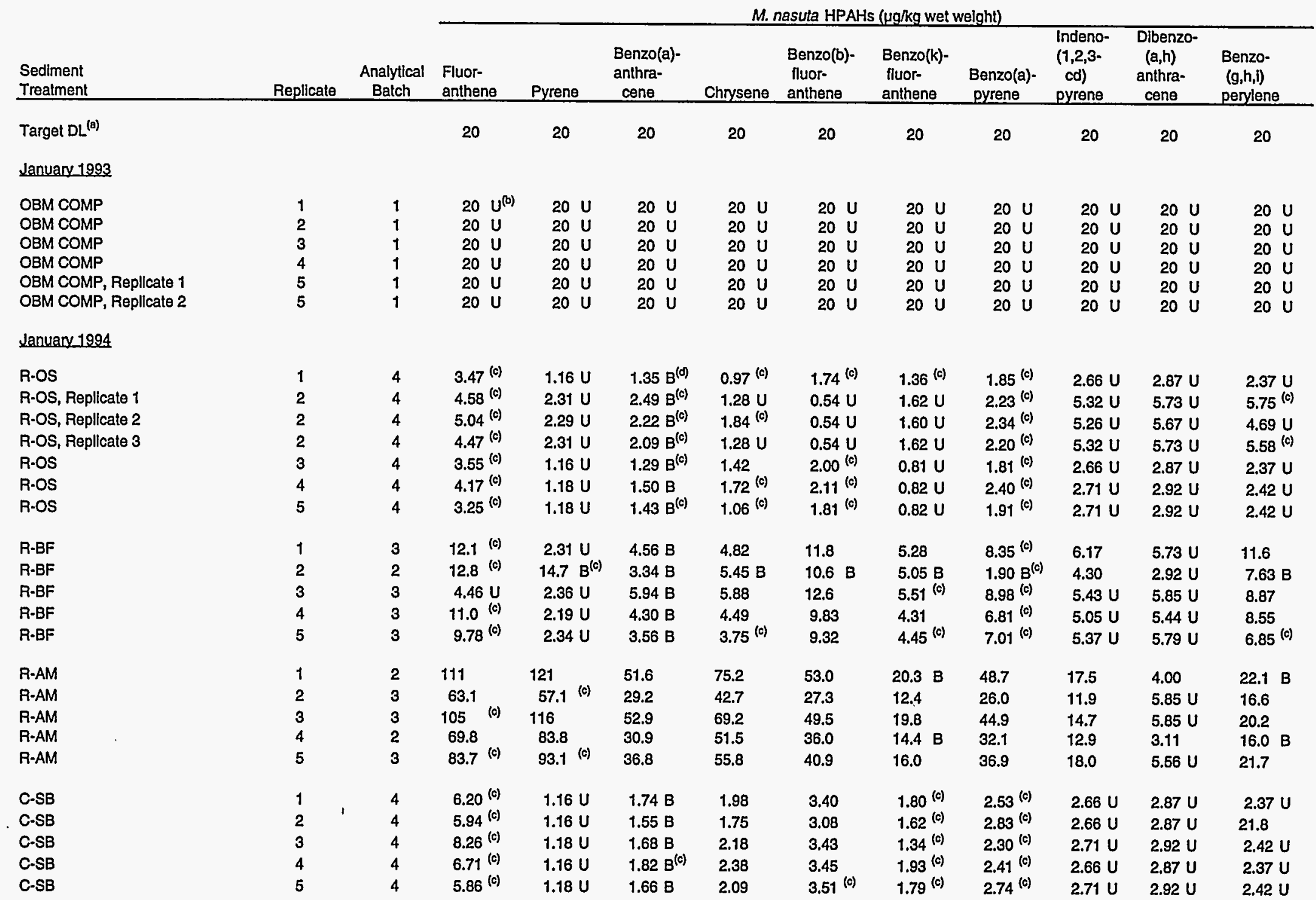




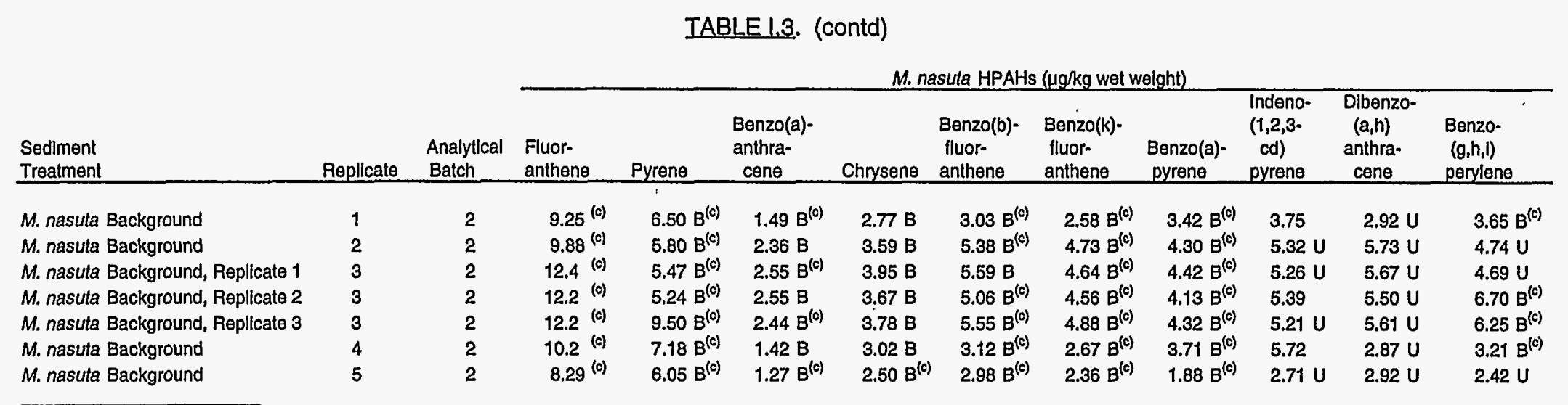

(a) DL Detection limit.

(b) U Undetected at or above detection limit.

(c) Ratio of confirmation ion to primary lon is outside of the theorelical ratio of

$20 \%$ established for EPA-CLP programs.

(d) B Analyte detected in sample at less than five times the value in assoclated method blank. 
TABLE 1.4. Total Detected Polynuclear Aromatic Hydrocarbons (PAHs), Dry Weight, in Tissue of $M$. nasuta, Older Bay Mud Study

\begin{tabular}{|c|c|c|c|c|c|c|}
\hline \multirow[b]{2}{*}{$\begin{array}{l}\text { Sediment } \\
\text { Treatment }\end{array}$} & \multirow[b]{2}{*}{ Replicate } & \multirow[b]{2}{*}{ Analytical } & \multirow[b]{2}{*}{$\begin{array}{c}\text { Percent } \\
\text { Dry }\end{array}$} & \multicolumn{3}{|c|}{ M. nasuta PAHs ( $\mu \mathrm{g} / \mathrm{kg}$ dry weight) } \\
\hline & & & & $\begin{array}{l}\text { Total } \\
\text { Low Molecular } \\
\text { Weight PAHs }\end{array}$ & $\begin{array}{l}\text { Total } \\
\text { High Molecular } \\
\text { Weight PAHs }\end{array}$ & $\begin{array}{l}\text { Total } \\
\text { PAHs }\end{array}$ \\
\hline
\end{tabular}

January 1993

OBM COMP
OBM COMP
OBM COMP
OBM COMP
OBM COMP, Replicate 1
OBM COMP, Replicate 2

1
2
3
4
5
5

1

1

1

1

1

January 1994

\section{R-OS}

R-OS, Replicate 1

R-OS, Replicate 2

R-OS, Replicate 3

R-OS

R-OS

R-OS

R-BF
R-BF
R-BF
R-BF
R-BF

R-AM
R-AM
R-AM
R-AM
R-AM
C-SB
C-SB
C-SB
C-SB
C-SB

M. nasuta Background

M. nasuta Background

M. nasuta Background, Replicate 1

M. nasuta Background, Replicate 2

M. nasuta Background, Replicate 3

M. nasula Background

M. nasuta Background

$\begin{array}{llll}13.6 & 0 & 0 & 0 \\ 13.2 & 0 & 0 & 0 \\ 12.3 & 0 & 0 & 0 \\ 12.3 & 0 & 0 & 0 \\ 11.4 & 0 & 0 & 0 \\ 12.0 & 0 & 0 & 0\end{array}$

$\begin{array}{rrrr}12.7 & 12 & 85 & 97 \\ 12.6 & 16 & 119 & 135 \\ 12.6 & 20 & 91 & 111 \\ 12.6 & 16 & 114 & 130 \\ 13.8 & 25 & 73 & 98 \\ 12.7 & 24 & 94 & 118 \\ 13.4 & 13 & 71 & 84\end{array}$

$\begin{array}{llll}15.3 & 29 & 423 & 452\end{array}$

$\begin{array}{llll}14.6 & 47 & 449 & 496\end{array}$

$\begin{array}{llll}14.8 & 73 & 323 & 396\end{array}$

$\begin{array}{llll}15.9 & 23 & 310 & 333\end{array}$

$\begin{array}{llll}14.9 & 13 & 300 & 313\end{array}$

$\begin{array}{llll}15.8 & 293 & 3321 & 3614\end{array}$

$\begin{array}{llll}13.8 & 212 & 2072 & 2284\end{array}$

$\begin{array}{llll}15.4 & 323 & 3188 & 3511\end{array}$

$\begin{array}{llll}14.5 & 276 & 2414 & 2690\end{array}$

$\begin{array}{llll}14.7 & 375 & 2739 & 3114\end{array}$

$\begin{array}{llll}14.4 & 23 & 122 & 146\end{array}$

$\begin{array}{llll}13.3 & 26 & 292 & 317\end{array}$

$\begin{array}{llll}14.0 & 26 & 137 & 163\end{array}$

$\begin{array}{llll}13.6 & 22 & 138 & 160\end{array}$

$\begin{array}{llll}13.6 & 22 & 130 & 152\end{array}$

$\begin{array}{llll}13.5 & 53 & 271 & 324\end{array}$

$\begin{array}{llll}12.0 & 63 & 300 & 363\end{array}$

$\begin{array}{llll}13.1 & 75 & 299 & 374\end{array}$

$\begin{array}{llll}13.1 & 87 & 379 & 466\end{array}$

$\begin{array}{llll}13.1 & 52 & 375 & 427\end{array}$

$\begin{array}{llll}14.2 & 57 & 283 & 340\end{array}$

$\begin{array}{llll}17.7 & 44 & 144 & 187\end{array}$

OLDER BAY MUD 
TABLE 1.5. Low Molecular Weight Polynuclear Aromatic Hydrocarbons (LPAHs), Dry Weight, in Tissue of M. nasuta, Older Bay Mud Study

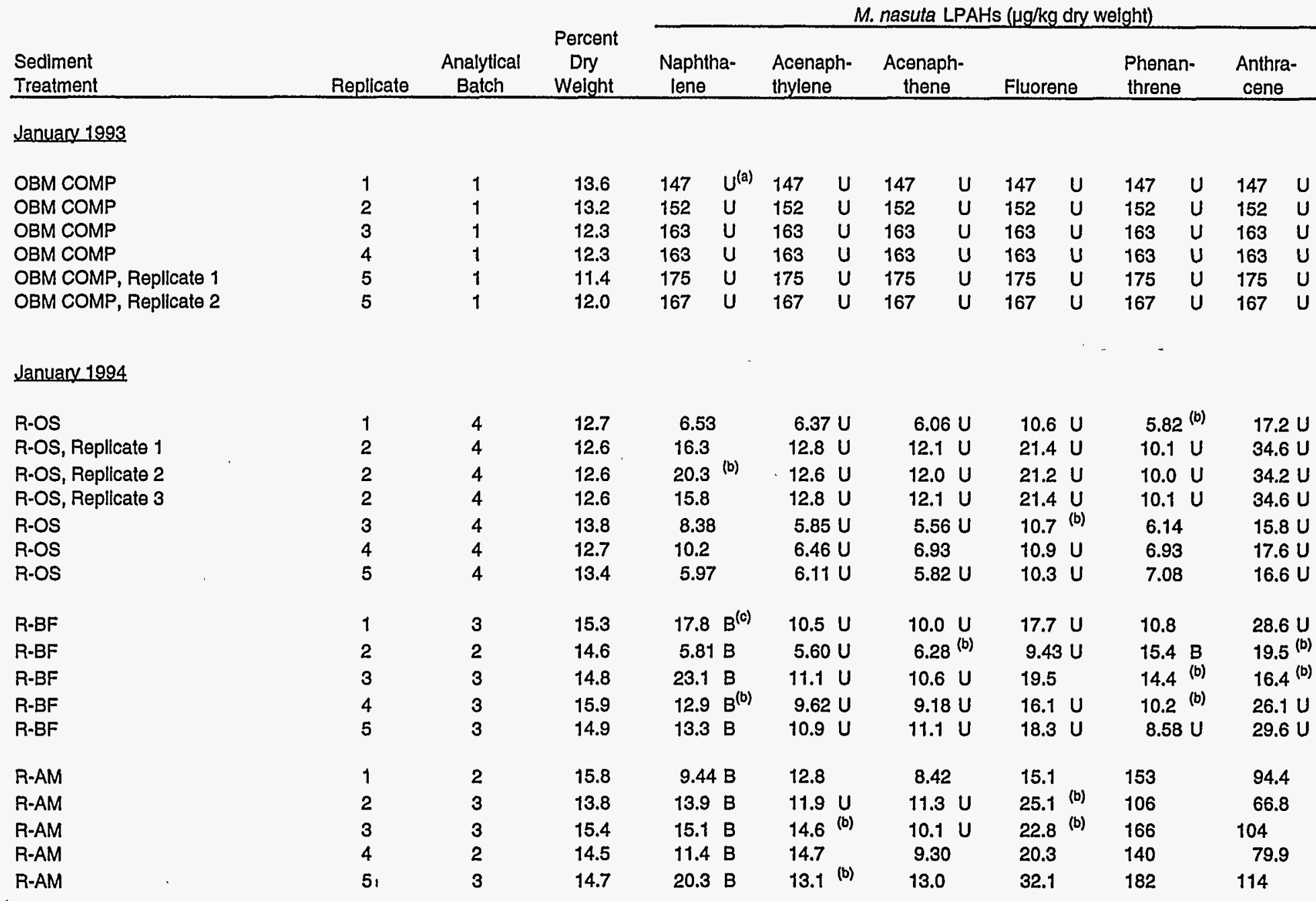




\begin{tabular}{|c|c|c|c|c|c|c|c|c|c|}
\hline \multirow[b]{2}{*}{$\begin{array}{l}\text { Sediment } \\
\text { Treatment }\end{array}$} & \multirow[b]{2}{*}{ Replicate } & \multirow[b]{2}{*}{$\begin{array}{l}\text { Analytical } \\
\text { Batch }\end{array}$} & \multicolumn{3}{|c|}{ TABLE 1.5 . (contd) } & \multicolumn{3}{|c|}{ M. nasuta LPAHs ( $\mu \mathrm{g} / \mathrm{kg}$ dry weight) } & \\
\hline & & & $\begin{array}{l}\text { Percent } \\
\text { Dry } \\
\text { Welght } \\
\end{array}$ & $\begin{array}{l}\text { Naphtha- } \\
\text { lene }\end{array}$ & $\begin{array}{l}\text { Acenaph- } \\
\text { thylene }\end{array}$ & $\begin{array}{c}\text { Acenaph- } \\
\text { thene }\end{array}$ & Fluorene & $\begin{array}{l}\text { Phenan- } \\
\text { threne }\end{array}$ & $\begin{array}{l}\text { Anthra- } \\
\text { cene }\end{array}$ \\
\hline C-SB & 1 & 4 & 14.4 & 13.3 & $5.61 \mathrm{U}$ & $5.34 \mathrm{U}$ & $9.36 \mathrm{U}$ & 10.0 & $15.1 U$ \\
\hline C-SB & 2 & 4 & 13.3 & 11.1 & $6.11 \mathrm{U}$ & $7.62^{(b)}$ & $10.2 U$ & $6.94^{\text {(b) }}$ & $16.5 \mathrm{U}$ \\
\hline C-SB & 3 & 4 & 14.0 & $5.70^{(b)}$ & $5.84 \mathrm{U}$ & $5.56 \mathrm{U}$ & $10.5^{\text {(b) }}$ & $10.0^{\text {(b) }}$ & $15.9 \mathrm{U}$ \\
\hline C-SB & 4 & 4 & 13.6 & $11.5^{\text {(b) }}$ & $5.97 \mathrm{U}$ & $5.67 \mathrm{U}$ & $9.95 \mathrm{U}$ & $10.5^{\text {(b) }}$ & $16.1 \mathrm{U}$ \\
\hline C-SB & 5 & 4 & 13.6 & $12.4^{\text {(b) }}$ & $6.03 \mathrm{U}$ & $5.74 \mathrm{U}$ & $10.1 \mathrm{U}$ & $9.41^{\text {(b) }}$ & $16.4 U$ \\
\hline M. nasuta Background & 1 & 2 & 13.5 & $8.40 \mathrm{~B}$ & $6.09 \mathrm{U}$ & $6.61^{(b)}$ & $10.3 \mathrm{U}$ & $21.2 \mathrm{~B}$ & $17.2^{(b)}$ \\
\hline M. nasuta Background & 2 & 2 & 12.0 & $18.0 \mathrm{~B}^{(b)}$ & $13.4 \mathrm{U}$ & 15.8 & $22.5 U$ & $28.8 \mathrm{~B}$ & $36.4 \mathrm{U}$ \\
\hline M. nasuta Background, Replicate 1 & 3 & 2 & 13.1 & $13.5 \mathrm{~B}^{(b)}$ & $12.2 \mathrm{U}$ & $11.6 \mathrm{U}$ & $20.5 \mathrm{U}$ & $27.8 \mathrm{~B}$ & $33.6^{(b)}$ \\
\hline M. nasuta Background, Replicate 2 & 3 & 2 & 13.1 & $11.9 B^{(b)}$ & $11.9 \mathrm{U}$ & $12.3^{\text {(b) }}$ & $19.8 \mathrm{U}$ & $28.7 \mathrm{~B}$ & 33.9 \\
\hline M. nasuta Background, Replicate 3 & 3 & 2 & 13.1 & $10.1 B^{(b)}$ & $12.1 U$ & $13.2^{\text {(b) }}$ & $20.2 U$ & $28.2 \mathrm{~B}$ & $32.8 \mathrm{U}$ \\
\hline M. nasuta Background & 4 & 2 & 14.2 & $6.19 \mathrm{~B}^{(b)}$ & $5.70 U$ & 8.37 & $9.50 \mathrm{U}$ & $25.9 \mathrm{~B}$ & $16.5^{\text {(b) }}$ \\
\hline M. nasuta Background & 5 & 2 & 17.7 & $4.70 B^{(b)}$ & $5.50^{(b)}$ & $4.87^{\text {(b) }}$ & $7.82 \mathrm{U}$ & $15.2 \mathrm{~B}$ & $13.5^{(b)}$ \\
\hline
\end{tabular}

(a) U Undetected at or above detection limit.

(b) Ratlo of confirmation lon to primary lon is outside of the theoretical ratio of $20 \%$ established for EPA-CLP programs.

(c) B Analyte detected in sample at less than five times value in associated method blank. 
TABLE 1.6. High Molecular Weight Polynuclear Aromatic Hydrocarbons (HPAHs), Dry Weight, in Tissue of M. nasuta, Older Bay Mud Study

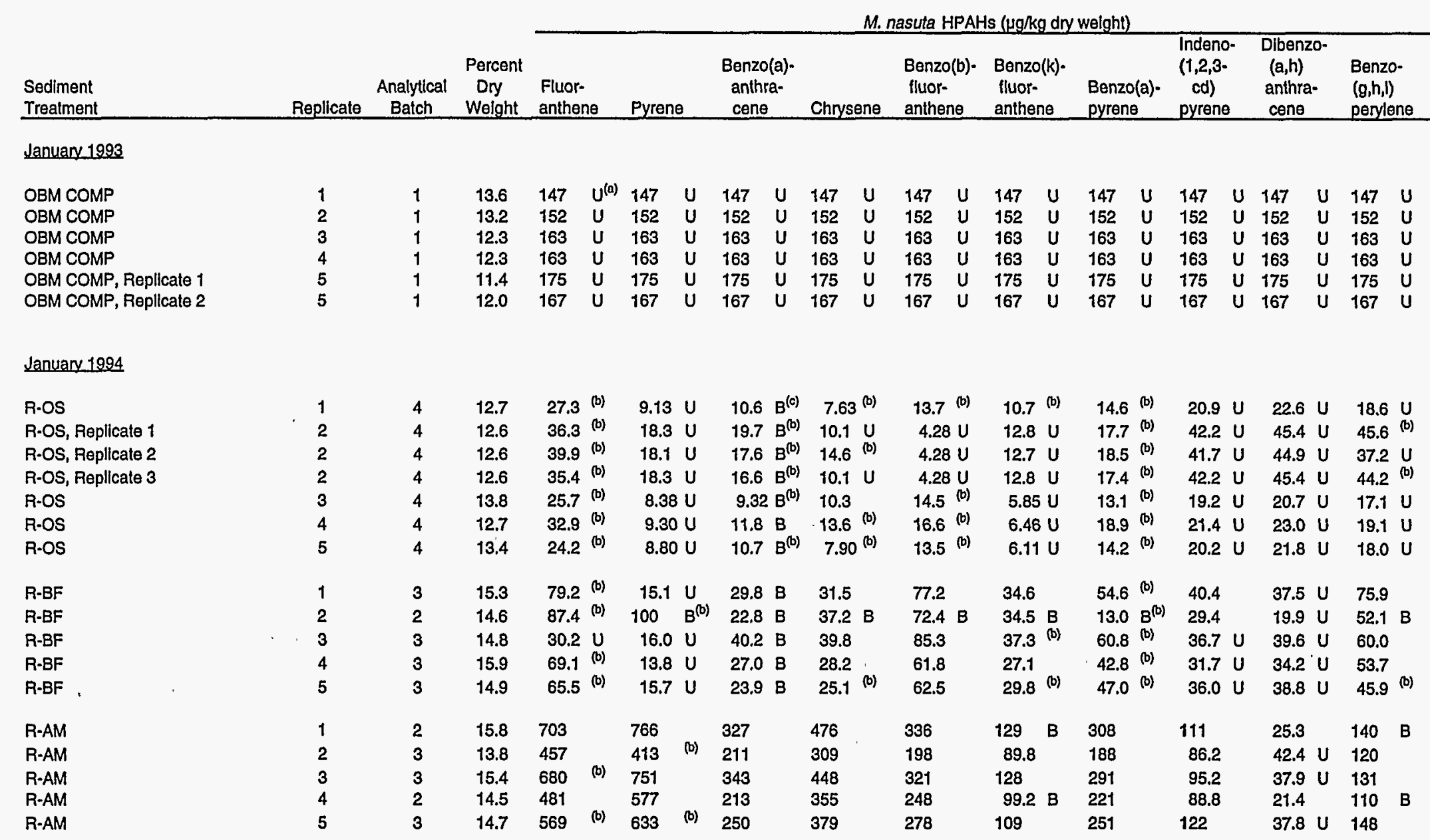




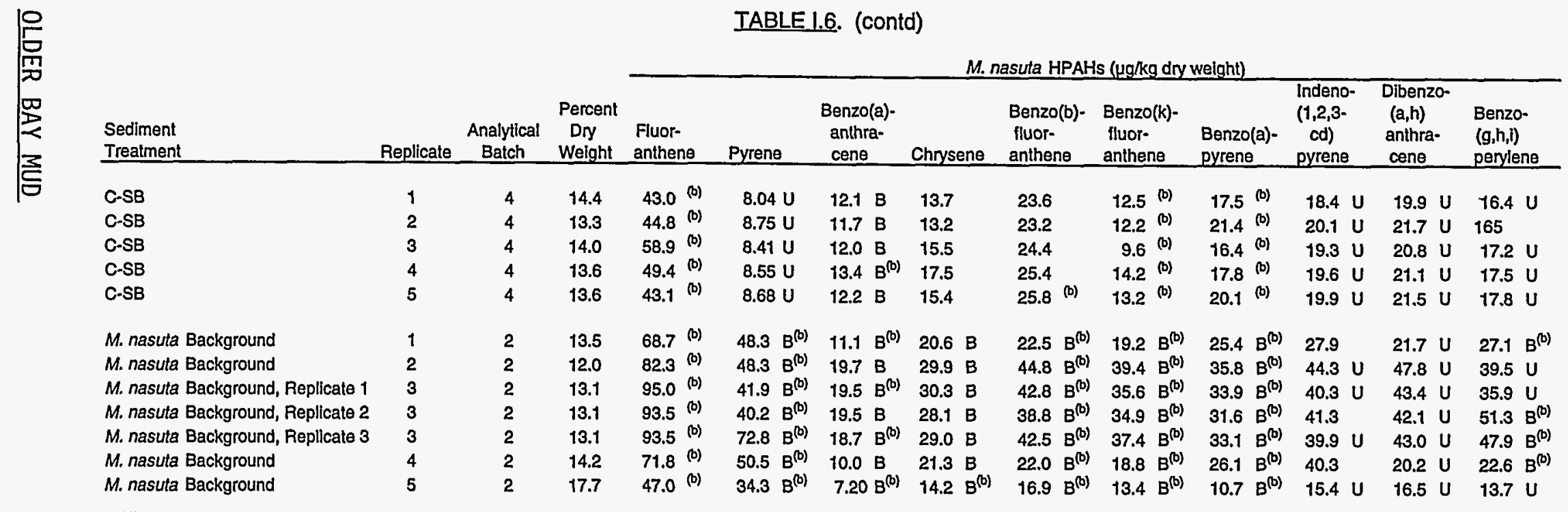

(1) (a) U Undetected at or above detection limit.

is (b) Ratlo of confirmation lon to primary lon is outside of the theoretical ratlo of

$20 \%$ established for EPA-CLP programs.

(c) B Analyte detected In sample at less than five times value in assoclated method blank. 


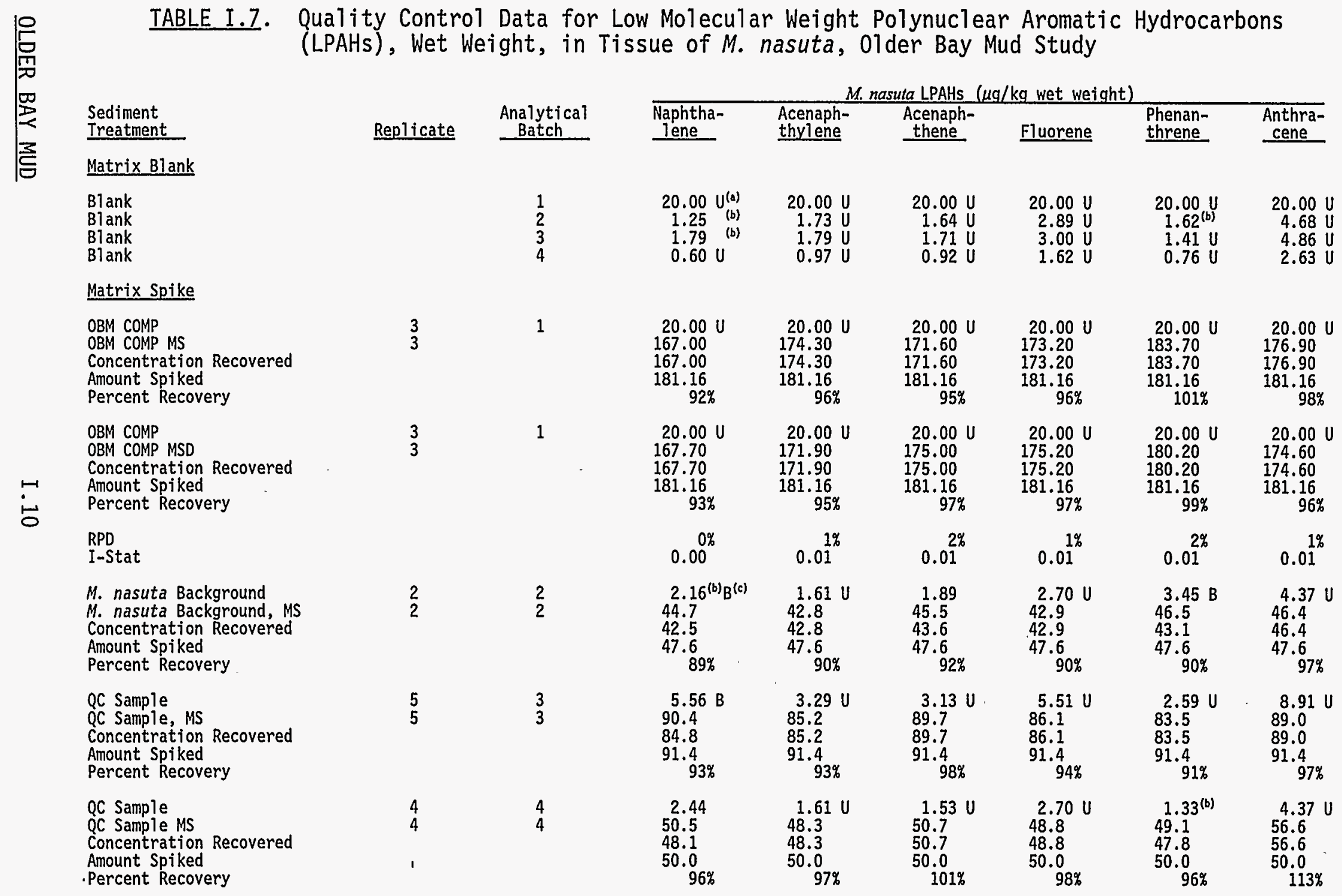


TABLE I.7. (contd)

Sediment

Analytical

\begin{tabular}{llll}
\multicolumn{5}{c}{ M. nasuta LPAHs ( $\mu \mathrm{g} / \mathrm{kg}$ wet weight) } \\
$\begin{array}{l}\text { Naphtha- } \\
\text { lene }\end{array}$ & $\begin{array}{l}\text { Acenaph- } \\
\text { thylene }\end{array}$ & $\begin{array}{l}\text { Acenaph- } \\
\text { thene }\end{array}$ Fluorene threne & Anthra- \\
cene
\end{tabular}

\section{Standard Reference Material}

Certified

Value NIST 1974

NIST 1974

$$
\underset{N A^{(0)}}{N(d)}
$$

Analytical Replicates

OBM COMP, Replicate 1

OBM COMP, Replicate

5
5

1

$20.00 \mathrm{U}$

$20.00 \mathrm{U}$

$20.00 \mathrm{U}$

NA

NC

NA

NC

5.6
\pm 1.4

0.75

RPD

I-Stat

M. nasuta Background, Replicate 13

M. nasuta Background, Replicate 23

$\begin{array}{ll}3 & 2 \\ 3 & 2 \\ 3 & 2\end{array}$

2
2
2

$\mathrm{NA}$

NA

$20.00 \mathrm{U}$

$20.00 \mathrm{U}$

$20.00 \mathrm{U}$

$20.00 \mathrm{U}$

$\mapsto \quad$ RSD

QC Sample, Replicate 1

QC Sample, Replicate 2

$\begin{array}{ll}2 & 3 \\ 2 & 3 \\ 2 & 3\end{array}$

$1.76^{(b)} B \quad 1.59 \mathrm{U}$

$1.55^{(b)} \mathrm{B}$

$1.55 \mathrm{U}$

NA

$20.00 \mathrm{U}$

$20.00 \mathrm{U}$

$20.00 \mathrm{U}$

QC Sample, Replicate 3

\section{$14 \%$}

NA

$1.52 \mathrm{U}$
$1.61^{(b)}$

$1.61^{(b)}$

NA

$20.00 \mathrm{U}$

$20.00 \mathrm{U}$

RSD

$\begin{array}{ll}3.58^{(\mathrm{b})} \mathrm{B} & 3.02 \mathrm{U} \\ 4.80 \mathrm{~B} & 2.96 \mathrm{U}\end{array}$

$\begin{array}{ll}4.80 \mathrm{~B} & 2.96 \mathrm{U}\end{array}$

$\mathrm{NA}$

$2.67 \mathrm{U}$

$2.59 \mathrm{U}$

$2.64 \mathrm{U}$

NA

NA

$22 \%$

NA

$2.88 \mathrm{U}$

$2.75 \mathrm{U}$

NA

$3.63 \mathrm{~B}$

$3.75 \mathrm{~B}$

$3.68 \mathrm{~B}$

$4.39^{(b)}$

$4.39(0)$
4.42

R-OS, Replicate

$R-O S, R$

R-OS, Replicate 3

$\begin{array}{ll}2 & 4 \\ 2 & 4 \\ 2 & 4\end{array}$

RSD

$$
\begin{aligned}
& 2.06 \\
& 2.56^{(b)} \\
& 2.00
\end{aligned}
$$$$
14 \%
$$

NA

$1.53 \mathrm{U}$

$1.53 \mathrm{U}$

NA
$5.07 \mathrm{U}$

$4.85 \mathrm{U}$

NA

$2.70 \mathrm{U}$

$2.67 \mathrm{U}$

NA
$2 \%$

NA

$2.38 \mathrm{U} \quad 8.20 \mathrm{U}$

$2.28 \mathrm{U} \quad 7.84 \mathrm{U}$

NA

NA

$1.27 \mathrm{U}$

$1.26 \mathrm{U}$

NA

$4.37 \mathrm{v}$

$4.32 \mathrm{U}$

$4.37 \mathrm{U}$

NA

(a) U Undetected at or above detection limit.

(b) Ratio of confirmation ion to primary ion is outside of the theoretical ratio of $20 \%$ established for EPA-CLP programs.

(c) B Analyte detected in sample at less than five times value in associated method blank.

d) NC Not certified. 


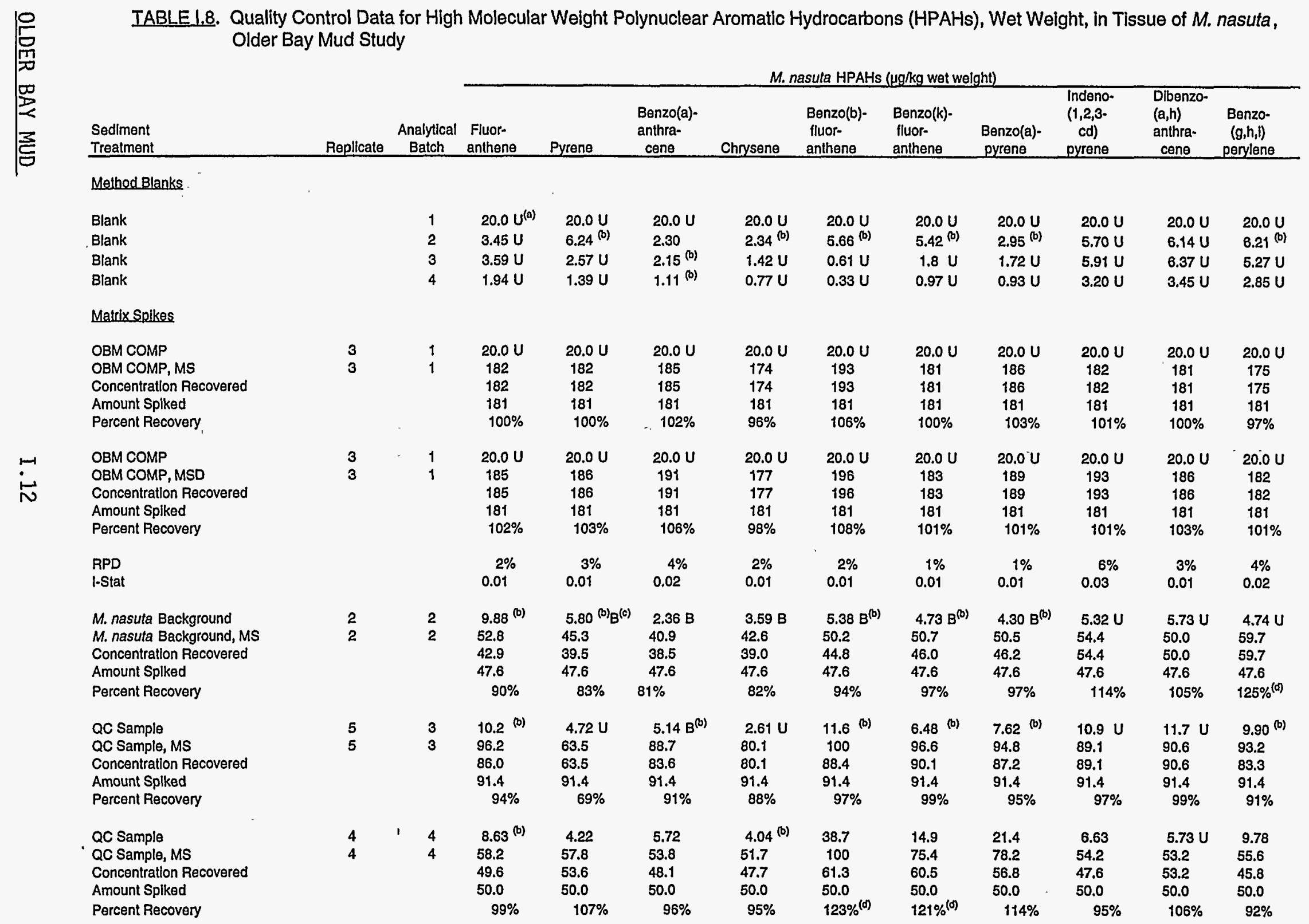


IABLE 1.8. (contd)

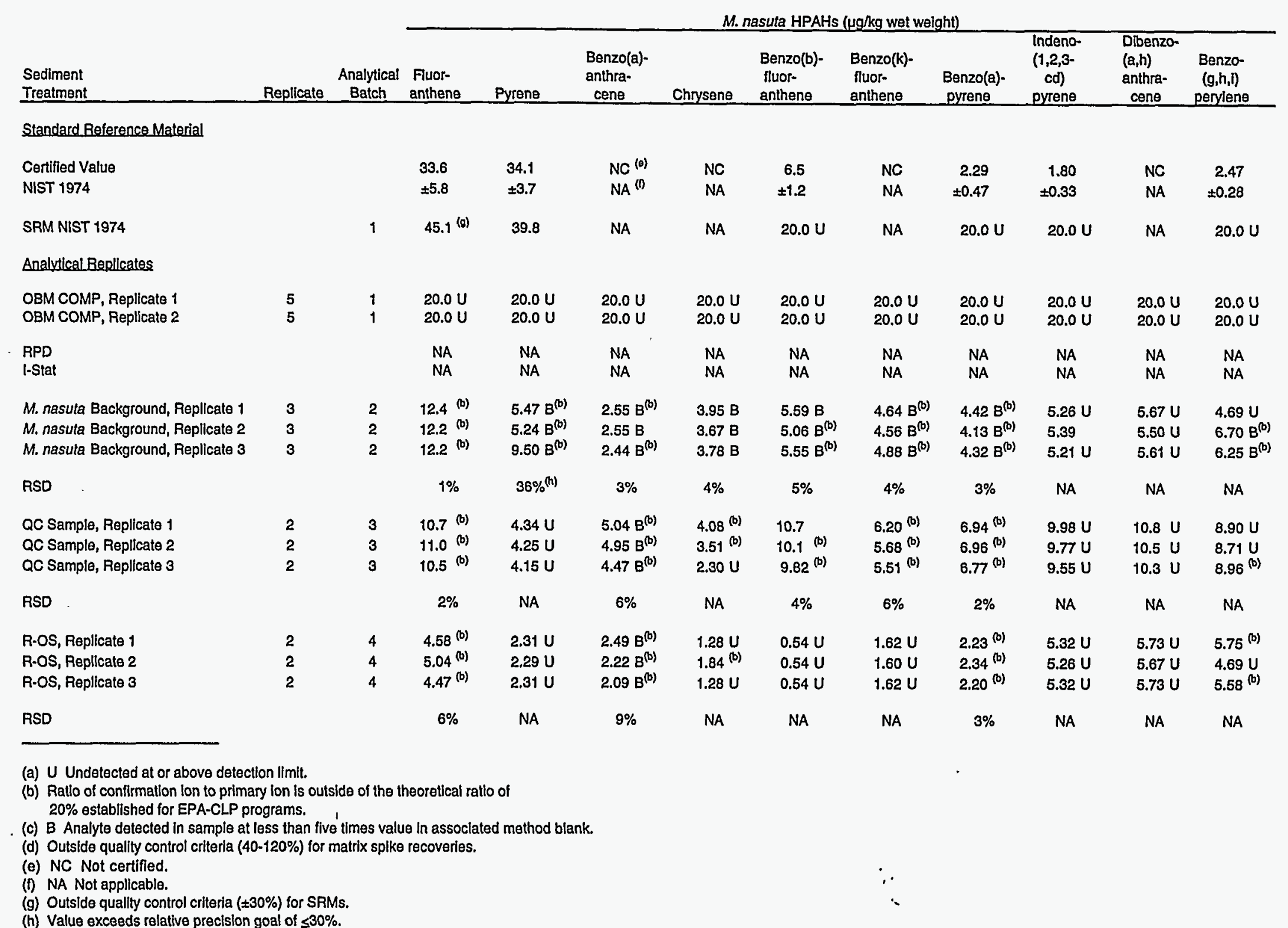




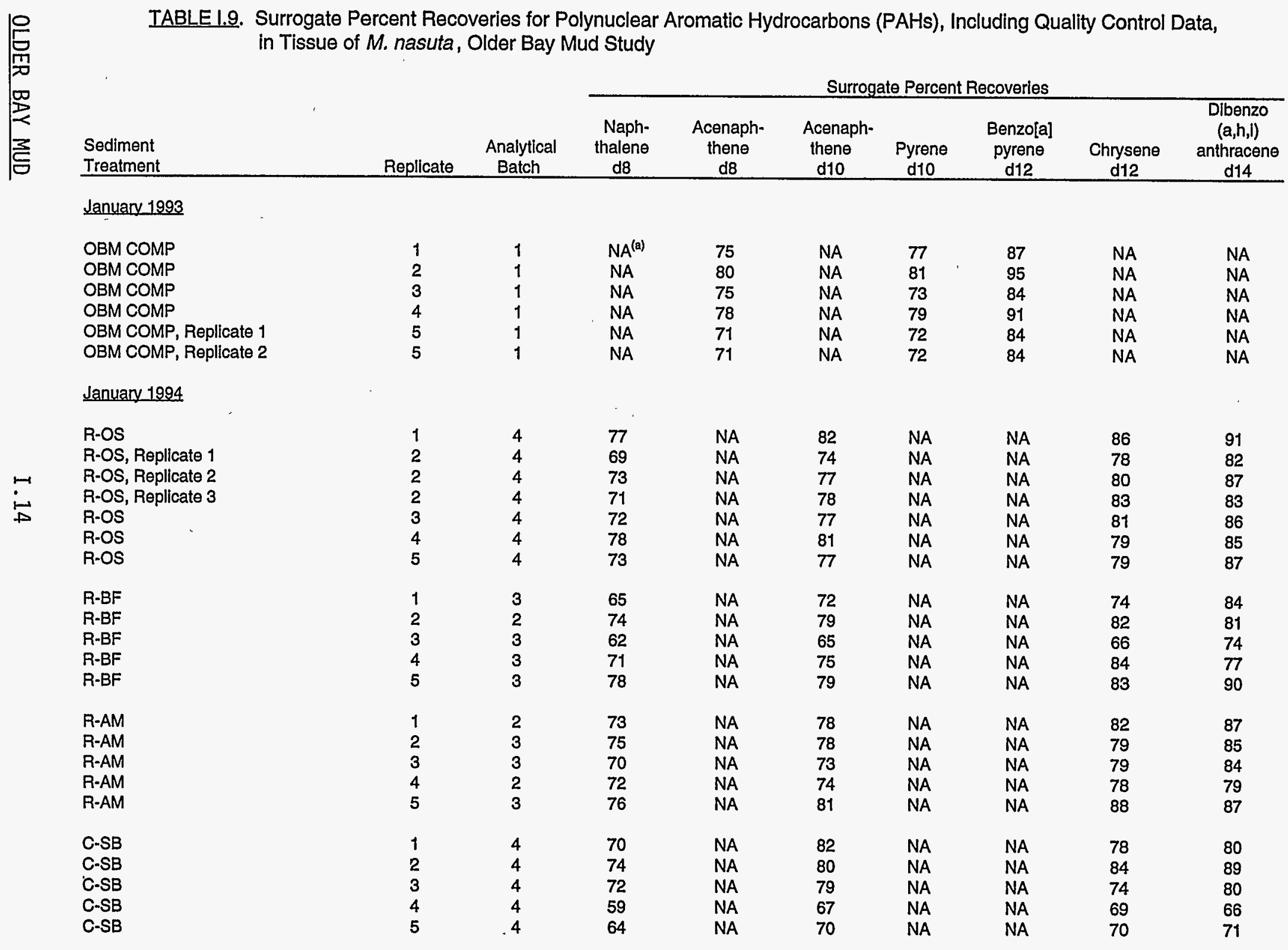


TABLE 1.9. (contd)

Surrogate Percent Recoveries

Sediment

Treatment

M. nasuta Background

M. nasuta Background

M. nasuta Background, Replicate 1

M. nasuta Background, Replicate 2

M. nasuta Background, Replicate 3

$M$. nasuta Background

M. nasuta Background

the

Quality Control Data

\section{Method Blanks}

\section{Blank}

Blank

Blank

$\mapsto \quad$ Blank

Matrix Spikes

OBM COMP MS

OBM COMP MSD

M. nasuta Background

M. nasuta Background, MS

QC Sample

QC Sample, MS

QC Sample

QC Sample, MS

Standard Reference Material

SRM NIST 1974

$\begin{array}{ll}3 & 1 \\ 3 & 1 \\ 2 & 2 \\ 2 & 2 \\ 5 & 3 \\ 5 & 3 \\ 4 & 4 \\ 4 & 4\end{array}$

$N A$
82
76
58

$\begin{array}{ll}84 & \text { NA } \\ \text { NA } & 77 \\ \text { NA } & 73 \\ \text { NA } & 57\end{array}$

NA
77
73
57

91
NA
NA
NA

99
$N A$
$N A$
$N A$

NA
77
71
73

NA

47

69
78

$\begin{array}{lllllll}\text { NA } & 80 & \text { NA } & 79 & 93 & \text { NA } & \text { NA } \\ \text { NA } & 77 & \text { NA } & 79 & 93 & \text { NA } & \text { NA } \\ 65 & \text { NA } & 71 & \text { NA } & \text { NA } & 72 & 69 \\ 67 & \text { NA } & 72 & \text { NA } & \text { NA } & 76 & 73 \\ 73 & \text { NA } & 76 & \text { NA } & \text { NA } & 75 & 85 \\ 76 & \text { NA } & 78 & \text { NA } & \text { NA } & 81 & 86 \\ 71 & \text { NA } & 77 & \text { NA } & \text { NA } & 91 & 75 \\ 76 & \text { NA } & 80 & \text { NA } & \text { NA } & 85 & 90\end{array}$

68

69

69

68
75

81

87

NA

87

104

NA

NA 
IABLE 1.9. (contd)

覂

\begin{tabular}{l} 
Sediment \\
Treatment \\
\hline Analytical Replicates \\
OBM COMP, Replicate 1 \\
OBM COMP, Replicate 2 \\
M. nasuta Background, Replicate 1 \\
M. nasuta Background, Replicate 2 \\
M. nasuta Background, Replicate 3 \\
QC Sample, Replicate 1 \\
QC Sample, Replicate 2 \\
QC Sample, Replicate 3 \\
R-OS, Replicate 1 \\
R-OS, Replicate 2 \\
R-OS, Replicate 3 \\
\hline
\end{tabular}

(a) NA Not applicable. 


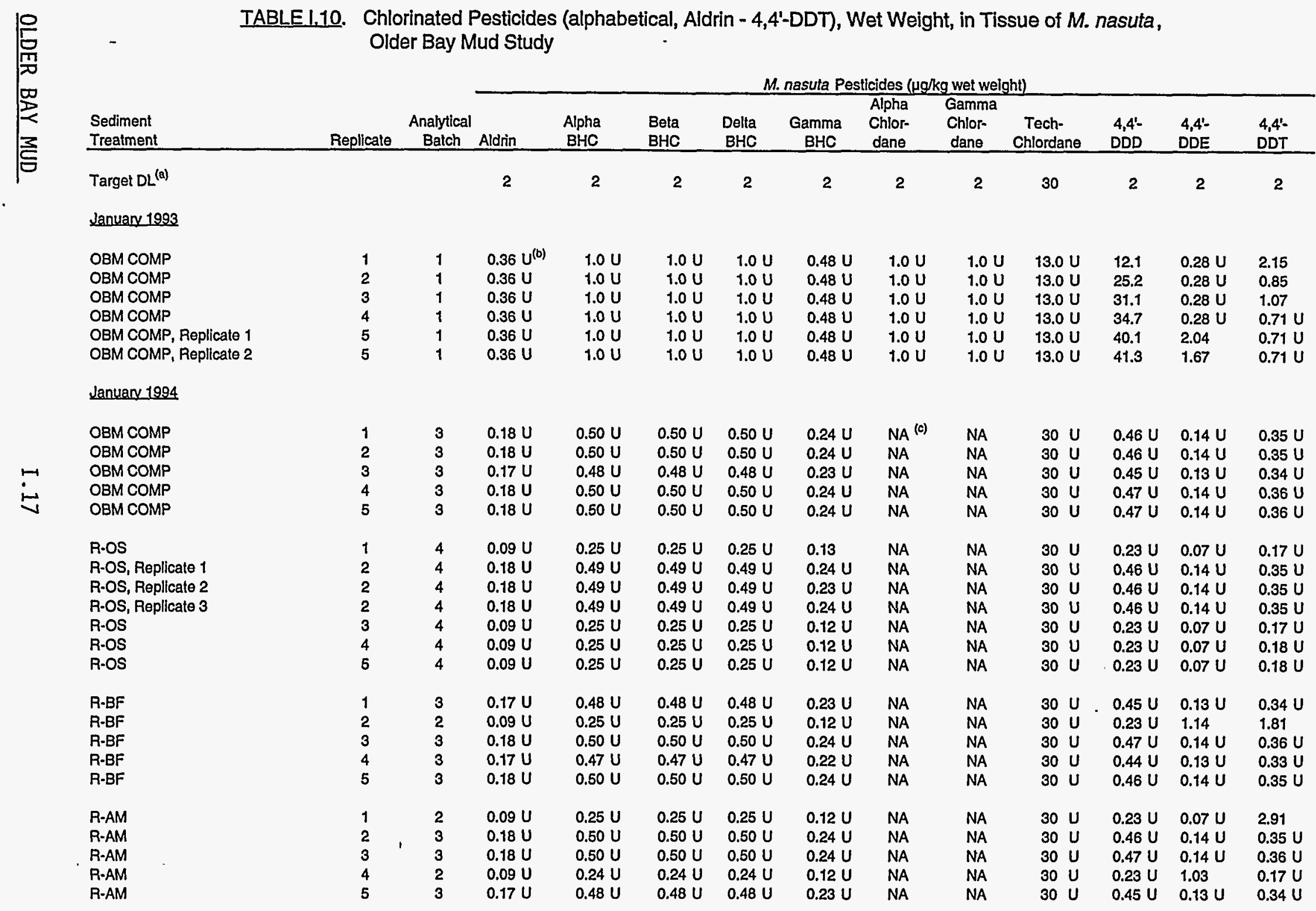




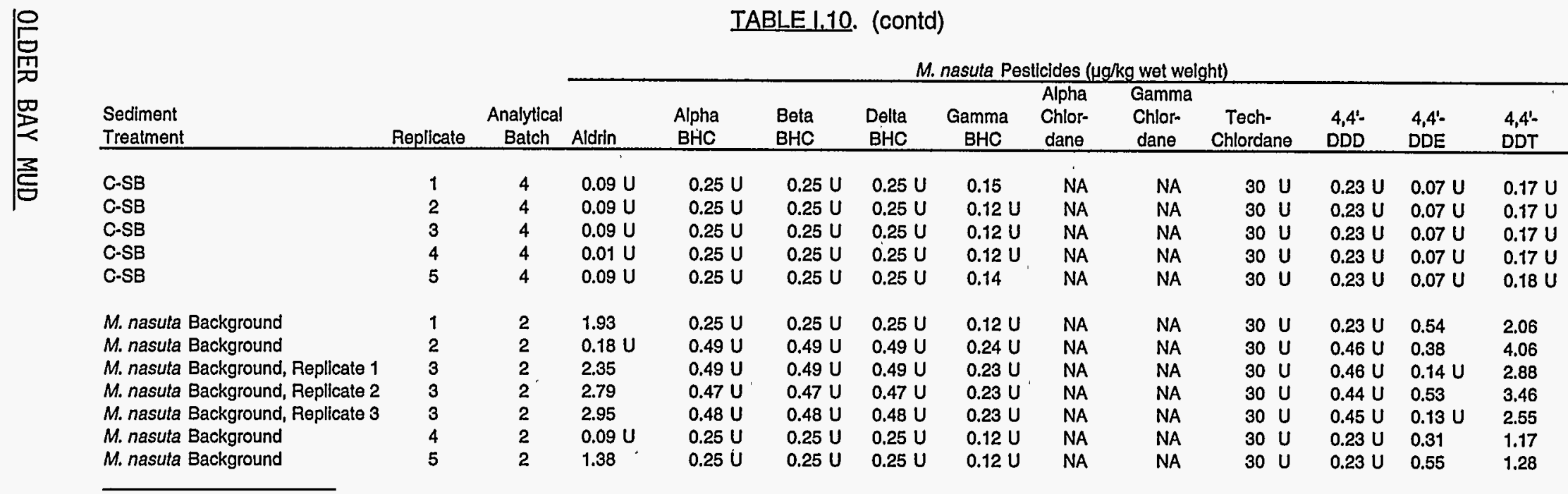

(a) DL Detectlon limit.

(b) U Undetected at or above detection limit.

(c) NA Not applicable. 
TABLE 1.11. Chlorinated Pesticides (alphabetical, Dieldrin - Toxaphene), Wet Weight, in Tissue of $M$. nasuta, Older Bay Mud Study

\begin{tabular}{|c|c|c|c|c|c|c|c|c|c|c|c|}
\hline \multirow[b]{2}{*}{$\begin{array}{l}\text { Sediment } \\
\text { Treatment }\end{array}$} & \multirow[b]{2}{*}{ Replicate } & \multirow[b]{2}{*}{$\begin{array}{c}\text { Analytical } \\
\text { Batch }\end{array}$} & \multicolumn{9}{|c|}{ M. nasuta Pesticides ( $\mu \mathrm{g} / \mathrm{kg}$ wet weight) } \\
\hline & & & Dieldrin & $\begin{array}{l}\text { Endo- } \\
\text { Sulfan } 1 \\
\end{array}$ & $\begin{array}{l}\text { Endo- } \\
\text { Sulfan ll }\end{array}$ & $\begin{array}{l}\text { Endo- } \\
\text { Sulfan- } \\
\text { Sulfate }\end{array}$ & Endrin & $\begin{array}{l}\text { Endrin } \\
\text { Aldehyde } \\
\end{array}$ & $\begin{array}{l}\text { Hepta- } \\
\text { chlor }\end{array}$ & $\begin{array}{l}\text { Hepta- } \\
\text { chlor } \\
\text { epoxide }\end{array}$ & $\begin{array}{l}\text { Toxa- } \\
\text { phene }\end{array}$ \\
\hline Target $\mathrm{DL}^{(a)}$ & & & 2 & 2 & 2 & 2 & 2 & 2 & 2 & 2 & 30 \\
\hline \multicolumn{12}{|l|}{ Januare 1993} \\
\hline OBM COMP & 1 & 1 & $1.0 \mathrm{U}^{(\mathrm{b})}$ & $1.0 \mathrm{U}$ & $1.0 \mathrm{U}$ & $1.0 \mathrm{U}$ & $1.0 \mathrm{U}$ & $1.0 \mathrm{U}$ & $0.30 \mathrm{U}$ & $0.98 \mathrm{U}$ & $16.0 \mathrm{U}$ \\
\hline OBM COMP & 2 & 1 & 2.57 & $1.0 \mathrm{U}$ & $1.0 \mathrm{U}$ & $1.0 \mathrm{U}$ & $1.0 \mathrm{U}$ & $1.0 \mathrm{U}$ & $0.30 \mathrm{U}$ & $0.98 \mathrm{U}$ & $16.0 \mathrm{U}$ \\
\hline OBM COMP & 3 & 1 & 1.94 & $1.0 \mathrm{U}$ & $1.0 \mathrm{U}$ & $1.0 \mathrm{U}$ & $1.0 \mathrm{U}$ & $1.0 \mathrm{U}$ & $0.30 \mathrm{U}$ & $0.98 \mathrm{U}$ & $16.0 \mathrm{U}$ \\
\hline OBM COMP & 4 & 1 & 2.64 & $1.0 \mathrm{U}$ & $1.0 \mathrm{U}$ & $1.0 \mathrm{U}$ & $1.0 \mathrm{U}$ & $1.0 \mathrm{U}$ & $0.30 \mathrm{U}$ & $0.98 \mathrm{U}$ & $16.0 \mathrm{U}$ \\
\hline OBM COMP, Replicate 1 & 5 & 1 & 3.21 & $1.0 \mathrm{U}$ & $1.0 \mathrm{U}$ & $1.0 \mathrm{U}$ & $1.0 \mathrm{U}$ & $1.0 \mathrm{U}$ & $0.30 \mathrm{U}$ & $0.98 \mathrm{U}$ & $16.0 \mathrm{U}$ \\
\hline OBM COMP, Replicate 2 & 5 & 1 & 3.38 & $1.0 \mathrm{U}$ & $1.0 \mathrm{U}$ & $1.0 \mathrm{U}$ & $1.0 \mathrm{U}$ & $1.0 \mathrm{U}$ & $0.30 \mathrm{U}$ & $0.98 \mathrm{U}$ & $16.0 \mathrm{U}$ \\
\hline \multicolumn{12}{|l|}{ Januany 1994} \\
\hline OBM СOMP & 1 & 3 & $0.31 U$ & $0.50 \mathrm{U}$ & $0.50 \mathrm{U}$ & $0.50 \mathrm{U}$ & $0.50 \mathrm{U}$ & $0.50 \mathrm{U}$ & $0.15 \mathrm{U}$ & $0.48 \mathrm{U}$ & $30 \mathrm{U}$ \\
\hline OBM СОMP & 2 & 3 & $0.31 \mathrm{U}$ & $0.50 \mathrm{U}$ & $0.50 \mathrm{U}$ & $0.50 \mathrm{U}$ & $0.50 \mathrm{U}$ & $0.50 \mathrm{U}$ & $0.15 \mathrm{U}$ & $0.48 U$ & $30 \mathrm{U}$ \\
\hline OBM COMP & 3 & 3 & $0.31 \mathrm{U}$ & $0.48 U$ & $0.48 U$ & $0.48 U$ & $0.48 \mathrm{U}$ & $0.48 \mathrm{U}$ & $0.14 \mathrm{U}$ & $0.47 \mathrm{U}$ & $30 \mathrm{U}$ \\
\hline OBM COMP & 4 & 3 & $0.32 \mathrm{U}$ & $0.50 \mathrm{U}$ & $0.50 \mathrm{U}$ & $0.50 \mathrm{U}$ & $0.50 \mathrm{U}$ & $0.50 \mathrm{U}$ & $0.15 \mathrm{U}$ & $0.49 \mathrm{U}$ & $30 \mathrm{U}$ \\
\hline OBM COMP & 5 & 3 & $0.32 \mathrm{U}$ & $0.50 \mathrm{U}$ & $0.50 \mathrm{U}$ & $0.50 \mathrm{U}$ & $0.50 \mathrm{U}$ & $0.50 \mathrm{U}$ & $0.15 \mathrm{U}$ & $0.49 U$ & $30 \mathrm{U}$ \\
\hline R-OS & 1 & 4 & $0.16 U$ & $0.25 \mathrm{U}$ & $0.25 \mathrm{U}$ & $0.25 \mathrm{U}$ & $0.25 \mathrm{U}$ & $0.25 \mathrm{U}$ & $0.07 \mathrm{U}$ & $0.24 U$ & $30 \mathrm{U}$ \\
\hline R-OS, Roplicate 1 & 2 & 4 & $0.31 \mathrm{U}$ & $0.49 \mathrm{U}$ & $0.49 \mathrm{U}$ & $0.49 \mathrm{U}$ & $0.49 \mathrm{U}$ & $0.49 U$ & $0.15 U$ & $0.48 U$ & $30 \mathrm{U}$ \\
\hline R-OS, Replicate 2 & 2 & 4 & $0.31 \mathrm{U}$ & $0.49 \mathrm{U}$ & $0.49 U$ & $0.49 \mathrm{U}$ & $0.49 \mathrm{U}$ & $0.49 \mathrm{U}$ & $0.15 \mathrm{U}$ & $0.47 \mathrm{U}$ & $30 \mathrm{U}$ \\
\hline R-OS, Replicate 3 & 2 & 4 & $0.31 \mathrm{U}$ & $0.49 \mathrm{U}$ & $0.49 \mathrm{U}$ & $0.49 \mathrm{U}$ & $0.49 \mathrm{U}$ & $0.49 \mathrm{U}$ & $0.15 \mathrm{U}$ & $0.48 \mathrm{U}$ & $30 \mathrm{U}$ \\
\hline R-OS & 3 & 4 & $0.16 \mathrm{U}$ & $0.25 U$ & $0.25 \mathrm{U}$ & $0.25 \mathrm{U}$ & $0.25 \mathrm{U}$ & $0.25 \mathrm{U}$ & $0.07 \mathrm{U}$ & $0.24 \mathrm{U}$ & $30 \mathrm{U}$ \\
\hline R-OS & 4 & 4 & $0.16 U$ & $0.25 \mathrm{U}$ & $0.25 \mathrm{U}$ & $0.25 \mathrm{U}$ & $0.25 \mathrm{U}$ & $0.25 \mathrm{U}$ & $0.08 \mathrm{U}$ & $0.24 U$ & $30 \mathrm{U}$ \\
\hline R.OS & 5 & 4 & $0.16 \mathrm{U}$ & $0.25 \mathrm{U}$ & $0.25 \mathrm{U}$ & $0.25 \mathrm{U}$ & $0.25 \mathrm{U}$ & $0.25 \mathrm{U}$ & $0.08 \mathrm{U}$ & $0.24 U$ & $30 \mathrm{U}$ \\
\hline R-BF & 1 & 3 & $0.31 \mathrm{U}$ & $0.48 \mathrm{U}$ & $0.48 \mathrm{U}$ & $0.48 \mathrm{U}$ & $0.48 \mathrm{U}$ & $0.48 U$ & $0.14 \mathrm{U}$ & $0.47 \mathrm{U}$ & $30 \mathrm{U}$ \\
\hline R-BF & 2 & 2 & $0.16 \mathrm{U}$ & $0.25 \mathrm{U}$ & $0.25 \mathrm{U}$ & $0.25 U$ & $0.25 \mathrm{U}$ & $0.25 \mathrm{U}$ & $0.08 \mathrm{U}$ & $0.24 U$ & $30 \mathrm{U}$ \\
\hline R-BF & 3 & 3 & $0.32 U$ & $0.50 \mathrm{U}$ & $0.50 \mathrm{U}$ & $0.50 \mathrm{U}$ & $0.50 \mathrm{U}$ & $0.50 \mathrm{U}$ & $0.15 \mathrm{U}$ & $0.49 \mathrm{U}$ & $30 \mathrm{U}$ \\
\hline R-BF & 4 & 3 & $0.30 \mathrm{U}$ & $0.47 \mathrm{U}$ & $0.47 \mathrm{U}$ & $0.47 \mathrm{U}$ & $0.47 \mathrm{U}$ & $0.47 \mathrm{U}$ & $0.14 \mathrm{U}$ & $0.46 \mathrm{U}$ & $30 \mathrm{U}$ \\
\hline A-BF & 5 & 3 & $0.31 \mathrm{U}$ & $0.50 \mathrm{U}$ & $0.50 \mathrm{U}$ & $0.50 \mathrm{U}$ & $0.50 \mathrm{U}$ & $0.50 \mathrm{U}$ & $0.15 \mathrm{U}$ & $0.48 \mathrm{U}$ & $30 \mathrm{U}$ \\
\hline R-AM & 1 & 2 & $0.16 \mathrm{U}$ & $0.25 \mathrm{U}$ & $0.25 U$ & $0.25 \mathrm{U}$ & $0.25 \mathrm{U}$ & $0.25 U$ & $0.07 \cup$ & $0.24 U$ & $30 \mathrm{U}$ \\
\hline R-AM & 2 & 3 & $0.31 \mathrm{U}$ & $0.50 \mathrm{U}$ & $0.50 \mathrm{U}$ & $0.50 \mathrm{U}$ & $0.50 \mathrm{U}$ & $0.50 \mathrm{U}$ & $0.15 \mathrm{U}$ & $0.48 \mathrm{U}$ & $30 \mathrm{U}$ \\
\hline R-AM & 31 & 3 & $0.32 \mathrm{U}$ & $0.50 \mathrm{U}$ & $0.50 \mathrm{U}$ & $0.50 \mathrm{U}$ & $0.50 \mathrm{U}$ & $0.50 \mathrm{U}$ & $0.15 \cup$ & $0.49 \mathrm{U}$ & $30 \mathrm{U}$ \\
\hline R-AM & 4 & 2 & $0.15 \mathrm{U}$ & $0.24 U$ & $0.24 U$ & $0.24 U$ & $0.24 \mathrm{U}$ & $0.24 \mathrm{U}$ & $0.07 \mathrm{U}$ & $0.24 U$ & $30 \mathrm{U}$ \\
\hline R-AM & 5 & 3 & $0.30 \mathrm{U}$ & $0.48 \mathrm{U}$ & $0.48 \mathrm{U}$ & $0.48 \mathrm{U}$ & $0.48 \mathrm{U}$ & $0.48 U$ & $0.14 U$ & $0.47 \mathrm{U}$ & $30 \mathrm{U}$ \\
\hline
\end{tabular}


Sediment

Treatment

C-SB

C-SB

C-SB

$\mathrm{C}-\mathrm{SB}$

C-SB

M. nasuta Background

$M$. nasuta Background

M. nasuta Background, Replicate 1

M. nasuta Background, Replicate 2

M. nasuta Background, Replicate 3

$M$. nasuta Background

M. nasuta Background

TABLE 1.11. (contd)

(a) DL Detection limit.

(b) U Undetected at or above detection limit.

is

M. nasuta Pestlcides ( $\mu \mathrm{g} / \mathrm{kg}$ wet weight)

Endo-

Sulfan. Endrin

Hepta-

Hepta-

chlor

Toxa-

Replicale Batch

$0.16 u$

Endo- 11 Sulfan-

$0.25 \mathrm{U}$

Aldehyde

chlor

$0.25 \mathrm{U} \quad 0.25 \mathrm{U}$

$0.25 \mathrm{U}$

$0.25 \mathrm{U}$

Aldehyde

chlor

epoxide

$0.16 \mathrm{U}$

$0.25 \mathrm{U}$

$0.25 \mathrm{U} \quad 0.25 \mathrm{U}$

$0.07 \mathrm{U}$

$30 \mathrm{U}$

$\begin{array}{lllllllll}0.16 U & 0.25 U & 0.25 U & 0.25 U & 0.25 U & 0.25 U & 0.07 U & 0.24 U & 30 U\end{array}$

$0.25 U \quad 0.25 U$

$0.07 U$

$0.24 \mathrm{U} \quad 30 \mathrm{U}$

$\begin{array}{llllllll}0.25 U & 0.25 U & 0.25 U & 0.25 U & 0.25 U & 0.01 U & 0.24 U & 30 U\end{array}$

0.16

$0.25 \mathrm{U}$

$0.25 \mathrm{U}$

$0.25 \mathrm{U}$

$0.25 \mathrm{U}$

$0.25 \mathrm{U}$

$0.08 \mathrm{U}$

$0.24 \mathrm{U}$

$30 \mathrm{U}$

$0.25 \mathrm{U}$

$0.25 \mathrm{U}$

$0.25 \mathrm{U}$

$0.25 \mathrm{U}$

$0.25 U$

$0.08 \mathrm{U}$

$0.24 \mathrm{U}$

$\begin{array}{ll}0.15 U & 0.48 U \\ 0.15 U & 0.47 U\end{array}$

$30 \mathrm{U}$

$0.31 \mathrm{U}$

$0.49 \mathrm{U}$

$0.49 \mathrm{U}$

$0.49 U$

$30 \mathrm{U}$

$0.47 \mathrm{U}$

$0.49 \mathrm{U} \quad 0.49 \mathrm{U}$

$0.49 \mathrm{U}$

$\begin{array}{lll}0.31 \mathrm{U} & 0.48 \mathrm{U} & 0.48 \mathrm{U}\end{array}$

$0.48 \mathrm{U} \quad 0.48 \mathrm{U}$

$0.48 \mathrm{U}$

$0.14 U \quad 0.47 U$

$30 \mathrm{U}$

$\begin{array}{lll}0.16 \mathrm{U} & 0.25 \mathrm{U} & 0.25 \mathrm{U}\end{array}$

$0.25 \mathrm{U}$

$0.25 \mathrm{U}$

$0.25 \mathrm{U}$

$0.07 \mathrm{U}$

$0.24 U \quad 30 \mathrm{U}$

$\begin{array}{lll}0.16 U & 0.25 \mathrm{U} & 0.25 \mathrm{U}\end{array}$

$0.25 \mathrm{U}$

$0.24 \mathrm{U}$

$30 \mathrm{U}$ 
TABLE 1.12. Chlorinated Pesticides (alphabetical, Aldrin - 4,4'-DDT), Dry Weight, in Tissue of M. nasuta, Older Bay Mud Study

\begin{tabular}{|c|c|c|c|c|c|c|c|c|c|c|c|c|c|c|}
\hline \multirow[b]{2}{*}{$\begin{array}{l}\text { Sediment } \\
\text { Treatment } \\
\end{array}$} & \multirow[b]{2}{*}{ Replicate } & \multirow[b]{2}{*}{$\begin{array}{c}\text { Analytical } \\
\text { Batch }\end{array}$} & \multirow[b]{2}{*}{$\begin{array}{c}\text { Percent } \\
\text { Dry } \\
\text { Weight }\end{array}$} & \multicolumn{11}{|c|}{ M. nasuta Pesticides ( $\mu \mathrm{g} / \mathrm{kg}$ dry weight) } \\
\hline & & & & Aldrin & $\begin{array}{l}\text { Alpha } \\
\text { BHC }\end{array}$ & $\begin{array}{l}\text { Beta } \\
\text { BHC } \\
\end{array}$ & $\begin{array}{l}\text { Delta } \\
\text { BHC }\end{array}$ & $\begin{array}{l}\text { Gamma } \\
\text { BHC }\end{array}$ & $\begin{array}{r}\text { Alpha- } \\
\text { Chlor- } \\
\text { dane } \\
\end{array}$ & $\begin{array}{c}\text { Gamma- } \\
\text { Chlor- } \\
\text { dane }\end{array}$ & $\begin{array}{r}\text { Tech- } \\
\text { Chlor- } \\
\text { dane }\end{array}$ & $\begin{array}{l}4,4^{\prime}- \\
\text { DDD }\end{array}$ & $\begin{array}{l}\text { 4,4- } \\
\text { DDE }\end{array}$ & $\begin{array}{l}4,4^{-}- \\
\text {DDT }\end{array}$ \\
\hline \multicolumn{15}{|l|}{ January 1993} \\
\hline OBM COMP & 1 & 1 & 13.6 & $2.6 U^{(a)}$ & $7.4 \mathrm{U}$ & $7.4 \mathrm{U}$ & $7.4 \mathrm{U}$ & $4.0 \mathrm{U}$ & $7.4 \mathrm{U}$ & $7.4 \mathrm{U}$ & $95.6 \mathrm{U}$ & 89.0 & $2.1 \mathrm{U}$ & 15.8 \\
\hline OBM COMP & 2 & 1 & 13.2 & $2.7 \mathrm{U}$ & $7.6 \mathrm{U}$ & $7.6 \mathrm{U}$ & $7.6 \mathrm{U}$ & $3.6 \mathrm{U}$ & $7.6 \mathrm{U}$ & $7.6 \mathrm{U}$ & $98.5 \mathrm{U}$ & 191 & $2.1 \mathrm{U}$ & 6.4 \\
\hline OBM COMP & 3 & 1 & 12.3 & $2.9 \mathrm{U}$ & $8.1 \mathrm{U}$ & $8.1 \mathrm{U}$ & $8.1 \mathrm{U}$ & $3.9 \mathrm{U}$ & $8.1 \mathrm{U}$ & $8.1 \mathrm{U}$ & $106 U$ & 253 & $2.3 \mathrm{U}$ & 8.7 \\
\hline OBM COMP & 4 & 1 & 11.4 & $3.2 \mathrm{U}$ & $8.8 \mathrm{U}$ & $8.8 \mathrm{U}$ & $8.8 \mathrm{U}$ & $4.2 U$ & $8.8 \mathrm{U}$ & $8.8 \mathrm{U}$ & $114 \mathrm{U}$ & 304 & $2.5 \mathrm{U}$ & $6.2 \mathrm{U}$ \\
\hline OBM COMP, Replicate 1 & 5 & 1 & 12.0 & $3.0 \mathrm{U}$ & $8.3 \mathrm{U}$ & $8.3 \mathrm{U}$ & $8.3 \mathrm{U}$ & $4.0 \mathrm{U}$ & $8.3 \mathrm{U}$ & $8.3 \mathrm{U}$ & $108 U$ & 334 & 17.0 & $5.9 U$ \\
\hline OBM COMP, Replicate 2 & 5 & 1 & 12.0 & $3.0 \mathrm{U}$ & $8.3 \mathrm{U}$ & $8.3 \mathrm{U}$ & $8.3 \mathrm{U}$ & $4.0 \mathrm{U}$ & $8.3 \mathrm{U}$ & $8.3 \mathrm{U}$ & $108 \mathrm{U}$ & 344 & 13.9 & $5.9 \mathrm{U}$ \\
\hline \multicolumn{15}{|l|}{ January 1994} \\
\hline OBM COMP & 1 & 3 & 14.0 & $1.28 \mathrm{U}$ & $3.6 \mathrm{U}$ & $3.6 \mathrm{U}$ & $3.6 U$ & $1.7 \mathrm{U}$ & $N A^{(b)}$ & NA & $210 U$ & $3.3 \mathrm{U}$ & $1.00 \mathrm{U}$ & $2.5 U$ \\
\hline OBM COMP & 2 & 3 & 13.2 & $1.37 \mathrm{U}$ & $3.8 \mathrm{U}$ & $3.8 \mathrm{U}$ & $3.8 \mathrm{U}$ & $1.8 \mathrm{U}$ & NA & NA & $230 \mathrm{U}$ & $3.5 \mathrm{U}$ & $1.06 \mathrm{U}$ & $2.7 \mathrm{U}$ \\
\hline OBM COMP & 3 & 3 & 12.2 & $1.39 \mathrm{U}$ & $3.9 \mathrm{U}$ & $3.9 \mathrm{U}$ & $3.9 \mathrm{U}$ & $1.9 \mathrm{U}$ & NA & NA & $250 U$ & $3.7 \mathrm{U}$ & $1.06 \mathrm{U}$ & $2.8 \mathrm{U}$ \\
\hline OBM COMP & 4 & 3 & 14.3 & $1.26 \mathrm{U}$ & $3.5 \mathrm{U}$ & $3.5 \mathrm{U}$ & $3.5 \mathrm{U}$ & $1.7 \mathrm{U}$ & NA & NA & $210 \mathrm{U}$ & $3.3 \mathrm{U}$ & $0.98 \mathrm{U}$ & $2.5 \mathrm{U}$ \\
\hline OBM COMP & 5 & 3 & 14.5 & $1.24 \mathrm{U}$ & $3.4 \mathrm{U}$ & $3.4 \mathrm{U}$ & $3.4 \mathrm{U}$ & $1.7 \mathrm{U}$ & NA & NA & $210 \mathrm{U}$ & $3.2 \mathrm{U}$ & $0.96 \mathrm{U}$ & $2.5 \mathrm{U}$ \\
\hline R.OS & 1 & 4 & 12.7 & $0.71 \mathrm{U}$ & $2.0 \mathrm{U}$ & $2.0 \mathrm{U}$ & $2.0 \mathrm{U}$ & 1.0 & NA & NA & $240 U$ & $1.8 \mathrm{U}$ & $0.6 U$ & $1.3 U$ \\
\hline R-OS, Repllicate 1 & 2 & 4 & 12.6 & $1.43 \mathrm{U}$ & $3.9 \mathrm{U}$ & $3.9 \mathrm{U}$ & $3.9 \mathrm{U}$ & $1.9 \mathrm{U}$ & NA & NA & $240 U$ & $3.6 \mathrm{U}$ & $1.11 \mathrm{U}$ & $2.8 \mathrm{U}$ \\
\hline R-OS, Replicate 2 & 2 & 4 & 12.6 & $1.43 \mathrm{U}$ & $3.9 \mathrm{U}$ & $3.9 \mathrm{U}$ & $3.9 \mathrm{U}$ & $1.8 \mathrm{U}$ & NA & NA & $240 U$ & $3.6 \mathrm{U}$ & $1.11 \mathrm{U}$ & $2.8 \mathrm{U}$ \\
\hline R-OS, Replicate 3 & 2 & 4 & 12.6 & $1.43 \mathrm{U}$ & $3.9 \mathrm{U}$ & $3.9 \mathrm{U}$ & $3.9 \mathrm{U}$ & $1.9 \mathrm{U}$ & NA & NA & $240 \mathrm{U}$ & $3.6 \mathrm{U}$ & $1.11 \mathrm{U}$ & $2.8 \mathrm{U}$ \\
\hline R-OS & 3 & 4 & 13.8 & $0.65 \mathrm{U}$ & $1.8 \mathrm{U}$ & $1.8 \mathrm{U}$ & $1.8 U$ & $0.9 \mathrm{U}$ & NA & NA & $220 \mathrm{U}$ & $1.7 \mathrm{U}$ & $0.5 \mathrm{U}$ & $1.2 \mathrm{U}$ \\
\hline R.OS & 4 & 4 & 12.7 & $0.71 \mathrm{U}$ & $2.0 \mathrm{U}$ & $2.0 \mathrm{U}$ & $2.0 \mathrm{U}$ & $0.9 \mathrm{U}$ & NA & NA & $240 \mathrm{U}$ & $1.8 \mathrm{U}$ & $0.6 \mathrm{U}$ & $1.4 U$ \\
\hline R.OS & 5 & 4 & 13.4 & $0.67 \mathrm{U}$ & $1.9 \mathrm{U}$ & $1.9 \mathrm{U}$ & $1.9 \mathrm{U}$ & $0.9 \mathrm{U}$ & NA & NA & $220 \mathrm{U}$ & $1.7 \mathrm{U}$ & $0.5 U$ & $1.3 \mathrm{U}$ \\
\hline $\mathrm{R} \cdot \mathrm{BF}$ & 1 & 3 & 15.3 & $1.11 \mathrm{U}$ & $3.1 \mathrm{U}$ & $3.1 \mathrm{U}$ & $3.1 \mathrm{U}$ & $1.5 U$ & NA & NA & $200 \mathrm{U}$ & $2.9 \mathrm{U}$ & $0.85 \mathrm{U}$ & $2.2 \mathrm{U}$ \\
\hline $\mathrm{R} \cdot \mathrm{BF}$ & 2 & 2 & 14.6 & $0.61 \mathrm{U}$ & $1.7 \mathrm{U}$ & $1.7 \mathrm{U}$ & $1.7 U$ & $0.8 \mathrm{U}$ & NA & NA & $210 \mathrm{U}$ & $1.6 \mathrm{U}$ & 7.79 & 12.4 \\
\hline$R \cdot B F$ & 3 & 3 & 14.8 & $1.22 \mathrm{U}$ & $3.4 \mathrm{U}$ & $3.4 \mathrm{U}$ & $3.4 \mathrm{U}$ & $1.6 \mathrm{U}$ & NA & NA & $200 \mathrm{U}$ & $3.2 \mathrm{U}$ & $0.95 \mathrm{U}$ & $2.4 \mathrm{U}$ \\
\hline $\mathrm{R}-\mathrm{BF}$ & 4 & 3 & 15.9 & $1.07 \mathrm{U}$ & $3.0 \mathrm{U}$ & $3.0 \mathrm{U}$ & $3.0 \mathrm{U}$ & $1.4 U$ & NA & NA & $190 U$ & $2.8 \mathrm{U}$ & $0.82 \mathrm{U}$ & $2.1 \mathrm{U}$ \\
\hline R-BF & 5 & 3 & 14.9 & $1.21 \mathrm{U}$ & $3.4 \mathrm{U}$ & $3.4 \mathrm{U}$ & $3.4 \mathrm{U}$ & $1.6 \mathrm{U}$ & NA & NA & $200 \mathrm{U}$ & $3.1 \mathrm{U}$ & $0.94 \mathrm{U}$ & $2.3 \mathrm{U}$ \\
\hline R-AM & 1 & 2 & 15.8 & $0.6 \mathrm{U}$ & $1.6 \mathrm{U}$ & $1.6 \mathrm{U}$ & $1.6 \mathrm{U}$ & $0.8 \mathrm{U}$ & NA & NA & $190 \mathrm{U}$ & $1.5 \mathrm{U}$ & $0.4 U$ & 18.4 \\
\hline R-AM & 2 & 3 & 13.8 & $1.30 \mathrm{U}$ & $3.6 \mathrm{U}$ & $3.6 \mathrm{U}$ & $3.6 \mathrm{U}$ & $1.7 \mathrm{U}$ & NA & NA & $220 \mathrm{U}$ & $3.3 \mathrm{U}$ & $1.01 \mathrm{U}$ & $2.5 \mathrm{U}$ \\
\hline R-AM & 3 & 3 & 15.4 & $1.17 \mathrm{U}$ & $3.2 \mathrm{U}$ & $3.2 \mathrm{U}$ & $3.2 U$ & $1.6 U$ & NA & NA & $190 U$ & $3.0 \mathrm{U}$ & $0.91 U$ & $2.3 \mathrm{U}$ \\
\hline R.AM & 4 & 2 & 14.5 & $0.62 \mathrm{U}$ & $1.7 \mathrm{U}$ & $1.7 \mathrm{U}$ & $1.7 U$ & $0.8 \mathrm{U}$ & NA & NA & $210 \mathrm{U}$ & $1.6 \mathrm{U}$ & 7.09 & $1.2 U$ \\
\hline R-AM & 5 & 3 & 14.7 & $1.16 \mathrm{U}$ & $3.3 \mathrm{U}$ & $3.3 \mathrm{U}$ & $3.3 \mathrm{U}$ & $1.6 U$ & NA & NA & $200 \mathrm{U}$ & $3.1 \mathrm{U}$ & $0.88 U$ & $2.3 \mathrm{U}$ \\
\hline
\end{tabular}




\begin{tabular}{|c|c|c|c|c|c|c|c|c|c|c|c|c|c|c|}
\hline \multirow[b]{2}{*}{$\begin{array}{l}\text { Sediment } \\
\text { Treatment } \\
\end{array}$} & \multirow[b]{2}{*}{ Replicate } & \multirow[b]{2}{*}{$\begin{array}{c}\text { Analytical } \\
\text { Batch }\end{array}$} & \multirow[b]{2}{*}{$\begin{array}{c}\text { Percent } \\
\text { Dy } \\
\text { Weight } \\
\end{array}$} & \multicolumn{11}{|c|}{ M. nasuta Pesticides ( $\mu \mathrm{g} / \mathrm{kg}$ dry welght) } \\
\hline & & & & Aldrin & $\begin{array}{l}\text { Alpha } \\
\text { BHC }\end{array}$ & $\begin{array}{l}\text { Beta } \\
\text { BHC }\end{array}$ & $\begin{array}{l}\text { Delta } \\
\text { BHC }\end{array}$ & $\begin{array}{l}\text { Gamma } \\
\text { BHC } \\
\end{array}$ & $\begin{array}{l}\text { Alpha- } \\
\text { Chlor- } \\
\text { dane }\end{array}$ & $\begin{array}{c}\text { Gamma- } \\
\text { Chlor- } \\
\text { dane }\end{array}$ & $\begin{array}{l}\text { Tech- } \\
\text { Chlor- } \\
\text { dane }\end{array}$ & $\begin{array}{r}4,44^{-} \\
\text {DDD }\end{array}$ & $\begin{array}{l}4,4 '- \\
D D E \\
\end{array}$ & $\begin{array}{l}4,4^{\prime}- \\
\text { DDT }\end{array}$ \\
\hline C-SB & 1 & 4 & 14.4 & $0.62 \mathrm{U}$ & $1.7 \mathrm{U}$ & $1.7 \mathrm{U}$ & $1.7 \mathrm{U}$ & 1.0 & NA & NA & $210 \mathrm{U}$ & $1.6 \mathrm{U}$ & $0.5 \mathrm{U}$ & $1.2 U$ \\
\hline C-SB & 2 & 4 & 13.3 & $0.68 \mathrm{U}$ & $1.9 \mathrm{U}$ & $1.9 \mathrm{U}$ & $1.9 \mathrm{U}$ & $0.9 \mathrm{U}$ & NA & NA & $230 \mathrm{U}$ & $1.7 \mathrm{U}$ & $0.5 \mathrm{U}$ & $1.3 \mathrm{U}$ \\
\hline C.SB & 3 & 4 & 14.0 & $0.64 \mathrm{U}$ & $1.8 \mathrm{U}$ & $1.8 \mathrm{U}$ & $1.8 \mathrm{U}$ & $0.9 \mathrm{U}$ & $\mathrm{NA}$ & NA & $210 u$ & $1.6 \mathrm{U}$ & $0.5 \mathrm{U}$ & $1.2 \mathrm{U}$ \\
\hline C-SB & 4 & 4 & 13.6 & $0.07 \mathrm{U}$ & $1.8 \mathrm{U}$ & $1.8 \mathrm{U}$ & $1.8 \mathrm{U}$ & $0.9 \mathrm{U}$ & NA & NA & $220 \mathrm{U}$ & $1.7 \mathrm{U}$ & $0.6 \mathrm{U}$ & $1.3 \mathrm{U}$ \\
\hline C-SB & 5 & 4 & 13.6 & $0.66 \mathrm{U}$ & $1.8 \mathrm{U}$ & $1.8 \mathrm{U}$ & $1.8 \mathrm{U}$ & 1.0 & NA & NA & $220 \mathrm{U}$ & $1.7 \mathrm{U}$ & $0.5 \mathrm{U}$ & $1.3 \mathrm{U}$ \\
\hline M. na. & 1 & 2 & & 14. & $1.9 \mathrm{U}$ & $1.9 \mathrm{U}$ & $1.9 \mathrm{U}$ & $0.9 \mathrm{U}$ & NA & NA & $220 \mathrm{U}$ & $1.7 \mathrm{U}$ & 4.01 & 15.3 \\
\hline M. nasuta Bac & 2 & 2 & 12.0 & $1.50 \mathrm{U}$ & $4.1 \mathrm{U}$ & $4.1 \mathrm{U}$ & $4.1 \mathrm{U}$ & $2.0 \mathrm{U}$ & NA & NA & $250 \mathrm{U}$ & $3.8 \mathrm{U}$ & 3.17 & 33.8 \\
\hline M. nasuta Background, Replicate 1 & 3 & 2 & 13.1 & 18.0 & $3.8 \mathrm{U}$ & $3.8 \mathrm{U}$ & $3.8 \mathrm{U}$ & $1.8 \mathrm{U}$ & NA & NA & $230 \mathrm{U}$ & $3.5 \mathrm{U}$ & $1.07 \mathrm{U}$ & 22.1 \\
\hline M. nasuta Background, Replicate 2 & 3 & 2 & 13.1 & 21.4 & $3.6 \mathrm{U}$ & $3.6 \mathrm{U}$ & $3.6 \mathrm{U}$ & $1.8 \mathrm{U}$ & NA & NA & $230 \mathrm{U}$ & $3.4 \mathrm{U}$ & 4.06 & 26.5 \\
\hline M. nasuta Background, Replicate 3 & 3 & 2 & 13.1 & 22.6 & $3.7 \mathrm{U}$ & $3.7 \mathrm{U}$ & $3.7 \mathrm{U}$ & $1.8 \mathrm{U}$ & NA & NA & $230 \mathrm{U}$ & $3.4 \mathrm{U}$ & $1.00 \mathrm{U}$ & 19.5 \\
\hline M. nasuta Background & 4 & 2 & 14.2 & $0.63 \mathrm{U}$ & $1.8 \mathrm{U}$ & $1.8 \mathrm{U}$ & $1.8 \mathrm{U}$ & $0.8 \mathrm{U}$ & NA & NA & $210 U$ & $1.6 \mathrm{U}$ & 2.18 & 8.23 \\
\hline M. nasuta Background & 5 & 2 & 17.7 & -7.82 & $1.4 \mathrm{U}$ & $1.4 \mathrm{U}$ & $1.4 \mathrm{U}$ & $0.7 \mathrm{U}$ & NA & NA & $170 \mathrm{U}$ & $1.3 \mathrm{U}$ & 3.12 & 7.25 \\
\hline
\end{tabular}

(a) U Undetected at or above detection limit.

(b) NA Not applicable.

i 
TABLE 1.13. Chlorinated Pesticides (alphabetical Dieldrin - Toxaphene), Dry Weight, in Tissue of M. nasuta, Older Bay Mud Study

January 1993

OBM COMP

OBM COMP

OBM COMP

OBM COMP

OBM COMP, Replicate 1

OBM COMP, Replicate 2

January 1994

OBM COMP

OBM COMP

OBM COMP

OBM COMP

w

\section{R-OS}

R-OS, Replicate 1

R-OS, Replicate 2

R-OS, Replicate 3

R-OS

R.OS

R-OS

R-BF

R-BF

$R \cdot B F$

$\mathrm{R}-\mathrm{BF}$

R-BF

R-AM

R-AM

R-AM

R-AM

$\begin{array}{llllllllll}13.6 & 7.4 U^{(a)} & 7.4 U & 7.4 U & 7.4 U & 7.4 U & 7.4 U & 2.2 U & 7.2 U & 118 U \\ 13.2 & 19.5 & 7.6 U & 7.6 U & 7.6 U & 7.6 U & 7.6 U & 2.3 U & 7.4 U & 121 U \\ 12.3 & 15.8 & 8.1 U & 8.1 U & 8.1 U & 8.1 U & 8.1 U & 2.4 U & 8.0 U & 130 U \\ 11.4 & 23.2 & 8.8 U & 8.8 U & 8.8 U & 8.8 U & 8.8 U & 2.6 U & 8.6 U & 140 U \\ 12.0 & 26.8 & 8.3 U & 8.3 U & 8.3 U & 8.3 U & 8.3 U & 2.5 U & 8.2 U & 133 U \\ 12.0 & 28.2 & 8.3 U & 8.3 U & 8.3 U & 8.3 U & 8.3 U & 2.5 U & 8.2 U & 133 U\end{array}$

M. nasuta Pesticides ( $\mu \mathrm{g} / \mathrm{kg}$ dry weight)

\begin{tabular}{|c|c|c|c|c|c|c|c|c|c|c|}
\hline eplicate & $\begin{array}{c}\text { Analytical } \\
\text { Batch }\end{array}$ & $\begin{array}{c}\text { Dry } \\
\text { Weigh }\end{array}$ & Dieldrin & $\begin{array}{l}\text { Endo- } \\
\text { Sulfan I }\end{array}$ & $\begin{array}{l}\text { Endo- } \\
\text { Sullan II }\end{array}$ & $\begin{array}{l}\text { Sulfan- } \\
\text { Sulfate }\end{array}$ & Endrin & $\begin{array}{l}\text { Endrin } \\
\text { Aldehyde }\end{array}$ & $\begin{array}{l}\text { Hepta- } \\
\text { chlor }\end{array}$ & $\begin{array}{l}\text { chlor } \\
\text { epoxide }\end{array}$ \\
\hline
\end{tabular}

Percent

Endo-

Endo-

Sullan II

Sulfate Endrin Andrin

Hepla-

Hepla-

chlor Toxa- 


\begin{tabular}{|c|c|c|c|c|c|c|c|c|c|c|c|c|}
\hline $\mid \begin{array}{l}0 \\
ٍ \\
\frac{\pi}{0}\end{array}$ & & & & IA & 1.13 & ntd) & asuta Pes & ticides $\mu \mathrm{g}$ & sg dry weigt & & & \\
\hline $\begin{array}{l}\text { Sediment } \\
\text { Treatment }\end{array}$ & Replicate & $\begin{array}{c}\text { Analytical } \\
\text { Batch }\end{array}$ & $\begin{array}{l}\text { Percent } \\
\text { Dry } \\
\text { Weight }\end{array}$ & Dieldrin & $\begin{array}{l}\text { Endo- } \\
\text { Sulfan I }\end{array}$ & $\begin{array}{l}\text { Endo- } \\
\text { Sulfan } 11\end{array}$ & $\begin{array}{l}\text { Endo- } \\
\text { Sulfan- } \\
\text { Sulfate } \\
\end{array}$ & Endrin & $\begin{array}{l}\text { Endrin } \\
\text { Aldehyde }\end{array}$ & $\begin{array}{l}\text { Hepta- } \\
\text { chlor }\end{array}$ & $\begin{array}{l}\text { Hepta- } \\
\text { chlor } \\
\text { epoxide }\end{array}$ & $\begin{array}{l}\text { Toxa- } \\
\text { phene }\end{array}$ \\
\hline $\begin{array}{l}C-S B \\
C-S B \\
C-S B \\
C-S B \\
C-S B\end{array}$ & $\begin{array}{l}1 \\
2 \\
3 \\
4 \\
5\end{array}$ & $\begin{array}{l}4 \\
4 \\
4 \\
4 \\
4\end{array}$ & $\begin{array}{l}14.4 \\
13.3 \\
14.0 \\
13.6 \\
13.6\end{array}$ & $\begin{array}{l}1.1 \mathrm{U} \\
1.2 \mathrm{U} \\
1.1 \mathrm{U} \\
1.2 \mathrm{U} \\
1.2 \mathrm{U}\end{array}$ & $\begin{array}{l}1.7 \mathrm{U} \\
1.9 \mathrm{U} \\
1.8 \mathrm{U} \\
1.8 \mathrm{U} \\
1.8 \mathrm{U}\end{array}$ & $\begin{array}{l}1.7 \mathrm{U} \\
1.9 \mathrm{U} \\
1.8 \mathrm{U} \\
1.8 \mathrm{U} \\
1.8 \mathrm{U}\end{array}$ & $\begin{array}{l}1.7 \mathrm{U} \\
1.9 \mathrm{U} \\
1.8 \mathrm{U} \\
1.8 \mathrm{U} \\
1.8 \mathrm{U}\end{array}$ & $\begin{array}{l}1.7 \mathrm{U} \\
1.9 \mathrm{U} \\
1.8 \mathrm{U} \\
1.8 \mathrm{U} \\
1.8 \mathrm{U}\end{array}$ & $\begin{array}{l}1.7 \mathrm{U} \\
1.9 \mathrm{U} \\
1.8 \mathrm{U} \\
1.8 \mathrm{U} \\
1.8 \mathrm{U}\end{array}$ & $\begin{array}{l}0.5 U \\
\dot{0} .5 U \\
0.5 U \\
0.1 U \\
0.6 U\end{array}$ & $\begin{array}{l}1.7 \mathrm{U} \\
1.8 \mathrm{U} \\
1.7 \mathrm{U} \\
1.8 \mathrm{U} \\
1.8 \mathrm{U}\end{array}$ & $\begin{array}{l}210 \mathrm{U} \\
230 \mathrm{U} \\
210 \mathrm{U} \\
220 \mathrm{U} \\
220 \mathrm{U}\end{array}$ \\
\hline $\begin{array}{l}\text { M. nasuta Background } \\
M . \text { nasuta Background } \\
M . \text { nasuta Background, Replicate } 1 \\
M . \text { nasuta Background, Replicate } 2 \\
M . \text { nasuta Background, Replicate } 3 \\
M . \text { nasuta Background } \\
M . \text { nasuta Background }\end{array}$ & $\begin{array}{l}1 \\
2 \\
3 \\
3 \\
3 \\
4 \\
5\end{array}$ & $\begin{array}{l}2 \\
2 \\
2 \\
2 \\
2 \\
2 \\
2 \\
2\end{array}$ & $\begin{array}{l}13.5 \\
12.0 \\
13.1 \\
13.1 \\
13.1 \\
14.2 \\
17.7\end{array}$ & $\begin{array}{l}1.2 U \\
2.6 U \\
2.4 U \\
2.3 U \\
2.4 U \\
1.1 U \\
0.9 U\end{array}$ & $\begin{array}{l}1.9 \mathrm{U} \\
4.1 \mathrm{U} \\
3.8 \mathrm{U} \\
3.6 \mathrm{U} \\
3.7 \mathrm{U} \\
1.8 \mathrm{U} \\
1.4 \mathrm{U}\end{array}$ & $\begin{array}{l}1.9 \mathrm{U} \\
4.1 \mathrm{U} \\
3.8 \mathrm{U} \\
3.6 \mathrm{U} \\
3.7 \mathrm{U} \\
1.8 \mathrm{U} \\
1.4 \mathrm{U}\end{array}$ & $\begin{array}{l}1.9 U \\
4.1 U \\
3.8 U \\
3.6 U \\
3.7 U \\
1.8 U \\
1.4 U\end{array}$ & $\begin{array}{l}1.9 \mathrm{U} \\
4.1 \mathrm{U} \\
3.8 \mathrm{U} \\
3.6 \mathrm{U} \\
3.7 \mathrm{U} \\
1.8 \mathrm{U} \\
1.4 \mathrm{U}\end{array}$ & $\begin{array}{l}1.9 \mathrm{U} \\
4.1 \mathrm{U} \\
3.8 \mathrm{U} \\
3.6 \mathrm{U} \\
3.7 \mathrm{U} \\
1.8 \mathrm{U} \\
1.4 \mathrm{U}\end{array}$ & $\begin{array}{l}0.6 U \\
1.25 U \\
1.15 U \\
1.07 U \\
1.07 U \\
0.5 U \\
0.5 U\end{array}$ & $\begin{array}{l}1.8 \mathrm{U} \\
4.0 \mathrm{U} \\
3.6 \mathrm{U} \\
3.5 \mathrm{U} \\
3.6 \mathrm{U} \\
1.7 \mathrm{U} \\
1.4 \mathrm{U}\end{array}$ & $\begin{array}{l}220 \mathrm{U} \\
250 \mathrm{U} \\
230 \mathrm{U} \\
230 \mathrm{U} \\
230 \mathrm{U} \\
210 \mathrm{U} \\
170 \mathrm{U}\end{array}$ \\
\hline
\end{tabular}

(a) U Undetected at or above detection limit. 


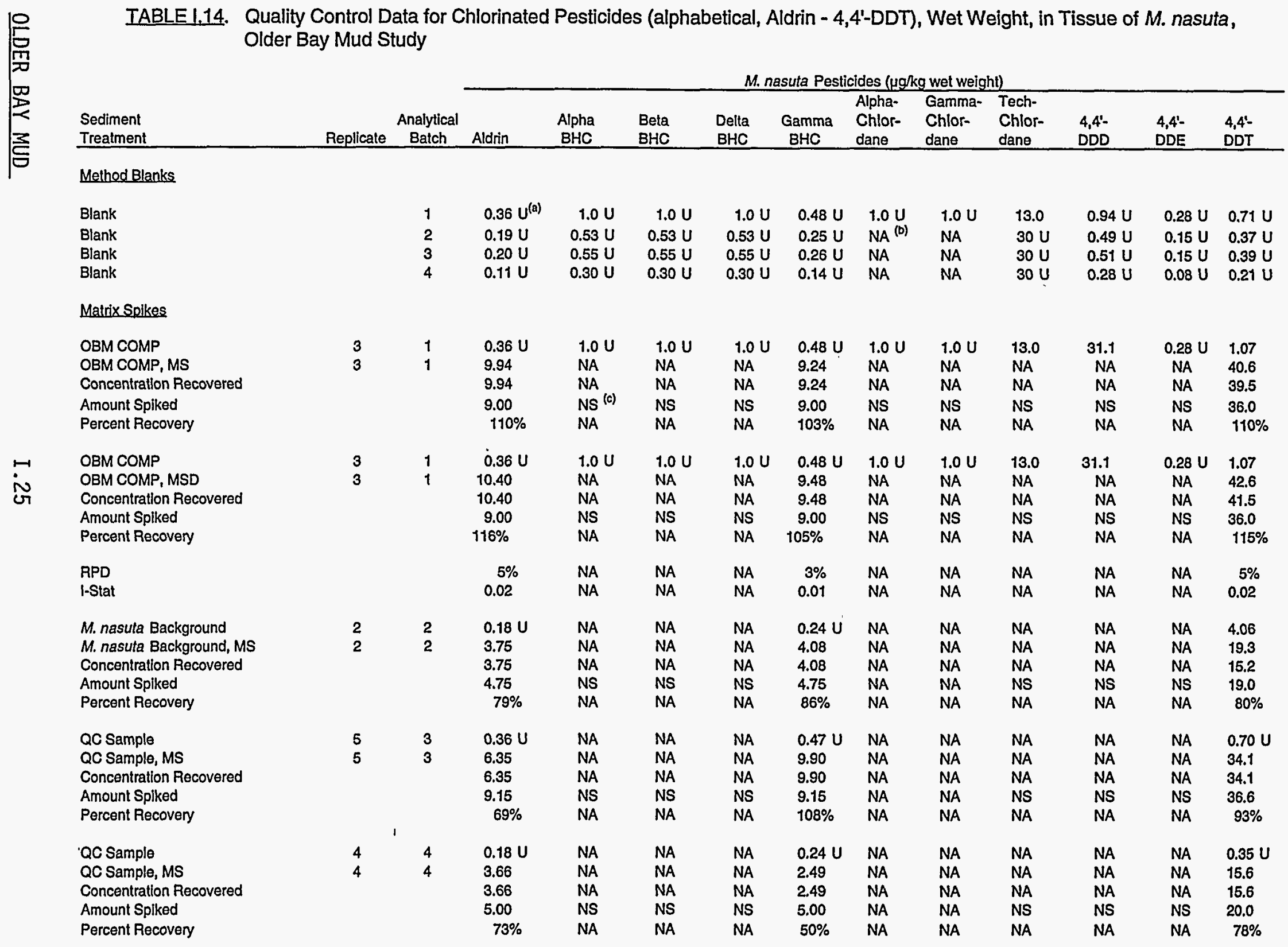


TABLE I.14. (contd)

\begin{tabular}{|c|c|c|c|c|c|c|c|c|c|c|c|c|c|}
\hline \multirow[b]{2}{*}{$\begin{array}{l}\text { Sediment } \\
\text { Treatment }\end{array}$} & \multirow[b]{2}{*}{ Replicate } & \multirow[b]{2}{*}{$\begin{array}{c}\text { Analytical } \\
\text { Batch }\end{array}$} & \multicolumn{11}{|c|}{ M. nasuta Pesticldes ( $(\mathrm{gg} / \mathrm{kg}$ wet welght) } \\
\hline & & & Aldrin & $\begin{array}{l}\text { Alpha } \\
\text { BHC }\end{array}$ & $\begin{array}{l}\text { Beta } \\
\text { BHC }\end{array}$ & $\begin{array}{l}\text { Delta } \\
\text { BHC }\end{array}$ & $\begin{array}{c}\text { Gamma } \\
\text { BHC }\end{array}$ & $\begin{array}{l}\text { Alpha- } \\
\text { Chlor- } \\
\text { dane }\end{array}$ & $\begin{array}{l}\text { Gamma- } \\
\text { Chlor- } \\
\text { dane }\end{array}$ & $\begin{array}{l}\text { Tech- } \\
\text { Chlor- } \\
\text { dane }\end{array}$ & $\begin{array}{l}4,4^{4}- \\
\text { DDD }\end{array}$ & $\begin{array}{l}4,4^{\prime-} \\
D D E\end{array}$ & $\begin{array}{l}4,4^{\prime}- \\
D D T\end{array}$ \\
\hline \multicolumn{14}{|l|}{ Standard Reference Material } \\
\hline $\begin{array}{l}\text { Non-certified value } \\
\text { NIST } 1974\end{array}$ & & & $N C^{(d)}$ & NC & NC & NC & NC & $\begin{array}{r}3.2 \\
\pm 0.2\end{array}$ & NC & NC & $\begin{array}{r}8.4 \\
\pm 0.4\end{array}$ & $\begin{array}{r}5.9 \\
\pm 0.2\end{array}$ & $\begin{array}{r}0.3 \\
\pm 0.3\end{array}$ \\
\hline NIST 1974 & & 1 & NA & NA & NA & NA & NA & 0.99 & NA & NA & 6.67 & $7.72^{(\theta)}$ & $9.09^{(0)}$ \\
\hline \multicolumn{14}{|l|}{ Analytical Repllicates } \\
\hline OBM COMP, Replicate 1 & 5 & 1 & $0.36 U$ & $1.0 \mathrm{U}$ & $1.0 \mathrm{U}$ & $1.0 \mathrm{U}$ & $0.48 \mathrm{U}$ & $1.0 \mathrm{U}$ & $1.0 \mathrm{U}$ & 13.0 & 40.1 & 2.04 & $0.71 U$ \\
\hline OBM COMP, Replicate 2 & 5 & 1 & $0.36 \mathrm{U}$ & $1.0 \mathrm{U}$ & $1.0 \mathrm{U}$ & $1.0 \mathrm{U}$ & $0.48 \mathrm{U}$ & $1.0 \mathrm{U}$ & $1.0 \mathrm{U}$ & 13.0 & 41.3 & 1.67 & $0.71 \mathrm{U}$ \\
\hline $\begin{array}{l}\text { RPD } \\
\text { I-Stat }\end{array}$ & & & NA & $\begin{array}{l}\text { NA } \\
\text { NA }\end{array}$ & $\begin{array}{l}\text { NA } \\
\text { NA }\end{array}$ & $\begin{array}{l}\text { NA } \\
\text { NA }\end{array}$ & $\begin{array}{l}\text { NA } \\
\text { NA }\end{array}$ & $\begin{array}{l}\text { NA } \\
\text { NA }\end{array}$ & $\begin{array}{l}\text { NA } \\
\text { NA }\end{array}$ & $0 \%$ & $3 \%$ & $\begin{array}{l}20 \% \\
0.10\end{array}$ & $\begin{array}{l}N A \\
N A\end{array}$ \\
\hline & & & & & & & & & & & & & \\
\hline M. nasuta Background, Replicate 1 & $\begin{array}{l}3 \\
3\end{array}$ & 2 & $\begin{array}{l}2.35 \\
2.79\end{array}$ & $0.49 \mathrm{U}$ & $\begin{array}{l}0.49 U \\
0.47 U\end{array}$ & $0.49 U$ & $0.23 \mathrm{U}$ & NA & NA & $30 \mathrm{U}$ & $0.46 U$ & $0.14 \mathrm{U}$ & 2.88 \\
\hline $\begin{array}{l}\text { M. nasuta Background, Replicate } 2 \\
\text { M. nasuta Background, Replicate } 3\end{array}$ & 3 & $\begin{array}{l}2 \\
2\end{array}$ & $\begin{array}{l}2.79 \\
2.95\end{array}$ & $0.47 \mathrm{U}$ & $0.48 \mathrm{U}$ & $0.48 \mathrm{U}$ & $\begin{array}{l}0.23 \mathrm{U} \\
0.23 \mathrm{U}\end{array}$ & $\begin{array}{l}\mathrm{NA} \\
\mathrm{NA}\end{array}$ & $\begin{array}{l}\text { NA } \\
\text { NA }\end{array}$ & $\begin{array}{l}30 U \\
30 U\end{array}$ & $0.45 \mathrm{U}$ & $\begin{array}{l}0.53 \\
0.13 \mathrm{U}\end{array}$ & $\begin{array}{l}3.46 \\
2.65\end{array}$ \\
\hline RSD & & & $12 \%$ & NA & NA & NA & NA & NA & NA & NA & NA & NA & $16 \%$ \\
\hline QC Sample, Replicate 1 & 2 & 3 & $0.34 \mathrm{U}$ & $0.92 \mathrm{U}$ & $0.92 U$ & $0.92 u$ & $0.44 U$ & NA & NA & $30 \mathrm{U}$ & $0.86 \mathrm{U}$ & $0.26 \mathrm{U}$ & $0.65 \mathrm{U}$ \\
\hline QC Sample, Replicate 2 & 2 & $\mathbf{3}$ & $0.33 \mathrm{U}$ & $0.90 \mathrm{U}$ & $0.90 \mathrm{U}$ & $0.90 \mathrm{U}$ & $0.43 U$ & NA & NA & $30 \mathrm{U}$ & $0.85 \mathrm{U}$ & $0.25 \mathrm{U}$ & $0.64 \mathrm{U}$ \\
\hline QC Sample, Repllicale 3 & 2 & 3 & $0.32 U$ & $0.88 U$ & $0.88 U$ & $0.88 \mathrm{U}$ & $0.42 U$ & NA & NA & $30 U$ & $0.83 U$ & $0.25 U$ & $0.63 \mathrm{U}$ \\
\hline RSD & & & NA & NA & NA & NA & NA & NA & NA & NA & NA & NA & NA \\
\hline R-OS, Peplicate 1 & 2 & 4 & $0.18 \mathrm{U}$ & $0.49 \mathrm{U}$ & $0.49 \mathrm{U}$ & $0.49 \mathrm{U}$ & & NA & NA & $30 \mathrm{U}$ & $0.46 \mathrm{U}$ & $0.14 \mathrm{U}$ & $0.35 \mathrm{U}$ \\
\hline R-OS, Replicate 2 & 2 & 4 & $0.18 U$ & $0.49 U$ & $0.49 \mathrm{U}$ & $0.49 \mathrm{U}$ & $0.23 \mathrm{U}$ & NA & NA & $30 \mathrm{U}$ & $0.46 \mathrm{U}$ & $0.14 \mathrm{U}$ & $0.35 \mathrm{U}$ \\
\hline R-OS, Replicate 3 & 2 & 4 & $0.18 U$ & $0.49 \mathrm{U}$ & $0.49 \mathrm{U}$ & $0.49 \mathrm{U}$ & $0.24 U$ & NA & NA & $30 \mathrm{U}$ & $0.46 \mathrm{U}$ & $0.14 U$ & $0.35 \mathrm{U}$ \\
\hline RSD & & & NA & NA & NA & NA & NA & NA & NA & NA & NA & NA & NA \\
\hline
\end{tabular}

(a) U Undetected at or above detection limit.

(b) NA Not applicable.

(c) NS Not splked.

(d) NC Not certified.

(e) Outside quality control criteria $( \pm 30 \%)$ for SRMS. 
TABLE 1.15. Quality Control Data for Chlorinated Pesticides (alphabetical, Dieldrin - Toxaphene), Wet Weight, in Tissue of $M$. nasuta, Older Bay Mud Study

\begin{tabular}{|c|c|c|c|c|c|c|c|c|c|c|c|}
\hline \multirow[b]{2}{*}{$\begin{array}{l}\text { Sediment } \\
\text { Treatment }\end{array}$} & \multirow[b]{2}{*}{ Replicate } & \multirow[b]{2}{*}{$\begin{array}{c}\text { Analytical } \\
\text { Batch }\end{array}$} & \multicolumn{9}{|c|}{ M. nasuta Pesticides ( $\mu \mathrm{g} / \mathrm{kg}$ wet weight) } \\
\hline & & & Dieldrin & $\begin{array}{l}\text { Endo- } \\
\text { Sulfan I }\end{array}$ & $\begin{array}{l}\text { Endo- } \\
\text { Sulfan II }\end{array}$ & $\begin{array}{l}\text { Endo- } \\
\text { Sulfan- } \\
\text { Sulfate } \\
\end{array}$ & Endrin & $\begin{array}{l}\text { Endrin } \\
\text { Aldehyde }\end{array}$ & $\begin{array}{l}\text { Hepta- } \\
\text { chlor }\end{array}$ & $\begin{array}{l}\text { Hepla- } \\
\text { chlor } \\
\text { epoxide }\end{array}$ & $\begin{array}{l}\text { Toxa- } \\
\text { phene }\end{array}$ \\
\hline \multicolumn{12}{|l|}{ Methed Blank } \\
\hline $\begin{array}{l}\text { Blank } \\
\text { Blank } \\
\text { Blank } \\
\text { Blank }\end{array}$ & & $\begin{array}{l}1 \\
2 \\
3 \\
4\end{array}$ & $\begin{array}{l}0.64 U^{(a)} \\
0.33 U \\
0.35 U \\
0.19 U\end{array}$ & $\begin{array}{l}1.0 \mathrm{U} \\
0.53 \mathrm{U} \\
0.55 \mathrm{U} \\
0.30 \mathrm{U}\end{array}$ & $\begin{array}{l}1.0 \mathrm{U} \\
0.53 \mathrm{U} \\
0.55 \mathrm{U} \\
0.30 \mathrm{U}\end{array}$ & $\begin{array}{l}1.0 \mathrm{U} \\
0.53 \mathrm{U} \\
0.55 \mathrm{U} \\
0.30 \mathrm{U}\end{array}$ & $\begin{array}{l}1.0 \mathrm{U} \\
0.53 \mathrm{U} \\
0.55 \mathrm{U} \\
0.30 \mathrm{U}\end{array}$ & $\begin{array}{l}1.0 \mathrm{U} \\
0.53 \mathrm{U} \\
0.55 \mathrm{U} \\
0.30 \mathrm{U}\end{array}$ & $\begin{array}{l}0.30 \mathrm{U} \\
0.16 \mathrm{U} \\
0.16 \mathrm{U} \\
0.09 \mathrm{U}\end{array}$ & $\begin{array}{l}0.98 U \\
0.51 U \\
0.53 U \\
0.29 U\end{array}$ & $\begin{array}{l}16 \mathrm{U} \\
30 \mathrm{U} \\
30 \mathrm{U} \\
30 \mathrm{U}\end{array}$ \\
\hline \multicolumn{12}{|l|}{ Matrix Spikes } \\
\hline OBM СOMP & 3 & 1 & 1.94 & $1.0 \mathrm{U}$ & $1.0 \mathrm{U}$ & $1.0 \mathrm{U}$ & $1.0 \mathrm{U}$ & $1.0 \mathrm{U}$ & $0.30 \mathrm{U}$ & $0.98 \mathrm{U}$ & $16 U$ \\
\hline $\begin{array}{l}\text { OBM COMP, MS } \\
\text { Concentration Recovered }\end{array}$ & 3 & 1 & $\begin{array}{l}41.1 \\
39.2\end{array}$ & $\begin{array}{l}N A^{(b)} \\
N A\end{array}$ & $\begin{array}{l}\text { NA } \\
\text { NA }\end{array}$ & $\begin{array}{l}\text { NA } \\
\text { NA }\end{array}$ & $\begin{array}{l}38.1 \\
38.1\end{array}$ & $\begin{array}{l}\text { NA } \\
\text { NA }\end{array}$ & $\begin{array}{l}9.65 \\
9.65\end{array}$ & $\begin{array}{l}\text { NA } \\
\text { NA }\end{array}$ & $\begin{array}{l}\text { NA } \\
\text { NA }\end{array}$ \\
\hline $\begin{array}{l}\text { Amount Spiked } \\
\text { Percent Recovery }\end{array}$ & & & $\begin{array}{l}36.0 \\
109 \%\end{array}$ & $\begin{array}{l}\text { NS } \\
\text { NA }\end{array}$ & $\begin{array}{l}\text { NS } \\
\text { NA }\end{array}$ & $\begin{array}{l}\text { NS } \\
\text { NA }\end{array}$ & $\begin{array}{l}36.0 \\
106 \%\end{array}$ & NS & $\begin{array}{l}9.00 \\
107 \%\end{array}$ & $\begin{array}{l}\text { NS } \\
\text { NA }\end{array}$ & $\begin{array}{l}\text { NS } \\
\text { NA }\end{array}$ \\
\hline $\begin{array}{l}\text { OBM COMP } \\
\text { OBM COMP, MSD } \\
\text { Concentration Recovered } \\
\text { Amount Spiked } \\
\text { Percent Recovery }\end{array}$ & $\begin{array}{l}3 \\
3\end{array}$ & $\begin{array}{l}1 \\
1\end{array}$ & $\begin{array}{l}1.94 \\
44.6 \\
42.7 \\
36.0 \\
119 \%\end{array}$ & $\begin{array}{l}1.0 \mathrm{U} \\
\text { NA } \\
\text { NA } \\
\text { NS } \\
\text { NA }\end{array}$ & $\begin{array}{l}1.0 \mathrm{U} \\
\mathrm{NA} \\
\mathrm{NA} \\
\mathrm{NS} \\
\mathrm{NA}\end{array}$ & $\begin{array}{l}1.0 \mathrm{U} \\
\text { NA } \\
\text { NA } \\
\text { NS } \\
\text { NA }\end{array}$ & $\begin{array}{l}1.0 \mathrm{U} \\
40.0 \\
40.0 \\
36.0 \\
111 \%\end{array}$ & $\begin{array}{l}1.0 \mathrm{U} \\
\text { NA } \\
\text { NA } \\
\text { NS } \\
\text { NA }\end{array}$ & $\begin{array}{l}0.30 \mathrm{U} \\
9.64 \\
9.64 \\
9.00 \\
107 \%\end{array}$ & $\begin{array}{l}0.98 \mathrm{U} \\
\text { NA } \\
\text { NA } \\
\text { NS } \\
\text { NA }\end{array}$ & $\begin{array}{l}16 U \\
\text { NA } \\
\text { NA } \\
\text { NS } \\
\text { NA }\end{array}$ \\
\hline $\begin{array}{l}\text { M. nasuta Background } \\
\text { M. nasuta Background, MS } \\
\text { Concentration Recovered }\end{array}$ & $\begin{array}{l}2 \\
2\end{array}$ & $\begin{array}{l}2 \\
2\end{array}$ & $\begin{array}{l}0.31 \mathrm{U} \\
16.3 \\
16.3\end{array}$ & $\begin{array}{l}\text { NA } \\
\text { NA } \\
\text { NA }\end{array}$ & $\begin{array}{l}\text { NA } \\
\text { NA } \\
\text { NA }\end{array}$ & $\begin{array}{l}\text { NA } \\
\text { NA } \\
\text { NA }\end{array}$ & $\begin{array}{l}0.49 U \\
15.9 \\
15.9\end{array}$ & $\begin{array}{l}\text { NA } \\
\text { NA } \\
\text { NA }\end{array}$ & $\begin{array}{l}0.15 U \\
3.79 \\
3.79\end{array}$ & $\begin{array}{l}\text { NA } \\
\text { NA } \\
\text { NA }\end{array}$ & $\begin{array}{l}\text { NA } \\
\text { NA } \\
\text { NA }\end{array}$ \\
\hline $\begin{array}{l}\text { Amount Spiked } \\
\text { Percent Recovery }\end{array}$ & & & $\begin{array}{l}19.0 \\
86 \%\end{array}$ & $\begin{array}{l}\text { NS } \\
\text { NA }\end{array}$ & $\begin{array}{l}\text { NS } \\
\text { NA }\end{array}$ & $\begin{array}{l}\text { NS } \\
\text { NA }\end{array}$ & $\begin{array}{l}19.0 \\
84 \%\end{array}$ & $\begin{array}{l}\text { NS } \\
\text { NA }\end{array}$ & $\begin{array}{l}4.75 \\
80 \%\end{array}$ & $\begin{array}{l}\text { NS } \\
\text { NA }\end{array}$ & $\begin{array}{l}\text { NS } \\
\text { NA }\end{array}$ \\
\hline $\begin{array}{l}\text { QC Sample } \\
\text { QC Sample, MS } \\
\text { Concentration Recovered } \\
\text { Amount Spiked }\end{array}$ & $\begin{array}{l}5 \\
5\end{array}$ & $\begin{array}{l}3 \\
3\end{array}$ & $\begin{array}{l}0.62 \mathrm{U} \\
30.6 \\
30.6 \\
36.6\end{array}$ & $\begin{array}{l}\text { NA } \\
\text { NA } \\
\text { NA } \\
\text { NS }\end{array}$ & $\begin{array}{l}\text { NA } \\
\text { NA } \\
\text { NA } \\
\text { NS }\end{array}$ & $\begin{array}{l}\text { NA } \\
\text { NA } \\
\text { NA } \\
\text { NS }\end{array}$ & $\begin{array}{l}0.98 \mathrm{U} \\
24.4 \\
24.4 \\
36.6\end{array}$ & $\begin{array}{l}\text { NA } \\
\text { NA } \\
\text { NA } \\
\text { NS }\end{array}$ & $\begin{array}{l}0.30 \mathrm{U} \\
4.53 \\
4.53 \\
9.15\end{array}$ & $\begin{array}{l}\text { NA } \\
\text { NA } \\
\text { NA } \\
\text { NS }\end{array}$ & $\begin{array}{l}\text { NA } \\
\text { NA } \\
\text { NA } \\
\text { NS }\end{array}$ \\
\hline Percent Recovery & & & $84 \%$ & NA & NA & NA & $67 \%$ & NA & $50 \%$ & NA & NA \\
\hline QC Samplo & $4^{\prime}$ & 4 & 6.54 & NA & NA & NA & $0.49 \mathrm{U}$ & NA & $0.15 U$ & NA & NA \\
\hline QC Sample, MS & 4 & 4 & 24.2 & NA & NA & NA & 12.7 & NA & 3.07 & NA & NA \\
\hline Concentration Recovered & & & 17.7 & NA & $N A$ & NA & 12.7 & NA & 3.07 & NA & NA \\
\hline Amount Spiked & & & 20.0 & NS & NS & NS & 20.0 & NS & 5.00 & NS & NS \\
\hline Percent Recovery & & & $88 \%$ & NA & NA & NA & $64 \%$ & NA & $61 \%$ & NA & NA \\
\hline
\end{tabular}


TABLE I.15. (contd)

\begin{tabular}{|c|c|c|c|c|c|c|c|c|c|c|c|}
\hline \multirow[b]{2}{*}{$\begin{array}{l}\text { Sediment } \\
\text { Treatment } \\
\end{array}$} & \multirow[b]{2}{*}{ Replicate } & \multirow[b]{2}{*}{$\begin{array}{c}\text { Analytical } \\
\text { Batch } \\
\end{array}$} & \multicolumn{9}{|c|}{ M. nasuta Pesticides ( $\mu \mathrm{g} / \mathrm{kg}$ wet weight) } \\
\hline & & & Dleldrin & $\begin{array}{l}\text { Endo- } \\
\text { Sulfan } 1 \\
\end{array}$ & $\begin{array}{l}\text { Endo- } \\
\text { Sulfan } 11\end{array}$ & $\begin{array}{l}\text { Endo- } \\
\text { Sulfan- } \\
\text { Sulfate } \\
\end{array}$ & Endrin & $\begin{array}{l}\text { Endrin } \\
\text { Aldehyde }\end{array}$ & $\begin{array}{l}\text { Hepta- } \\
\text { chlor }\end{array}$ & $\begin{array}{l}\text { Hepta- } \\
\text { chlor } \\
\text { epoxide }\end{array}$ & $\begin{array}{l}\text { Toxa- } \\
\text { phene }\end{array}$ \\
\hline \multicolumn{12}{|l|}{ Standard Reference Material } \\
\hline $\begin{array}{l}\text { Non-certifled value } \\
\text { NIST } 1974\end{array}$ & & & $\begin{array}{r}1.0 \\
\pm 0.5\end{array}$ & $N C^{(d)}$ & NC & NC & NC & NC & NC & NC & NC \\
\hline NIST 1974 & & 1 & $2.87^{(\theta)}$ & NA & NA & NA & NA & NA & NA & NA & NA \\
\hline \multicolumn{12}{|l|}{ Analytical Replicates } \\
\hline $\begin{array}{l}\text { OBM COMP, Replicate } 1 \\
\text { OBM COMP, Replicate } 2\end{array}$ & $\begin{array}{l}5 \\
5\end{array}$ & $\begin{array}{l}1 \\
1\end{array}$ & $\begin{array}{l}3.21 \\
3.38\end{array}$ & $\begin{array}{l}1.0 \mathrm{U} \\
1.0 \mathrm{U}\end{array}$ & $\begin{array}{l}1.0 \mathrm{U} \\
1.0 \mathrm{U}\end{array}$ & $\begin{array}{l}1.0 \mathrm{U} \\
1.0 \mathrm{U}\end{array}$ & $\begin{array}{l}1.0 \mathrm{U} \\
1.0 \mathrm{U}\end{array}$ & $\begin{array}{l}1.0 \mathrm{U} \\
1.0 \mathrm{U}\end{array}$ & $\begin{array}{l}0.30 \mathrm{U} \\
0.30 \mathrm{U}\end{array}$ & $\begin{array}{l}0.98 U \\
0.98 U\end{array}$ & $\begin{array}{l}16 U \\
16 U\end{array}$ \\
\hline $\begin{array}{l}\text { RPD } \\
\text { I-Stat }\end{array}$ & & & $\begin{array}{l}5 \% \\
0.03\end{array}$ & $\begin{array}{l}\text { NA } \\
\text { NA }\end{array}$ & $\begin{array}{l}\text { NA } \\
\text { NA }\end{array}$ & $\begin{array}{l}\text { NA } \\
\text { NA }\end{array}$ & $\begin{array}{l}\text { NA } \\
\text { NA }\end{array}$ & $\begin{array}{l}N A \\
\text { NA }\end{array}$ & $\begin{array}{l}\text { NA } \\
\text { NA }\end{array}$ & $\begin{array}{l}\text { NA } \\
\text { NA }\end{array}$ & $\begin{array}{l}\text { NA } \\
\text { NA }\end{array}$ \\
\hline $\begin{array}{l}\text { M. nasuta Background, Replicate } 1 \\
\text { M. nasuta Background, Replicate } 2 \\
\text { M. nasuta Background, Replicate } 3\end{array}$ & $\begin{array}{l}3 \\
3 \\
3\end{array}$ & $\begin{array}{l}2 \\
2 \\
2\end{array}$ & $\begin{array}{l}0.31 U \\
0.30 U \\
0.31 U\end{array}$ & $\begin{array}{l}0.49 U \\
0.47 U \\
0.48 U\end{array}$ & $\begin{array}{l}0.49 U \\
0.47 U \\
0.48 U\end{array}$ & $\begin{array}{l}0.49 U \\
0.47 U \\
0.48 U\end{array}$ & $\begin{array}{l}0.49 U \\
0.47 U \\
0.48 U\end{array}$ & $\begin{array}{l}0.49 U \\
0.47 U \\
0.48 U\end{array}$ & $\begin{array}{l}0.15 U \\
0.14 U \\
0.14 U\end{array}$ & $\begin{array}{l}0.47 U \\
0.46 U \\
0.47 U\end{array}$ & $\begin{array}{l}30 \mathrm{U} \\
30 \mathrm{U} \\
30 \mathrm{U}\end{array}$ \\
\hline RSD & & & NA & NA & NA & NA & NA & NA & NA & NA & NA \\
\hline $\begin{array}{l}\text { QC Sample, Replicate } 1 \\
\text { QC Sample, Replicate } 2 \\
\text { QC Sample, Replicate } 3\end{array}$ & $\begin{array}{l}2 \\
2 \\
2\end{array}$ & $\begin{array}{l}3 \\
3 \\
3\end{array}$ & $\begin{array}{l}0.59 U \\
0.57 U \\
0.56 U\end{array}$ & $\begin{array}{l}0.92 U \\
0.90 U \\
0.88 U\end{array}$ & $\begin{array}{l}0.92 U \\
0.90 U \\
0.88 U\end{array}$ & $\begin{array}{l}0.92 U \\
0.90 U \\
0.88 U\end{array}$ & $\begin{array}{l}0.92 U \\
0.90 U \\
0.88 U\end{array}$ & $\begin{array}{l}0.92 U \\
0.90 U \\
0.88 U\end{array}$ & $\begin{array}{l}0.28 U \\
0.27 U \\
0.27 U\end{array}$ & $\begin{array}{l}0.90 \mathrm{U} \\
0.88 \mathrm{U} \\
0.86 \mathrm{U}\end{array}$ & $\begin{array}{l}30 U \\
30 U \\
30 U\end{array}$ \\
\hline RSD & & & NA & NA & NA & NA & NA & NA & NA & NA & NA \\
\hline $\begin{array}{l}\text { R-OS, Replicate } 1 \\
\text { R-OS, Replicate } 2 \\
\text { R-OS, Replicate } 3\end{array}$ & $\begin{array}{l}2 \\
2 \\
2\end{array}$ & $\begin{array}{l}4 \\
4 \\
4\end{array}$ & $\begin{array}{l}1.03 \\
0.31 U \\
0.31 U\end{array}$ & $\begin{array}{l}0.49 U \\
0.49 U \\
0.49 U\end{array}$ & $\begin{array}{l}0.49 U \\
0.49 U \\
0.49 U\end{array}$ & $\begin{array}{l}0.49 U \\
0.49 U \\
0.49 U\end{array}$ & $\begin{array}{l}0.49 U \\
0.49 U \\
0.49 U\end{array}$ & $\begin{array}{l}0.49 U \\
0.49 U \\
0.49 U\end{array}$ & $\begin{array}{l}0.15 U \\
0.15 U \\
0.15 U\end{array}$ & $\begin{array}{l}0.48 U \\
0.47 U \\
0.48 U\end{array}$ & $\begin{array}{l}30 \mathrm{U} \\
30 \mathrm{U} \\
30 \mathrm{U}\end{array}$ \\
\hline RSD & & & NA & NA & NA & NA & NA & NA & NA & NA & NA \\
\hline
\end{tabular}

(a) U Undetected at or above detection limit.

(b) NA Not applicable.

(c) NS Not spiked.

(d) NC Not certifled.

(e) Outside quality control criteria $( \pm 30 \%)$ for SRMs. 
TABLE 1.16. Polychlorinated Biphenyls (PCBs), Wet Weight, in Tissue of M. nasuta, Older Bay Mud Study

\begin{tabular}{|c|c|c|c|c|c|c|c|c|c|c|}
\hline \multirow{2}{*}{$\begin{array}{l}\text { Sediment } \\
\text { Treatment }\end{array}$} & \multirow[b]{2}{*}{ Replicate } & \multirow[b]{2}{*}{$\begin{array}{c}\text { Analytical } \\
\text { Batch }\end{array}$} & \multicolumn{8}{|c|}{ M. nasuta PCBs ( $\mu \mathrm{g} / \mathrm{kg}$ wet weight) } \\
\hline & & & \multicolumn{2}{|c|}{$\begin{array}{l}\text { Aroclor } \\
1242\end{array}$} & \multicolumn{2}{|c|}{$\begin{array}{l}\text { Aroclor } \\
1248\end{array}$} & \multicolumn{2}{|c|}{$\begin{array}{l}\text { Aroclor } \\
1254\end{array}$} & \multicolumn{2}{|c|}{$\begin{array}{l}\text { Arocior } \\
1260\end{array}$} \\
\hline Target $\mathrm{DL}^{(\mathrm{a})}$ & & & 20 & & 20 & & 20 & & 20 & \\
\hline \multicolumn{11}{|l|}{ Januàry 1993} \\
\hline OBM СОМР & 1 & 1 & 3.2 & $U^{(b)}$ & 3.2 & & 3.2 & $\mathrm{U}$ & 3.2 & $\mathrm{u}$ \\
\hline OBM COMP & 2 & 1 & 3.2 & U & 3.2 & & 3.2 & $U$ & 3.2 & U \\
\hline OBM COMP & 3 & 1 & 3.2 & $U$ & 3.2 & U & 3.2 & $\mathrm{U}$ & 3.2 & $\mathrm{U}$ \\
\hline OBM COMP & 4 & 1 & 3.2 & 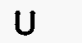 & 3.2 & $u$ & 3.2 & U & 3.2 & $u$ \\
\hline OBM COMP, Replicate 1 & 5 & 1 & 3.2 & $u$ & 3.2 & $u$ & 3.2 & $U$ & 3.2 & $\mathrm{U}$ \\
\hline OBM COMP, Replicate 2 & 5 & 1 & 3.2 & U & 3.2 & $\mathrm{U}$ & 3.2 & $U$ & 3.2 & $u$ \\
\hline \multicolumn{11}{|l|}{ January 1994} \\
\hline OBM COMP & 1 & 3 & 20 & $\mathbf{U}$ & 20 & u & 20 & $\mathrm{U}$ & 20 & $u$ \\
\hline OBM COMP & 2 & 3 & 20 & $\mathrm{U}$ & 20 & $\mathrm{U}$ & 20 & U & 20 & $\mathrm{U}$ \\
\hline OBM COMP & 3 & 3 & 20 & $\mathrm{U}$ & 20 & $u$ & 20 & $U$ & 20 & $\mathbf{U}$ \\
\hline OBM COMP & 4 & 3 & 20 & U & 20 & $u$ & 20 & $\mathbf{U}$ & 20 & $U$ \\
\hline OBM COMP & 5 & 3 & 20 & $U$ & 20 & U & 20 & $U$ & 20 & $\mathrm{U}$ \\
\hline R-OS & 1 & 4 & 20 & $\mathrm{U}$ & 20 & U & 20 & $u$ & 20 & $\mathrm{u}$ \\
\hline R-OS, Replicate 1 & 2 & 4 & 20 & $\mathrm{U}$ & 20 & $U$ & 20 & $u$ & 20 & $\mathbf{u}$ \\
\hline R-OS, Replicate 2 & 2 & 4 & 20 & $U$ & 20 & $u$ & 20 & $u$ & 20 & $\mathrm{U}$ \\
\hline R-OS, Replicate 3 & 2 & 4 & 20 & $u$ & 20 & $u$ & 20 & $U$ & 20 & $\mathrm{U}$ \\
\hline R-OS & 3 & 4 & 20 & $U$ & 20 & $u$ & 20 & $\mathrm{u}$ & 20 & $\mathbf{u}$ \\
\hline R-OS & 4 & .4 & 20 & $U$ & 20 & $u$ & 20 & $\mathrm{U}$ & 20 & $U$ \\
\hline R-OS & 5 & 4 & 20 & $\mathrm{U}$ & 20 & $u$ & 20 & $U$ & 20 & $\mathrm{U}$ \\
\hline R-BF & 1 & 3 & 20 & $U$ & 20 & $u$ & 20 & $u$ & 20 & $\mathbf{u}$ \\
\hline R-BF & 2 & 2 & 20 & $U$ & 20 & $u$ & 20 & $U$ & 20 & $\mathbf{U}$ \\
\hline R-BF & 3 & 3 & 20 & $\mathrm{U}$ & 20 & $u$ & 20 & $\mathrm{U}$ & 20 & U \\
\hline R-BF & 4 & 3 & 20 & $U$ & 20 & $u$ & 20 & $u$ & 20 & U \\
\hline R-BF & 5 & 3 & 20 & $U$ & 20 & U & 20 & $U$ & 20 & $u$ \\
\hline R-AM & 1 & 2 & 20 & $U$ & 20 & $U$ & 20 & $u^{-}$ & 20 & $U$ \\
\hline R-AM & 2 & $\mathbf{3}$ & 20 & $\mathrm{U}$ & 20 & $\mathrm{U}$ & 20 & $U$ & 20 & $U$ \\
\hline R-AM & 3 & 3 & 20 & $U$ & 20 & $u$ & 20 & $\mathrm{U}$ & 20 & $\mathbf{U}$ \\
\hline R-AM & 4 & 2 & 20 & U & 20 & $u$ & 20 & $\mathrm{U}$ & 20 & $\mathrm{U}$ \\
\hline R-AM & 5 & 3 & 20 & $\mathrm{U}$ & 20 & $U$ & 20 & $U$ & 20 & $U$ \\
\hline C-SB & 1 & 4 & 20 & & 20 & $U$ & 20 & $u$ & 20 & $\mathrm{U}$ \\
\hline C-SB & 2 & 4 & 20 & $\mathrm{U}$ & 20 & $\mathrm{u}$ & 20 & $u$ & 201 & $u$ \\
\hline C-SB & 3 & 4 & 20 & $U$ & 20 & $U$ & 20 & $U$ & 20 & $U$ \\
\hline C-SB & 4 & 4 & 20 & U & 20 & $U$ & 20 & $U$ & 20 & $\mathrm{U}$ \\
\hline C-SB & 5 & 4 & 20 & $U$ & 20 & $U$ & 20 & $U$ & 201 & $U$ \\
\hline
\end{tabular}


TABLE 1.16. (contd)

\begin{tabular}{l} 
Sediment \\
Treatment \\
\hline M. nasuta Background \\
M. nasuta Background \\
M. nasuta Background, Replicate 1 \\
M. nasuta Background, Replicate 2 \\
M. nasuta Background, Replicate 3 \\
M. nasuta Background \\
M. nasuta Background \\
\hline
\end{tabular}

Replicate

Analytical
Batch

\begin{tabular}{cccc}
\multicolumn{4}{c}{ M. nasuta PCBs $(\mu \mathrm{g} / \mathrm{kg}$ wet weight) } \\
\hline Aroclor & Aroclor & Aroclor & Aro \\
1242 & 1248 & 1254 & 1
\end{tabular}

Aroclor 1260

(a) DL Detection limit.

(b) Undetected at or above detection limit. 
TABLE 1.17. Polychlorinated Biphenyls (PCBs), Dry Weight, in Tissue of M. nasuta, Older Bay Mud Study

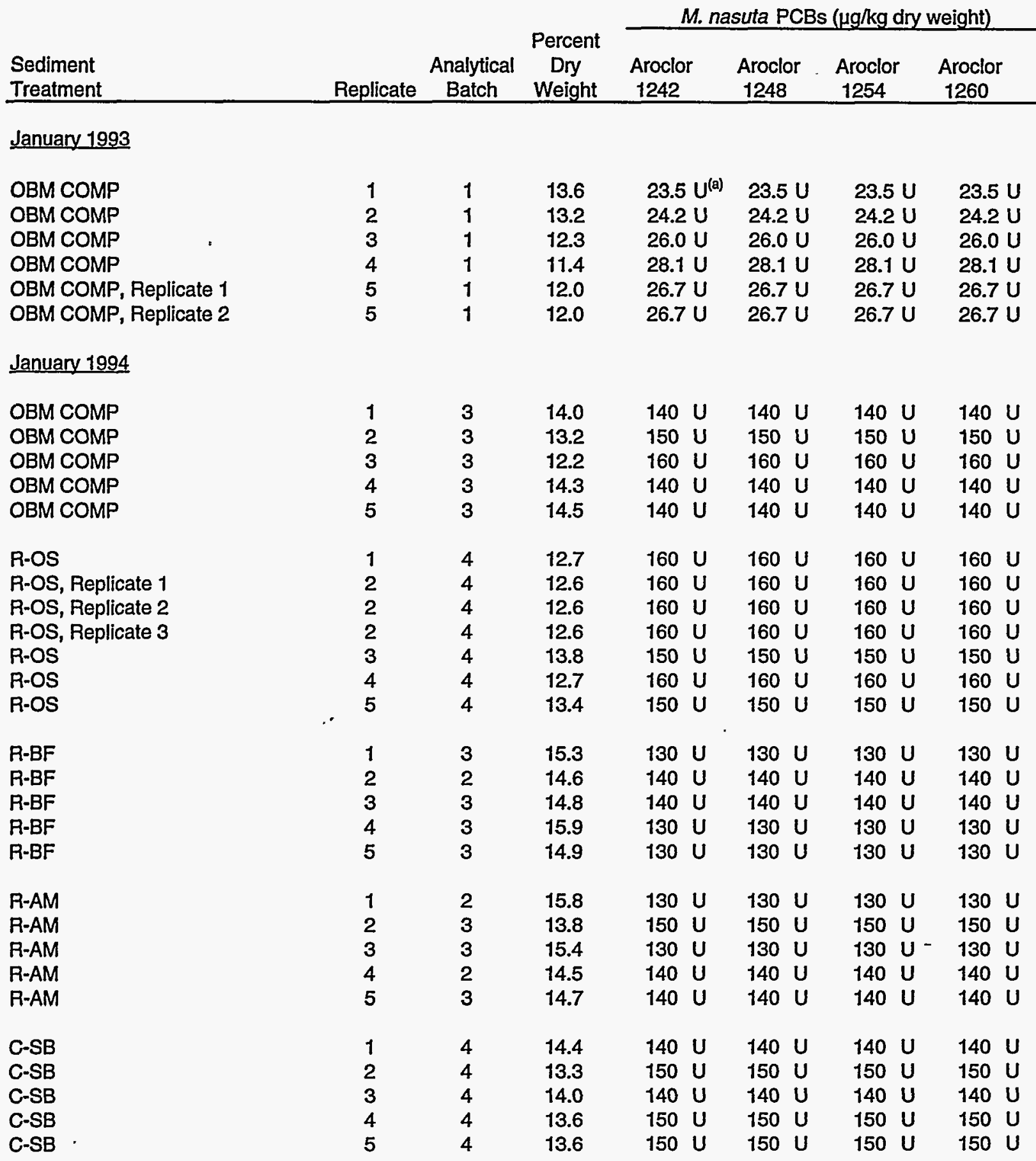


TABLE 1.17. (contd)

\begin{tabular}{|c|c|c|c|c|c|c|c|}
\hline \multirow[b]{2}{*}{$\begin{array}{l}\text { Sediment } \\
\text { Treatment }\end{array}$} & \multirow[b]{2}{*}{ Replicate } & \multirow[b]{2}{*}{$\begin{array}{c}\text { Analytical } \\
\text { Batch }\end{array}$} & \multirow[b]{2}{*}{$\begin{array}{l}\text { Percent } \\
\text { Dry } \\
\text { Weight }\end{array}$} & \multicolumn{4}{|c|}{ M. nasuta PCBs ( $\mu \mathrm{g} / \mathrm{kg}$ dry weight) } \\
\hline & & & & $\begin{array}{l}\text { Aroclor } \\
1242\end{array}$ & $\begin{array}{l}\text { Aroclor } \\
1248\end{array}$ & $\begin{array}{l}\text { Aroclor } \\
1254\end{array}$ & $\begin{array}{l}\text { Aroclor } \\
1260\end{array}$ \\
\hline M. nasuta Backgroúnd & 1 & 2 & 13.5 & $150 \mathrm{U}$ & $150 \mathrm{U}$ & $150 \mathrm{U}$ & 150 \\
\hline M. nasuta Background & 2 & 2 & 12.0 & $170 \mathrm{U}$ & $170 \mathrm{U}$ & $170 \mathrm{U}$ & $170 \mathrm{l}$ \\
\hline M. nasuta Background, Replicate 1 & 3 & 2 & 13.1 & $150 \mathrm{U}$ & $150 \mathrm{U}$ & $150 \mathrm{U}$ & $150 \mathrm{l}$ \\
\hline M. nasuta Background, Replicate 2 & 3 & 2 & 13.1 & $150 \mathrm{U}$ & $150 U$ & $150 \mathrm{U}$ & $150 \mathrm{l}$ \\
\hline M. nasuta Background, Replicate 3 & 3 & 2 & 13.1 & $150 \mathrm{U}$ & $150 \mathrm{U}$ & $150 \mathrm{U}$ & $150 \mathrm{~L}$ \\
\hline M. nasuta Background & 4 & 2 & 14.2 & $140 U$ & $140 U$ & $140 U$ & $140 \mathrm{l}$ \\
\hline M. nasuta Background & 5 & 2 & 17.7 & $110 \mathrm{U}$ & $110 \mathrm{U}$ & $110 \mathrm{U}$ & $110 \mathrm{~L}$ \\
\hline
\end{tabular}

(a) Undetected at or above detection limit. 
TABLE 1.18. Quality Control Data for Polychlorinated Biphenyls (PCBs), Wet Weight, in Tissue of $M$. nasuta, Older Bay Mud Study

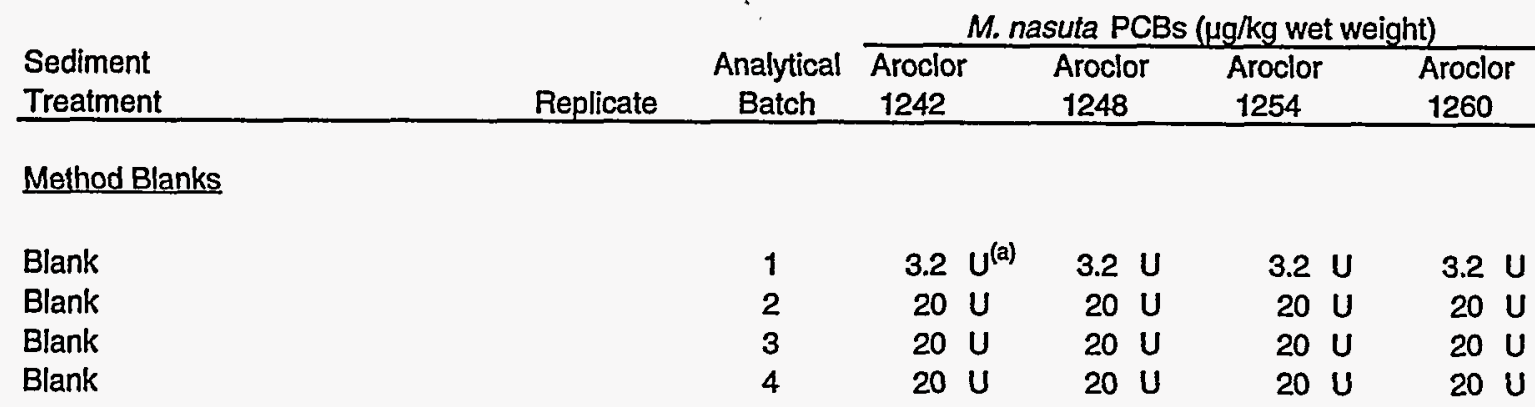

Matrix Spikes

\begin{tabular}{|c|c|c|c|c|c|c|}
\hline OBM COMP & 3 & 1 & $3.2 \mathrm{U}$ & $3.2 U$ & $3.2 U$ & $3.2 \mathrm{U}$ \\
\hline OBM COMP, MS & 3 & 1 & $N A^{(b)}$ & NA & 207.6 & NA \\
\hline Concentration Recovered & & & NA & NA & 207.6 & NA \\
\hline Amount Spiked & & & NS ${ }^{(c)}$ & NS & 180.0 & NS \\
\hline Percent Recovery & & & NA & NA & $115 \%$ & NA \\
\hline OBM COMP & 3 & 1 & $3.2 \mathrm{U}$ & $3.2 \mathrm{U}$ & $3.2 \mathrm{U}$ & $3.2 \mathrm{U}$ \\
\hline OBM COMP, MSD & 3 & 1 & NA & NA & 222.3 & NA \\
\hline Concentration Recovered & & & NA & NA & 222.3 & NA \\
\hline Amount Spiked & & & NS & NS & 180.0 & NS \\
\hline Percent Recovery & & & NA & NA & $124 \%{ }^{(d)}$ & NA \\
\hline RPD & & & NA & NA & $7 \%$ & NA \\
\hline I-Stat & & & NA & NA & 0.03 & NA \\
\hline M. nasuta Background & 2 & 2 & NA & NA & $20 \mathrm{U}$ & NA \\
\hline M. nasuta Background, MS & 2 & 2 & NA & NA & 101 & NA \\
\hline Concentration Recovered & & & NA & NA & 101 & NA \\
\hline Amount Spiked & & & NS & NS & 95 & NS \\
\hline Percent Recovery & & & NA & NA & $106 \%$ & NA \\
\hline QC Sample & 5 & 3 & NA & NA & $20 \mathrm{U}$ & NA \\
\hline QC Sample, MS & 5 & 3 & NA & NA & 131 & NA \\
\hline Concentration Recovered & & & NA & NA & 131 & NA \\
\hline Amount Spiked & & & NS & NS & 183 & NS \\
\hline Percent Recovery & & & NA & NA & $72 \%$ & NA \\
\hline QC Sample & 4 & 4 & NA & NA & $20 U$ & NA \\
\hline QC Sample, MS & 4 & 4 & NA & NA & 101 & NA \\
\hline Concentration Recovered & & & NA & NA & 101 & NA \\
\hline Amount Spiked & & & NS & NS & 100 & NS \\
\hline Percent Recovery & & & NA & NA & $101 \%$ & NA \\
\hline
\end{tabular}

Standard Reference Material

Certified SRM not available for PCBs. 
TABLE I.18. (contd)

\begin{tabular}{|c|c|c|c|c|c|c|}
\hline \multirow[b]{2}{*}{$\begin{array}{l}\text { Sediment } \\
\text { Treatment }\end{array}$} & \multirow[b]{2}{*}{ Replicate } & \multirow[b]{2}{*}{$\begin{array}{c}\text { Analytical } \\
\text { Batch }\end{array}$} & \multicolumn{4}{|c|}{ M. nasuta PCBs ( $\mu \mathrm{g} / \mathrm{kg}$ wet weight) } \\
\hline & & & $\begin{array}{l}\text { Aroclor } \\
1242 \\
\end{array}$ & $\begin{array}{c}\text { Aroclor } \\
1248\end{array}$ & $\begin{array}{l}\text { Aroclor } \\
1254\end{array}$ & $\begin{array}{c}\text { Aroclor } \\
1260\end{array}$ \\
\hline \multicolumn{7}{|l|}{ Analytical Replicates } \\
\hline OBM COMP, Replicate 1 & 5 & 1 & $3.2 \mathrm{U}$ & $3.2 U$ & $3.2 U$ & $3.2 \mathrm{U}$ \\
\hline OBM COMP, Replicate 2 & 5 & 1 & $3.2 \mathrm{U}$ & $3.2 \mathrm{U}$ & $3.2 \mathrm{U}$ & $3.2 \mathrm{U}$ \\
\hline RPD & & & NA & NA & NA & NA \\
\hline I-Stat & & & NA & NA & NA & NA \\
\hline M. nasuta Background, Replicate 1 & 3 & 2 & $20 \mathrm{U}$ & $20 \mathrm{U}$ & $20 \mathrm{U}$ & $20 U$ \\
\hline M. nasuta Background, Replicate 2 & 3 & 2 & $20 U$ & $20 \mathrm{U}$ & $20 \mathrm{U}$ & $20 \mathrm{U}$ \\
\hline M. nasuta Background, Replicate 3 & 3 & 2 & $20 \mathrm{U}$ & $20 U$ & $20 \mathrm{U}$ & $20 \mathrm{U}$ \\
\hline RSD & & & NA & NA & NA & NA \\
\hline QC Sample, Replicate 1 & 2 & 3 & $20 \mathrm{U}$ & $20 \mathrm{U}$ & $20 \mathrm{U}$ & $20 U$ \\
\hline QC Sample, Replicate 2 & 2 & 3 & $20 \mathrm{U}$ & $20 U$ & $20 U$ & $20 U$ \\
\hline QC Sample, Replicate 3 & 2 & 3 & $20 \mathrm{U}$ & $20 \mathrm{U}$ & $20 \mathrm{U}$ & $20 U$ \\
\hline RSD & & & NA & NA & NA & NA \\
\hline R-OS, Replicate 1 & 2 & 4 & $20 U$ & $20 \mathrm{U}$ & $20 \mathrm{U}$ & $20 U$ \\
\hline R-OS, Replicate 2 & 2 & 4 & $20 \mathrm{U}$ & $20 \mathrm{U}$ & $20 U$ & $20 \mathrm{U}$ \\
\hline R-OS, Replicate 3 & 2 & 4 & $20 \mathrm{U}$ & $20 \mathrm{U}$ & $20 \mathrm{U}$ & $20 U$ \\
\hline RSD & & & NA & NA & NA & NA \\
\hline
\end{tabular}
(a) U Undetected at or above detection limit.
(b) NA Not applicable.
(c) NS Not spiked.
(d) Exceeds quality control criteria (40\% - 120\%) for matrix spike recoveries. 
TABLE 1.19. Surrogate Percent Recoveries and Quality Control Data for Pesticides and Polychlorinated Biphenyls (PCBs), Wet Weight, in Tissue of $M$. nasuta, Older Bay Mud Study

\begin{tabular}{|c|c|c|c|c|c|c|}
\hline \multirow{2}{*}{$\begin{array}{l}\text { Sediment } \\
\text { Treatment }\end{array}$} & \multirow[b]{2}{*}{ Replicate } & \multirow{2}{*}{$\begin{array}{c}\text { Analytical } \\
\text { Batch }\end{array}$} & \multicolumn{4}{|c|}{ Surrogate Percent Recoveries } \\
\hline & & & PCB 103 & PCB 198 & TCMX & OCN \\
\hline \multicolumn{7}{|l|}{ January 1993} \\
\hline OBM COMP & 1 & 1 & $N A^{(a)}$ & NA & 111 & $135^{\text {(b) }}$ \\
\hline OBM COMP & 2 & 1 & NA & NA & 110 & $162^{\text {(b) }}$ \\
\hline OBM COMP & 3 & 1 & NA & NA & 114 & $129^{\text {(b) }}$ \\
\hline OBM COMP & 4 & 1 & NA & NA & 110 & $129^{(b)}$ \\
\hline OBM COMP, Replicate 1 & 5 & 1 & NA & NA & 112 & $124^{(b)}$ \\
\hline OBM COMP, Replicate 2 & 5 & 1 & NA & NA & 112 & $129^{(b)}$ \\
\hline \multicolumn{7}{|l|}{ January 1994} \\
\hline OBM COMP & 1 & 3 & 66 & 51 & NA & NA \\
\hline OBM COMP & 2 & 3 & 66 & 54 & NA & NA \\
\hline OBM COMP & 3 & 3 & 61 & 53 & NA & NA \\
\hline OBM COMP & 4 & 3 & 65 & 55 & NA & NA \\
\hline OBM COMP & 5 & 3 & 72 & 61 & NA & NA \\
\hline R-OS & 1 & 4 & 83 & 69 & NA & NA \\
\hline R-OS, Replicate 1 & 2 & 4 & 73 & 62 & NA & NA \\
\hline R-OS, Replicate 2 & 2 & 4 & 74 & 66 & NA & NA \\
\hline R-OS, Replicate 3 & 2 & 4 & 71 & 66 & NA & NA \\
\hline R-OS & 3 & 4 & 78 & 67 & NA & NA \\
\hline R-OS & 4 & 4 & 79 & 73 & NA & NA \\
\hline R-OS & 5 & 4 & 77 & 69 & NA & NA \\
\hline R-BF & 1 & 3 & 64 & 63 & NA & NA \\
\hline R-BF & 2 & 2 & 69 & 70 & NA & NA \\
\hline R-BF & 3 & 3 & 59 & 53 & NA & NA \\
\hline R-BF & 4 & 3 & 75 & 62 & NA & NA \\
\hline R-BF & 5 & 3 & 74 & 70 & NA & - NA \\
\hline R-AM & 1 & 2 & 72 & 75 & $N A$ & NA \\
\hline R-AM & 2 & 3 & 75 & 72 & NA & NA \\
\hline R-AM & 3 & 3 & 72 & 66 & NA & NA \\
\hline R-AM & 4 & 2 & 69 & 65 & NA & NA \\
\hline R-AM & 5 & 3 & 76 & 68 & NA & NA \\
\hline C-SB & 1 & 4 & 78 & 87 & NA & NA \\
\hline C-SB & 2 & 4 & 82 & 77 & NA & NA \\
\hline C-SB & 3 & 4 & 79 & 73 & $N A$ & NA \\
\hline C-SB & 4 & 4 & 74 & 62 & NA & NA \\
\hline C-SB & 5 & 4 & 77 & 65 & NA & NA \\
\hline
\end{tabular}


TABLE I.19. (contd)

Sediment

Analytical

Surrogate Percent Recoveries

Treatment

Replicate Batch

PCB 103

M. nasuta Background

M. nasuta Background

M. nasuta Background, Replicate 1

M. nasuta Background, Replicate 2

$M$. nasuta Background, Replicate 3

$M$. nasuta Background

M. nasuta Background

$\begin{array}{ll}2 & 67 \\ 2 & -67 \\ 2 & 70 \\ 2 & 63 \\ 2 & 62 \\ 2 & 67 \\ 2 & 71\end{array}$

\section{7}

67

70

PCB 198

TCMX

OCN

Quality Control Data

\section{Method Blank}

Blank
Blank
Blank
Blank

80

NA NA

63

NA NA

62

NA NA

93

80

NA NA

$67 \quad 116$

NA NA

NA NA

75

NA

NA

Matrix Spike

OBM COMP, MS

OBM COMP, MSD

M. nasuta Background

M. nasuta Background, MS

QC Sample

QC Sample, MS

QC Sample

QC Sample, MS

Analytical Replicates

OBM COMP, Replicate 1

OBM COMP, Replicate 2

M. nasuta Background, Replicate 1

$M$. nasuta Background, Replicate 2

M. nasuta Background, Replicate 3
1

2

3

NA

73

77

70

4

NA

NA

67

69

71

73

78

81

4

4

NA

NA

70

63

62

NA
77
68
74

110

NA NA

NA NA

NA NA

NA NA

NA


TABLE I.19. (contd)

Sediment

Analytical Surrogate Percent Recoveries

Treatment

Replicate Batch

QC Sample, Replicate 1

QC Sample, Replicate 2

QC Sample, Replicate 3

$\begin{array}{llllll}2 & 3 & 71 & 61 & \text { NA } & \text { NA } \\ 2 & 3 & 66 & 57 & \text { NA } & \text { NA } \\ 2 & 3 & 73 & 64 & \text { NA } & \text { NA }\end{array}$

R-OS, Replicate 1

R-OS, Replicate 2

R-OS, Replicate 3

$\begin{array}{llllll}2 & 4 & 73 & 62 & \text { NA } & \text { NA } \\ 2 & 4 & 74 & 66 & \text { NA } & \text { NA } \\ 2 & 4 & 71 & 66 & \text { NA } & \text { NA }\end{array}$

(a) NA Not applicable.

(b) Exceeds quality control criteria $(40 \%-120 \%)$ for percent recoveries. 


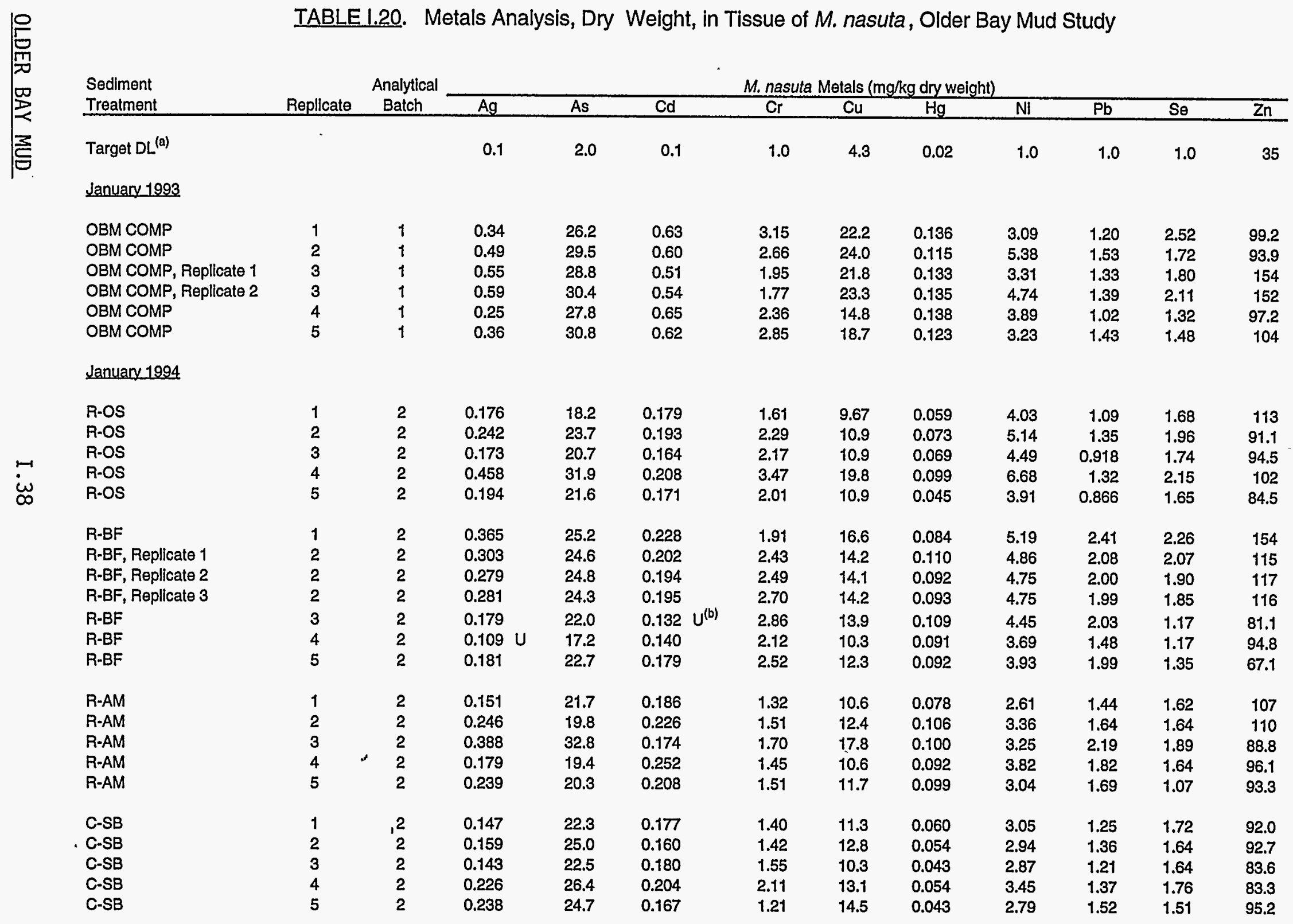



Replicate Batch

Batch

M. nasuta Background

M. nasuta Background

M. nasuta Background

1
2
3
4
5

$1 \quad 0.748$

$M$. nasuta Background

20.399

0.399

0.371

0.680

0.262

TABLE 1.20. (contd)

(a) DL Detection limit.

(b) U Undetected at or above detection limit.

w 
TABLE 1.21. Metals Analysis, Wet Weight, in Tissue of M. nasuta, Older Bay Mud Study

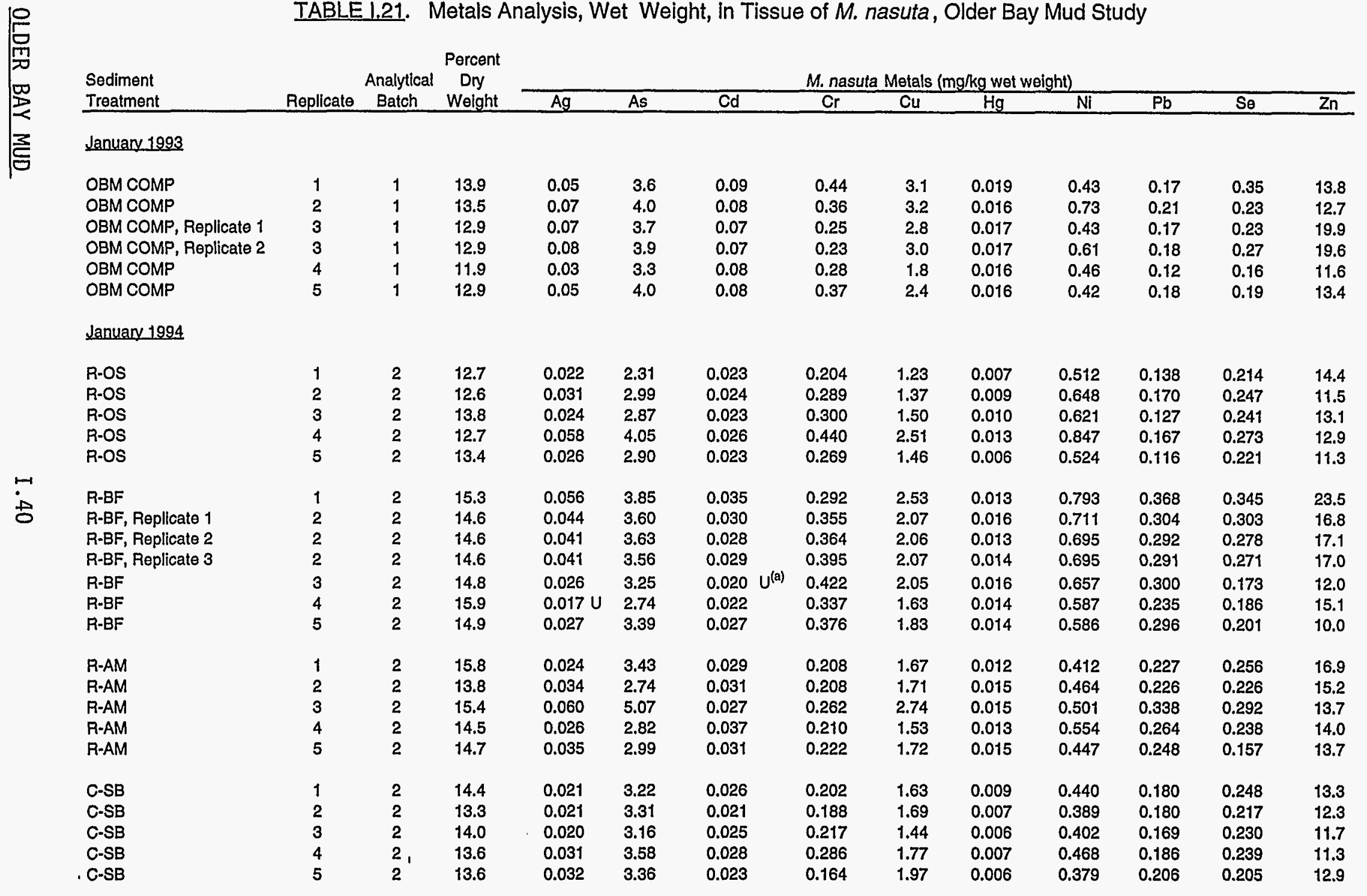


TABLE 1.21. (contd)

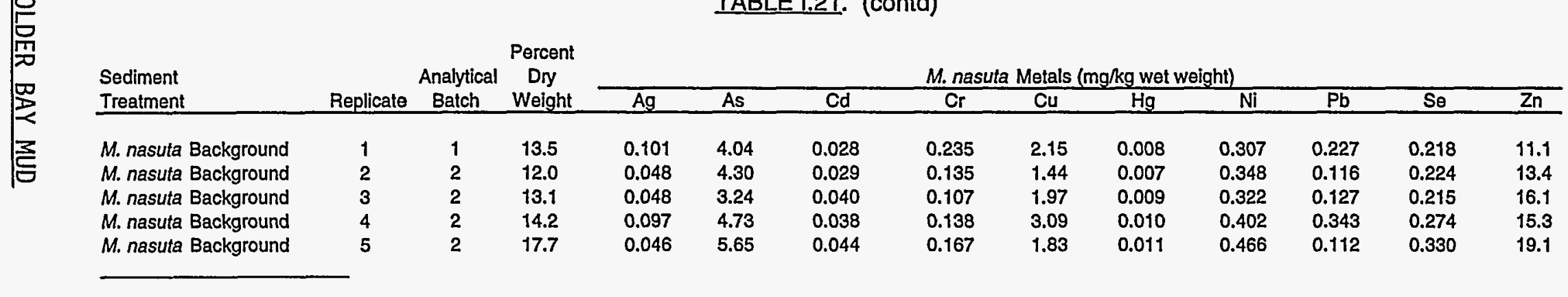

(a) U Undetected at or above detection limit. 


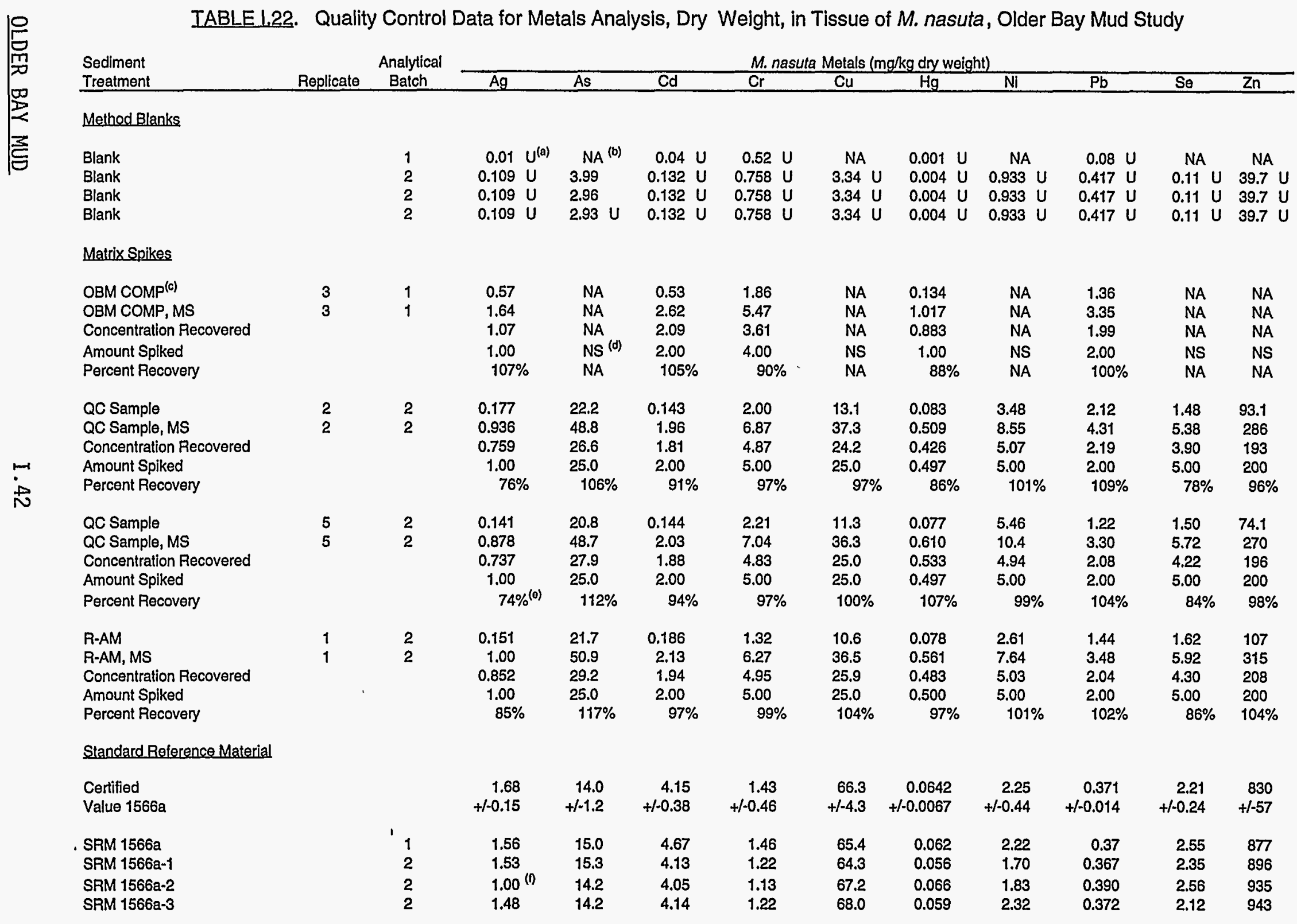




\begin{tabular}{|c|c|c|c|c|c|c|c|c|c|c|c|c|c|}
\hline \multirow{4}{*}{ 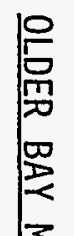 } & \multicolumn{13}{|c|}{ TABLE 1.22. (contd) } \\
\hline & \multirow{2}{*}{$\begin{array}{l}\text { Sediment } \\
\text { Treatment }\end{array}$} & \multirow[b]{2}{*}{ Replicate } & \multirow{2}{*}{$\begin{array}{c}\text { Analytical } \\
\text { Batch }\end{array}$} & \multicolumn{10}{|c|}{ M. nasuta Metals (mg/kg dry weight) } \\
\hline & & & & $\mathrm{Ag}$ & As & $\mathrm{Cd}$ & $\mathrm{Cr}$ & $\mathrm{Cu}$ & $\mathrm{Hg}$ & $\mathrm{Ni}$ & $\mathrm{Pb}$ & $\mathrm{Se}$ & $\mathrm{Zn}$ \\
\hline & Analytical Replicates & & & & & & & & & & & & \\
\hline \multirow{11}{*}{ E } & OBM COMP, Replicate 1 & 3 & 1 & 0.55 & 28.8 & 0.51 & 1.95 & 21.8 & 0.133 & 3.31 & 1.33 & 1.81 & 154.1 \\
\hline & OBM COMP, Replicate 2 & 3 & 1 & 0.59 & 30.4 & 0.54 & 1.77 & 23.3 & 0.135 & 4.74 & 1.39 & 2.11 & 152.0 \\
\hline & RPD & & & $7 \%$ & $5 \%$ & $6 \%$ & $10 \%$ & $7 \%$ & $1 \%$ & $36 \%(9)$ & $4 \%$ & $15 \%$ & $1 \%$ \\
\hline & l-Stat & & & 0.04 & 0.03 & 0.03 & 0.05 & 0.03 & 0.01 & 0.18 & 0.02 & 0.08 & 0.01 \\
\hline & QC Sample, Replicate 1 & 2 & 2 & 0.121 & 30.9 & 0.208 & 1.43 & 9.30 & 0.099 & 3.44 & 2.00 & 2.06 & 117 \\
\hline & QC Sample, Replicate 2 & 2 & 2 & 0.122 & 31.6 & 0.190 & 1.57 & 9.51 & 0.092 & 3.40 & 2.02 & 1.92 & 119 \\
\hline & QC Sample, Replicate 3 & 2 & 2 & 0.112 & 31.4 & 0.196 & 1.59 & 9.52 & 0.098 & 3.43 & 2.11 & 1.97 & 117 \\
\hline & RSD & & & $5 \%$ & $1 \%$ & $5 \%$ & $6 \%$ & $1 \%$ & $4 \%$ & $1 \%$ & $3 \%$ & $4 \%$ & $1 \%$ \\
\hline & QC Sample, Replicate 1 & 4 & 2 & 0.177 & 23.7 & 0.234 & 2.20 & 11.7 & 0.058 & 3.59 & 2.21 & 1.76 & 97.6 \\
\hline & QC Sample, Replicate 2 & 4 & 2 & 0.171 & 22.2 & 0.213 & 1.90 & 11.2 & 0.058 & 3.61 & 1.98 & 1.57 & 91.0 \\
\hline & QC Sample, Replicate 3 & 4 & 2 & 0.161 & 21.3 & 0.204 & 1.72 & 10.9 & 0.070 & 3.40 & 1.84 & 1.64 & 89.5 \\
\hline$\mapsto$ & RSD & & & $5 \%$ & $5 \%$ & $7 \%$ & $13 \%$ & $4 \%$ & $11 \%$ & $3 \%$ & $9 \%$ & $6 \%$ & $5 \%$ \\
\hline \multirow[t]{6}{*}{$\vec{\omega}$} & R-BF, Replicate 1 . & 2 & 2 & 0.303 & 24.6 & 0.202 & 2.43 & 14.2 & 0.110 & 4.86 & 2.08 & 2.07 & 115 \\
\hline & R-BF, Replicate 2 & 2 & 2 & 0.279 & 24.8 & 0.194 & 2.49 & 14.1 & 0.092 & 4.75 & 2.00 & 1.90 & 117 \\
\hline & R-BF, Replicate 3 & 2 & 2 & 0.281 & 24.3 & 0.195 & 2.70 & 14.2 & 0.093 & 4.75 & 1.99 & 1.85 & 116 \\
\hline & RSD & & & $5 \%$ & $1 \%$ & $2 \%$ & $6 \%$ & $0 \%$ & $10 \%$ & $1 \%$ & $2 \%$ & $6 \%$ & $1 \%$ \\
\hline & \multicolumn{13}{|c|}{$\begin{array}{l}\text { (a) U Undetected at or above detection limit. } \\
\text { (b) NA Not applicable. } \\
\text { (c) Value is a mean of replicate three. } \\
\text { (d) NS Not spiked. } \\
\text { (e) Outside quality control range }(75-125 \%) \text { for matrix splke recoveries. } \\
\text { (f) Outside quality control criteria }( \pm 30 \%) \text { for SRMs. }\end{array}$} \\
\hline & (g) Value exceeds relative & Ion goal o & $30 \%$ & & & & & & & & & & \\
\hline
\end{tabular}


IABLE 1.23. Butyltin Results, Wet and Dry Weight, in Tissue M. nasuta, Older Bay Mud Study

\begin{tabular}{|c|c|c|c|c|c|c|c|c|}
\hline \multirow{2}{*}{$\begin{array}{l}\text { Sediment } \\
\text { Treatment } \\
\end{array}$} & \multirow[b]{2}{*}{ Replicate } & \multirow[b]{2}{*}{$\begin{array}{c}\text { Analytical } \\
\text { Batch }\end{array}$} & \multirow{2}{*}{$\begin{array}{l}\text { Tripentyltin } \\
\% \text { Interna! } \\
\text { Standard } \\
\end{array}$} & \multicolumn{2}{|c|}{ ( $\mu \mathrm{g} / \mathrm{kg}$ wet weight) } & \multirow{2}{*}{$\begin{array}{c}\text { Percent } \\
\text { Dry } \\
\text { Weight }\end{array}$} & \multicolumn{2}{|c|}{ ( $\mu g / \mathrm{kg}$ dry weight) } \\
\hline & & & & $\begin{array}{c}\text { Tri- } \\
\text { Butyltin }\end{array}$ & $\begin{array}{c}\text { Di- } \\
\text { Butyltin }\end{array}$ & & $\begin{array}{c}\text { Tri- } \\
\text { Butyitin }\end{array}$ & $\begin{array}{c}\text { Di- } \\
\text { Butyltin }\end{array}$ \\
\hline Target $\mathrm{DL}^{(\mathrm{a})}$ & & NA & $N A^{(B)}$ & 1.00 & 1.00 & NA & NA & NA \\
\hline \multicolumn{9}{|l|}{ January 1993} \\
\hline OBM COMP & 1 & 1 & 78 & 6.9 & 6.6 & 13.6 & 50.7 & 48.5 \\
\hline OBM COMP & 2 & 1 & 83 & 8.4 & 7.6 & 13.2 & 63.6 & 57.6 \\
\hline OBM COMP, Replicate 1 & 3 & 1 & 94 & 7.2 & 6.0 & 12.3 & 58.5 & 48.8 \\
\hline OBM COMP, Replicate 2 & 3 & 1 & 83 & 7.6 & $4.3 \mathrm{~J}^{(c)}$ & 12.3 & 61.8 & $35.0 \mathrm{~J}$ \\
\hline OBM СОMP & 4 & 1 & $\pi 7$ & 6.6 & 7.0 & 11.4 & 57.9 & 61.4 \\
\hline OBM СOMP & 5 & 1 & 80 & 6.4 & 6.9 & 12.0 & 53.3 & 57.5 \\
\hline \multicolumn{9}{|l|}{ January 1994} \\
\hline OBM СОМР & 1 & 3 & 99 & 1.61 & $1.39 U^{(0)}$ & 14.0 & 11.5 & $9.92 \mathrm{U}$ \\
\hline OBM СOMP & 2 & 3 & 94 & 2.03 & 1.72 & 13.2 & 15.4 & 13.1 \\
\hline ОВМ СОМР & 3 & 3 & 100 & 1.89 & $1.39 \mathrm{U}$ & 12.2 & 15.5 & $11.4 \mathrm{U}$ \\
\hline OBM COMP & 4 & 3 & 94 & 1.89 & 1.53 & 14.3 & 13.2 & 10.7 \\
\hline OBM COMP & 5 & 3 & 98 & 1.83 & $1.39 \mathrm{U}$ & 14.5 & 12.6 & $9.58 \mathrm{U}$ \\
\hline R-OS & 1 & 3 & 106 & 1.66 & 2.02 & 12.7 & 13.1 & 15.9 \\
\hline R-OS & 2 & 3 & 52 & 1.94 & 1.76 & 12.6 & 15.4 & 13.9 \\
\hline R-OS & 3 & 3 & 61 & 1.85 & $1.39 \mathrm{U}$ & 13.8 & 13.4 & $10.0 \mathrm{U}$ \\
\hline R-OS & 4 & 3 & 99 & 1.75 & $1.39 \mathrm{U}$ & 12.7 & 13.8 & $11.0 \mathrm{U}$ \\
\hline R-OS, Replicate 1 & 5 & 3 & 99 & 1.82 & $1.39 \mathrm{U}$ & 13.4 & 13.6 & $10.4 \mathrm{U}$ \\
\hline R-OS, Replicate 2 & 5 & 3 & 107 & 1.86 & 1.47 & 13.4 & 13.9 & 11.0 \\
\hline R-OS, Replicate 3 & 5 & 3 & 98 & 1.73 & $1.39 \mathrm{U}$ & 13.4 & 12.9 & $10.4 \mathrm{U}$ \\
\hline R-BF & 1 & 3 & 98 & 2.95 & $1.39 \mathrm{U}$ & 15.3 & 19.3 & $9.10 \mathrm{U}$ \\
\hline R-BF & 2 & 2 & 82 & 2.30 & $1.39 \mathrm{U}$ & 14.6 & 15.7 & $9.49 \mathrm{U}$ \\
\hline R-BF & 3 & 3 & 102 & 3.11 & 1.57 & 14.8 & 21.0 & 10.6 \\
\hline R-BF & 4 & 2 & 96 & 2.74 & 1.92 & 15.9 & 17.2 & 12.1 \\
\hline R-BF & 5 & 3 & 100 & 2.38 & 1.69 & 14.9 & 16.0 & 11.3 \\
\hline R-AM & 1 & 2 & 93 & 3.88 & 1.40 & 15.8 & 24.6 & 8.87 \\
\hline R-AM & 2 & 2 & 85 & 4.87 & 2.10 & 13.8 & 35.3 & 15.2 \\
\hline R-AM & 3 & 2 & 94 & 3.31 & $1.39 \mathrm{U}$ & 15.4 & 21.4 & $9.00 \mathrm{U}$ \\
\hline R-AM & 4 & 2 & 91 & 3.86 & $1.39 \mathrm{U}$ & 14.5 & 26.6 & $9.57 \cup$ \\
\hline R-AM & 5 & 3 & 92 & 4.45 & 1.49 & 14.7 & 30.3 & 10.1 \\
\hline C-SB & 1 & 4 & 95 & 1.56 & 1.39 & 14.4 & 10.8 & 9.63 \\
\hline C-SB & 2 & 4 & 97 & 1.39 & $1.39 \mathrm{U}$ & 13.3 & 10.5 & $10.5 \mathrm{U}$ \\
\hline C-SB & 3 & 4 & 90 & 1.47 & $1.39 \mathrm{U}$ & 14.0 & 10.5 & $9.91 \mathrm{U}$ \\
\hline C-SB & 4 & 4 & 90 & 1.60 & $1.39 \mathrm{U}$ & 13.6 & 11.8 & $10.2 \mathrm{U}$ \\
\hline C-SB & 5 & 4 & 90 & 1.41 & $1.39 \mathrm{U}$ & 13.6 & 10.4 & $10.2 U$ \\
\hline M. nasuta Background & 1 & 2 & 89 & 0.55 & $1.39 \mathrm{U}$ & 13.5 & 4.09 & $10.3 U$ \\
\hline M. nasuta Background & 2 & 2 & 95 & 0.53 & $1.39 \mathrm{U}$ & 12.0 & 4.42 & $11.6 \mathrm{U}$ \\
\hline M. nasuta Background & 3 & 2 & 96 & 0.65 & $1.39 \mathrm{U}$ & 13.1 & 4.98 & $10.7 \mathrm{U}$ \\
\hline M. nasuta Background & 4 & 2 & 66 & $0.48 \mathrm{U}$ & $1.39 \mathrm{U}$ & 14.2 & $3.38 \mathrm{U}$ & $9.78 \mathrm{U}$ \\
\hline M. nasuta Background & 5 & 2 & 91 & 0.83 & 1.57 & 17.7 & 4.70 & 8.90 \\
\hline
\end{tabular}

(a) DL Detection limit.

(b) NA Not applicable.

(c) J Analyte detected below method detection limit (MDL), but above instrument detection limit (IDL).

(d) U Undetected at or above detection limit. 
TABLE 1.24. Quality Control Data for Butylin Results, Wet Weight, in Tissue of M. nasuta, Older Bay Mud Study

\begin{tabular}{|c|c|c|c|c|c|}
\hline \multirow[b]{2}{*}{$\begin{array}{l}\text { Sediment } \\
\text { Treatment }\end{array}$} & \multirow[b]{2}{*}{ Replicate } & \multirow[b]{2}{*}{$\begin{array}{c}\text { Analytical } \\
\text { Batch }\end{array}$} & \multirow{2}{*}{$\begin{array}{l}\text { Tripentyltin } \\
\% \text { Internal } \\
\text { Standard }\end{array}$} & \multicolumn{2}{|c|}{ ( $\mu \mathrm{g} / \mathrm{kg}$ wet weight) } \\
\hline & & & & $\begin{array}{c}\text { Tri- } \\
\text { Butyltin }\end{array}$ & $\begin{array}{c}\text { Di- } \\
\text { Butyltin }\end{array}$ \\
\hline \multicolumn{6}{|c|}{ Method Blanks } \\
\hline Blank & & 1 & 111 & $1.6 U^{(a)}$ & $3.9 \mathrm{~J}^{(b)}$ \\
\hline Blank & & 2 & 100 & $0.48 \mathrm{U}$ & $1.39 \mathrm{U}$ \\
\hline Blank & & 3 & 103 & $0.48 \mathrm{U}$ & $1.39 \mathrm{U}$ \\
\hline Blank & & 4 & 97 & $0.48 \mathrm{U}$ & $1.39 \mathrm{U}$ \\
\hline
\end{tabular}

Matrix Spikes

\begin{tabular}{|c|c|c|c|c|c|}
\hline OBM COMP & 4 & 1 & 77 & 6.6 & 7.0 \\
\hline OBM COMP, MS & 4 & 1 & 94 & 221.0 & 228.2 \\
\hline Concentration Recovered & & & & 214.4 & 221.2 \\
\hline Amount Spiked & & & & 211.9 & 211.9 \\
\hline Percent Recovery & & & & $101 \%$ & $104 \%$ \\
\hline OBM COMP & 4 & 1 & 77 & 6.6 & 7.0 \\
\hline OBM COMP, MSD & 4 & 1 & 91 & 233.0 & 237.6 \\
\hline Concentration Recovered & & & & 226.4 & 230.6 \\
\hline Amount Spiked & & & & 219.3 & 219.3 \\
\hline Percent Recovery & & & & $103 \%$ & $105 \%$ \\
\hline RPD & & & & $2 \%$ & $1 \%$ \\
\hline I-Stat & & & & 0.01 & 0.00 \\
\hline QC Sample & 2 & 2 & 95 & 0.77 & $1.39 \mathrm{U}$ \\
\hline QC Sample, MS & 2 & 2 & 98 & 54.2 & 46.6 \\
\hline Concentration Recovered & & & $N A^{(c)}$ & 54.2 & 46.6 \\
\hline Amount Spiked & & & NA & 50.0 & 50.0 \\
\hline Percent Recovery & & & NA & $108 \%$ & $93 \%$ \\
\hline OBM COMP & 3 & 3 & 100 & 1.89 & $1.39 \mathrm{U}$ \\
\hline OBM COMP, MS & 3 & 3 & 99 & 49.0 & 48.7 \\
\hline Concentration Recovered & & & NA & 47.1 & 48.7 \\
\hline Amount Spiked & & & NA & 49.6 & 49.6 \\
\hline Percent Recovery & & & NA & $95 \%$ & $98 \%$ \\
\hline C-SB & 4 & 4 & 90 & 1.60 & $1.39 \mathrm{U}$ \\
\hline C-SB, MS & 4 & 4 & 93 & 52.5 & 49.8 \\
\hline Concentration Recovered & & & NA & 50.9 & 49.8 \\
\hline Amount Spiked & & & NA & 48.7 & 48.7 \\
\hline Percent Recovery & & & NA & $105 \%$ & $102 \%$ \\
\hline
\end{tabular}


TABLE I.24. (contd)

\begin{tabular}{|c|c|c|c|c|c|}
\hline \multirow[b]{2}{*}{$\begin{array}{l}\text { Sediment } \\
\text { Treatment }\end{array}$} & \multirow[b]{2}{*}{ Replicate } & \multirow[b]{2}{*}{$\begin{array}{c}\text { Analytical } \\
\text { Batch } \\
\end{array}$} & \multirow{2}{*}{$\begin{array}{l}\text { Tripentyltin } \\
\% \text { Internal } \\
\text { Standard } \\
\end{array}$} & \multicolumn{2}{|c|}{ ( $\mu \mathrm{g} / \mathrm{kg}$ wet weight) } \\
\hline & & & & $\begin{array}{c}\text { Tri- } \\
\text { Butyltin }\end{array}$ & $\begin{array}{c}\text { Di- } \\
\text { Butyltin }\end{array}$ \\
\hline \multicolumn{6}{|l|}{ Analytical Replicates } \\
\hline OBM COMP, Replicate 1 & 3 & 1 & 94 & 7.2 & 6.0 \\
\hline OBM COMP, Replicate 2 & 3 & 1 & 83 & 7.6 & $4.3 \mathrm{~J}$ \\
\hline RPD & & & & $5 \%$ & $33 \%{ }^{(d)}$ \\
\hline I-Stat & & & & 0.03 & 0.17 \\
\hline QC Sample, Replicate 1 & 1 & 2 & 92 & 1.21 & $1.39 U$ \\
\hline QC Sample, Replicate 2 & 1 & 2 & 96 & 1.26 & $1.39 U$ \\
\hline QC Sample, Replicate 3 & 1 & 2 & 95 & 1.11 & $1.39 U$ \\
\hline RSD & & & NA & $6 \%$ & NA \\
\hline R-OS, Replicate 1 & 5 & 3 & 99 & 1.82 & $1.39 \mathrm{U}$ \\
\hline R-OS, Replicate 2 & 5 & 3 & 107 & 1.86 & 1.47 \\
\hline R-OS, Replicate 3 & 5 & 3 & 98 & 1.73 & $1.39 \mathrm{U}$ \\
\hline RSD & & & NA & $4 \%$ & NA \\
\hline QC Sample, Replicate 1 & 5 & 4 & 99 & 2.97 & $1.39 \mathrm{U}$ \\
\hline QC Sample, Replicate 2 & 5 & 4 & 92 & 2.82 & $1.39 \mathrm{U}$ \\
\hline QC Sample, Replicate 3 & 5 & 4 & 95 & 2.97 & $1.39 \mathrm{U}$ \\
\hline RSD & & & NA & $3 \%$ & NA \\
\hline
\end{tabular}

(a) U Undetected at or above detection limit.

(b) J Analyte detected below method detection limit (MDL), but above instrument detection limit (IDL).

(c) NA Not applicable.

(d) Value exceeds relative precision goal of $\leq 30 \%$. 